SH 379

. U5 C63

Copy 1

LIBRARY OF CONGRESS

||||||||||||||||||||||||||||||||||||||||||||||

$0001736438 ?$ 

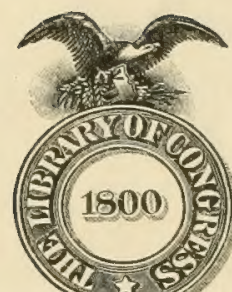

Class_St 379
Book_ U $5 \mathrm{C}_{63}$ 






\section{FRESH-WATER MUSSELS AND MUSSEL INDUSTRIES}

OF THE UNITED STATES : : : By Robert E. Coker

From BULLETIN OF THE BUREAU OF FISHERIES, Volume XXXVI, 1917-18 Document No.865: : : : : $\quad: \quad$ Issued October 25,1929

ב-_._.

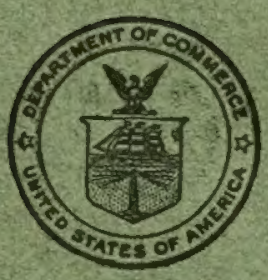

PRICE, 40 CENTS

Sold only by the Superintendent of Documents, Government Printing Office, Washington, D. C.

WASHINGTON : : : : : : GOVERNMENT PRINTING OFHICE : : $: \quad: \quad: \quad: \quad: \quad 1919$ 



\section{FRESH-WATER MUSSELS AND MUSSEL INDUSTRIES}

OF THE UNITED STATES : : : By Robert E. Coker

From BULLETIN OF THE BUREAU OF FISHERIES, Volume XXXVI, I917-18

Document No.865 : : : : : : : : : : : Issued October 25, I9I9

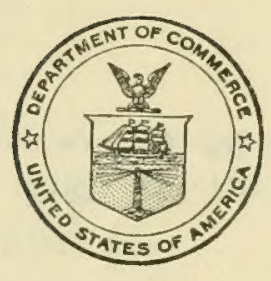

Sold only by the Superintendent of Documents, Government Printing Office, Washington, D. C. 


$$
5 x^{13} c^{379}
$$

5. $0 \pm .20$

noy 29 1919

$\therefore \vdots$ 


\section{CONTENTS.}

\section{*}

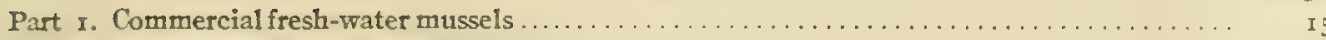

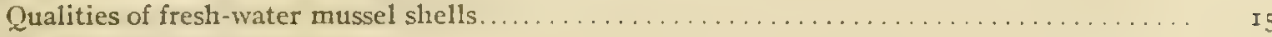

Varieties of commercial shells. . . . . . . . . . . . . . . . . . . . . . . . . . .

Quadrula class. . . . . . . . . . . . . . . . . . . . . . . . . . . . . . . . . . . .

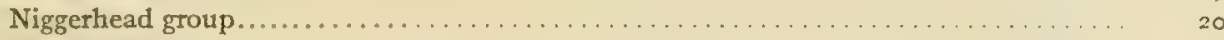

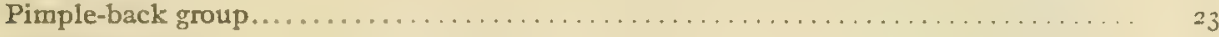

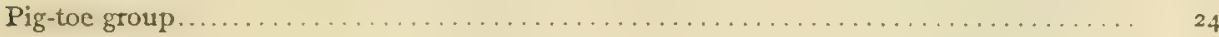

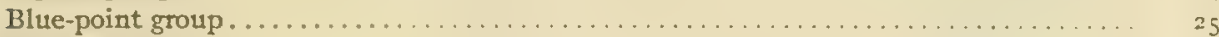

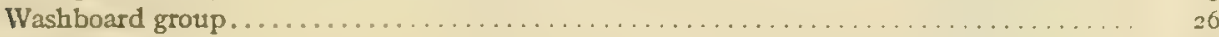

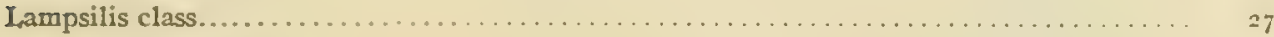

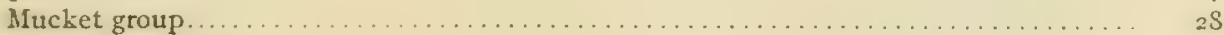

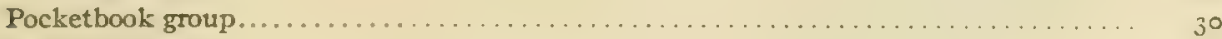

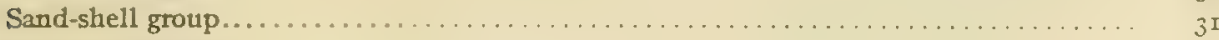

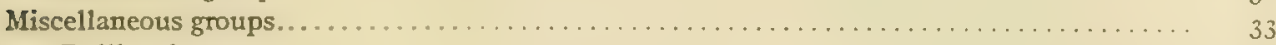

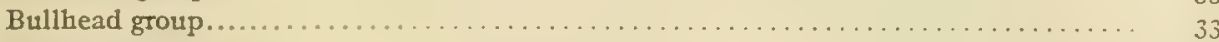

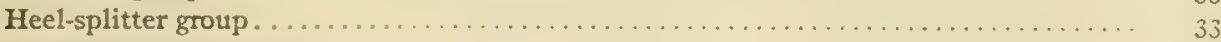

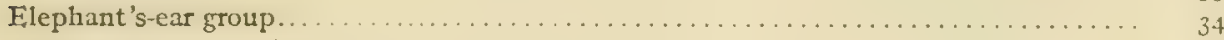

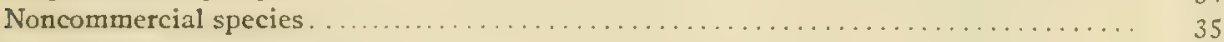

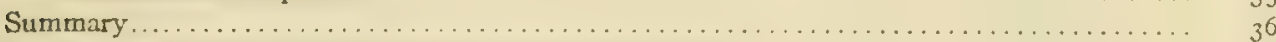

Publications treating mussel resourees of various streams ................... . . . . 37

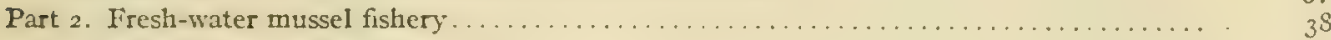

Value and extent of the fishery . . . . . . . . . . . . . . . . . . . . . . . . .

Some local and temporary aspects of the fishery $\ldots \ldots \ldots \ldots \ldots \ldots \ldots \ldots$

Depletion of the mussel resources. . . . . . . . . . . . . . . . . . . . . . . . . . .

Apparatus and methods of fishery . . . . . . . . . . . . . . . . . . . . . . .

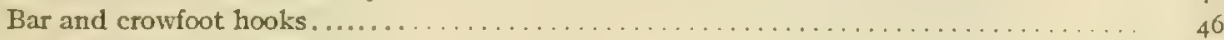

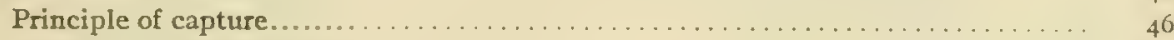

Description of apparatus. . . . . . . . . . . . . . . . . . . . . . . .

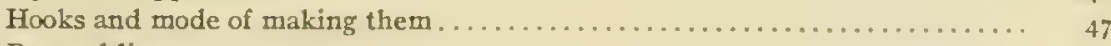

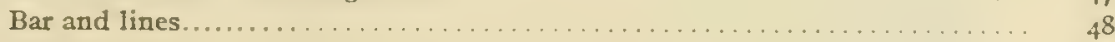

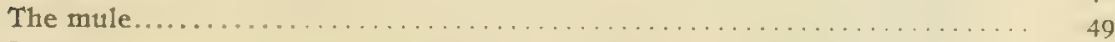

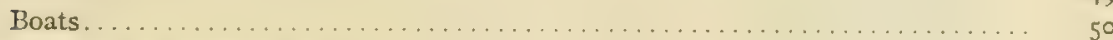

Operation of the crowfoot bar. . . . . . . . . . . . . . . . . . . . . .

Advantages and disadvantages of the method........................ $5^{2}$

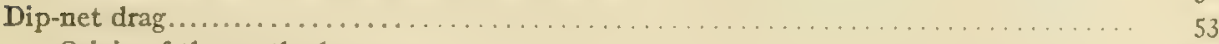

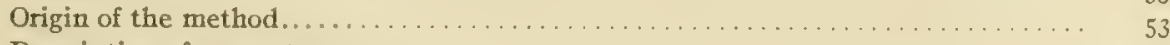

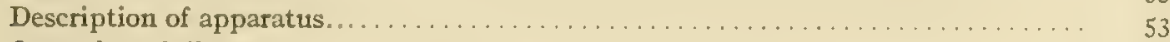

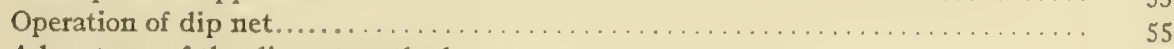

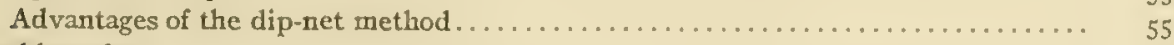

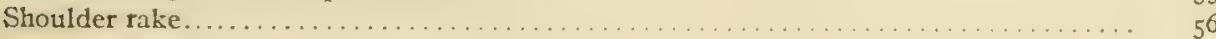

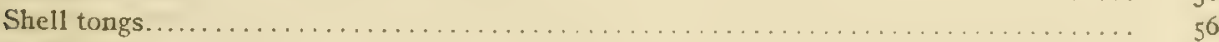

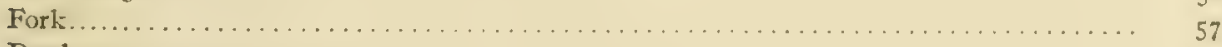

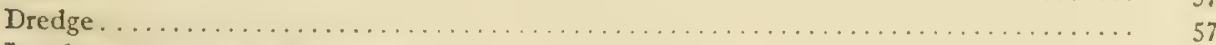

Local modifications of methods . . . . . . . . . . . . . . . . . . . . . . 58

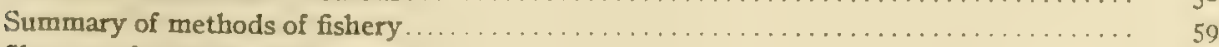

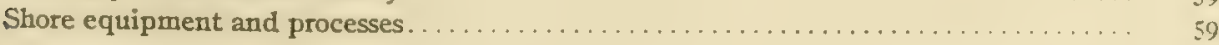


Part 2. Firesh-water mussel fishery-Continued.

Page.

Elements of waste $\ldots \ldots \ldots \ldots \ldots \ldots \ldots \ldots \ldots \ldots \ldots \ldots$

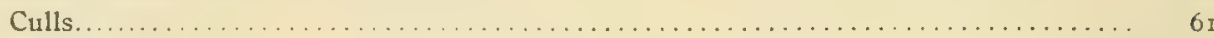

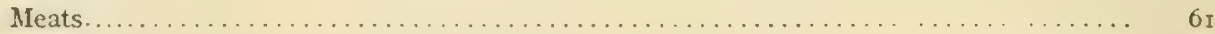

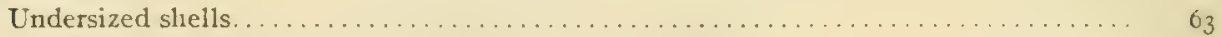

Part 3. Manufacture of pearl buttons from fresh-water mussel shells.................. 14

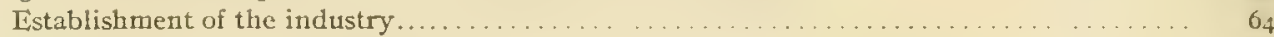

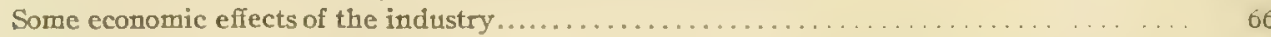

Development of the industry . . . . . . . . . . . . . . . . 66

Development relative to other branches of the button industry................ 67

Imports and exports of buttons . . . . . . . . . . . . . . . . . . . . 68

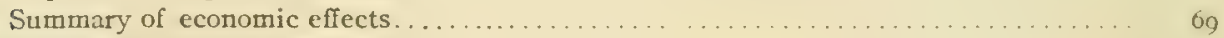

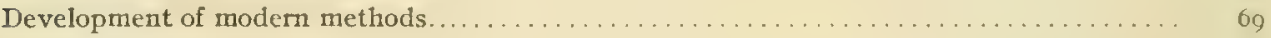

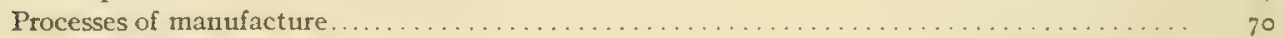

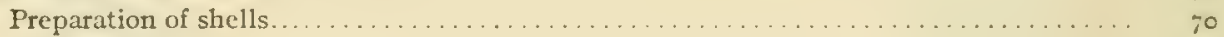

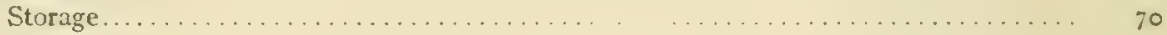

Classifying.........................................

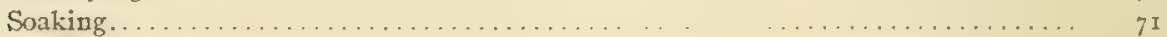

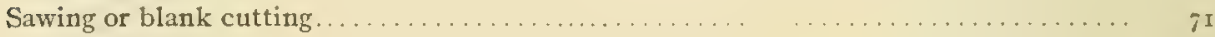

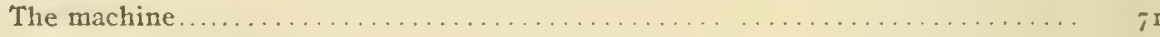

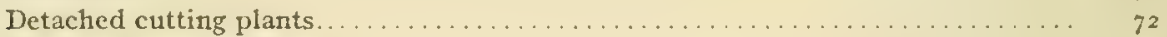

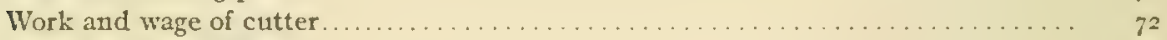

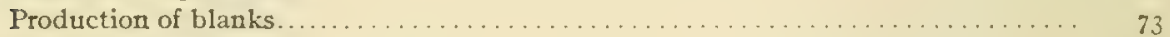

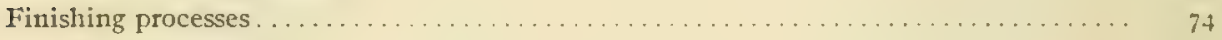

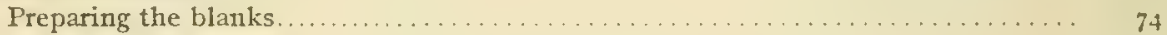

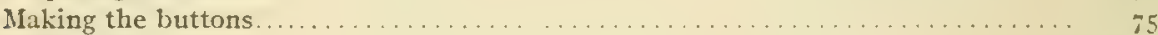

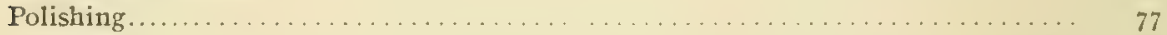

Sorting . . . . . . . . .

Bleaching and dyeing . . . . . . . . . . . . . $\ldots \ldots \ldots \ldots \ldots \ldots \ldots$

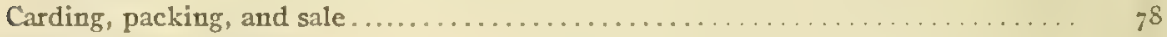

Utilization of waste products. . . . . . . . . . . . . . . . . . . . . . . . . . .

Use of shells for novelties. . . . . . . . . . . . . . . . . . . . . . . . . . . . So

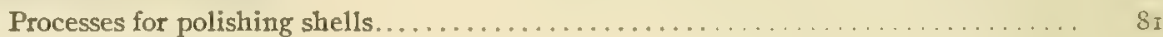

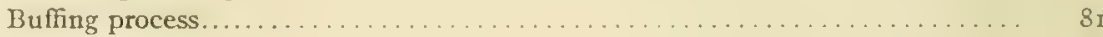

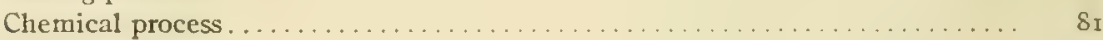

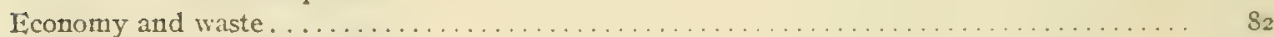

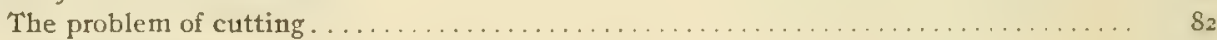

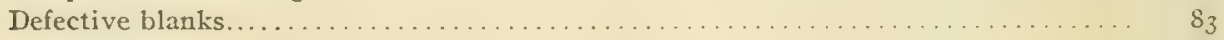

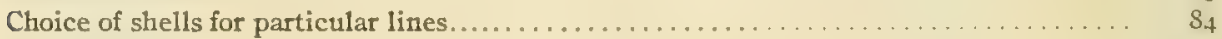

Shop management.

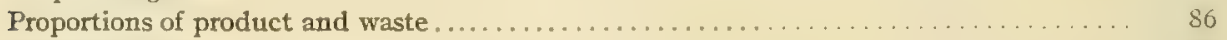

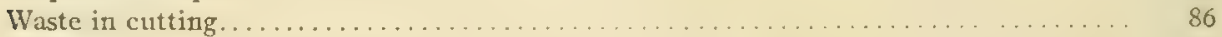

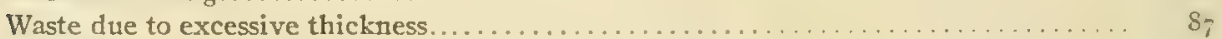

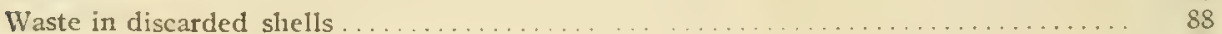

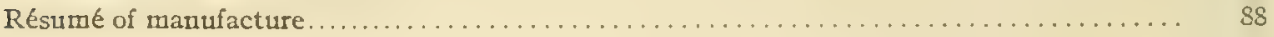




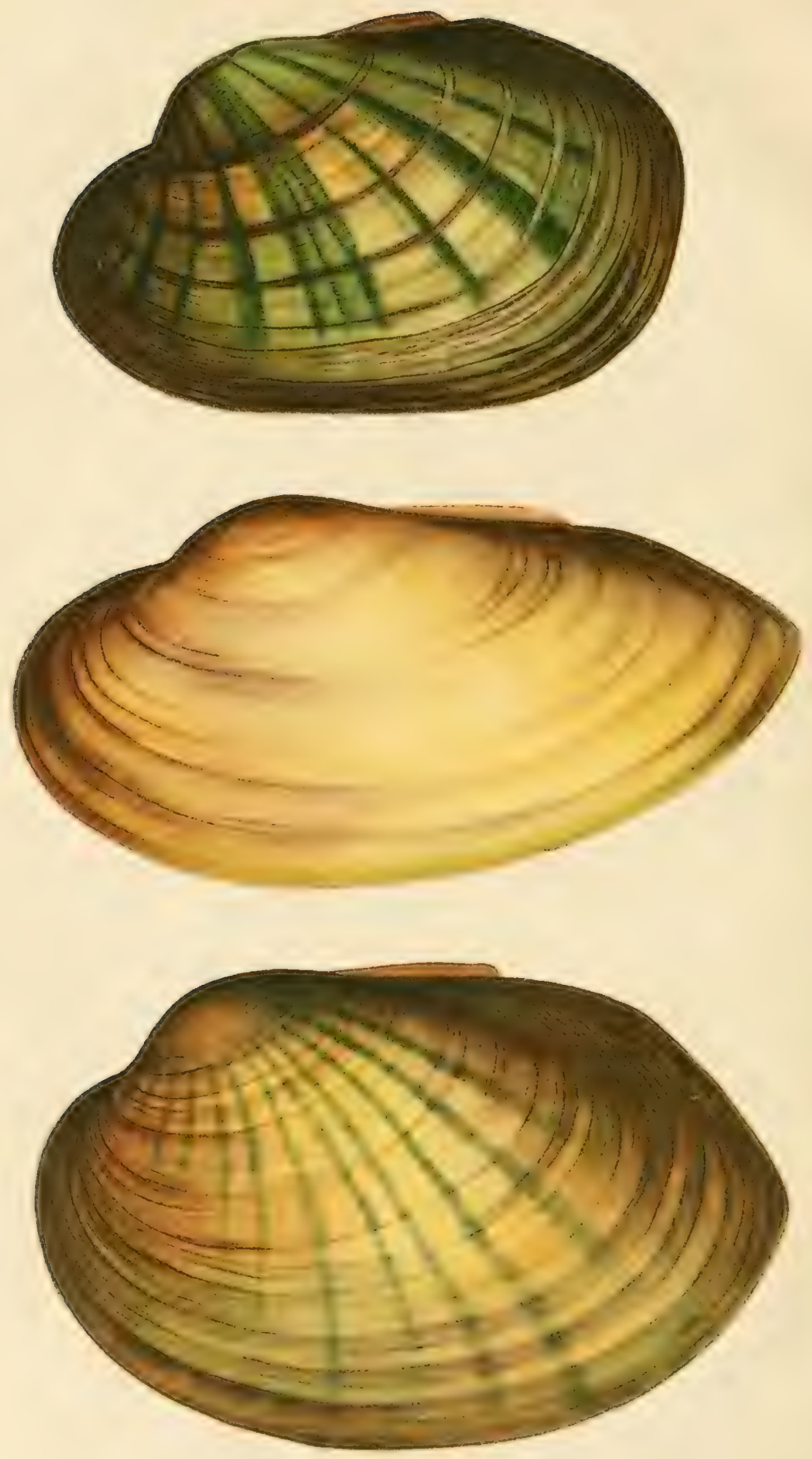

Lake Yepin mucket, female, Lamipsilis Inteoln (Lamarck) 


\title{
FRESH-WATER MUSSELS AND MUSSEL INDUSTRIES OF THE UNITED STATES.
}

\author{
2 \\ BY ROBERT E. COKER, Ph. D., \\ Assistant in charge of Scientific Inquiry, U. S. Bureau of Fisheries.
}

*

Part 1. COMMERCIAL FRESH-WATER MUSSELS. ${ }^{a}$

QUALITIES OF FRESH-WATER MUSSEL SHELLS.

Those who are familiar with only the common shellfish of the American seacoast or with the chalky, brittle shells of the streams of the Atlantic slope can have but little conception of the nature and quality of the mussel resources of the Mississippi Basin. In streams large and small throughout the greater part of this wide region, from the Appalachian Mountains to Arkansas and Dakota and from Louisiana to Mississippi, there is a wealth of pearly mussels of a variety of species, the shells of which are thick and firm, with clear, pearly luster, and in some cases displaying beautiful iridescence. Often the shells are strikingly ornamented with knobs and ridges, and the nacre, or mother-of-pearl, may be clear white, delicately tinted, or deeply colored with various shades of pink, salmon, red, or purple. The shells that are most striking in appearance are not, however, the most important. Of greatest value are those having the surface of the shell free from ornamentation or irregularities and with nacre of clear, lustrous white without stains or colors. It is these qualities, combined with a peculiar toughness or absence of brittleness or chalkiness, that lend to the fresh-water mussel shells the value they now possess as the basis for important manufacture.

Until the mussels assumed economic importance the several species were without distinguishing common names. With the development of the fishery the shellers on the several streams applied the common names which have suggested themselves as appropriate to the appearance of the shell or those which seem to have originated in a spirit of facetiousness. Since the shellers move from place to place, those of one State frequently mingling with those of distant regions, there has come to prevail a greater degree of uniformity of names of mussels than of the names of fishes.

As primary products or as by-products of manufacture the mussel shells are brought into commerce in the form of buttons, novelties, jewelry, chicken feed, road materials, composition marble, and otherwise. By far the chiefest use of mussel shells is, however,

a The author wishes to acknowledge his indebtedness to the late J. F. Boepple, shell expert at the Fisheries Biological Station at Fairport, Iowa, who prepared for the station in IgII a series of memoranda on the commercial values of shells. These data have been of invaluable aid. H. W. Clark and J. B. Southall, of this station, and Firnest Danglade have been consulted with profit. Auch information has been gained from time to time, too, through the generous advice of rnanufacturers, among whom special mention should be made of D. W. MacWillie of La Crosse, J. F. Krouse of Davenport, and Henry Umlandt of Muscatine. None of the persons named can be held responsible for any mistakes or for such opinions as are expressed. The color drawings of Plate I were made by Mrs. A. F. Shira; the photographs of shells are mostly by J. B. Southall. 
for the manufacture of pearl buttons, now wom by nearly every individual from the cradle to the shroud. The pearly mussels are also valuable in the production of pearls at a value of about $\$ 364,000$ a year, but our concern in this paper is with the adaptability of the shells for the manufacture of buttons.

When the manufacture of buttons from fresh-water shells began in I89r, the yellow sand-shell was the first to be used. As the industry grew, the supply of these shells soon proved to be insufficient. According to Mr. Boepple, the mucket, pocketbook, and black sand-shell were then brought into use, but it was not until 1894 that the niggerhead shell was tried. The niggerhead proved to be an excellent shell, with firm texture and beautiful luster, while a portion of it was found to be highly iridescent. This shell gained rapidly in favor and became the standard of price, while in time the valuable but less abundant yellow sand-shells became monopolized by the export trade.

It was the custom of the early shellers, as now, to gather the river-run of mussels and cook out the meats of all, but the shells of only two or three species were saved, while the others were thrown away as worthless. The shellers cooked out the entire lot of mussels in the hope of finding additional pearls and slugs. The shelling and the button industries, therefore, have a history similar to many other American industries in that the pioneers wasted large quantities of good material through lack of knowledge and experience and while secure in the thought that the supply was inexhaustible. In the course of time other shells were brought into use, until now $4 \mathrm{I}$ species in all are employed in the manufacture of buttons and novelties.

There are approximately 500 species of fresh-water mussels in the United States. The commercial species are practically restricted to flowing waters derived from the drainage of limestone regions. Such waters include most of the streams of the Mississippi Basin and some of those of the Great Lakes and Gulf drainages. Here the mollusk finds an abundance of lime, as well as of food, with the depths of water, currents, and other conditions favorable to its reproduction and growth. Many species of mussel occur in the streams of the Atlantic coast, but their shells are either chalky and eroded or else too small and too thin for commercial use. Fresh-water mussels of commercial value are not as yet known from streams of the Pacific slope.

An ideal button shell would have the following qualities: The nacre pearly white, or preferably iridescent, free from spots, stains, or colorings; the texture firm throughout, neither brittle nor chalky, nor yet too hard; the inner surface smooth; the outer surface free from ridges or protuberances; the thickness uniform, with low umbones or beaks, and tips relatively thick; the shape flattish, oval; the size sufficient to permit of cutting several blanks. There are, however, no ideal button shells to be found. Some, valuable for certain desirable qualities, are yet far from perfection in other respects. A few approach the ideal, but the same species is not always uniform in quality in different rivers nor even in different parts of the same river.

A given species may yield a good working shell in one river, while in another stream its shell shows hard and soft spots, stains, dullness of nacre, or other poor qualities. For example, the washboard of the upper Illinois River, while extra large, is badly stained; yet the same species, in the lower stretches of this river, though much smaller, is flatter and so free from spots as to make a much better material for buttons. The muckets of the Kankakee, Wabash, and upper Mississippi Rivers are of extra good quality, while in the Illinois and some other rivers they are scarce and of second quality. 
An excellent illustration is afforded by the fat mucket. It is the most common shell of the lakes of the upper portion of the Mississippi Basin, but in these localities it is nearly always very thin, sometimes almost papery. In parts of the upper Mississippi it attains a large size, and has a shell of good quality and thickness except for the relatively thin tip (the hinder portion of the shell). In Lakes Pepin and St. Croix the same species is not only of the best quality, but of such degree of uniformity in thickness as to be practically tipless. ${ }^{a}$

A shell can not always be judged by its appearance. The Bureau, having a shelltesting shop at the Fairport station, makes a practice of testing out the shells submitted by the field parties. Pocketbook shells of exceptionally fine appearance received from the Sauk River proved upon test to be so brittle as to be worthless. Niggerhead shells collected in some lowland waters along the Mississippi in Louisiana had an appearance of first quality, but in the cutting test showed a chalky character and a tendency to split, which gave them a second-grade rating. It happens, too, that a shell having a nacre which is white upon the surface may be found in process of finishing to be discolored beneath.

Besides the useful shells, there are found in all rivers, but not in any uniform proportion, those which are useless on account of being too thin or discolored. Some of the most beautifully colored shells are of no commercial value.

\section{VARIETIES OF COMMERCIAL SHELLS.}

Most of the commercial fresh-water mussels, considered with regard to the quality of shell, fall into two main classes, which may be termed the Quadrula class and the Lampsilis class, giving to each class the name of the genus to which belong most of the common species exhibiting the characters of the class. There remain a few groups of species of less importance, which have little in common with the others and which may be classed together under the head of "Miscellaneous groups." Each class naturally divides itself into several groups, which may be conveniently designated by the name of the principal species of the group. It is rather significant that the classes and groups correspond approximately to the general plan of scientific classification. Mussels close in systematic relation possess, roughly speaking, similar qualities of shell, but this must not be taken as a universal rule. For our present purposes, we are not primarily concerned with the scientific classification, but it happens conveniently that general statements can be made regarding the natural history of the mussels of some of the respective groups.

In view of the large number of species used more or less for commercial purposes in the manufacture of buttons or novelties, it is somewhat difficult to decide which species to include. Especially is this the case since a number of mussels useless to the manufacturer have an importance in the production of pearls. In the following pages several species are discussed which are not at present of known economic inportance, but it is believed that none is mentioned that is not familiar to fishermen in one region or

a In the terminology of pearl-button manufacture a tip is a blank (unfinished button) less than one-twentieth of an inch in thickness, or that portion of the shell from which only blanks of such thinness are cut. In an ordinarily good shell not roore than one-fourth of the area of the shell is tip. If the thickness of a shell is unusually well sustained in the hinder portion, the shell is without tip; at the other extreme a shell is spoken of as all tip, and such a shell is of no value. However, the term "tip" is somewhat differently employed by some manuacturers. 
another. Nearly all of the mussels mentioned will occasionally reach a factory along with other shells. The little rainbow shell ( $L$. iris) is commonly mistaken by shellers for a young mucket: therefore we have mentioned iris in connection with the mucket in the hope of aiding fishermen to make the proper distinction.

One can not grasp the significance of scientific names or appreciate the sense of scientific classification unless the remarkable fact of convergence is understood. This means that species of shells not closely related may yet take the same form in certain characters, as in the form and color of the shell. Let us take, for example, two species of mussels which are so much alike in external appearance that the novice can scarcely distinguish between them. Both are much compressed from side to side, possess very thin shells, and are commonly known as paper-shells. One of these, known to science as Lampsilis gracilis, seems to be nearly related both to the mucket and to the inflated pocketbook shell, Lampsilis ventricosa. The other compressed species, which is Proptera lavissima, is closely related to another pocketbook type of shell, the much-inflated Proptera capax. In all features of body structure and of life history, the two paper-shells possess relatively little in common, and the same may be said of the two pocketbooks. These are cases where appear ances are deceiving not only to fishermen but to anyone who looks upon only external characters. A very obvious case of convergence is the familiar one of the pink heel-splitter Lampsilis alata and the white heel-splitter Symphynota complanata. In this case the resemblance is only on the outside, and a sheller will readily see the difference on the inner surface from the very distinct character of hinge and teeth in the two species (Pl. XXII).

It will materially simplify our discussion to dispose of paper-shells together and pocketbooks together, etc. Therefore, the commercial grouping is followed, but, as previously suggested, the deviation from scientific classification is not generally so wide as might be expected.

In the following pages the quality and distribution of the more common commercial species are considered. ${ }^{a}$ The list immediately below indicates the relations of the various species, showing the order in which the different species are considered, and gives references to plates on which they are represented and to pages on which they are discussed. In the list the use of brackets indicates that a species is discussed, but is not regarded at present as of commercial value.

Order in witcil Different Species and tueir Relations are Consideren, with the Plate NumBERS AND PAGES.

\begin{tabular}{|c|c|c|c|}
\hline Class, group, and common name. & Scientific name, & Plate. & Page. \\
\hline 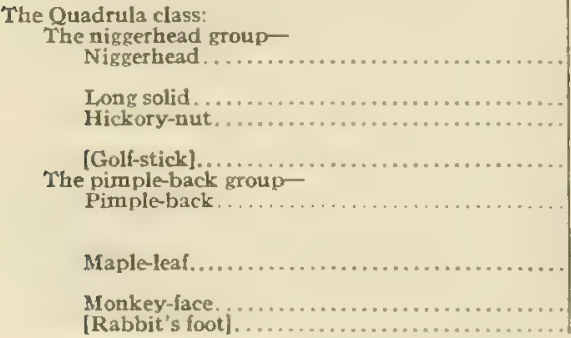 & 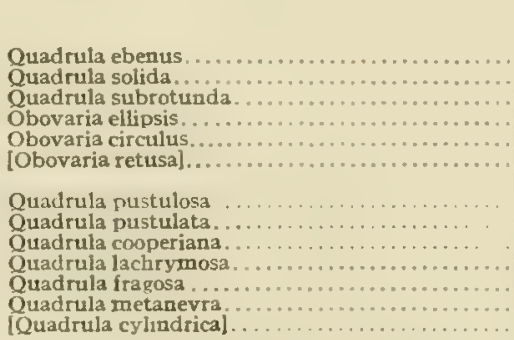 & 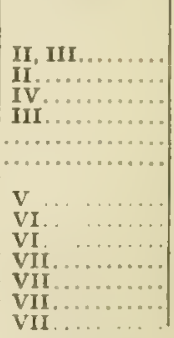 & $\begin{array}{l}20 \\
22 \\
22 \\
22 \\
22 \\
22 \\
\\
23 \\
23 \\
23 \\
23 \\
24 \\
24 \\
24\end{array}$ \\
\hline
\end{tabular}

a In the list and following descriptive account of commercial mussels, the scientific nomenclacture of Simpson is followed. 


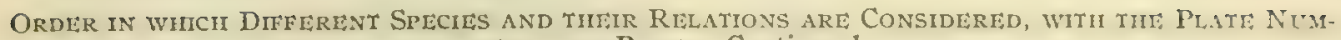
BERS AND PAGES-Continued.

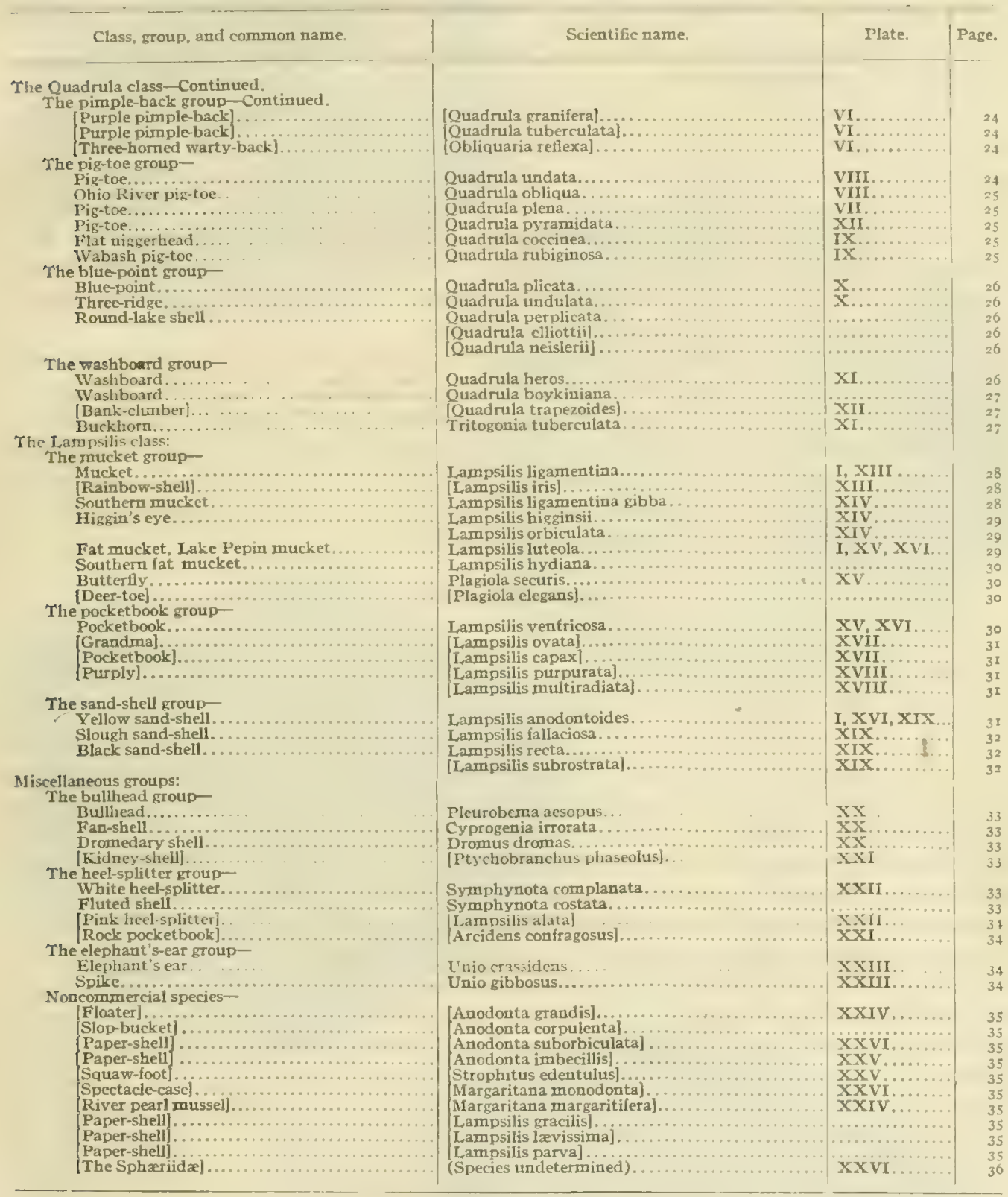

\section{QUADRULA CLASS.}

This includes the niggerhead, the pimple-back, the blue-point, the washboard, and others of minor muportance. Nearly all of the mutssels thus classed together are shortterm or summer breeders. This means that the eggs are fertilized and incubated in 
the gill pouches of the female, passed out to become parasitic upon fish, and liberated after the period of parasitism, all within a relatively short period of weeks or months and generally during the summer season. Most of these species are tolerably restricted in their parasitism, and for this reason, as well as on account of the short breeding season, they lent themselves less readily to propagation by artificial neans. The chief dependence for their conservation must now be placed upon protective measures in order to insure a plentiful supply of spawners in nature, and, as is equally important, upon efforts to promote the abundance of the fishes upon which the mussels become parasitic. These mussels were not the first to be used and appreciated, but after coming into use their popularity grew until in recent years they have constituted the greatest portion of the raw material for manufacture. Other species of mussels fell into disfavor, but now, with the discovery of better material in the Lampsilis class, the pioneer mussels in commerce are again returning to favor.

From the best to the worst there is a wide extreme, but, generally speaking, Quadrula shells are harder and of better luster and iridescence than others; these superior qualities are doubtless associated with their comparatively slow rate of growth. The individual shells show greater extremes of thickness than Lampsilis mussels (such as the mucket) so that, in cutting and finishing buttons from them, there is a relatively high proportion of waste. In addition to the relative ease of propagation, therefore, there are several practical advantages in favor of the Lampsilis mussels.

\section{NIGGERHAED GROUP.}

The shells of the niggerhead group distinguish themselves from all others of the Quadrula class by combining a smocth exterior surface with a high degree of uniformity of quality. The niggerhead takes first place among the Quadrulas.

The niggerhead, Quadrulu cbenus (I,ea) (Pls. II and III) came to be the mussel most sought, and a few years ago, at least, it was the common standard of value. The better shells were suited to the export demand and accordingly have advanced in price. Its preeminent qualities, as compared with other species of this and the following groups, are its clear, pearly luster (equaled by only a few), the relative thickness of the iridescent portion, and its abundance in favorable streams. The nacre is of fine regular grain and lustrous white, except where iridescent. In buying mussels for button manufacture the price is often based upon the percentage of niggerheads.

The niggerhead forms 80 per cent of some mussel beds of the Mississippi but is not so common in the tributaries. It is usually restricted to the larger streams. It was once thought that the Mississippi niggerheads were better than any other, but this is not always the case. Some of the niggerheads from Arkansas are unsurpassed, especially those of the St. Francis River. Like other mussels, the niggerhead varies quite a little in form. Those which are more flat and round are preferred (Pl. III, middle shell), as compared with examples which are elongate (Pl. III, upper shell) or in which there is a noticeable step-off from the thicker forward and central portions to the thinner hinder third of the shell. The shells formerly taken in the Des Moines Rapids above Keokuk were of the better character.

A notable feature of the niggerhead mussel is the markedly iridescent hinder portion of the shell, and the thickness of this portion is generally better sustained in the niggerhead mussel than in any other species displaying iridescence. The buttons finished from 


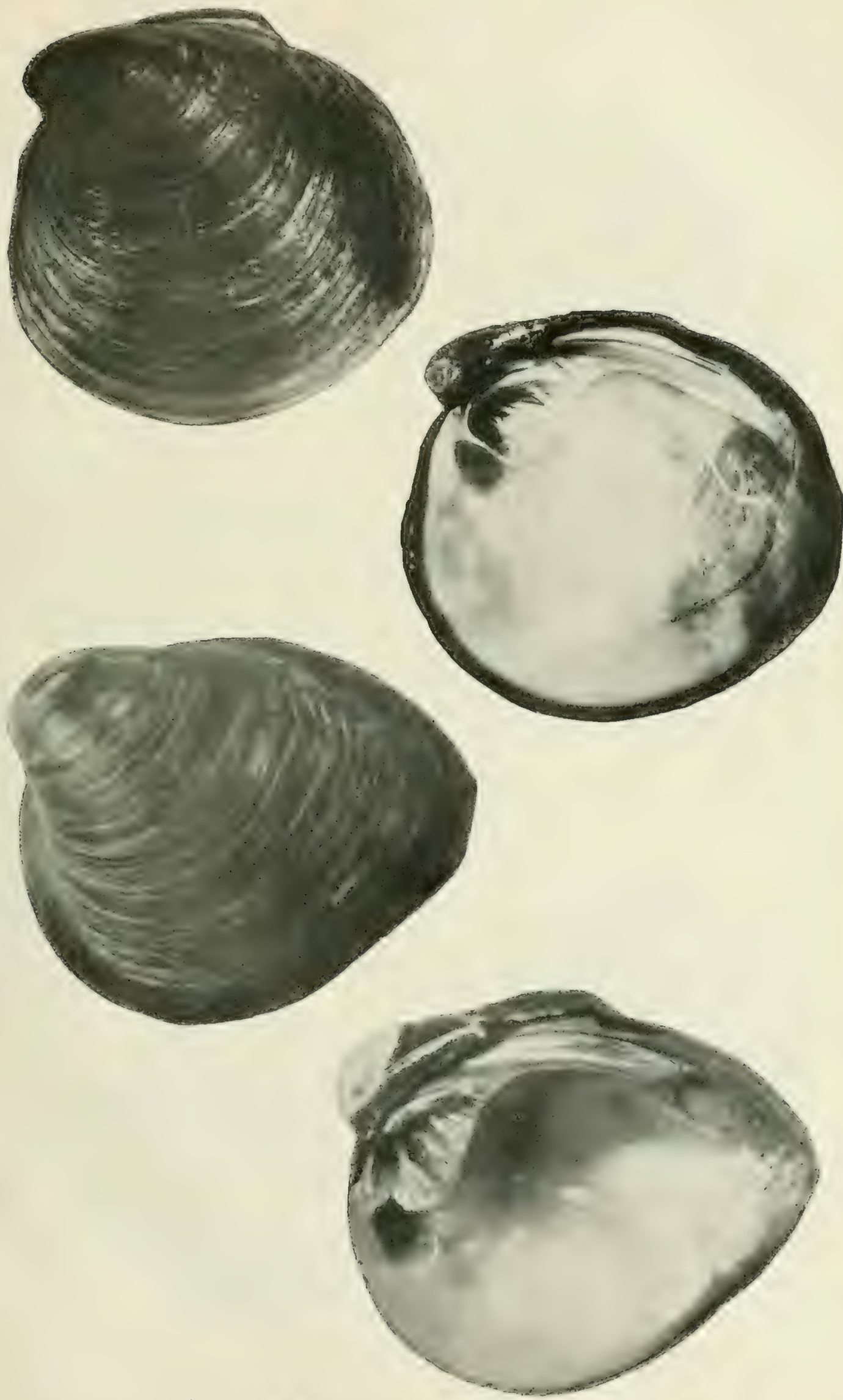



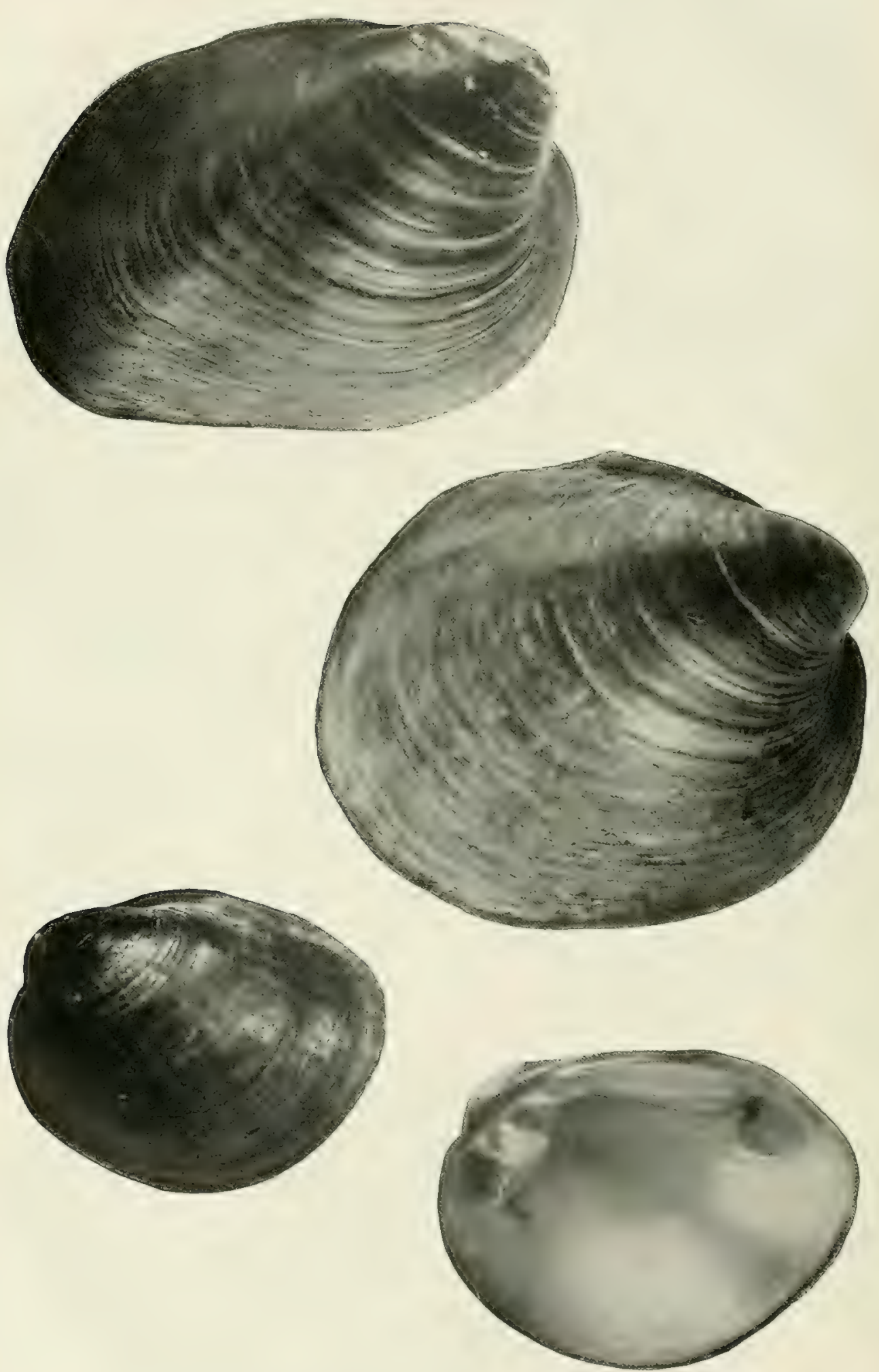

Upper and middle: Nigcerhead, Quadrula ebenus (Lea), from $\Lambda$ ississippi River. (See p. 20.) Lower pair: Hickory-nut, Ohovara ellipsis (Lea), from Mississippi River. (See p. 22.) 
the hinder portion of the shell constitute the shiny backs, as they were originally called, or iridescents, as they are now more generally termed. The iridescents are of exceptional quality and command a substantial premium in the market, where they rival the highpriced buttons made from so-called "ocean pearl," or the shells of certain marine mollusks. While it is usually customary to finish the face of the blank which corresponds to the inner surface of the shell, a better product is obtained with iridescent buttons if the face corresponding to the outer surface, or back, of the shell be finished to make the face of the button.

There is some difficulty not only in keeping the two sorts of blanks separate, but also in insuring that the blanks are cut entirely from the iridescent portion instead of partly from the iridescent and partly from the lustrous white surface. Since comparatively few are obtained in any case, it is not a general practice to cut for iridescents, and most of the iridescents of commerce are cut and finished by chance, as it were, and simply sorted out in the process of grading the finished buttons. A prominent manufacturer stated at one time that a much higher price could be obtained for iridescents if one could obtain a sufficient number upon which to build a line of trade. As it is, iridescents are generally an incidental product.

As compared with shells like the Lake Pepin mucket, or the ordinary river mucket, there is considerably more waste in niggerheads, on account of the heavy hinge and teeth and the relative differences of thickness between the forward and hinder parts of the shell. For this reason particularly, relatively small niggerhead shells, from $\mathrm{I} .5$ to 2.5 inches in greatest dimension, are preferred. Such are the shells taken in the Mississippi about Le Claire, Iowa, and in the White and St. Francis Rivers of Arkansas. In the early years of mussel fishery in any niggethead stream, a large proportion of heavy, coarse shells were taken, and they were much less desirable. Owing to the generally depleted condition of most niggerhead beds, few large shells are now taken, but occasional specimens are found that are upward of 4 inches in length. Some of these are of excellent quality, but there is a great deal of waste in cutting them, as most of the blanks are very thick and have to be ground to the desired degree of thinness for buttons.

The relative economy in use of niggerhead mussels of different sizes is shown by" the following record of tests as to number of blanks per shell and per ton:

Sizes, Weighis, and Button Production for Niggeriead Shells (Approximate Figures).

\begin{tabular}{|c|c|c|c|c|}
\hline \multicolumn{2}{|c|}{ Longest dimension. } & \multirow{2}{*}{$\begin{array}{l}\text { Number } \\
\text { of mussels } \\
\text { per ton. }\end{array}$} & \multirow{2}{*}{$\begin{array}{l}\text { I8-line } \\
\text { blanks } \\
\text { per single } \\
\text { shell. }\end{array}$} & \multirow{2}{*}{$\begin{array}{l}\text { Quantity } \\
\text { of blanks } \\
\text { per ton. }\end{array}$} \\
\hline $\begin{array}{l}\text { Greater } \\
\text { than- }\end{array}$ & Less than - & & & \\
\hline Inches. & Inches. & 174,000 & & Gross. \\
\hline$I^{.4}$ & $I^{2} / 4$ & 110,000 & $\cdots \cdots$ & .......... \\
\hline$I^{1}+$ & 1,3 & 55,000 & ... & \\
\hline $15 / 3$ & $23 / 4$ & $33, \infty 0$ & $1-2$ & 688 \\
\hline $13 / 4$ & 2 & 26,000 & 3 & I,, 083 \\
\hline 2 & $23 / 4$ & 20,000 & 4 & $x, x 1 x$ \\
\hline $23 / 4$ & $21 / 3$ & 15,000 & 5 & 1,042 \\
\hline $21 / 2$ & $23 / 4$ & ro, 500 & 7 & $\mathrm{I}, 02 \mathrm{I}$ \\
\hline $23 / 4$ & 3 & 8,500 & a 8 & 944 \\
\hline 3 & $3^{3 / 2}$ & 6,200 & $a_{10}$ & 868 \\
\hline $3^{2} / 2$ & 4 & 4,000 & $a_{13}$ & 667 \\
\hline 4 & & 3,200 & $a_{14}$ & 622 \\
\hline
\end{tabular}

a At the time of making this table only a few of the larger-sized shells were available, so that the estimates of blanks are less accurate for these sizes. 
Because of the denand for the smaller sizes, a large number of very small shells are being marketed, many of them entirely too small to be of any service whatever.

In the years just preceding 1914 there was a growing export tiade in niggerhead shells of small and medium size, the price reaching $\$ 40$ per ton on the river. In consequence of the export demand, the domestic market was diverted more and more to the inferior grade of shells. Since I9I 4 the domestic market has found a larger supply of the niggerheads available to it, and consequently the domestic demand for lower-grade shells has declined. During several years prior to 1914 the prices paid for niggerhead shells for domestic manufacture varied from $\$ 18$ to $\$ 27$ per ton; in 1919 the price per ton ranges from $\$ 40$ to $\$ 80$.

The niggerlead mussel appears to have two spawning periods, one in spring and another in early and midsummer, but the periods are yet to be accurately defined if they are actually distinct. Like other mussels, the niggerhead is parasitic upon fish, but the only species of fisl known to carry it successfully is the river herring, Pomolobus chrysochloris. Since this fish is characteristic of deeper and swifter streams, the distribution of the niggerhead mussel is restricted accordingly. Even in such a large but generally sluggish river as the Illinois the niggerhead is rare, and Forbes and Richardson report that the river herring is very uncommon in that stream. There are many herring in Lake Pepin, but few niggerheads are taken there, so that other conditions must be unfavorable in this place. The niggerhead is generally found in hard, gravelly or rocky bottoms, and it is very abundant in such rapids as occur on the Mississippi. Its distribution is, however, rather hard to define, since some of the larger examples have been taken in deep and slowly flowing water. The White River of Indiana, the Scioto River of Ohio, and the Duck River of Tennessee have yielded some particularly large shells.

Quadrula solida (Lea) (Pl. II) is very like Quadrula cbenus and is generally regarded by mussel fishermen as the same. The material is equal to that of the niggerhead. Although widely distributed through the Mississippi Basin, the mussel is relatively rare and small and can not be rated as of much importance.

Quadrula subrotunda (Lea) (Pl. IV) is found in the Ohio, Cumberland, and Tennessee River systems. It resembles the niggerhead, and the adults are difficult to distinguish from the latter. At Clarksville, Tenn., it is called the "long solid," and is regarded as one of the best button shells of the lower Cumberland.

The hickory-nut, Obovaria cllipsis (Lea) (Pl. III) must be grouped with the niggerhead in respect to commercial qualities, although it is not closely related to it. This is perhaps the only conspicuous case in which different mussels agrce closely in quality of shell while being rather distantly related in systematic characters. The hickory-nut mussel possesses a shell of essentially the same quality as the niggerhead and has sometimes been called the Missouri niggerhead. The mussel differs from the Quadrulas as a class in being a long-term breeder, carrying the young in the marsupial pouches over the winter period.

Closely related species are Obovaria circulus (Lea) and Obovaria retusa (Lamarck). The former is found principally in the southwestern portion of the basin. It is too small to be of much commercial significance, but will yield a few small blanks. The golf-stick, Obovaria relusa (Lamarck), is found in the Ohio, Cumberland, and Tennessee systems. Wilson and Clark report that it attains a rather large size in the Cumberland, "but the 
BULL. U. S. B. F., I9I7-IS.

PLATIS II:
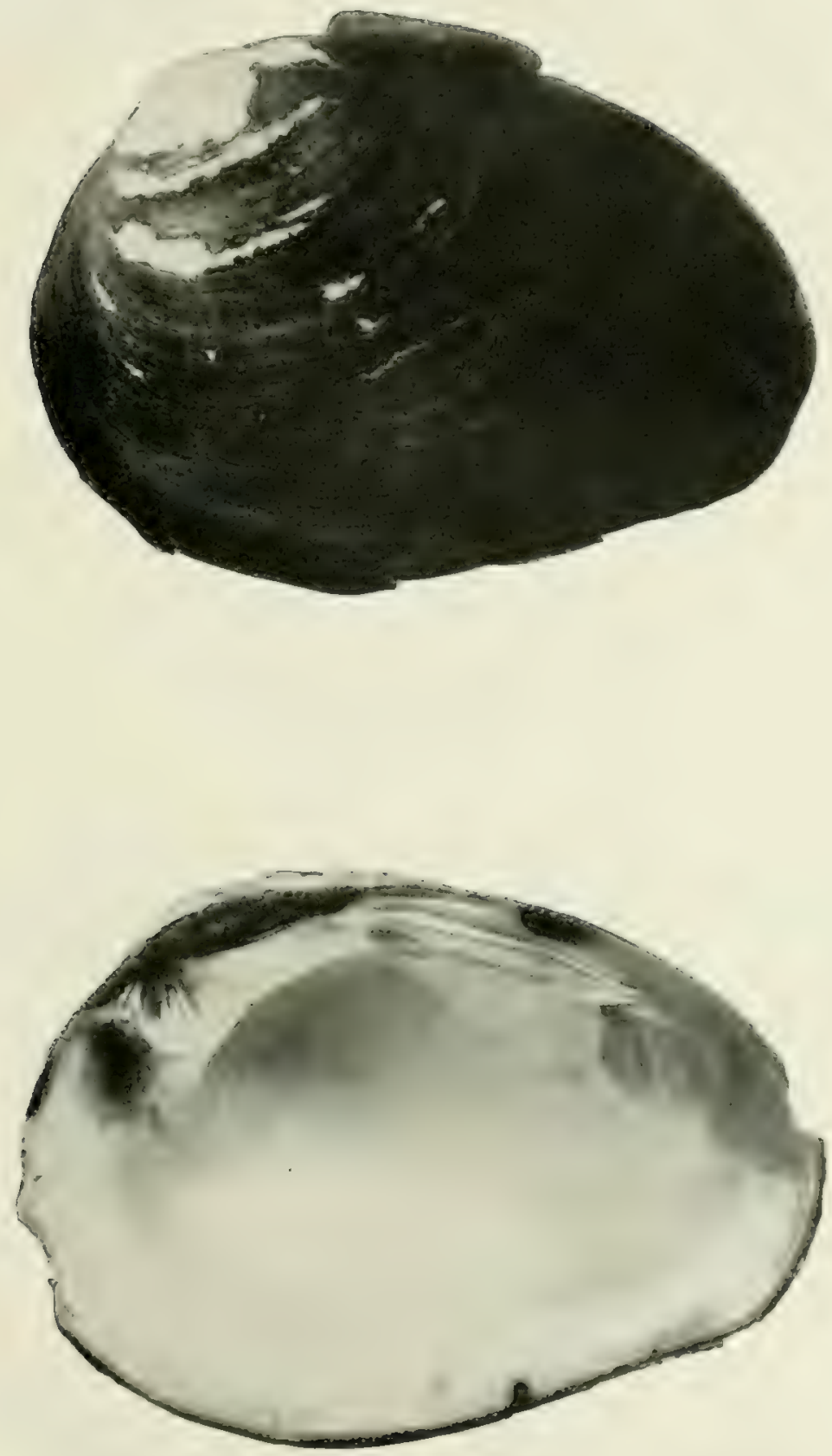

Lonz solid, Qunisula subrotunda (Lea), from Cumberland River. (See: 
BULL. U. S. L. F., I917-I8.

PLATE V.

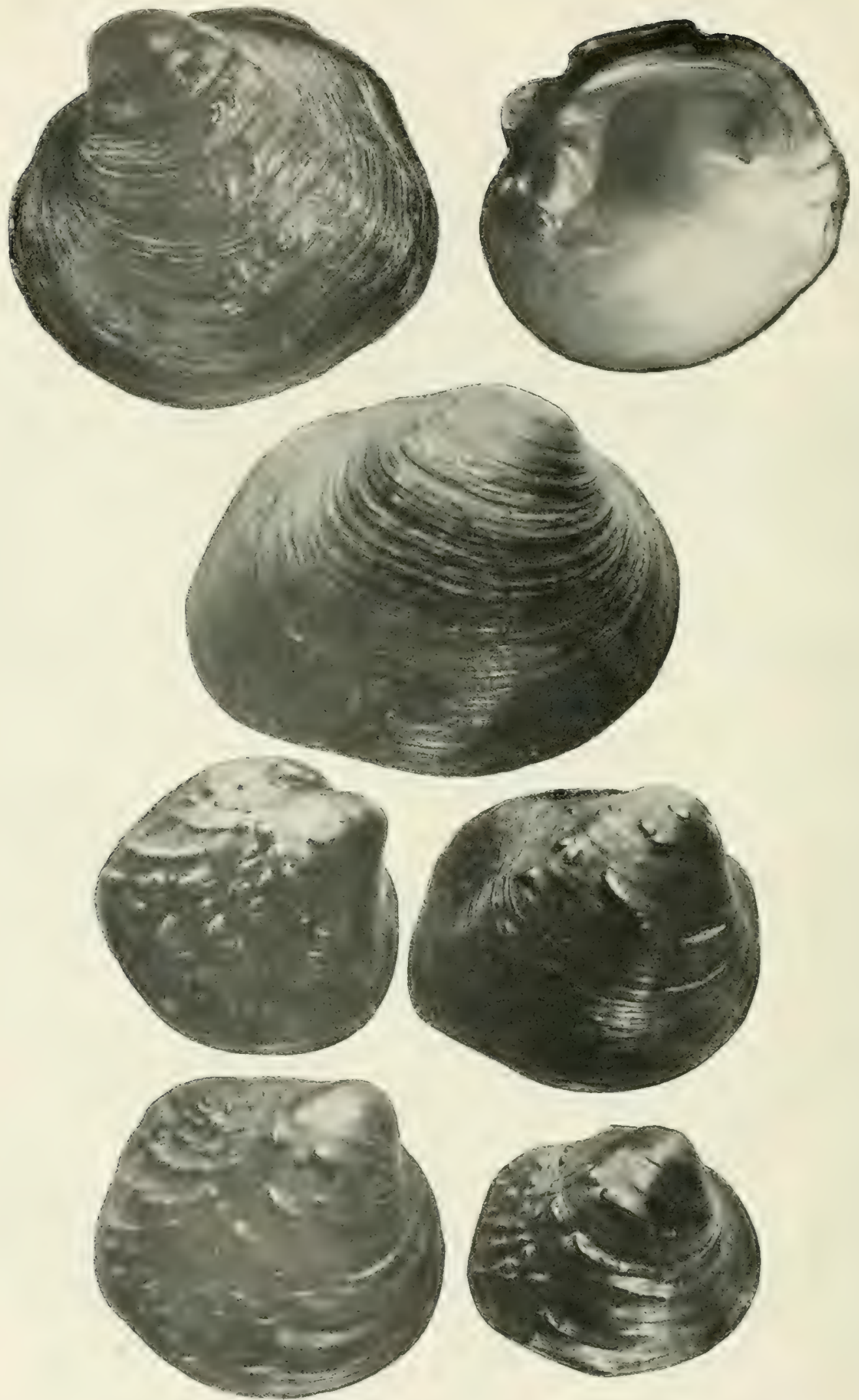

Pimple-back. Quadrula frustulnsa (Le2), from Mississippi Kiver, illustrating diversity of this species in form and sculpture, (Sce P. 23.) 
deep purple of that portion of the nacre withn the pallial line makes it valueless for buttons."

\author{
PIMPLE-BACK GROUP.
}

The better shells of this group have the same general qualities as the niggerhead. The best are inferior to the niggerhead only in that the backs are rough or warty, and the thickness of the tip is less well sustained. The luster is fine, and a portion of the shell is iridescent. The poorer shells of the group are worthless because of color of nacre, shape, or some other objectionable quality.

I,ike the niggerhead, they are short-time (summer) breeders and tolerably restricted in parasitism, as far as is known. Unlike the niggerhead, they rarely, if ever, occur in such numbers as to constitute the principal species in a mussel bed.

The pimple-back, Qualrula pustulosa (Lea) (Pl. V), is distributed throughout the whole Mississippi Basin in different forms and sizes but does not often attain a length greater than 2.5 inches. It occurs mixed in with other species and sometimes forns Io per cent of the mussels in the beds. It is one of the best mussels of the Illinois River. It varies greatly as regards the size and number of pustules and rarely displays an almost entirely smooth shell. Its diversity of form is well illustrated by the several figures in Plate V.

In the earlier years of the industry the pimple-back was not used. The workmen did not like it on account of the pustules on the back, which made it difficult to cut. Later, as button-making material became scarcer, it came into use and is now bought and worked up along with the niggerhead, having the same market value.

The texture is firm, and the shell has a tolerably uniform thickness; since its thickness diminishes rather uniformly toward the tip, it can be worked up economically. It is principally used for small-sized buttons. The color of the nacre is lustrous white, and there is a fine iridescence in the hinder portion.

The pimple-back spawns in early sunmer and midsummer, and the glochidia are parasitic, chiefly upon several species of catfish.

Quadrula pustulata (Lea) (Pl. VI) is like pustulosa but is smaller and with fewer warts. It is comparatively rare and is not distinguished commercially from pustulosa.

Quadrula cooperiana (L,ea) (P1. VI) is a more southern form of pimple-back found in the Cumberland and Tennessce systems. It is called pimple-back, but, unlike the northern form, the nacre may be white or from a pale to a deep shade of pink. A blank of from 30 to 36 lines can be cut from the white shells.

The maple-leaf, Quadrula lachrymosa (Lea) (Pl. VII), is not found in great quantities but occurs in small numbers among other mussels; for this reason it was once known as the "stranger." The material is of a good, white luster and firm texture, but, owing to the thin tips, about half of the blanks can be used only as "tips," which is the commercial term for blanks less than one-twentieth of an inch in thickness. ${ }^{a}$ A small proportion of iridescents is obtained, and, but for the thinnish tips and knobby back, the shell would be equal to that of the niggerhead. When found in considerable numbers in the shell piles at the cutting plants they are sometimes sorted out and cut separately. 
The shells are of about the same size as the niggerhead. Those 2.5 to 3 inches long are fairly large. Mr. Boepple reported that the Scioto and Duck Rivers yielded examples of maple-leaf 4 to 5 inches long. The maple-leaf mussels probably spawn in early summer and midsummer.

Quadrula fragosa (Conrad) (P1. VII) is a very rare species of the maple-leaf, more quadrate in form than Quadrula lachrymosa; while Tritogonia nobilis (Conrad), having a similar external appearance, is confused with the maple-leaf.

The monkey-face, Quadrula metanevra (Rafinesque) (P1. VII), is found in relatively small numbers. It occurs infrequently in the large mussel beds, but is usually found near the bank or outside the main beds. Owing to the large pustules and the very uneven outer surface it is difficult to cut, but with careful handling it may be cut into a few blanks of small size which are of excellent quality. The shell is often used to advantage for cutting one 24 or 30 line button from each shell. In value the shell is sometimes classed with pig-toes. The spawning time is early or midsummer.

The rabbit's foot, Quadrula cylindrica (Say) (Pl. VII), is a very long and narrow form that is familiar to the fishermen of the southern portion of the Mississippi Basin. It is too narrow, convex, and uneven of surface to be of value for button manufacture.

One or the other of the purple pimple-backs, Quadrula granifera (Lea) (PI. VI) and Quadrula tuberculata (Rafinesque) (PI. VI), is found in most large rivers of the Mississippi and Great Lakes Basins, but they are not generally distinguished. The species tuberculata is flattish and is probably found more often in the smaller or tributary streams. Both species are found in small numbers scattered among others. Owing to the purple color of the nacre, the shells have no commercial value. The layers are said to split apart in cutting. The shells have a very attractive appearance and will take a beautiful polish when finished as souvenirs. The mussels are of value in the rivers, since they produce a relatively high number of pearls. Scarcely a tuberculata could be taken in the Grand River in Michigan in 1909 without finding some sort of pearl formation. The spawning period is early summer.

The three-horned warty-back, Obliquaria reflexa (Rafinesque) (Pl. VI), is not at all closely related to the pimple-backs or purple warty-backs. It has one row of large knobs on each shell, and the knobs are remarkable in that those of the two sides are not opposite, but alternate in position; the species can not, therefore, be mistaken for any other.

The three-horned warty-back is found in small quantities along with other mussels. The forward portion of the shell is thick, the tip thin. The form and the knobs are objectionable, and the size is not large, but the texture is good, and the nacre is clear and white and makes first-grade button material.

The species is widely distributed in the Mississippi drainage and elsewhere. It appears to be a summer breeder.

\section{PIG-TOE GROUP.}

This group is rather limited both in variety of species and, except in certain streams, in general abundance of the mussels. None of the mussels is of the best quality.

The pig-toe, Quadrula undata (Barnes) (P1.VIII), is found in small quantities, principally in the Mississippi, and also in some of its tributaries. White River, Ind., has examples of unusually large sizes. While the material is somewhat similar to that 
I3ULL. U. S. B. IF., I9זフ-IS.
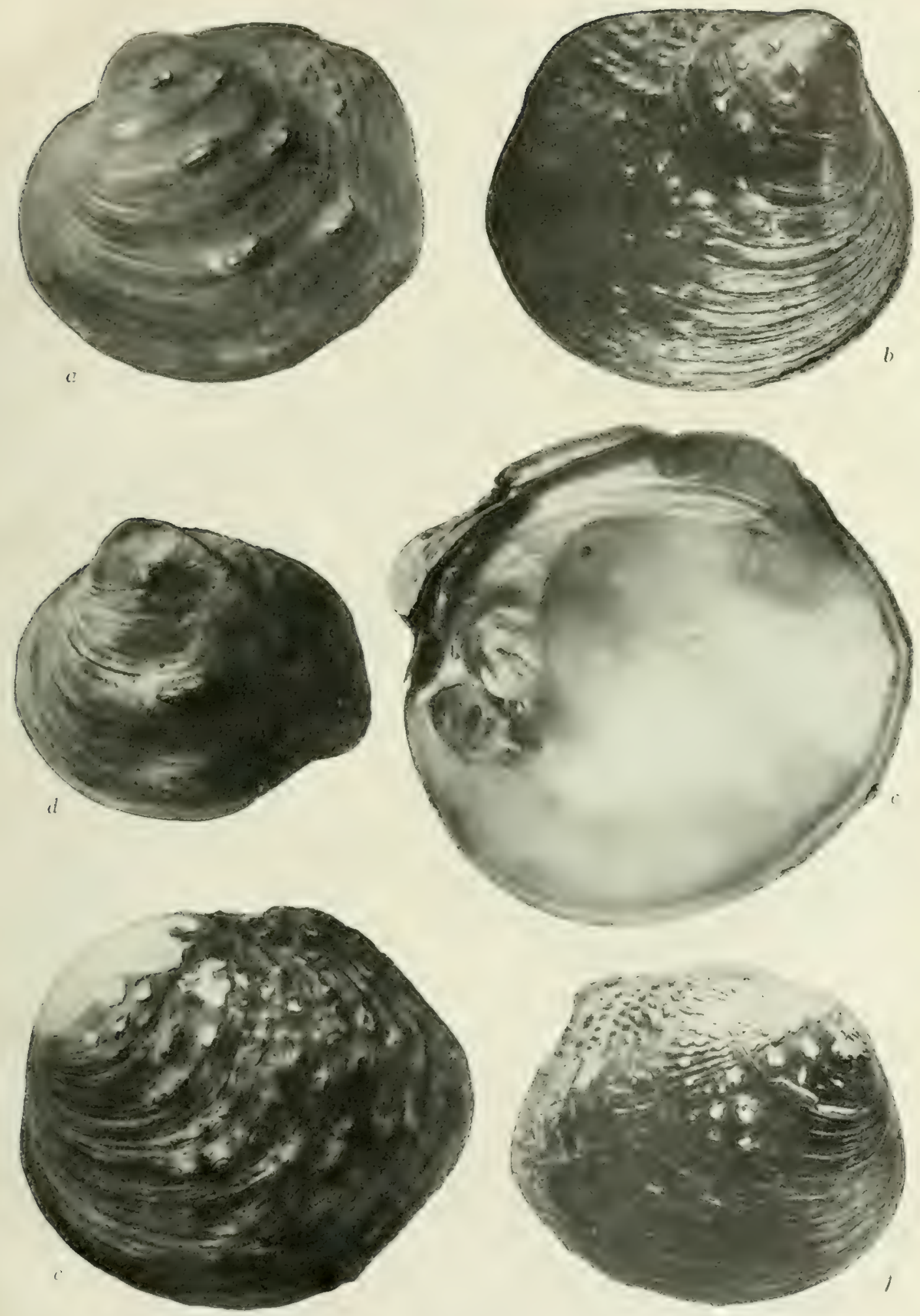

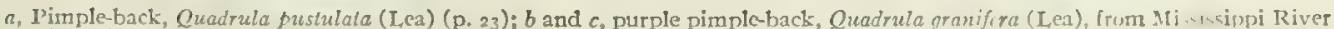

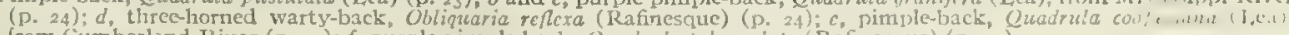
from Cumberland IRiver ( $p .23) ; f$, purple pimple-back, Quadrula luiscrilala (Ratinesquc) (p. 24). 
BLLL. TT.S. B. F., I 9 I $7-$ IS.

PLATE VII.

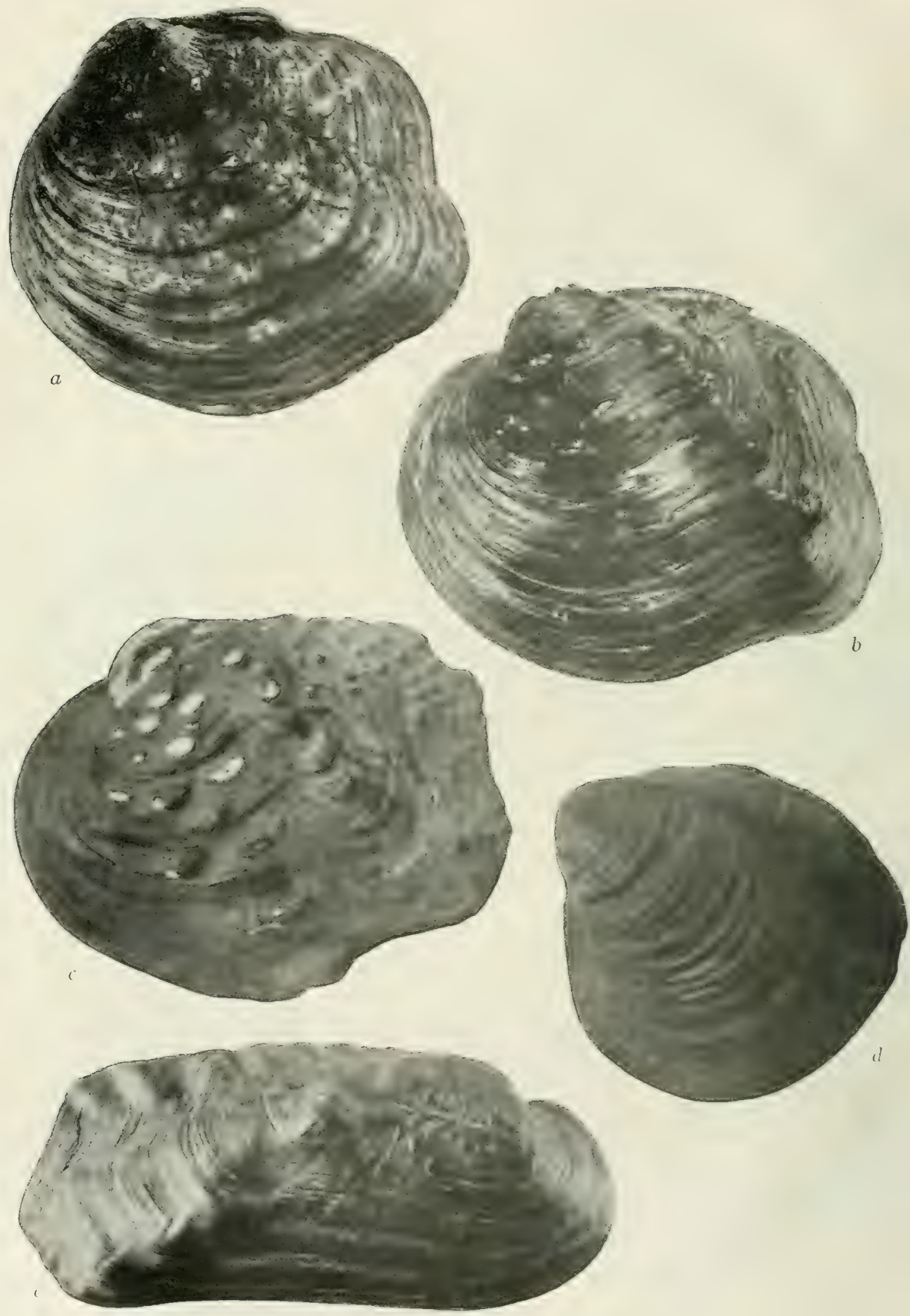

a. Monkev-face, Quadrula melancura (Rafinesque) (p. 24); b, maple-leaf, Quadrula lachrymosa (T,ea) ( 7ula frajosa (Conrad), from Ohio River (p. 24); $\mathcal{H}_{\text {, pig-toe, Quadr }}$
foot, Quadrula cylindrica (Say), from White River, Ark. (p. 24). 
BULL. U. S. B. F., I9I7-I8.

Piatis VIIT.

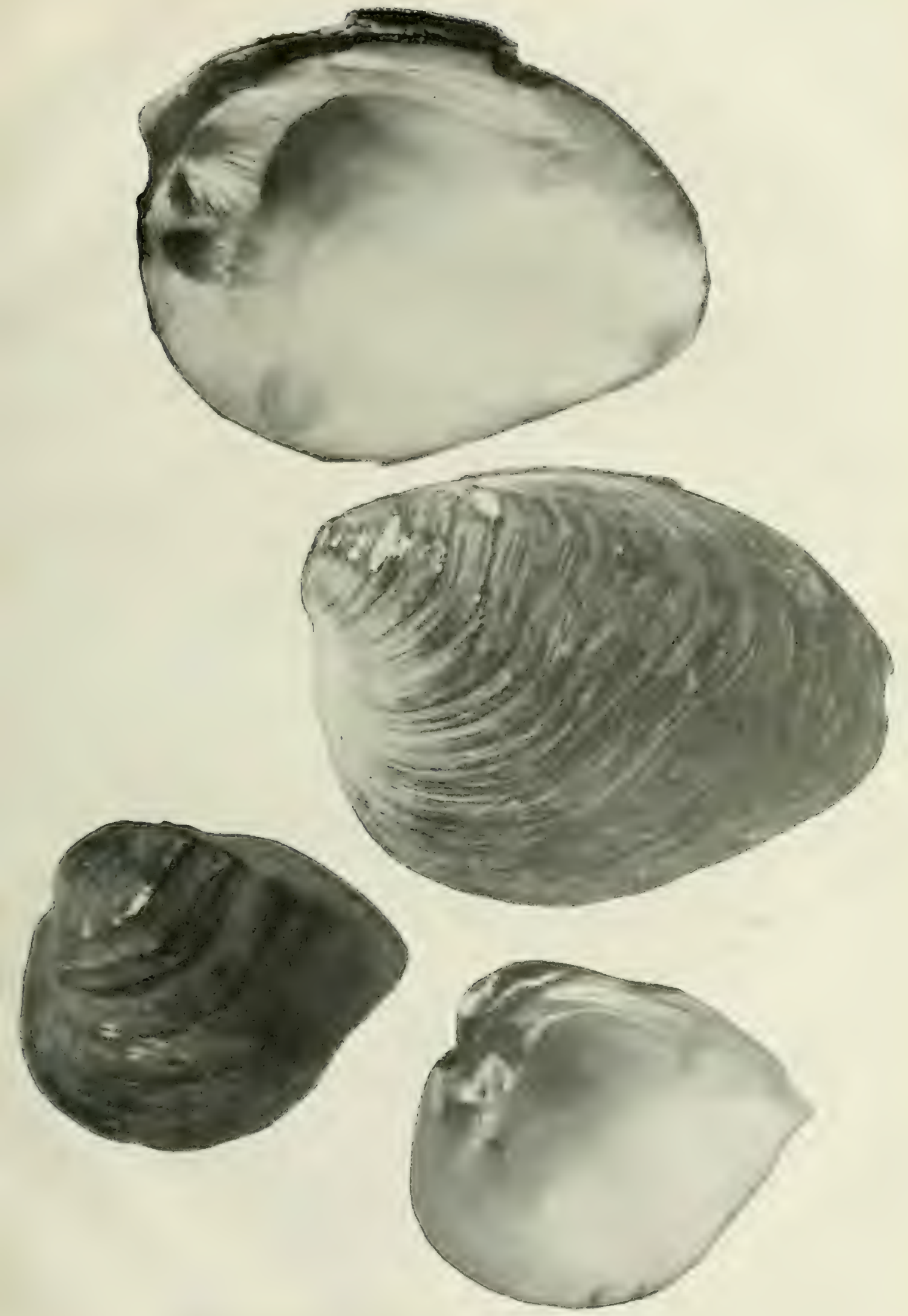

Upper pair: Ohio River pir-tae, Quadrula nblicua (Lamtarck), from Ohio River. (See p. 25.)

Lower pair: 1'ig-toe, Quadrula undala (Barues), from Illiuois River. (See p. 24.) 

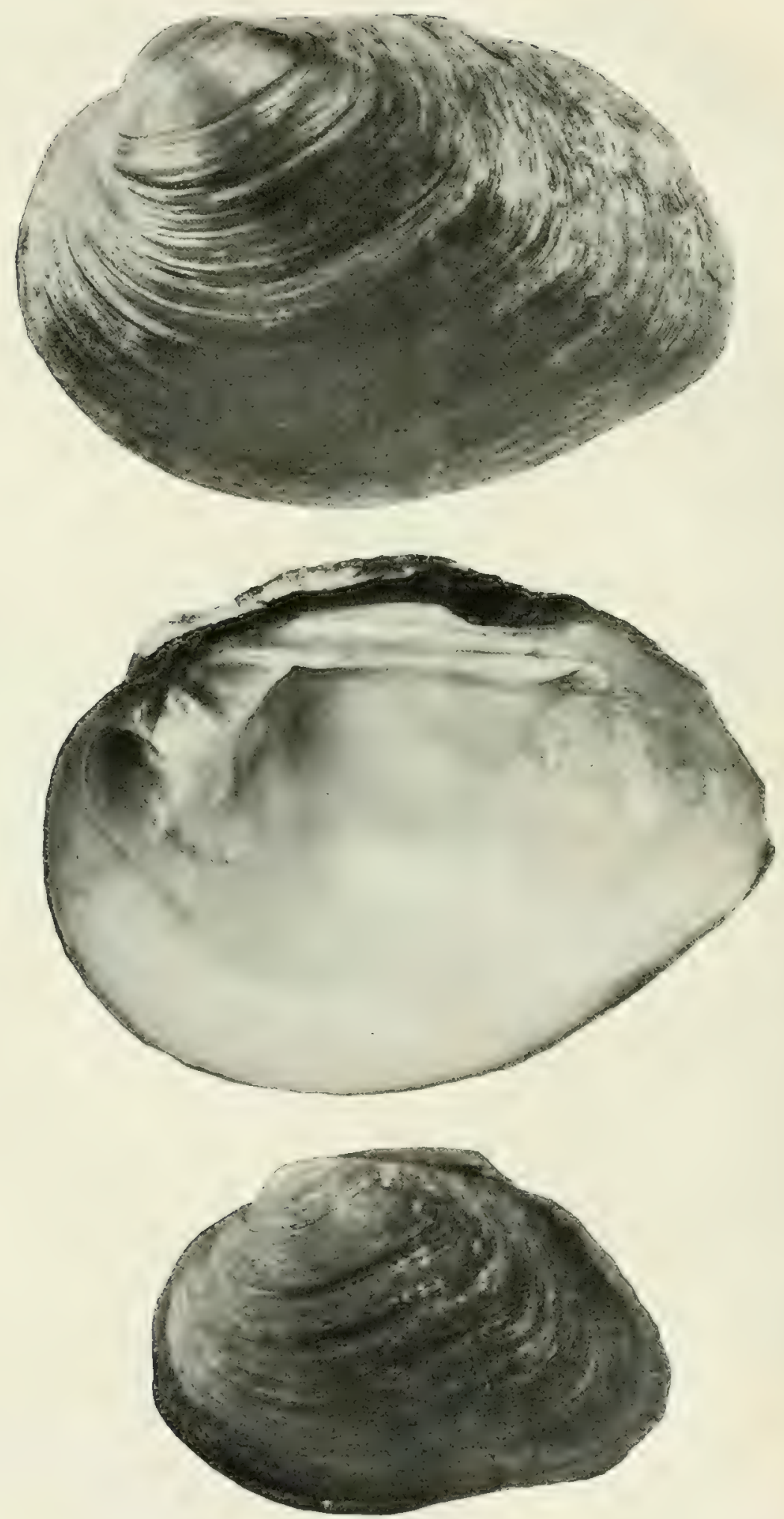

Upper pair: Flat nigcerhead, Oudrula coccinea (Conrad), from Fox River. (Sce p. 25.) At hottom: Wahash pig-toe, Quadrula ruhiginosa (L,ea), from Cedar Creek, Ind. (See p. 25.) 
of $Q$. cbenus, its commercial value is not of first rank; the shell can not be worked up as economically as that of some other species and is usually cut into small-sized buttons. The pig-toe (formerly called Quadrula trigona) is a summer breeder.

Ohio River pig-toe, Quadrula obliqua (Lamarck) (Pl. VIII), is the commonest mussel in the Ohio River. It is found throughout its entire length as far as mussel beds extend. It often forms 80 per cent of the mussels in a bed. In some places in the Cumberland River this is the most common mussel, and the shells from the Cumberland River are superior to those of the Ohio. It is found also in the Illinois River, but is rarely, if ever, seen in the Mississippi.

The commercial value of its shell is not high. When first marketed from the Ohio River it brought only $\$_{1}$ to $\$ 2$ per ton, and buyers were difficult to obtain at that price. In 1910 the price reached $\$ S$ per ton, but it has been higher since $(\$ 12$ to $\$ 13$ in I9I 4 , and about $\$ 30$ in 1919). The material has a poor luster and is chalky, and only the butt part of the shell can be used, as the iridescent portion of the shell is too thin. The nacre is often marked with green spots, and many shells are eroded at the umbones, these qualities being more evident in the shells from the upper portion of the river.

Quadrula plena (Lea) (Pl. VII) and Quadrula pyramidata (Lea) (Pl. XII) are two species that are distinguished taxonomically, but they can not be differentiated commercially from the other pig-toes.

The flat niggerhead, Quadrula coccinca (Conrad) (Pl. IX) and the Wabash pig-toe, Quadrula rubiginosa (Lea) (P1. IX), are found principally in the small rivers. Both species are reported from the Grand River, Mich., and coccinea is common in the James River, S. Dak. They are not uncommon in the small outlets of lakes of the northern States. While the extreme forms are readily recognized, the two species run into each other (in external appearance), so that they are often confused. Rubiginosa has a pronounced posterior ridge. In shape the shells are sometimes rather circular (as is especially true of coccinca) or rhomboidal. They are more compressed than the ordinary run of niggerheads or pig-toes and have a relatively light-colored epidermis. The shells are somewhat puzzling to fishermen but are often called flat niggerheads or thin niggerheads. They are not, however, closely related to the niggerheads in scientific characters or commercial qualities.

Mr. Southall states that the nacre is sometimes rather soft, like the pig-toe, and sometimes very hard, like the bullhead (Pleurobema asopus). It so happens that coccinea (but not rubiginosa) is placed by Dr. Ortmann in the genus Plcurobema. It is probable, therefore, that the commercial qualities, as well as the scientific positions of the two species, are quite distinct; but, in the lack of final information and with the present confusion in common parlance, they are mentioned together. The nacre of both species is of fair quality, but the iridescent part is too thin to be used. Coccinca often has a pink nacre, and in this case it is sometimes called "pink niggerhead."

The spawning times of both species are probably early summer and midsummer.

\section{BLUE-POINT GROUP.}

We come now to species that are much larger in size, always with rough, ridged backs and with a quality of nacre somewhat inferior to the shells of the niggerhead. Many of them are well esteemed, especially because so many blanks can be cut from the single shell, and because they are adapted for the larger sizes of buttons. 
The species are not so restricted in parasitism as the niggerhead and the pimplebacks, and plicata, at least, is carried by several of the game fishes.

The blue-point, Quadrula plicata (Say) (PI. X), and the three-ridge, Quadrula undulata (Barnes) (Pl. X), two very similar mussels, called by the mussel fishermen blue-point and three-ridge, are among the most widely distributed species in the whole Mississippi Basin, being found in most of the rivers and larger creeks in different sizes and forms. Plicata is the thicker species, with heavier umbones, common in the deeper and more sluggish waters, while undulata is flattish and characteristic of headwater or tributary streams. The species seem to intergrade, so that it is frequently difficult or impossible to distinguish them. The clammers do not seem to recognize the two species, but apply the term three-ridge or blue-point indiscriminately.

Generally speaking, these mussels, even when clear of spots, work with a good deal of waste, on account of the heavy hinge and teeth, and they yield a considerable number of second and third grade buttons, although some buttons of very good quality are also produced, including a few iridescents. Blue-points, three-ridges, and washboards (see below) were worth about $\$ 12$ per ton in 1914 , and about $\$ 30$ in 19 I9.

The commercial value of the shells varies greatly in different rivers and creeks. In the Mississippi River, for example, the young mussels can be sold with the niggerheads. The value of the shell decreases as the mussel grows older. The shell loses iridescence and becomes more brittle and hard, and consequently difficult to work up; the layers lose their fimness of attachment, so that they split off easily. Old shells, moreover, are frequently spotted. It is found in manufacture that the iridescence of tips from these shells is enhanced by the processes of bleaching. These mussels spawn in midsummer.

In the streams of the gulf drainage in Florida, Georgia, and westward these species are replaced by Quadrula perplicata (Conrad), Quadrula elliotti (Lea), and Quadrula neislerii (Lea). Quadrula perplicata occurs in the Cumberland under the common name of round-lake shell.

\section{WASHBOARD GROUP.}

This group comprises, practically speaking, only a single species.

The washboard, Quadrula heros (Say) (Pl. XI), is the largest and heaviest species of mussel in the Mississippi Basin. One example 8 inches wide and I inches long and weighing over 4 pounds with the flesh, was collected by the late J. F Boepple in the Salt River, $\mathrm{Ky}$. The empty shell weighed about $3 \frac{\mathrm{T}}{2}$ pounds.

The washboard is found chiefly in large rivers in quiet, deep water and on gravel and mud bottoms.

The Wabash and Illinois Rivers have the highest percentages of washboard, although there are beds in the Ohio River where this species forms nearly 50 per cent of the catch. The shell is generally of an oval outline and more or less elongated. It is valued chiefly because of its large size, making it suitable for cutting the largest-sized buttons. The material is tough and the grain uniform and regular. The iridescent part breaks easily in sawing, owing to the undulations on the back. The nacre is usually discolored with yellowish or greenish spots, and the older the shell the larger are the spots. We have received pink shells from the Illinois River. Young mussels from 3 to 4 inches long have only a few spots or none, and the iridescent part is as thick as in the older mussels, being thick enough for buttons. This part of the washboard is very similar to the 
BULL. U. S. B. F., I9I7-r8.

PLATE X

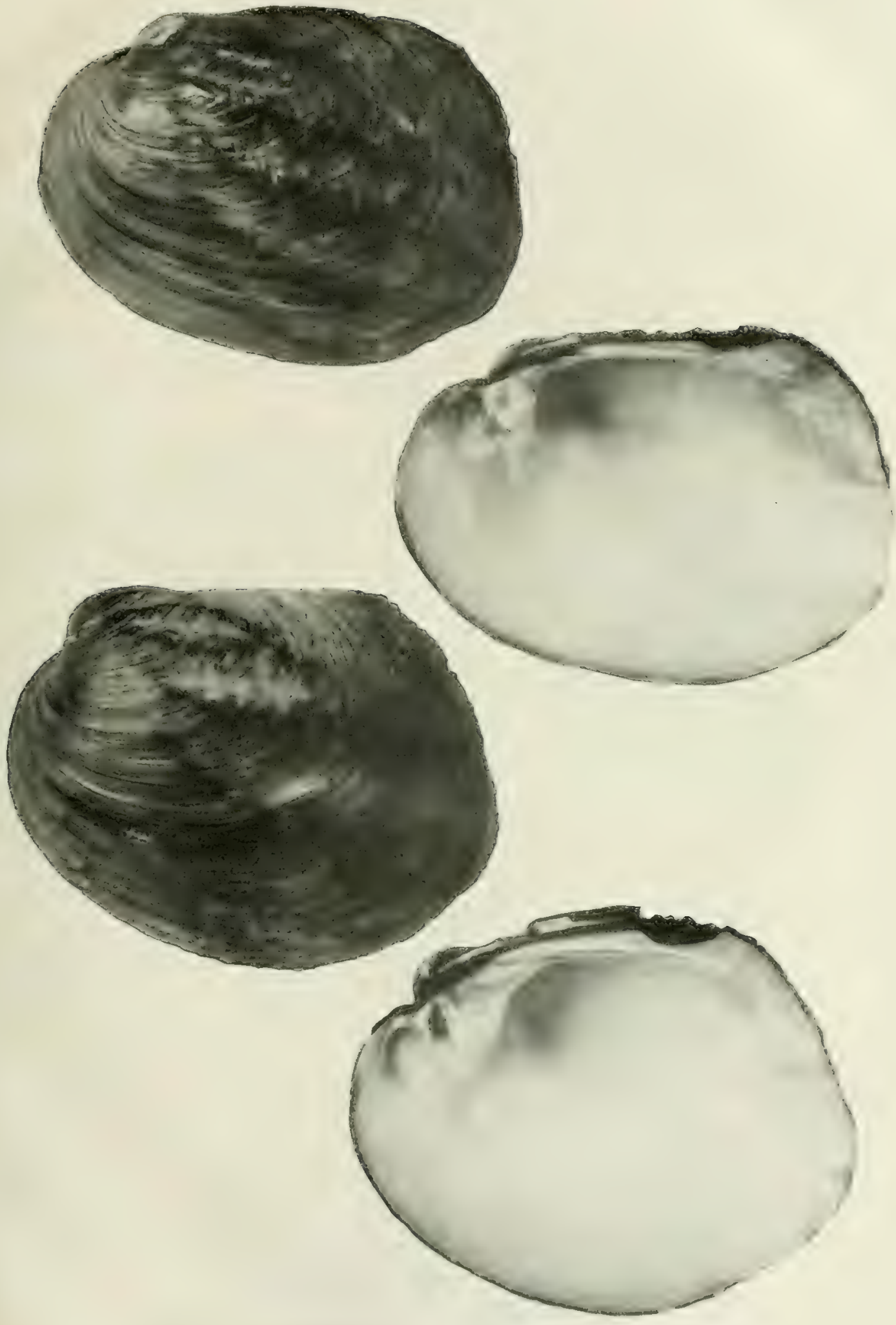

Upper pair: Three-ridce, Quadrula undulata (Bames), from James River, S. Dak. (See p. 26.)

Lower pair: Blue-puint, Qudeula plicata (Say), from Illinois River. (See p. 26 . 

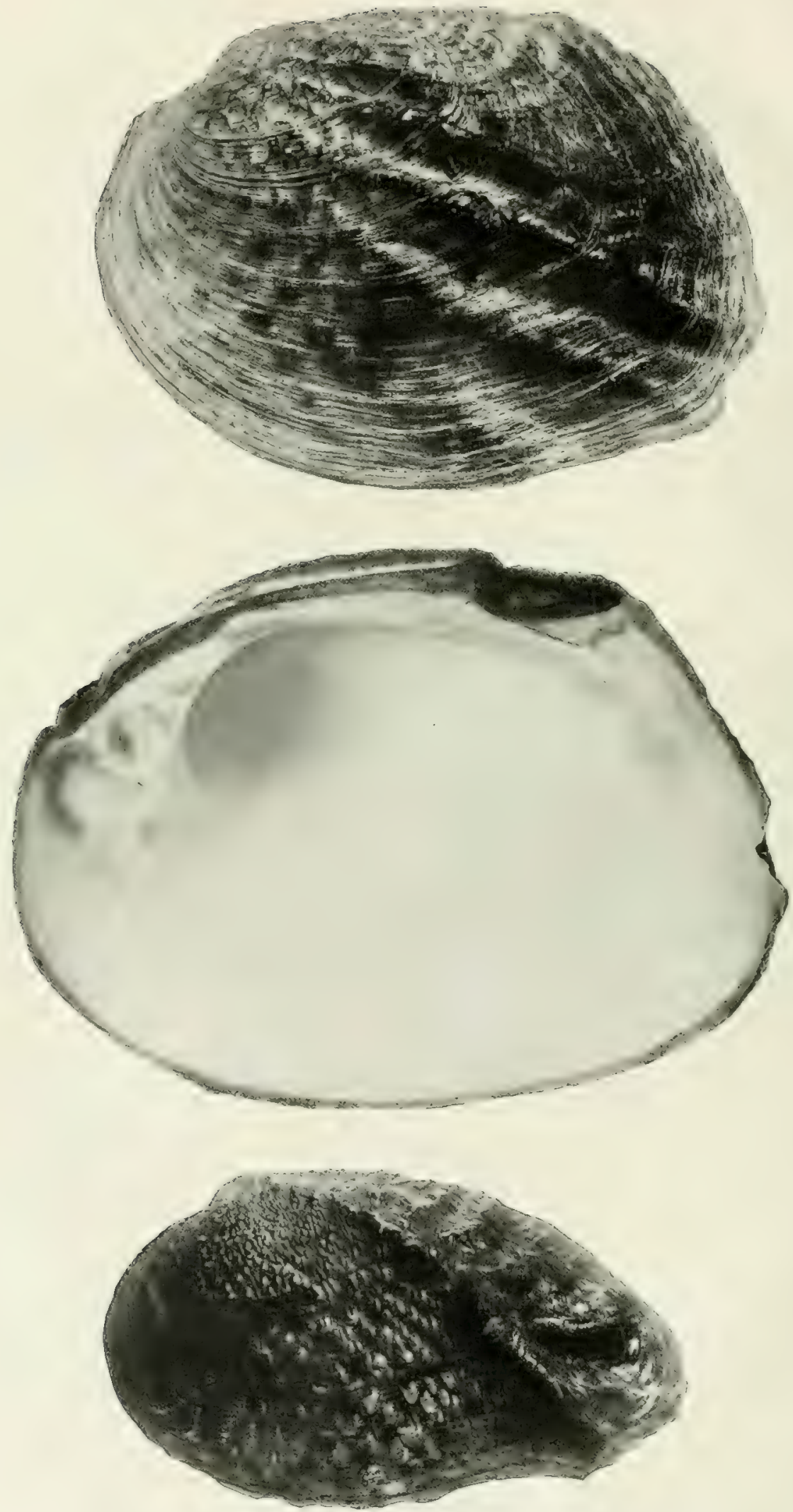

Upper and middle: Washboard, Quadrula heros (Say), from Mississippi River. (Sce p. 26.) At battom: Buckhorn, Triloumia tuberculala (B.rnes), from Mississippi River. (See p. 27. 
BULL. U.S. B. F., I9I7-18.

PLATF XII.
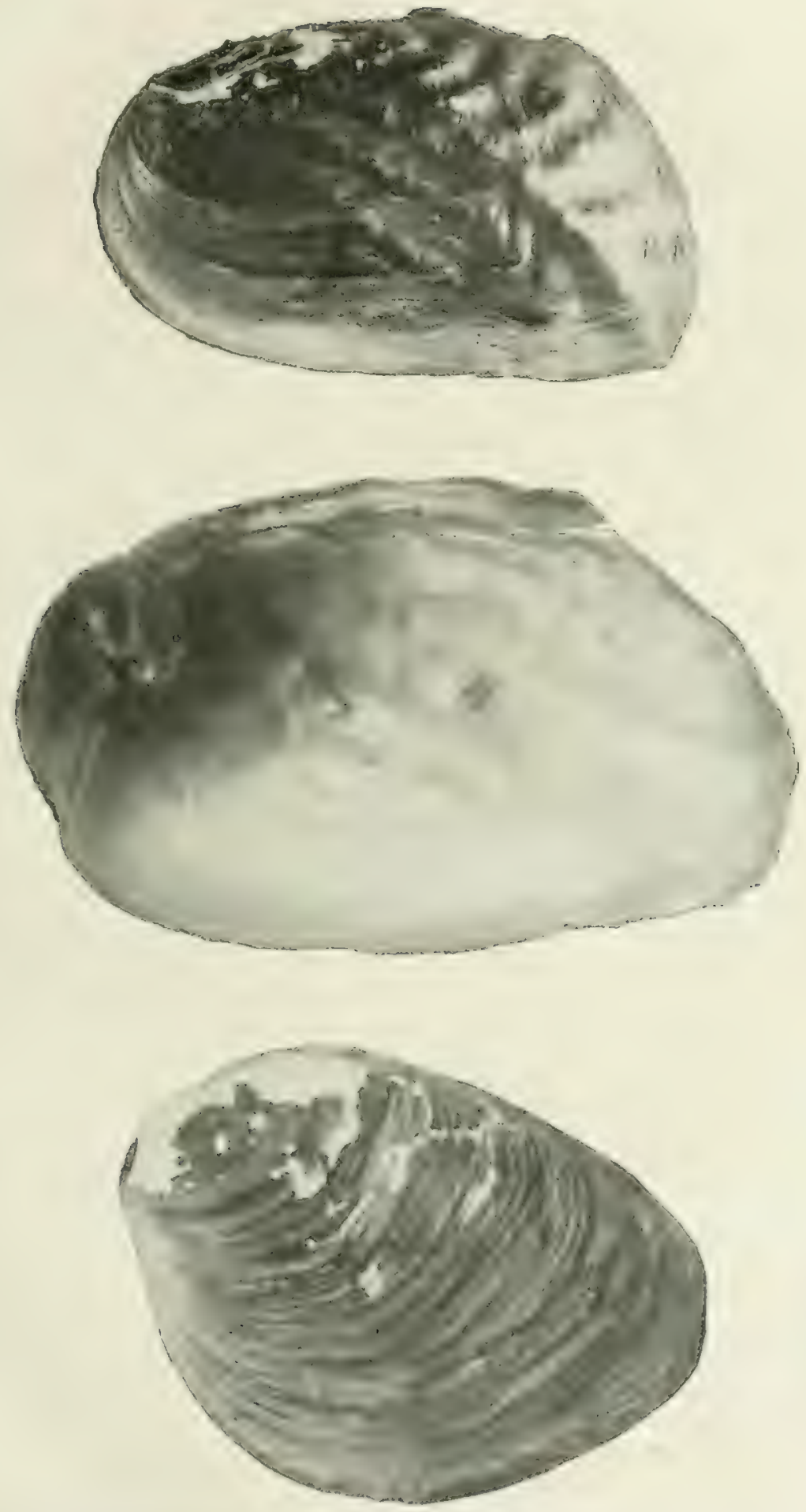

Upper and middle: Bank-climber, Quadrula trapercides (Lea), from White River, Ark. (Sce p. an.) At bottom: I'ig-toe, Quadrula pyramidata (I,ea), from Cumberland River. (Sce N. 25. 

mother-of-pearl of the ocean. The washyoard spawns in the late summer and carly fall.

In places in Florida, Georgia, and A' 2 bama heros is replaced by Quadrula boykiniuna (Lea).

The bank climber, Quadrula traperoiles (I.ea) (I'I. XII), should be mentioned in this connection. It is found in streams flowing into the Gulf of Mexico, from Alabama to Texas, and northward in the Mississippi system to Tennessee and Arkansas. The shell has a deep purple nacre and is quite valueless for manufacture. Possibly it yields a proportion of pearls. It is a very familiar shell in Louisiana, Arkansas, and eastern 'Texas.

The buck-horn, Tritogonia tuberculata (Bames) (P1. XI), is, perhaps, better named in connection with the washboard than anywhere else. It has a naturally white nacre of good texture and quality, but is often spotted. It is thinnish at the tip and has a very rough back; some shells huve a pinkish tinge. It has also been called pistol-grip, a name appropriate to the form of elongate examples. There is a short form characteristic of males and a much more elongate form common to females. It is found widely in the Mississippi and Gulf drainages and is reported as a summer breeder.

\section{LAMPSILIS CLASS.}

Such familiar and valuable shells as the mucket, the Lake Pepin mucket, and the sand shells are representatives of this class of mussels. In many respects they are quite distinct from the Quadrulas.

In commercial quality there is a wider range, not only between the species composing the class, but even within the individual species in most cases. The highest-priced shells of all are of a Lampsilis species, while some of the most worthless paper-shells are species of the same genus. Muckets may possess excellent qualities, or again they may be pink or otherwise inferior; some pocketbooks are good, some are worthless. Fat muckets from one region may sell for scarcely less than niggerheads, while those from another locality would not be looked upon with the thought of marketing. The species of Quadrulia, as a rule, have more uniformity wherever found; some are better than others, but when a Quadrula is found there is a reasonable presumption that it is a shell of a certain grade, according to its species.

The primary commercial difference between Quadrula and Lampsilis is that the latter rarely shows any marked iridescence. Sometimes iriclescent qualities are referred to, but this generally means merely an unusually bright luster. On the other hand, Lampsilis mussels have a more uniform thickness, and therefore yield a. larger number of blanks per ton than any of the Quadrulas.

Some of these mussels are not surpassed in texture and luster, as will appear, and therefore this class of shells has been growing in favor in recent years. As previously mentioned, the raw materials first used in fresh-water button manufacture were species of Lampsilis.

The Lampsilis mussels are more rapid of growth than the Quadrulus, and they are long-term breeders. In the latter part of the summer, as a rule, the marsupial pouches are filled with eggs which develop into glochiclia, and in this condition all or : large proportion of them are held over the winter. Glochidia can be found in the gills of the females at almost any season of the year. July and August, principally, constitute the $110306^{\circ}-19-2$ 
intermediate season, when few glochidia can be found. These months, it is important to note, are the height of the breeding season for most of the Quadrulas.

\section{MUCKET GRPUP.}

Ve include in this group three abundant and important shells, the mucket, the fat mucket, and the southern mucket, and three species less abundant and less readily distinguished.

The mucket, Lampsilis ligamentina (Lamarck) (Pls. I and XIII), is one of the most generally distributed mussels in the United States. The commercial value of the shells varies primarily. with the rivers from which they are taken. The muckets of the Mississippi River have not been highly esteemed. The butt (or heavy) portion is considered too chalky, and the tips are rather thin. In many of the shells the nacre is pink in color, which greatly reduces the value. There are, however, some places in the river where the quality is superior. The muckets of the Wabash River have been considered very fine, but they are now rather scarce. The Yellow River, Ind., has produced excellent muckets. In the Ohio River better muckets are found higher up the river. Mr. Boepple reported them abundant and of good quality at Marietta, Ohio. They are abundant in the Green River, Ky., and are of excellent quality in the Little Barren River, Ky. Mr. Boepple also stated that he had found muckets which approached marine shell in luster in the Cottonwood River, Kans. Muckets are comparatively scarce in the Illinois River, but some of the fishernen believe they are becoming more numerous.

The mucket can be found in alnost any sort of stream, and the best shells are usually found where there is a good current, but this is not a universal rule. In the Grand River, Mich., where the current is good, the nuckets have an excellent luster, but too large a proportion of the shell is very thin.

The material works up well; it is soft and has a straight grain, although in old shells the nacre splits, and the nearer to the hinge one is cutting the worse this trouble becomes. Some muckets have excellent luster and clear color, but these qualities vary with the locality. The color varies even in the same bed; pink muckets and white muckets are found side by side, and the cause of this difference in color is as yet unexplained. The values on the basis of ton price in I9I4 and 1919 , respectively, may be stated as approximately $\$ \mathrm{I} 7$ and $\$ 45$.

The mucket may, perhaps, liberate its glochidia to some extent in the fall, but principally in spring and early summer. It has a relatively wide range of fish hosts, principally among the game fishes.

The little rainbow shell, Lampsitis iris (Lea) (Pl. XIII), with its bright-green, broken rays on a yellowish shell, is often mistaken for a young mucket. It is found in the Ohio River system, and also in the streams of Illinois, WVisconsin, Michigan, and eastward.

The southern mucket or yellow-back mucket, Lampsilis ligamentina gibba Simpson (P1. XIV), one of the finest of all shells, differs from the common mucket in being shorter and more compressed. The shell is therefore flatter and the thickness more even; the texture and luster are unsurpassed, and the material works easily and economically. This form is found in streams south of the Ohio River and perhaps, too, in that 

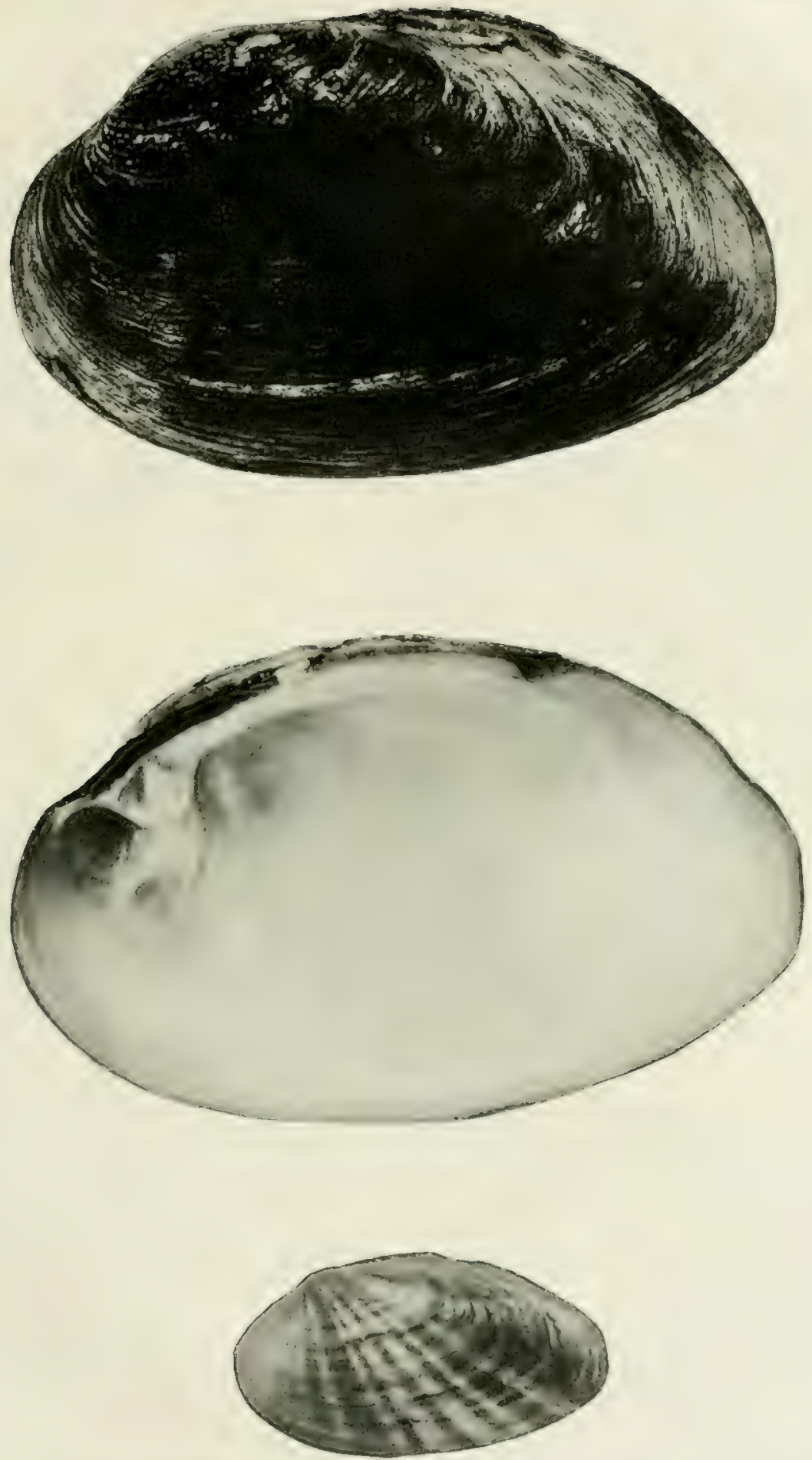

Upper and middle; Mucket, Lampsilis ligamentina (Lamarck). (See p. 28.) At bottom: Jainbow-shell, Lampsilis iris (Lea), from Tippecanoe River, Ind. (Siee $\mathrm{p}$. $2 \mathrm{R}$. 
BULL. U.S. B. F., I9I7-IS.

PIATE XIV.

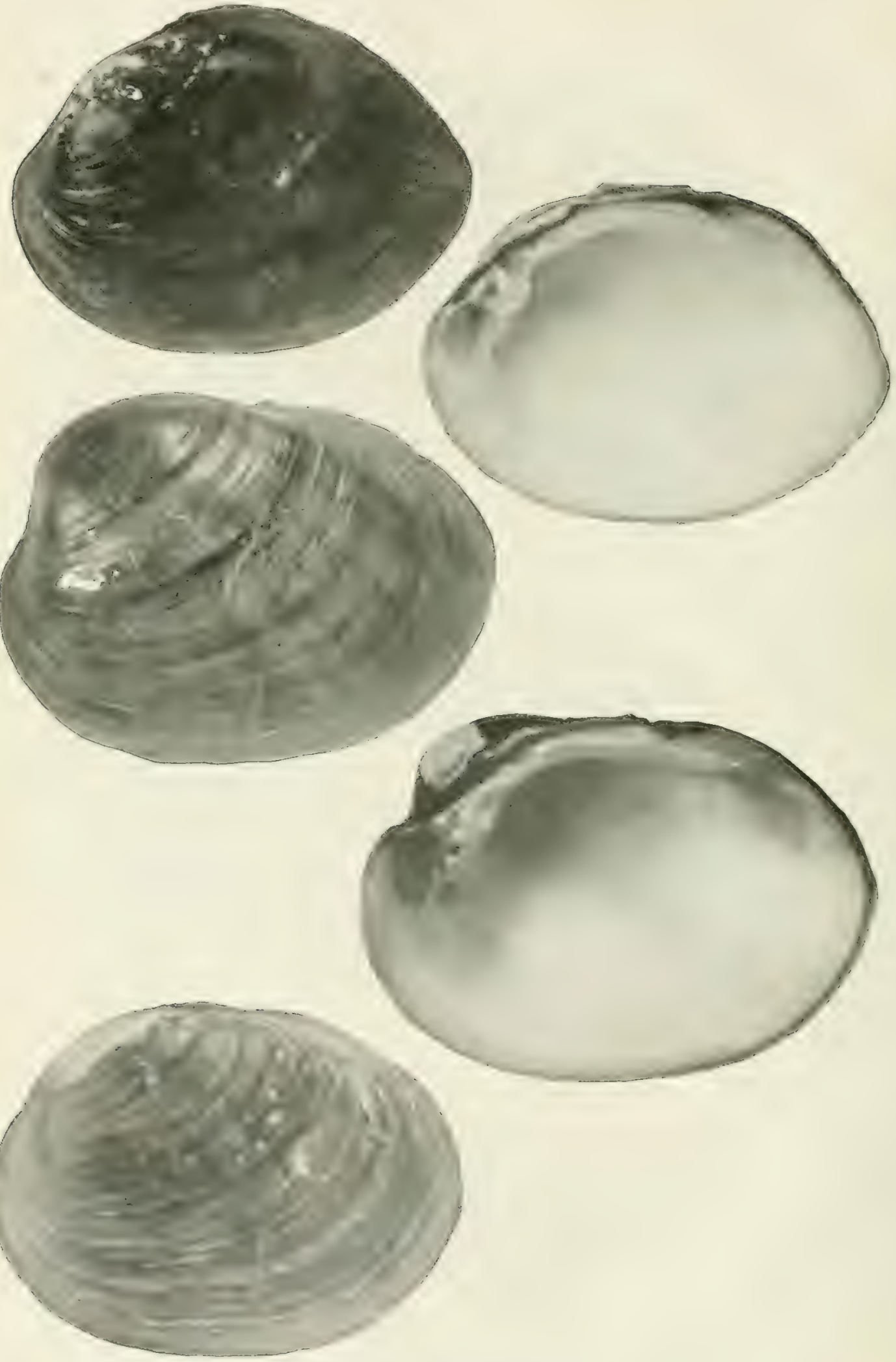

Upper pair: Southern mucket, Lampsilis ligamentina gibba (Simpson), from Black River, Ark. (See p. 28 .

Middle pair: Higgin's eye, Lam psilis hivoinsia (Lea), from Mississippi River. (See p. 27.)
At brttom: Lampsilis orbiculata (Hildreth), from Cumberland River. (See p. 29.) 
river. Our collections have been principally from the Cumberland, Clinch, and IIolston Rivers.

The Higgin's eye, Lampsilis higginsii (Lea) (Pl. XIV) ${ }^{a}$ is a rather unconmon species, but a few may be found in almost any carload of mixed shells from the ()hio or Illinois Rivers, or from the middle section of the Mississippi River. The nacre is often yellowish or pinkish, but white shells are of first grade, with good thickness and luster.

Lampsilis orbiculata (Hildreth) (PI. XIV) very closely resembles Lampsilis hiyginsii, but is more southem in its distribution. Its qualities are about the same as those of the preceding species.

The fat mucket or Lake P'epin mucket, Lampsilis luteola (Lamarck) (I'ls. I, XV and XVI), would not have been classed some years ago as an important commercial shell. Now, since the Lake Pepin form has come into use, the species is considered one of the best. It is widely distributed over the upper half of the Mississippi Basin, the Great Lakes drainage, and, according to Simpson, the entire Dominion of Canada east of the Rocky Mountains. Its occurrence as an economic form is quite restricted. The fat mucket is rarely found in rapidly moving water but is adapted to slow or still water. It is the principal shell of the lakes of the Middle West, both in the Mississippi and the Great Lakes drainage, but such waters are not generally suited to the production of commercial shell. The fat muckets of the lakes are usually somewhat dwarfed and inflated, with the shell strongly curved, and too thin to produce 1...vis than one or two small blanks, if any. In some cases they might be confused with dwarfed pocketbooks. The species is also found in rivers and creeks, but usually close along shore, perhaps well up on the banks and out of the main current. Examples from such locations generally have an inflated but more elongate form, the forward part (or, in commercial terms, the butt) of the shell being thick enough for blanks, while from one-third to one-half of the shell, or more, is so thin as to produce only tips at best. In this form the fat mucket is sometimes much like the slough sand-shell in strperficial appearance. Such shells can be used, but they are not always valued highly.

Within recent years the beds of Lakes Pepin and St. Croix have been discovered commercially. These lakes yield a very distinct type of fat mucket, which is remarkably even in thickness, with a surface relatively flat in males, and even in females much less curved than usual. Practically the entire surface can be cut into blanks which are of a suitable thickness. No other shell of any species cuts with so little waste, either as to the proportionate weight of shell that is thrown away after cuting out the blanks or as to the small amount to be ground from the blanks in reducing them to a proper thickness for buttons. The shell is clear white, the texture good, and the luster leaves nothing to be desired. The Lake Pepin mucket brought in 1914 and 1919, respectively, about $\$ 20$ and $\$ 35$ per ton.

In the brilliancy and the extent of the iridescent portion the Lake Pepin mucket is not quite equal to the niggerhead and pimple-back, but a measure of iridescence is found, and in pearly character of the nacre it is fully equal to any other. As regards conomy, it has been found that 14 or 15 pounds of blanks are a very good return from 100 pounds of niggerhead shells, while more than 20 pounds of blanks may be obtained

a This species and the following may be more closely related to the pocketbook than to the mucket, as Ortmann holds for orbiculate. Our classification is only for shell qualities, of course. 
from Ioo pounds of Lake Pepin muckets. This shell is, therefore, the nearest approach to an ideal button shell now found among fresh-water mussels.

The rate of growth is relatively rapid. At the Fairport station mussels of this species have grown to a length of more than I inch within six months after the date of infection upon the fish. These were in floating crates in the river. The age of commercial shells can not yet be positively stated but it is probably from 4 to 6 years. ${ }^{a}$ Like most others of the genus, it is a long-term breeder. Its fish hosts are the common game fishes, such as the basses, crappies, sunfishes, perches, and sand pikes. Some have been grown in ponds at the Fairport station to a length of about I inch in a season, and very thin buttons have been cut from such shells at the end of the second growing season. The Lake Pepin mucket lends itself to methods of artificial propagation better than any other species.

Lampsilis hydiana (Lea) may be called the southern fat mucket, being found in the lower portion of the Mississippi Basin. The specimens we have had might easily be confused with the Lake Pepin form and appear to resemble it in qualities of shell. It occurs in Louisiana, Texas, Arkansas, and neighboring States.

The butterfly, Plagiola securis (Lea) (Pl. XV), presents another case of a mussel which must be placed far from its systematic position. Its shell qualities place it more nearly with the muckets than with any others. It is a well-known mussel of the larger streams of the Mississippi and Ohio drainages and is reported from Alabama. Its beautiful form and markings give it the name of butterfly. Mr. Boepple remarked that comparatively few females were found, and that they are of much lower commercial value than the males, on account of being so much thicker and lacking in luster.

The shells of the males are very flat and have a white color and good luster, with a rather uniform thickness over most of the shell. There are few places where roo pounds can be obtained, but they are often met with in mixed shipments, and are valued.

It is a long-term breeder, and its most common fish host is the fresh-water drum, or sheepshead, Aplodinotus grunniens.

A smaller species, the deer-toe, Plagiola clegans (Lea), is very common, but rarely attains a size sufficient for cutting blanks.

\section{POCKETBOOK GROUP.}

The pocketbook, Lampsilis rentricosa (Barnes) (PIs. XV and XVI), is a large and very inflated mussel found throughout the Mississippi and Great Iakes drainages (as well as in the Nelson River), in large and small rivers, and in some lakes. It is one of the species most familiar to the fishermen and most readily obtained. It is found in gravel bars or sandy bottom, sometimes alongshore and sometimes in the deeper water.

The commercial value of the pocketbook is generally rather low. The shells of the male are better than those of the female. There are some rivers in which the pocketbook becomes a very good shell for button manufacture. Mr. Boepple had an example from the Yellow River of Indiana, from one side of which 52 i 8 -line blanks were obtained, all of which would make good buttons. The Yellow River specimens are among the best, since the hinder or tip portion of the shell is thick enough for buttons. As a rule better shells are found in small rivers and creeks than in the large rivers.

a At ages of $3^{1 / 2}$ and $4^{\frac{1}{3}}$ years some Lake Pepin muckets reared in a pond at the Fairport station yielded 12 to 2214 -line blanks over $2 \frac{2}{2}$ lines in thickness. 

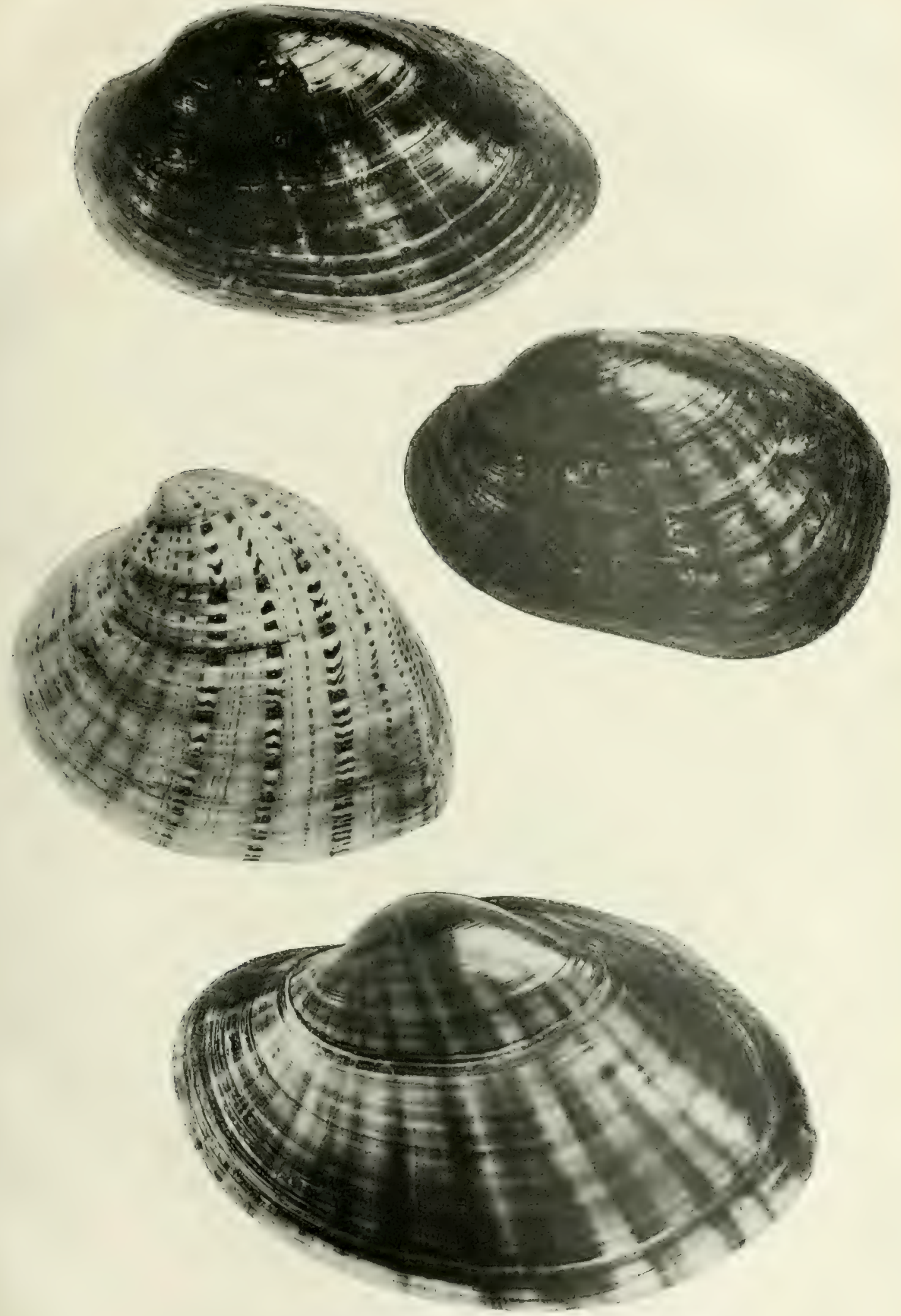

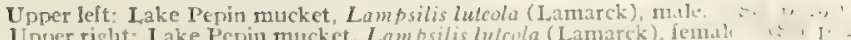

I.ower left: Butterfly, Plaginla securis (I.ea). (See p. 30 )

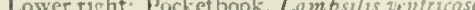



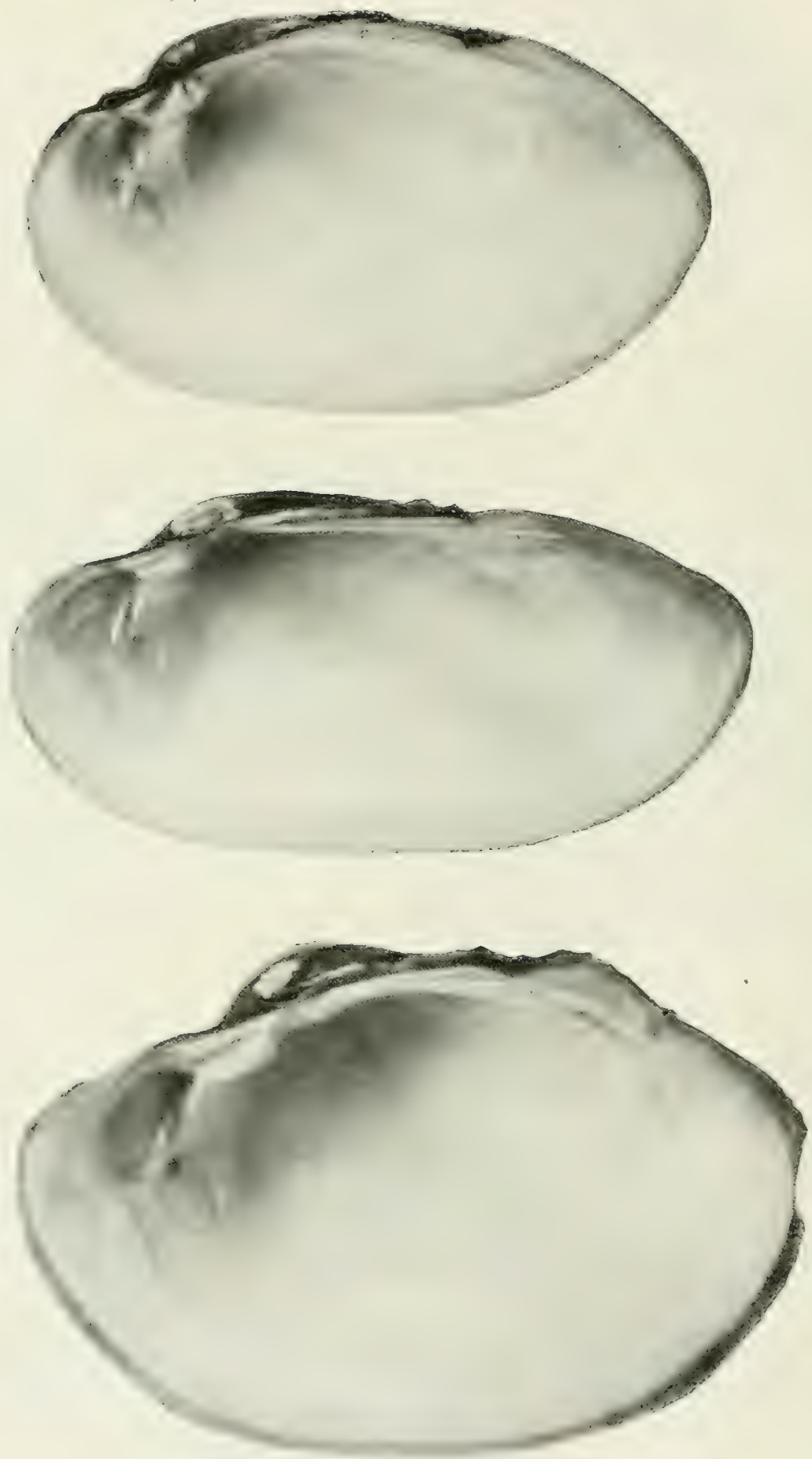

Upper: Iake Pepin mucket, Lampsilss tutcola (Lamarck). (See p. 20.)

Middle: Fellow sand-shell, Lampsalis anodonloides (Lea). (See p. 31.)

Jower: Packetbouk, Lamisilis aniricosa (Barnes). (See p. 3c.) 


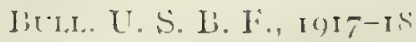

PLATES XIII
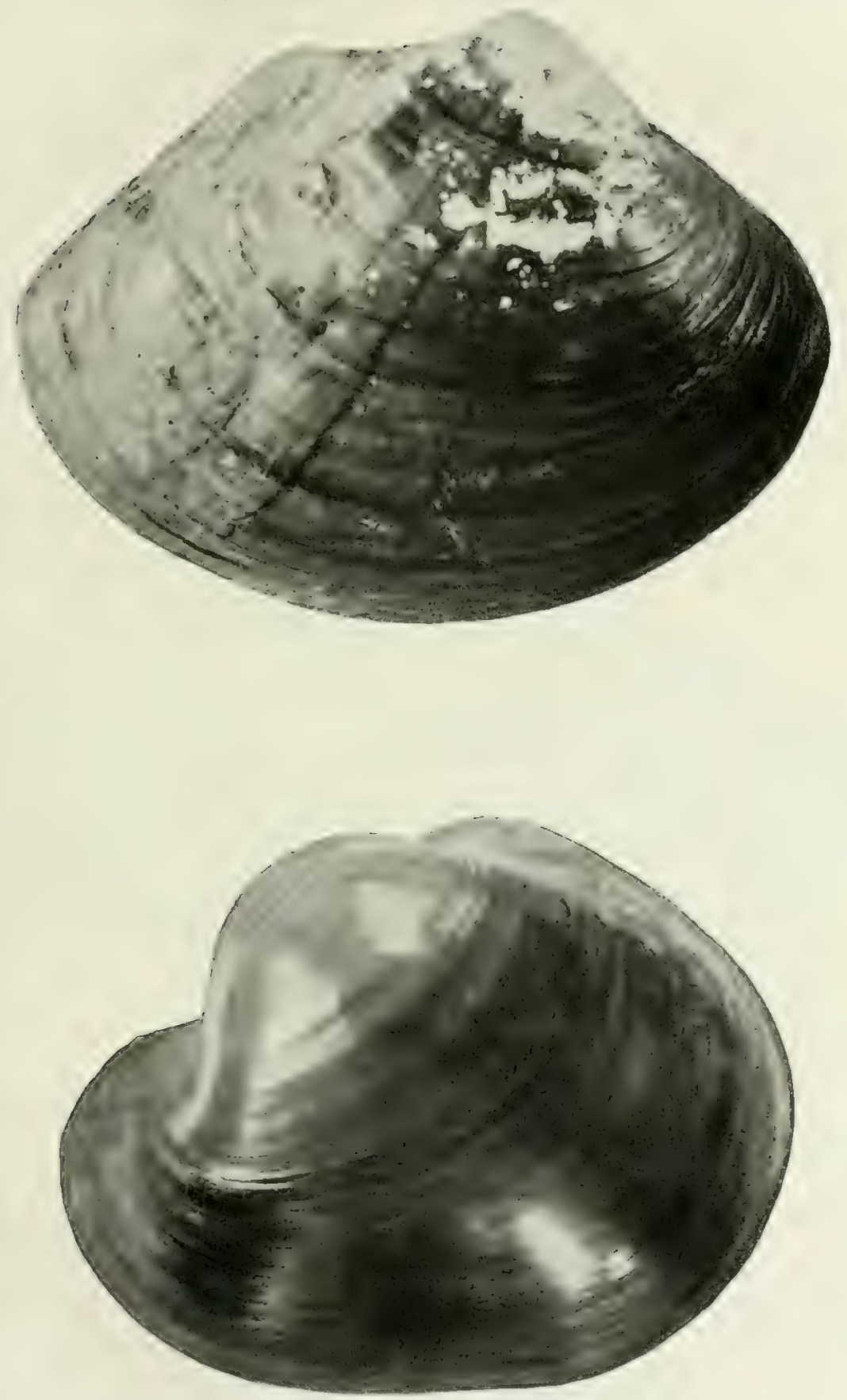

Upper: Grandma, Lampsilis mala (Say), from Cumberland River. (See n. 3r.)
Lower: 1'uckethuok, Lampsiles capar (Green), from Mississippi River. (Sce p. 3I.) 
BUL.I. U. S. B. Ti., I9I7-r8.

PLATF XVIII.
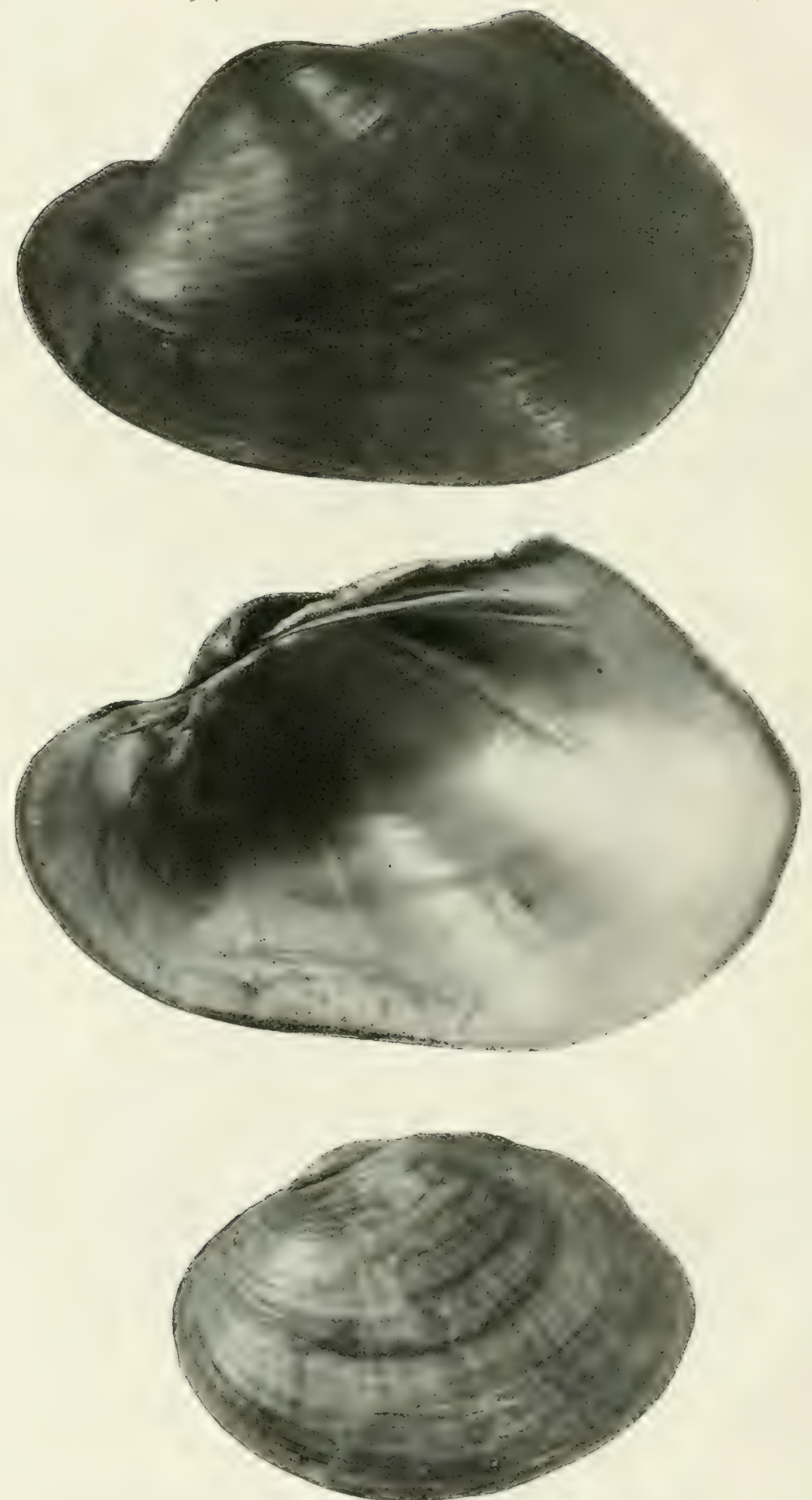

Upper pair: Turply, Lambsilis purburala (Lamarck), from Kiamichi Rirer, Ok13. (Seep At lottom: Lampsilis muluradiata (Lea), from Stone River, Tenn. (Sec p. 3 $\tau_{\text {. }}$ ) 
Often the forward or butt part of the shell is somewhat chalky and comprises scarcely more than one-fourth of the shell surface, while the remaining three-fourths is too thin and brittle. A noteworthy feature of the shell is the lateral hinge, which has a beautiful pearly luster. The cardinal teeth, too, have an attractive form and are used in the manufacture of cheap jewelry.

Lampsilis orata (Say) (PI. XVII), the southern pocketbook or grandma, is not ordinarily distinguished from ventricosa. It is found in the Ohio River and tributaries, as in the Clinch, Holston, and Cumberland Rivers. It is rather thinner and inferior to the common northern pocketbook.

Lampsilis (Proptcra) capax (Green) (Pl. XVII), also called pocketbook and confused with the others, is not closely related to them in spite of its superficial resemblance. It is quite too thin for value in button manufacture. The purply Lampsilis (Proptcra) purpurata (Lamarck) (P1. XVIII) is probably related to capax. It is very familiar to shellers in Texas, Louisiana and Arkansas, but the thinness of the shell, as well as the deep purple nacre, makes it unfit for the trade. It is one of the most beautiful shells.

Another species which looks something like a young pocketbook, but which never attains so large a size, is Lampsilis multiradiata (Lea) (Pl. XVIII) of the Ohio drainage and southern Michigan. Its shining greenish-yellow, bright-rayed shell is very attractive to the eye.

\section{SAND-SHELL GROUP.}

There are three sand-shells, the yellow, the slough, and the black.

The yellow sand-shell, Lampsilis anodontoides (Lea) (PIs. I, XVI and XIX), is the most highly prized of all commercial shells. It is never very abundant, but it is probably the most widely distributed of all the species discussed. Its distribution as given by Simpson is: "Entire Mississippi drainage, except, probably, the upper Missouri. All the Gulf drainage from the Withlacoochce River, Fla., to the Rio Grande, and into Mexico." The common name is derived from the clear yellow or brownish-yellow extcrior color.

These shells are too valuable for use in button manufacture; consequently they are always sorted out. Many tons of them are bought from the fishermen on the rivers to be used for export. Even those that reach the factories in mixed cars are sorted out in the yard to be sold again to shell jobbers. In very recent years, however, due to war conditions, many sand-shells have been cut into buttons in domestic manufacture. Some years ago it was said that the sand-shells were shipped chiefly to France; in the few years preceding I 914 the greater part seemed to have been destined for the German market, and the price on the rivers in 1913 was $\$ 60$ per ton. The export was necessarily interrupted in 1914 , but in the early part of 1911 the writer was informed of an offer of \$92.50 per ton $\mathrm{f}$. o. b. New York, and a consular report from Hamburg quoted these shells at prices equivalent to from \$IO8 to \$I5I per long ton, when niggerheads were quoted in the same market at $\$ 54$, and muckets at from $\$ 47$ to $\$$ I 19 . About three pairs of sand-shells (the sliells from three mussels) usually make a pound, so that the mussels were worth at least I cent apiece on the river and, at the date of the consular report, 2 cents apiece or more in Hamburg. In 1919, with some export demand, yellow sand-shells bring about \$go per ton.

The shell owes its value to the following characteristics: (I) Its luster and pearly qualities are almost if not quite equal to the marine shells; (2) its texture is smooth ancl 
firm; (3) the shape of the snell is long and straight, so that pieces suitable for knife handles or other novelty objects can easily be cut from it; and (4) the comparative uniformity of thickness and the light hinge make the shell yield the best return in proportion to its weight:

This species is found in small quantity mixed with other mussels in the principal mussel beds or on the more sandy or gravelly shoals. It seems also to live well in muddy bottoms.

Like others of the genus, it is a long-term breeder, but is, so far as known, very restricted in parasitism. No other hosts than the several species of gars seem to carry it well, but there is reason to believe that the large-mouth black bass may also serve as host. It is a peculiar fact that the two species of most restricted parasitism are the niggerhead and the yellow sand-shell. We know only one host for the niggerhead, yet it is a very abundant mussel; there are several species of gars, and they are quite plentiful; but the sand-shell is never very numerous in any locality.

A noticeable characteristic of the yellow sand-shells is the habit of wandering about on the bottom; for they travel more than the mussels of any other species. The yellow sand-shells are frequently observed to crawl up on the shoals with the rising water, and it is common report that after the subsidence of floods they may sometimes be found far out in the swamps.

The sand-shell has a relatively rapid rate of growth, probably attaining a market size in four to six years. Its growth is undoubtedly more rapid in the South, as in Arkansas, than in the North. If any species should prove adapted for commercial rearing in private waters, it would seem that the yellow sand-shell and the Lake Pepin mucket offer the best promise.

The slough sand-shell, Lampsilis fallaciosa (Smith) Simpson (P1. XIX), is similar to the yellow sand-shell but is generally smaller and rather too thin. Its geographic range is wide, and it is said to have been much more abundant formerly than now. There are few places in which the slough sand-shell is at all numerous. It is common in the lower part of the Illinois River, and is a very familiar shell in the Wabash River, where it is mistakenly called bank-climber.

The black sand-shell, Lampsilis recta (Lamarck) (Pl. XIX), is also widely distributed in the Mississippi River and the Alabama River drainages, the Red River of the North, and the St. Lawrence system. It is found principally in the upper part of the Mississippi Basin.

The shell is generally more compressed and heavier than the other sand-shells. The nacre has an excellent surface, but its economic qualities are variable. Often the nacre is deeply colored, pink, salmon, or purplish. White shells are the rule in the Mississippi and in some other streams, and many of them are of very superior quality. They were sometimes exported with the yellow sand-shell. The black sand-shell has a peculiarly good luster and pearliness and even iridescence; some of the most beautiful specimens the author has seen were, however, condemned by manufacturers as too brittle and as otherwise inferior.

Lampsilis subrostrata (Say) (PI. XIX) night sometimes be confused with the black sand-shell or more easily, perhaps, with very dark-colored slough sand-shells. It is entirely too thin to be of value. 
BULL. U. S. B. F., I9I7-18.

I'I.ITI: XIX.
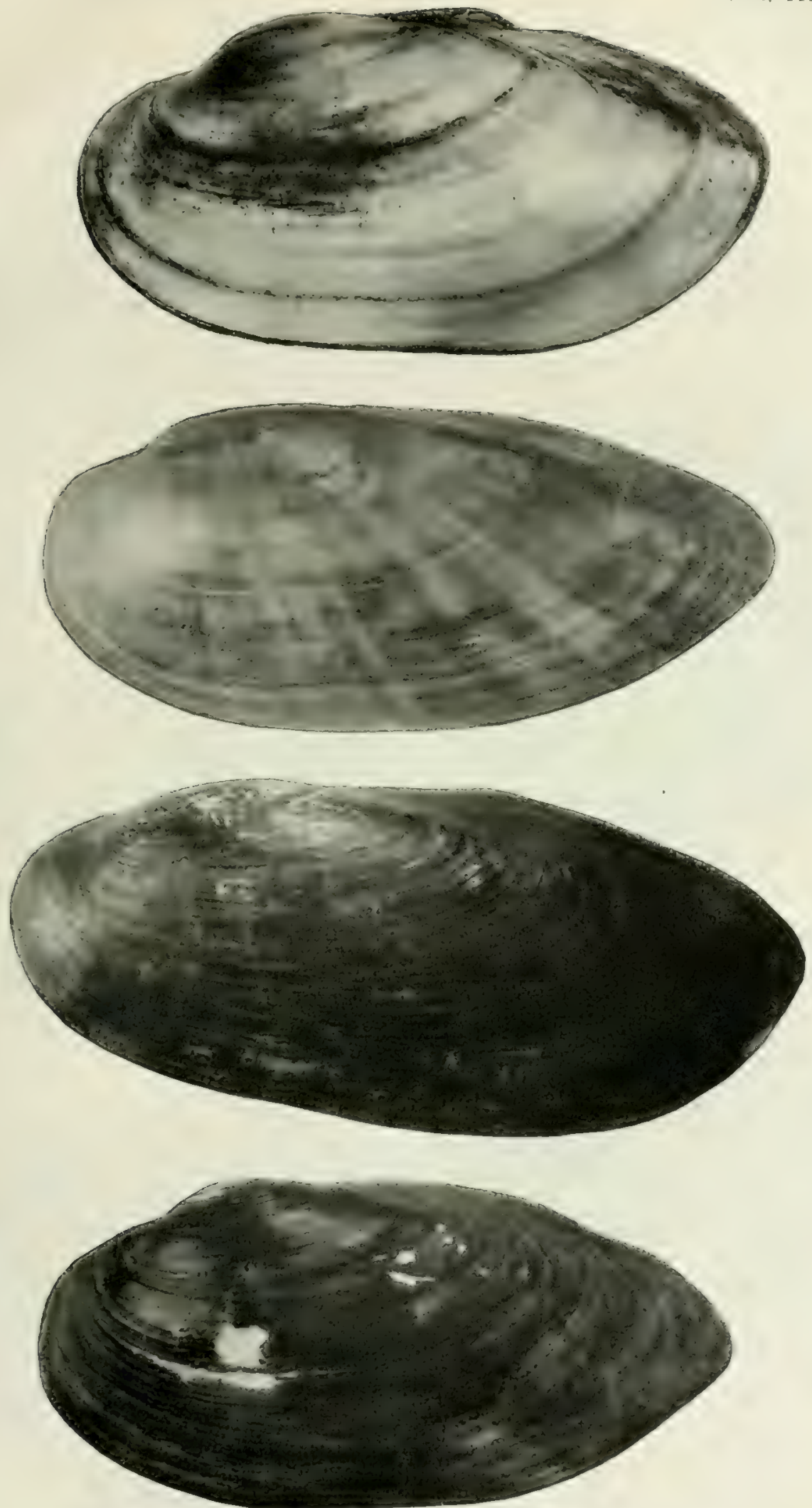

Yellow sand-shell, Lampsitis cnodontoides (Lea), from Mrississippi River. (See p. 3r.)

Slough saud-shell, Lampsilis fallaciosa (Smith) Simpson, from Mississippi Kiver. (See p. .2. Black sand-shell, Lampsilis recta (Lamarck). from Ml ississippi River. (Sce D. 32, , 


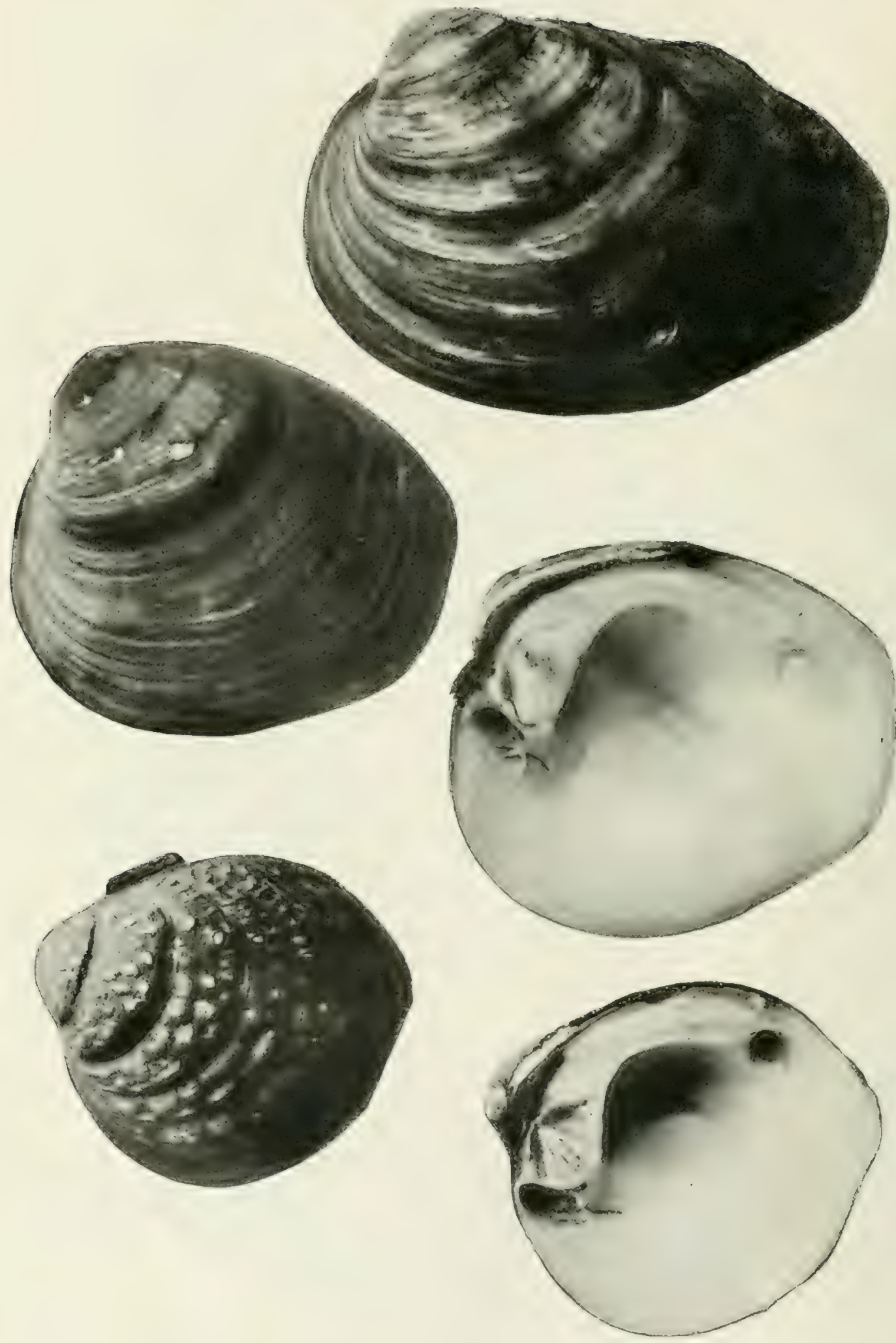

Top: Bullhead, Plcurobema aesopus (Grcen), from IVabash River. (See p. 33.) (See p. 33.)

Lower pair: Han-shell, Cyprogsnia irrorala (Lea), from Cumberland River. (See p. 33.) 
BULL. U. S. B. F., I9I7-I8.

I'LATE XXI.
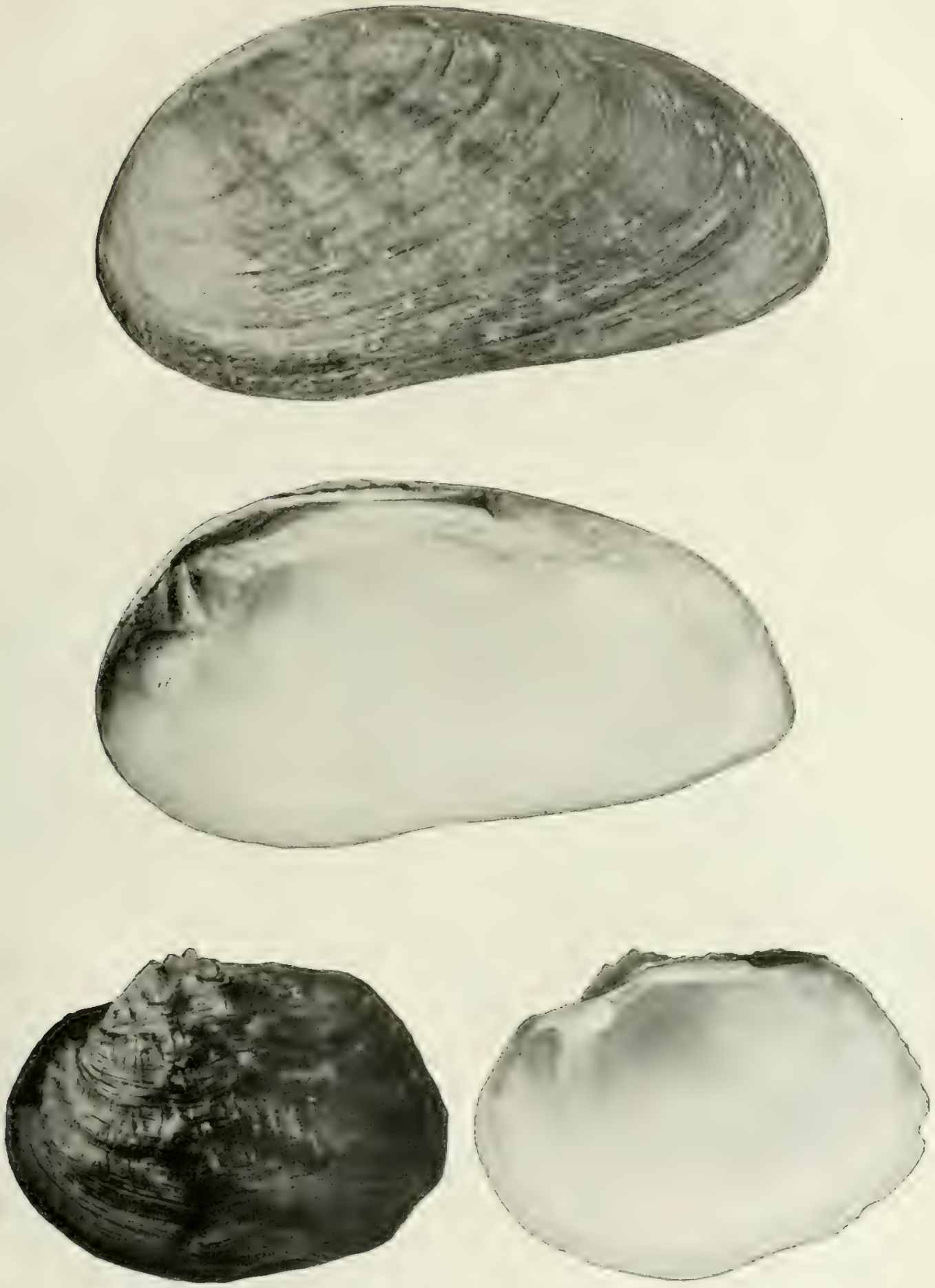

Upper pair: Kidney-shell, Plychobranchus phascolus (Hildreth), from Obey River, Ky: (See p. 33.) Lower pair: Rock pocketbook, Arcidens confragosus (Say), from Mississippi River. (See P. 34.) 

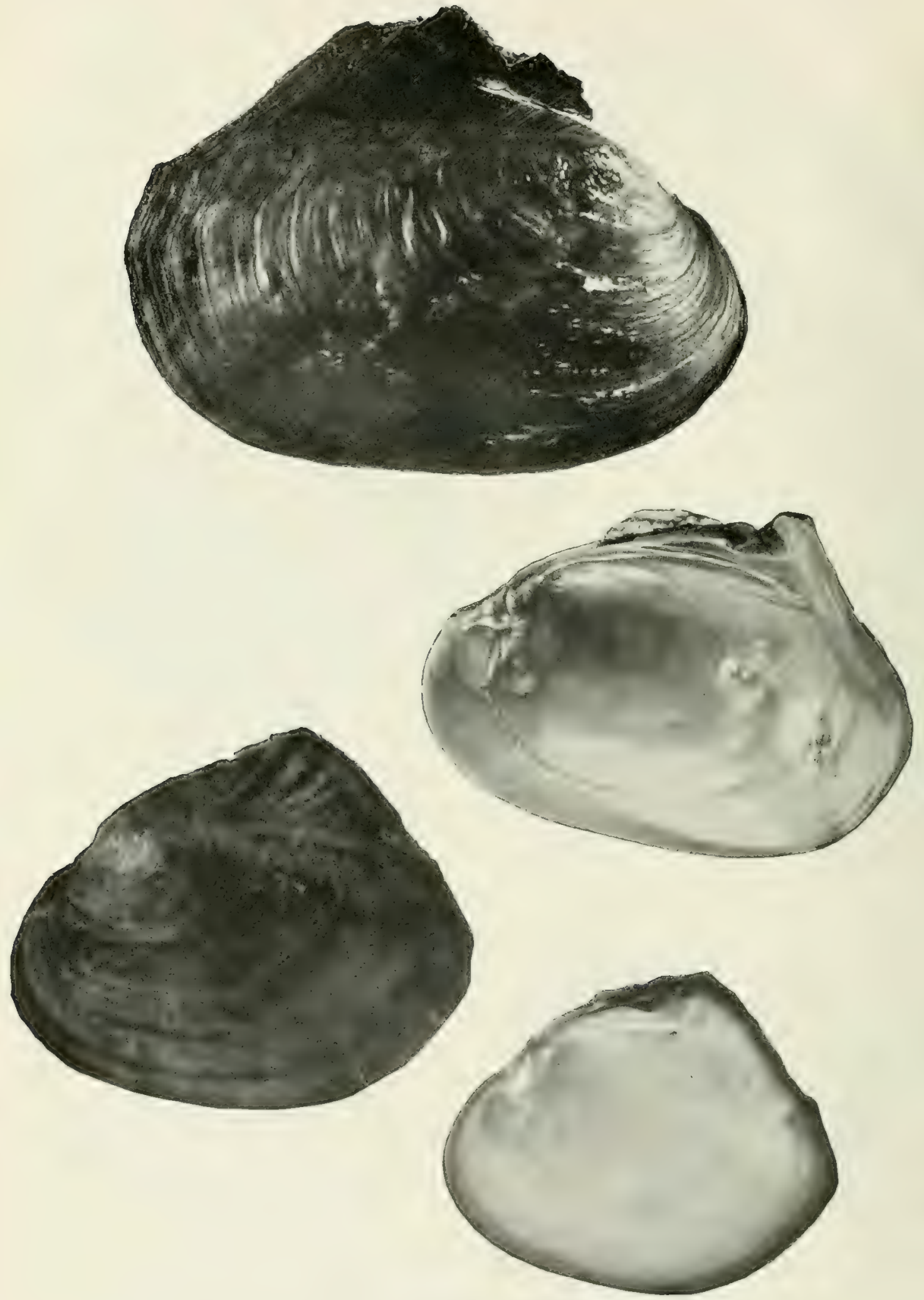

Upper left and middle right: Pink heel-splitter, Lampsilis alata (Say), from Mississippi River. (See p. 33.) Lower left and lower right; White heel-splitter, Symphynola complanata (Barges), from Kankakee River. (See p. 33.) 
MISCELLANEOUS GROUPS.

There remain for brief mention about a dozen species which have little in common. None is very numerous, generally speaking, but all are more or less familiar to fishermen and manufacturers, while nearly all enter to some extent into button manufaclue, although they are rarely bought intentionally. Some, at least, have certain good qualities.

\section{BULLHEAD GROUP.}

The bullhead, Pleurobema asopus (Green) (Pl. XX), is a yellow-back, thick, knobby shell, with nacre of excellent whiteness and luster. It is, however, exceedingly hard in texture, difficult, therefore, to cut, and injurious to the saws. After the blank is cut, the button is finished readily and takes a good polish. The fishemen in some localities have facetionsly dubbed this shell the "clear profit," because it can be thrown in to add weight at a profit to themselves and, supposedly, at a loss to the buyer. Sheepnose is another name, referring to its form. It is a mussel of rather wide distribution in the Ohio drainage and eastern part of the Mississippi Basin northward.

The fan-shell, or ringed warty-back, Cyprogenia irrorata (L.ea) (Pl. XX), is a smaller and flatter mussel of good foum and appearance, but its qualities are reported to be similar to those of the bullhead. It occurs in the Ohio drainage, especially Tennessee and Kentucky.

The dromedary mussel, Dromus dromas (Lea) (P1. XX), is somewhat like the fan-shell, but without the low protuberances on the back of that shell. It is found in the Tennessee and Cumberland River systems. In appearance it suggests the southern mucket, but its qualities, so far as known, correspond to those of the fan-shell.

The kidney-shell, Ptychobranchus phaseolus (Hildreth) (PI. XXI), is a much more elongate shell, with hard nacre and an undesirable steely luster. It is found in the Ohio drainage and is reported to extend northward to Michigan and southwestward to Louisiana, Arkansas, and Kansas.

\section{HEEL-SPLITTER GROUP.}

The white heel-splitter, or pancake, Symphynota complanata (Barnes) (P1. XXII), is of wide distribution in the upper Mississippi and Ohio drainages, the upper St. Lawrence drainage, and the Mackenzie River. It has a large, fine surface, but unfortunately, the shell is nearly always thin. In some localities it becomes very large and of suitable thickness but is brittle. The buttons can be finished with good luster, but the shell is liable to split into pieces when the blanks are being cut. It is said that they can be cut readily when fresh from the river and before the shell has so dried out as to be checking and splitting.

In some places the name elephant's ear is applied to this species. The name is appropriate enough, except that it has already been so generally applied to another species to be discussed later.

The fluted shell, Symphynota costata (Rafinesque), a comparatively thin-shelled mussel of wide distribution, has recently come into use from certain streams in Wisconsin. 
The pink heel-splitter, Lampsilis alata (Say) (P1. XXII), is mentioned in this connection only because of the confusion of names. It has about the shape and thickness of the white heel-splitter but is always purple or pink and is worthless for button manufacture. The beauty of the nacre and of the teeth makes it useful in novelty work. It occurs in the Mississippi drainage at least as far south as Arkansas, as well as in the drainages of the St. Lawrence River and the Red River of the North.

The rock-pocketbook, or bastard shell, Arcidens confragosus (Say) (Pl. XXI), has little resemblance to the white heel-splitter in form, but its nacre seems to be of the same character. It has the rough exterior of a blue-point, with the inflation of a pocketbook, which accounts for its common names. It is probably related to the Symphynotas. The species is rare but widely distributed.

\section{ELEPHANT'S-EAR GROUP.}

This is the last group of commercial mussels, and the shells possess peculiar features, good and bad. There are only two species to be considered, the elephant's ear, Unio crassidens (Lamarck) (Pl. XXIII), and the spike or lady-finger, Unio gibbosus (Barnes) (P1. XXIII). The former is distributed through the Mississippi drainage generally, and occurs also in the Alabama, Tombigbee, and Chattahoochee Rivers. The spike has a very similar distribution, but extends into the St. Lawrence and its tributaries, being common, for example, in the small streams of Michigan.

As regards economic qualities, the characterization of the two species must be the same, except that the spike has generally a poorer form and is more often inferior in texture. The elephant's ear is broader, more rectangular in form, and heavier. The spike, as the name implies, is more elongate and thinner at the tip. The entire shell is sometimes very thin, as found in small streams.

Both species generally have an appearance described as "solid," with a thick anterior (butt) portion and often with a very uneven surface. The color may be deep purple, reddish, or salmon, or occasionally white, and is often particularly beautiful. Unfortunately, coloration of any kind detracts from the commercial quality of a shell.

The thickness is good, but the most favorable feature of the shell is its texture, which is probably equal to that of marine shells. A manufacturer stated that cutting elephant's ears as compared with ordinary hard, white shells was like sawing a cake of firm soap as compared with sawing a board, and quoted a trade maxim: "When you find a pink shell you find a good shell"; that is, a shell which cuts well, although its color may make it undesirable. Analysis shows that the color is a feature of the organic matter in the shell and not of the crystalline or lime content. No clue has yet been obtained as to the nature of the coloring matter, nor has any entirely satisfactory method of bleaching been discovered, unless quite recently. If the color could be removed from the nacre by a cheap process that would not injure the texture or luster of the shell, the elephant's ear would become a most popular material.

Elephant's ears, when purchased in mixed lots, can be used to advantage for the production of smoked-pearl buttons, if stained with silver nitrate. Occasionally carload lots of this shell have been purchased on the rivers toward the close of the season, but the practice has been discouraged by the tendency of shellers to throw in all manner of pink, purple, and otherwise useless material. Both soecies are used in making novelties. These mussels are probably short-term summer breeders. 
BrLL. U. S. B. F., I9I7-IS.
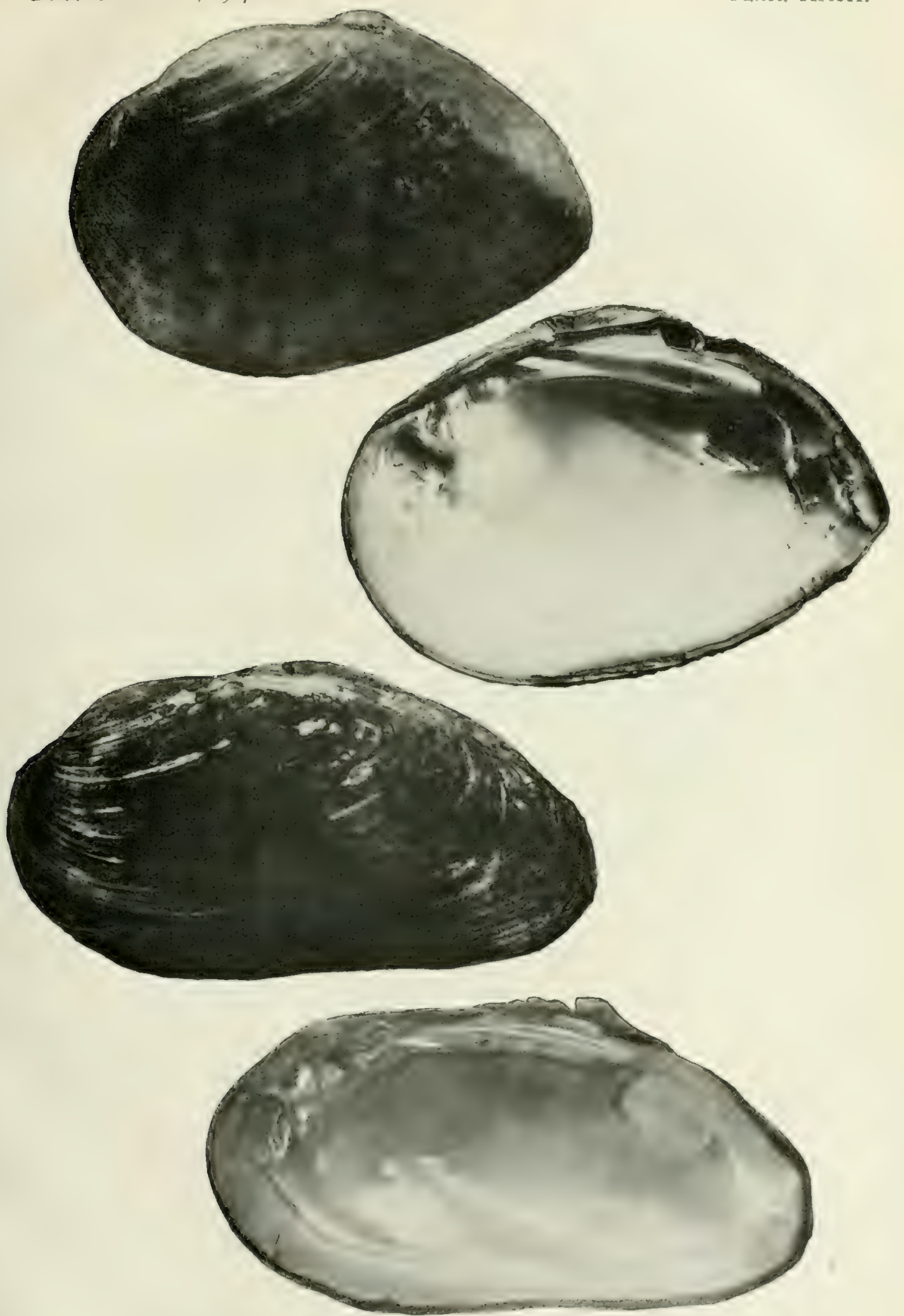

Upper paix: Elephant's ear, Unio crassidms (Lamarck), from Miscissippi River. (See p. 34.) Lower pair: Spike, Unio gibbostus (Barnes), from Mississippi River. (Sec P. 34.) 

BULL. U. S. B. F., I9I7-I8.
PLATE XXIV.
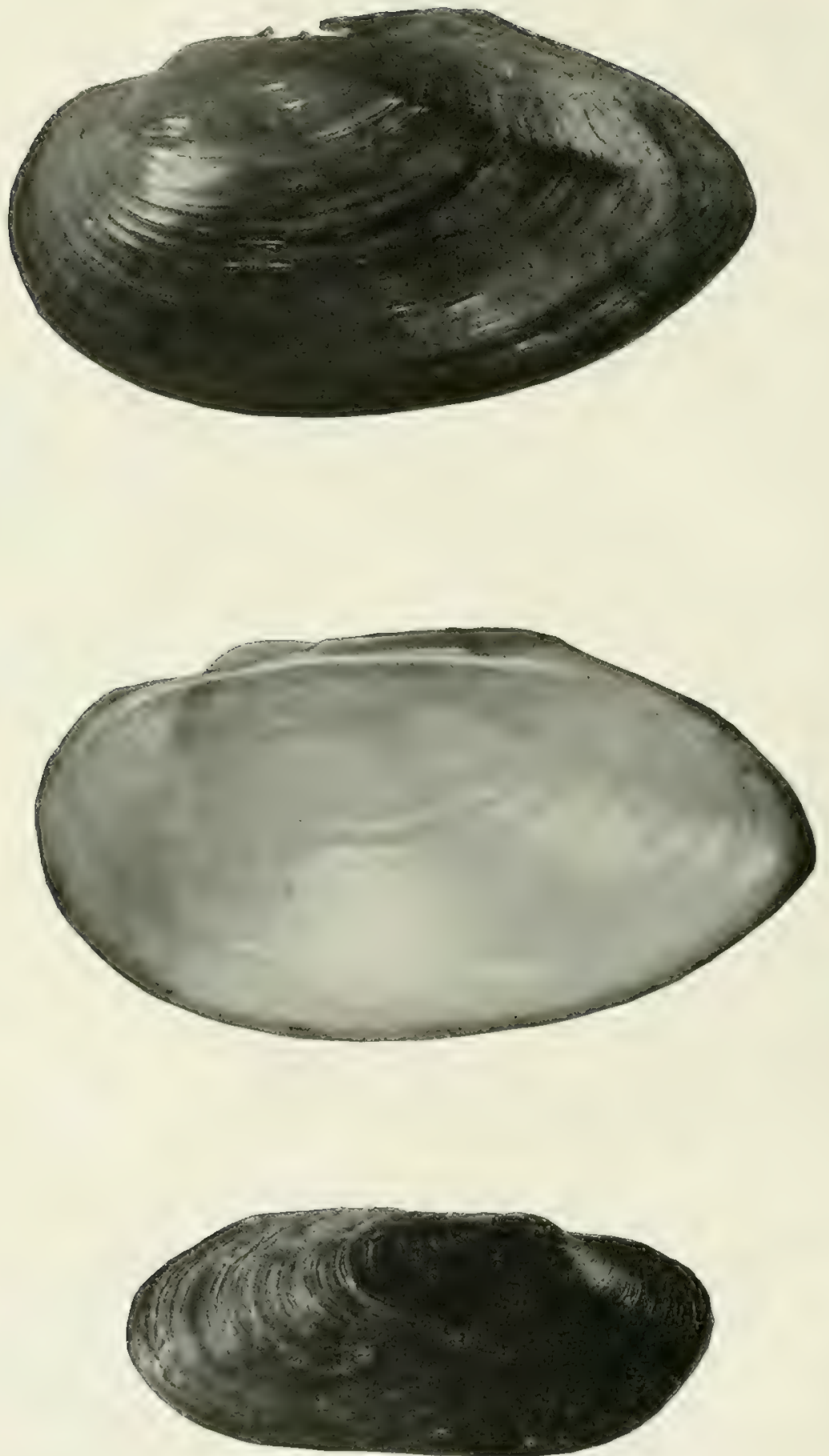

Upper and middle: Floater, Anodonta grandis (Say), from James River, S. Dak. (See p. $3=$ ) Lower: River pearl mussel, Margarilana margantifera (I, inneus), from Freejcrt, Me. (See p. 35 .) 
BUL. U. S. B. F., 1917-I8.

PLATE XXT:
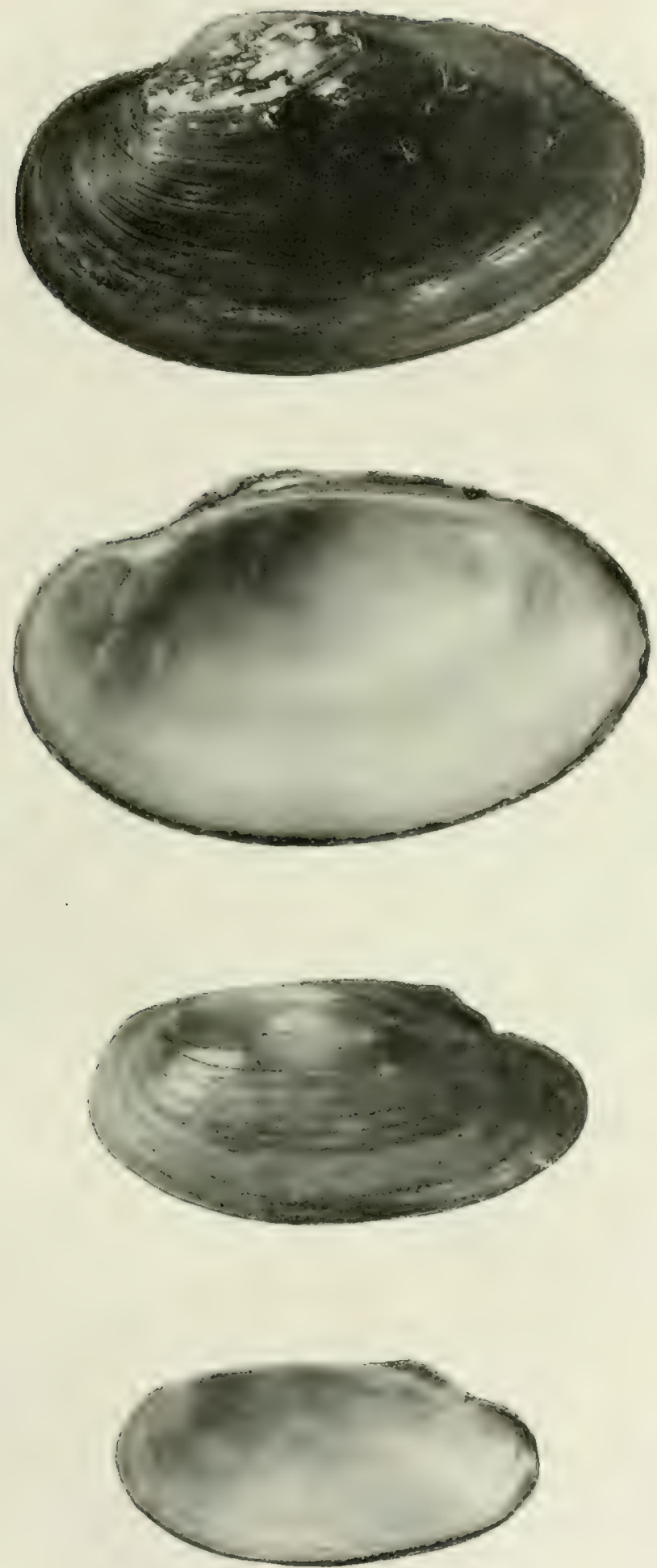

Upper pair: Siquaw-foot, Sirophitus pdentulus (Say). (See T) 35.)

lower pair: Paper-shell, Anulemla imberillis (Say). (See 1).35.) 

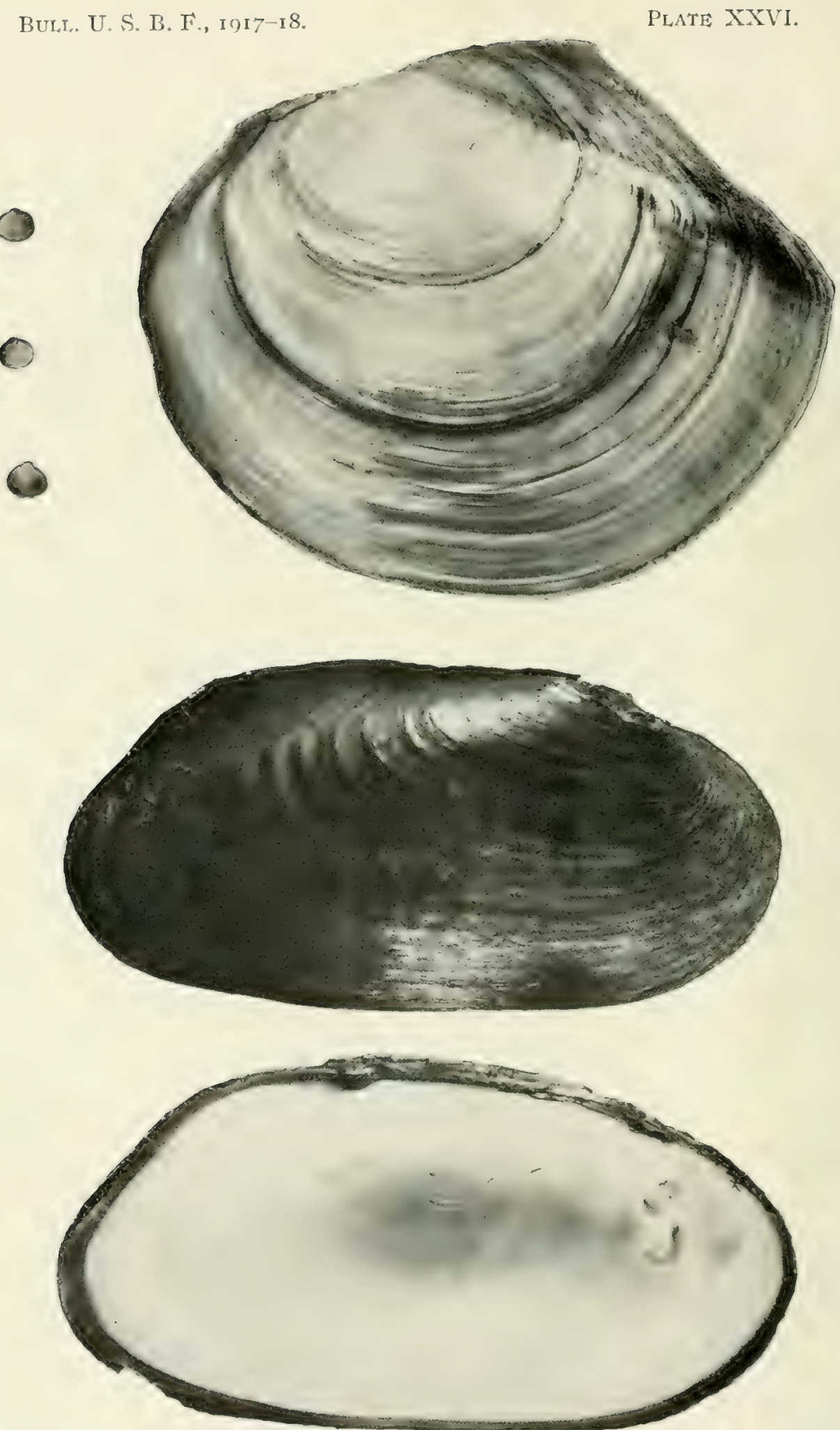

Upper: Paper-shell, Anodonla suborbiculata (Say). (See P. .35) Wississipoi River, (See D. .35)

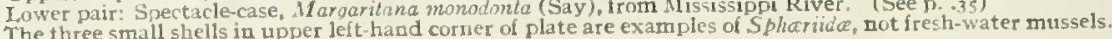


NONCOMMERCIAL, SPECIES.

We have completed the list of mussels of some economic value, numbering about $4 \mathrm{r}$ in all. There are approximately 533 species of the Unionidxe in North Anericil (Simpson). Therefore, though granting a few omissions in the present list for species from localities little studied, it is discovered that the great majority of the American species are not of economic use. It is desirable to mention only a few of those forms which are most abundant and most familiar to shellers, or of particular interest for other reasons. Most of the noncommercial species are not numerous, and some are quite rare and restricted in distribution. Even in the economic investigations of fresh-water mussels it is necessary to devote some attention to the useless forms, because the study of such mussels often throws significant light upon the propagation, habits, and other relations of the economic forms.

The floaters, Anodonta grandis (Say) (PI. XXIV) and other species, and the slopbucket, Anodonta corpu!cnta (Coope1), are familiar shells of the slack waters along river shores or in sloughs. The shell is very thin and brittle and entirely useless. In one of the overflow lakes near Fairport there are found numbers of the very large and compressed Anodonta suborbiculata (Say) (Pl. XXVI). The most interesting species of Anolonta is the small, elongate, and paper-shelled Anodonta imbecillis (Say) (Pl. $\mathrm{XXV}$ ), which has been found to develop without parasitism.

Another species which has been observed to develop without parasitism, but which has also been found to develop with a stage of parasitism on fish, is the squaw-foot, Strophitus edentulues (Say) (PI. XXV), which is widely distributed in the Mississippi and Atlantic drainages. The Anodontas are not only thin-shelled but also are marked by the entire absence of hinge teeth; Strophitus has no teeth but a thickened hinge line. The shell is thicker than that of Anodontas but is too thin for commercial use; the nacre is generally of a dirty-yellowish color.

The spectacle-case is a thin-shelled mussel of the elongated form suggested by its name. The species is Margaritana monodonta (Say) (Pl. XXVI), of the Ohio, Cumberland, and Tennessee systems, but rare in the Illinois River. Its interest consists in the fact that it is the nearest relative of the river pearl mussel, Margaritana margaritifera (Linneus) (P1. XXIV), the principal pearl-bearing mussel of Europe and New England.

The paper-shells, as the name indicates, are too thin for utility, although of attractive appearance. They are very common and of wide distribution through the Mississippi Basin and elsewhere. The principal species are Lampsilis gracilis (Barnes) and Lampsilis (Proptera) lavissima (Lea).

Just as there are minnows among the fishes which are very small, even when adults, so there are small forms of mussels; an instance is afforded by the rainbow-shell, mentioned on an earlier page. One of the smallest of all true fresh-water mussels is Lumpsilis para (Bames), which grows abundantly in the ponds at the Fairport station. It is narrow in form and never attains a length much excecding I inch. Much of the skepticism of practical men regarding the results of investigations of the life history of mussels has been due to a lack of acquaintance with the small species. Time and again shellers or others have found reason to believe that mussels bring forth their young in an advanced stage of development, because they have found supposedly young niggerheads attached to, or inclosed within the dead shells of old niggetheads. 
In nearly every case the little mollusks thus found are not the young of larger mussels, nor are they mussels of any character. It should be clearly and generally understood that; while all the larger clams of the rivers are mussels, there are clams which are not mussels at all, being markedly different in structure and development. There is no common name for these, but they pertain to several species of Spharium, Musculium, and Comeocyclas (Pisidium) (PI. XXVI). The usual diameter is 0.25 to 0.5 inch. They are frequently found attached to stones or to old shells in the mud. A dead shell may be found to be full of them. The Unionidæ (fresh-water mussels) and the Sphæriidæ live side by side in our rivers, but each family is more nearly related to different families of ocean shells than to each other.

\section{SUMMARY.}

Of the North American species of fresh-water mussels, more than 500 in all, we have named 66 as more or less familiar to the fishermen, but of these only 4 I can be classed as having commercial value in the shell trade. Some of the others are valuable as producers of pearls.

Looking at the $4 \mathrm{I}$ used in manufacture more closely we find only $\mathrm{I} 7$ that are of real importance at the present time. - It is desirable to name these separately.

Quadrula class:

Niggerhead.

Hickory-nut.

Pimple-back.

Maple-leaf.

Monkey-face.

Pig-toe.

Ohio River pig-toe.

Blue-point.

Three-ridge.

Washboard.

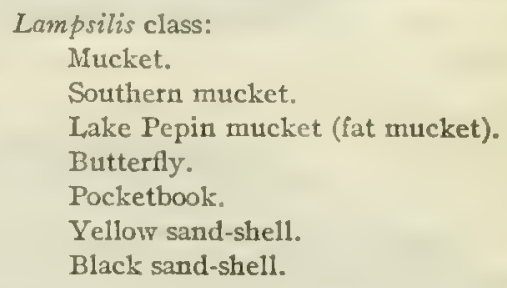

Many manufacturers or buyers would reduce this list by omitting several of the species, but there would probably be little agreement as to the species to be eliminated.

The best of all species at the present time are the yellow sand-shell, the niggerhead, the southern mucket, and the Lake Pepin mucket, the last three being of approximately equal value. The yellow sand-shell has been used entirely for export and commands a price nearly double that of other species. Many niggerheads were exported a few years ago, causing a distinctly advanced price.

There is a great deal of variation in quality among the several species. Some shells are better for one purpose, while others are better for another.

Within the species there is variation according to the locality in which the mussels have grown. A mussel may have a shell of good quality in one stream and of poor quality in another. The differences may apply to color, luster, texture (firm, chalky, brittle, or hard), and form (shape and thickness).

Within the same mussel bed there may be differences in quality in the same species. We may find side by side pink muckets, white muckets, etc.

The shells of the Quadrula class show more uniformity in quality over the entire region of distribution than those of the Lampsilis class.

Iriclescence is best slown in the niggerhead and pimpleback groups, but only a very small percentage of truly iridescent buttons can be obtained in any case. 
The requisite qualities are pearliness, luster, absence of color, and a texture firm but not too hard; and these qualities are as good in the better Lampsilis shells as in the better Quadrulas.

The most conmon defects for nearly all shell species are spotting or staining, due, in many cases, undoubtedly, to parasites, and natural nacre colors, such as pink, salmon, or purple. Stains are most common in sluggish rivers. Colored shells seem more prevalent in clear, shallow streams, but no universal rule has been observed.

Many of the tiny shells found attached to old shells are not young fresh-water mussels, as is often assumed by shellers, but belong to an entirely different family of bivalves.

\section{PUBLICATIONS TREATING MUSSEL RESOURCES OF VARIOUS STREAMS.}

COKLR, ROBLRT E.

1912. Mussel resources of the Holston and Clinch Rivers of eastern Tennessee. U. S. Bureau of Fisheries Document No. $765,1_{3}$ p. Washington.

19I5. Mussel resources of the Tensas River of Louisiana. Economic Circular No. 14, U. S. Bureau of Fisheries, 7 p. Washington.

COKER, ROBERT E., and SOUTHAiL, JOHN B.

1915. Mussel resources in tributaries of the upper Missouri River. (With description of shell found. ir the James River, Huron, S. Dak., July 27, I9r3.) Appendix IV, Report, U. S. Commissioner of Fisheries for $\mathrm{x}_{9} \mathrm{I} 4, \mathrm{I} 7 \mathrm{p}$., I pl., I map. Washington.

DANGLADE, ERnEST.

19r4. The Mussel Resources of the Illinois River. Appendix VI, Report, U. S. Commissioner of Fisheries for $19 \mathrm{r} 3,48 \mathrm{p}, 6 \mathrm{pl}$., including $\mathrm{I}$ map. Washington.

ELDRIDGE, JOHN A.

Igr4. The mussel fishery of the Fox River. Appendix VII, 8 p., Ibid.

ISELY, F. B.

I914. Mussel streams of eastern Oklahoma. Economic Circular No. 9, U. S. Bureau of Fisheries, $6 \mathrm{p}$. Washington.

MEEK, S. E., and CLARK, H. WALTON.

I912. The mussels of the Big Buffalo Fork of White River, Arkansas. U. S. Bureau of Fisheries Document No. 759, 20 p. Washington.

Smra, Austin F.

I913. The mussel fisheries of Caddo Lake and the Cypress and Sulphur Rivers of Texas and Louisiana. Economic Circular No. 6, U. S. Bureau of Fisheries, to p. Washington.

[UTTERBACK, W. I.]

Igr4. Mussel resources in Missouri. Economic Circular No. Io, U. S. Bureau of Fisheries, 6 p. Washington.

WILSON, ChaRLES B., and Clark, H. WALTON.

1912. Mussel beds of the Cumberland River in I9II. Economic Circular No. I, U. S. Bureau of Fisheries, 4 p. Washington.

I912. The mussel fauma of the Maumee River. U. S. Bureau of Fisheries Document No. 757 , 72 p., 2 pl. Washington.

1912. The mussel fauna of the Kankakee Basin. U. S. Bureau of Fisheries Document No. $75^{\delta}$ 52 p., I pl., x chart. Washington.

Igr4. The mussels of the Cumberland River and its tributaries. U. S. Bureau of Fisheries Document No. $78 \mathrm{I}, 63$ p., $\mathrm{x}$ pl. Washington.

Wilson, Criarles B., and Danglade, ERNest.

I912. Mussels of central and northern Minnesota. Economic Circular No. 3, U. S. Bureau of Fisheries, 6 p. Washington.

1914. The mussel fauna of central and northern Minnesota. Appendix V Report, U. S. Commissioner of Fisheries for 1913,26 p., I map. Washington. 


\section{Part 2. FRESH-WATER MUSSEL FISHERY. ${ }^{\circ}$}

\section{VALUE AND EXTENT OF THE FISHERY.}

The fresh-water mussel fishery is older than the fresh-water pearl-button industry, since the mussels have been taken in the search for pearls since i 857 at least, although but locally and irregularly. The importance of the fishery, in its two phases of pearling and shelling, dates from the beginning of the manufacturing industry, in $\mathrm{r} 89 \mathrm{r}$. It is interesting to note that at the present time the value of the pearl product is equal to about one-half that of the shell product. In some streams, chiefly the smaller ones, the pearls bring a better return to the fishermen than the shells, the Black River of Arkansas being a notable instance; but generally the value of the shells is considerably greater than the return from the pearls; the usual ratio is about 2 to $\mathrm{I}$.

The present paper is intended to refer primarily to the shelling industry and to give somewhat briefly an account of the territory and methods of the fishery. Since the pearls are usually taken incidentally in preparing the shells, the pearling methods are essentially the same, except that in regions where pearling is almost the exclusive object the practice of cooking out is not followed, owing to the belief that heat is detrimental to the pearls. In the shell fishery many noneconomic mussels are taken and cooked out along with the commercial shells with the hope that additional pearls may be found.

It would be of interest to compare the shell production of earlier years with the more recent statistical data for the mussel fishery. The earliest available estimates of the mussel fishery are contained in Statistics of the Fisheries of the Interior Waters of the United States, by Hugh M. Smith. ${ }^{b}$ The quantity of mussel shells taken in 1894 is stated at 195,500 pounds (equivalent to 97.75 tons), having a value of $\$ 2,737$. The small quantity of shells and the high unit value indicate that the industry was in a very rudimentary condition then, when few shells were required, and those bought were by the pound. It is well known from other sources that, owing to the great abundance of shells in proportion to the market demands, the price soon reached a low level, about $\$ 5$ per ton, fluctuating from $\$+$ to $\$ \mathrm{ro}$; but the supply was such that the fishermen made better wages then than at the present time, when the price received per ton is many times higher.

Smith ${ }^{c}$ states that in $\mathrm{I} S 97,3,502$ tons of shells were taken in Iowa and Illinois with a value of $\$ 40,408$, and in $1898,3,641$ tons with a value of $\$ 37,008$. Almost the entire fishery was within the limits of these two States at that time. It would appear that the average price per ton was about $\$ 11.50$ in 1897 and about $\$ 10$ in 1898 .

A census report for 1889 shows that 23,824 tons of shells were taken, with a value of $\$ 216,404$ (average price, $\$ 9.04$ per ton), and a census report for 1908 gives the tonnage as 38,133 , worth $\$ 386,000$ ( $\$ 10.02$ per ton).

a Ėrnest Danglade, formerly assistant in the Bureau of Fisheries, aided materially in the preparation of the description of the methods of fishery.

$b$ U. S. Commission of Fish and Fisheries: Report of the Commissioner for the year ending June 30,1896 . Washington, 1897 .

c Smith, Huch M.: The mussel fishery and pearl-button industry of the Mississippi River. Bulletin, U. S. Fish Commission for $\times 898$, Vol. XVIII, p. 289-314. Washington, 2899 . 
The latest data are found in detailed statistical reports of the Burean of Fisheries covering the territory of mussel fishery by sections. ${ }^{a}$ In $19 \times 2$ about one-third of the territory produced 19,715 tons, valued at $\$ 294,606$, and another third produced in the following year 23,317 tons, at a value of $\$ 3 \$ 2,210$. The remaining third, including the Mississippi River, canvassed for I9I4, a year of very poor fishery, yielded 8,539 tons, bringing to the fishermen $\$ 148,960$. It seems a fair estimate that the total production of shells varies in different years from 40,000 to 60,000 tons, with a value of from $\$ \$ 00,000$ to upward of $\$ 1,000,000$ (not including the value of pearls sold). The shells consumed in manufacture in 1912 aggregated 55,671 tons. ${ }^{b}$

The territory surveyed for 1912 comprised the southern portion of the Gulf drainage and the southern portion of the Mississippi Basin up to and including the Ohio River and up to, but not including, the Missouri or its tributaries. Arkansas was credited with nearly one-half of the total production. The average price of shells in Arkansas was nearly $\$ 20$ per ton, but the average ton price for the entire region was $\$$ I 4.94 (I 9 I 2 ). The territory covered in 1913 was that north of the Ohio and east of the Mississippi. The Illinois and Rock Rivers were credited with more than half of the total product for this territory and year, and, although the average price of shells in those streams was about \$1 4 per ton, the average ton price for the territory and year (1913) was \$16.82.

For 1914 the survey covered the Mississippi River and its tributaries from Kansas northward. The Mississippi River produced more than three-fourths of the tonnage, and the average price per ton for that river was $\$ 19.47$ per ton, as against $\$ 17.44$ average ton price for all streams covered in the survey for that year.

Combining the three surveys, it is found that the average price per ton of all shells was $\$ 16$ for that period. Shells have advanced so materially in price during the years from I9I4 to IgIg that the average price per ton is now about roo per cent higher.

The history of the fresh-water mussel fishery since the beginning of the button industry has been marked by a continual extension of territory from the point of origin on the Mississippi River near Muscatine, Iowa. The rate of spread has been directly correlated with the rate of depletion of the more central territory. At various times the Wabash, the Ohio, the Illinois, and the rivers of Arkansas (White, Black, and St. Francis) have taken turn as the principal seats of mussel fishery. That the spread of the fishery lias not been to the eastward and southward alone is shown by the fact that the fisheries have been prosecuted in South Dakota and Kansas and extensively in Minnesota. Unquestionably Lake I'epin in the Mississippi River between Minnesota and Wisconsin has recently been yiclding a greater quantity of shells per linear mile than any other stream or portion of a stream.

The principal mussel streams are listed in the table following. The total value of the pearl and shell product is shown, as well as the year of the survey, and the last column indicates what proportion of the total income of the mussel fishery in cach st ream is derived from pearls. The data are taken from the statistical bulletins previously cited.

a [Fresh-water mussel fishery of streams tributary to the Gulf of Mexicofrom the Ohio River southward in Igr2.] Report, U. S. Commissioner of Fisheries for 19i4, p. 26-30. Washington.

[Fresh-water mussel fishery of streams tributary to the Great Lakes and the Ohio and Mississippi Rivers north of the Ohio and east of the Mississippi River in 19r3.] Report, U. S. Commissioner of Fisheries for 7985, p. 64-69. Washington.

[Fresh-water mussel fishery of the Mississippi River and its western tributaties from Kansas northward in I9r4.] Report, U. S. Commaissioner of Fisheries for 1916, p. 55-5\%. Washington.

o [Fresh-water pearl-button industry of the United States in 1912.] Report, U. S. Commissioner of Fisheries for 19r4, p. 3i-34. Washington. 


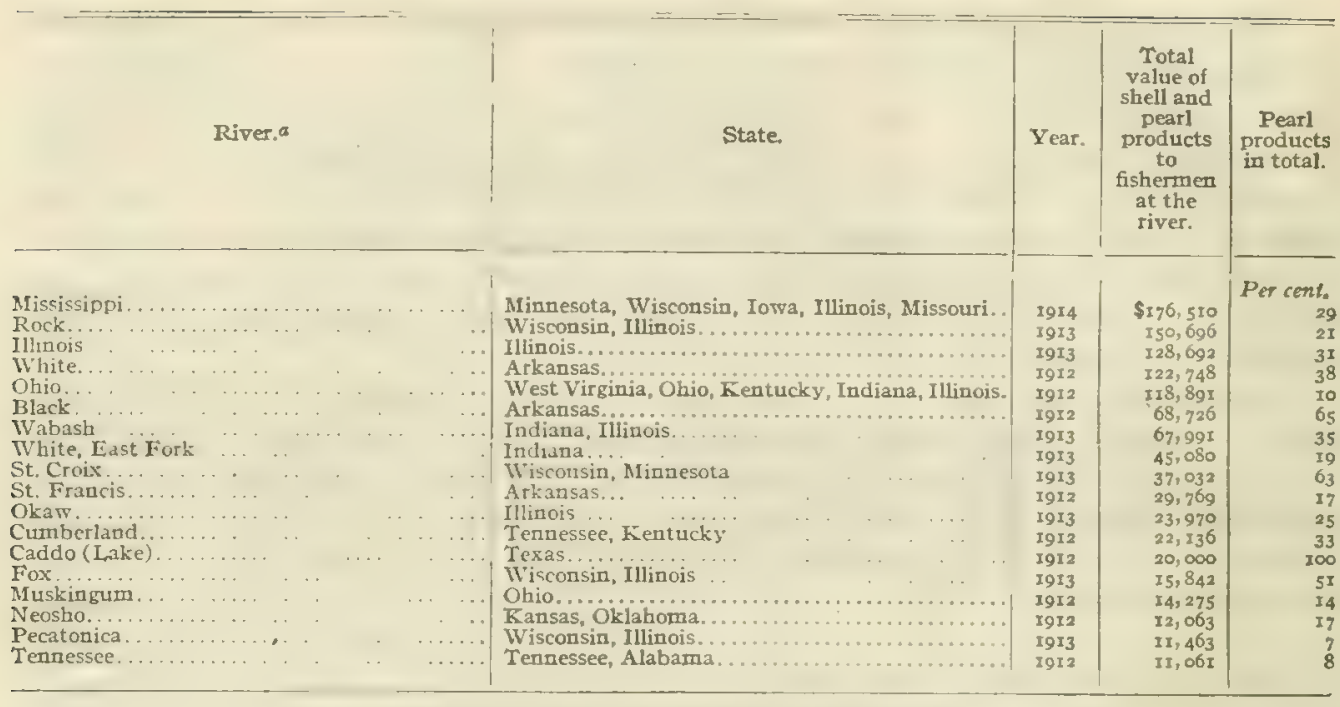

a Minor tributaries are included with the main stream.

Minor mussel streams not included in the foregoing table may be classified as follows: (I) Those with shell product exceeding pearl product in value and (2) those with pearl product greater than shell product. The streams in each of these two classes are as follows, the arrangement being alphabetical:

I. Big Sunflower, Miss.; Blue, Kans.; Bourbeuse, Mo.; Cedar, Iowa; Cottonwood, Kans.; Des Moines, Iowa; Eel, Ind.; Embarrass, Ill.; Grand, Mich.; Green, Ky.; Holston, Tenn.; Huron and Raisin, Mich.; Iroquois, Ill. ; James, S. Dak, ; Ialamazoo, Mich.; Kankakee, Ind. and Ill.; Little, branch of Red,
Ark.; Little, branch of St. Francis, Ark.; Little Missouri, Ark.; Little Wabash, I1l,; Maple, Mich.; Marais de Cygnes, Mo. and Kans.; Maumee, Ohio and Ind.; Meramec, Mo.; Minnesota, Minn.; Mississinewa, Ind.; Muskegon, Mich.; Nebraska, Kans;; Ouachita, Ark. and La.; Osage, Mo. and Kans.; Pearl, Miss. and
La.; Saline, Ark.; St. Joseph, Mich. and Ind.; Shell Rock, Iowa; South Skunk, Iowa; Tombigbee, Ala.; Tuscarawas, Ohio; White, West Fork, Ind.; and miscellaneous smaller streams.

2. Clinch, Tenn.; Duck, Tenn.; Iowa, Iowa; Sangamon, I11.; and doubtless many creeks.

There are also probably a few mussel streams, especially in the South, which have not yet been surveyed.

The mussel fishery is pursued more or less actively in the following i 9 States:

Mississippi River or westward: South Dakota, Minnesota, Iowa, Missouri, Kansas, Arkansas, Oklahoma, Louisiana, and Texas.

Mississippi River or eastward: Minnesota, Wisconsin, Michigan, Illinois, Indiana, Ohio, Kentucky, TVest Virginia, Tennessee, Louisiana, Mississippi, and Alabama.

Manufacturing States, such as New I ork, Massachusetts, New Jersey, Pennsylvania, and Maryland, are indirectly interested in the mussel fishery on account of having manufacturing industries based upon the shells received from the mussel streams. Thus, at least one-half of the States have an inmediate interest in the preservation of the mussel resources.

The accompanying map shows the territory of the fishery and the principal mussel streams. 


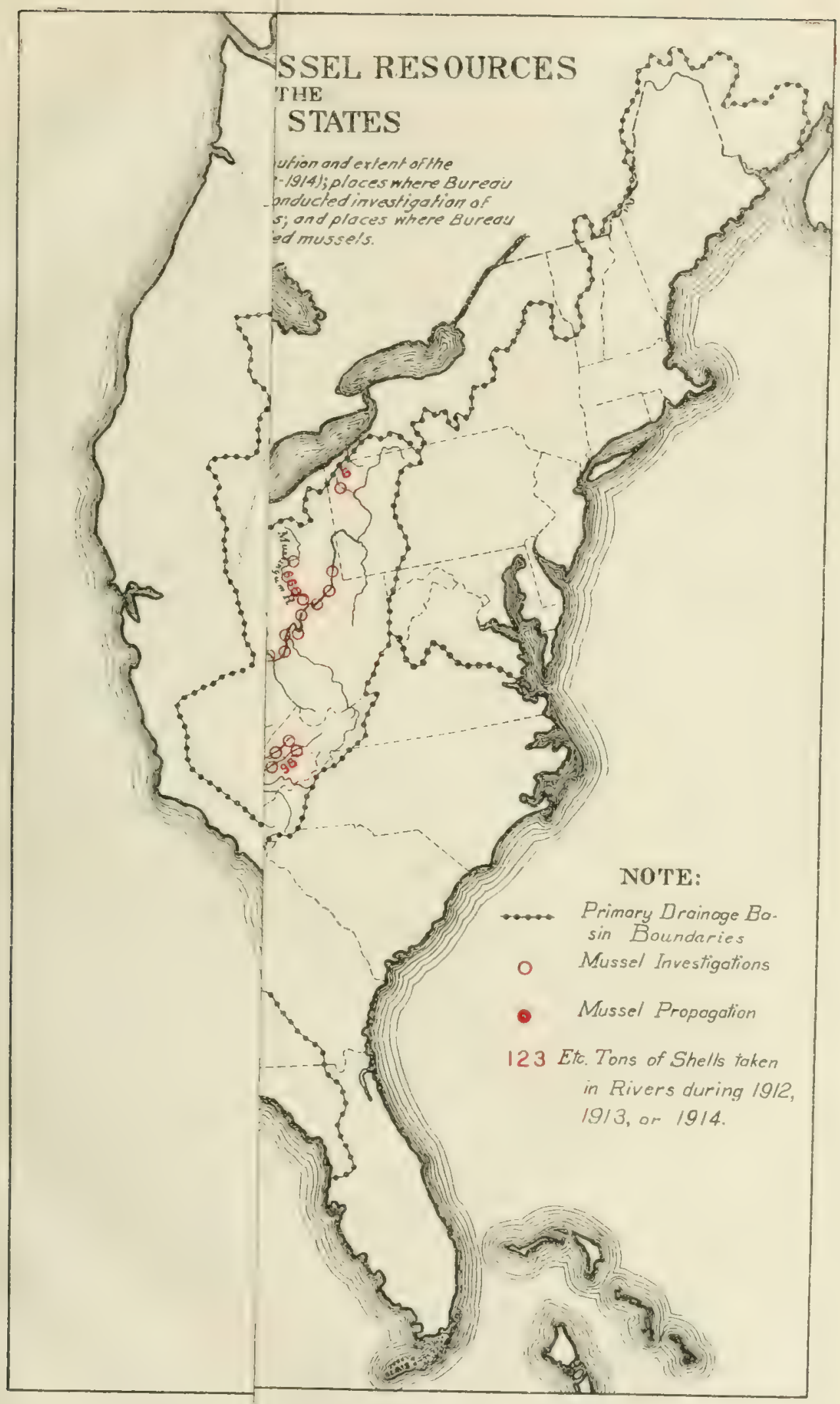





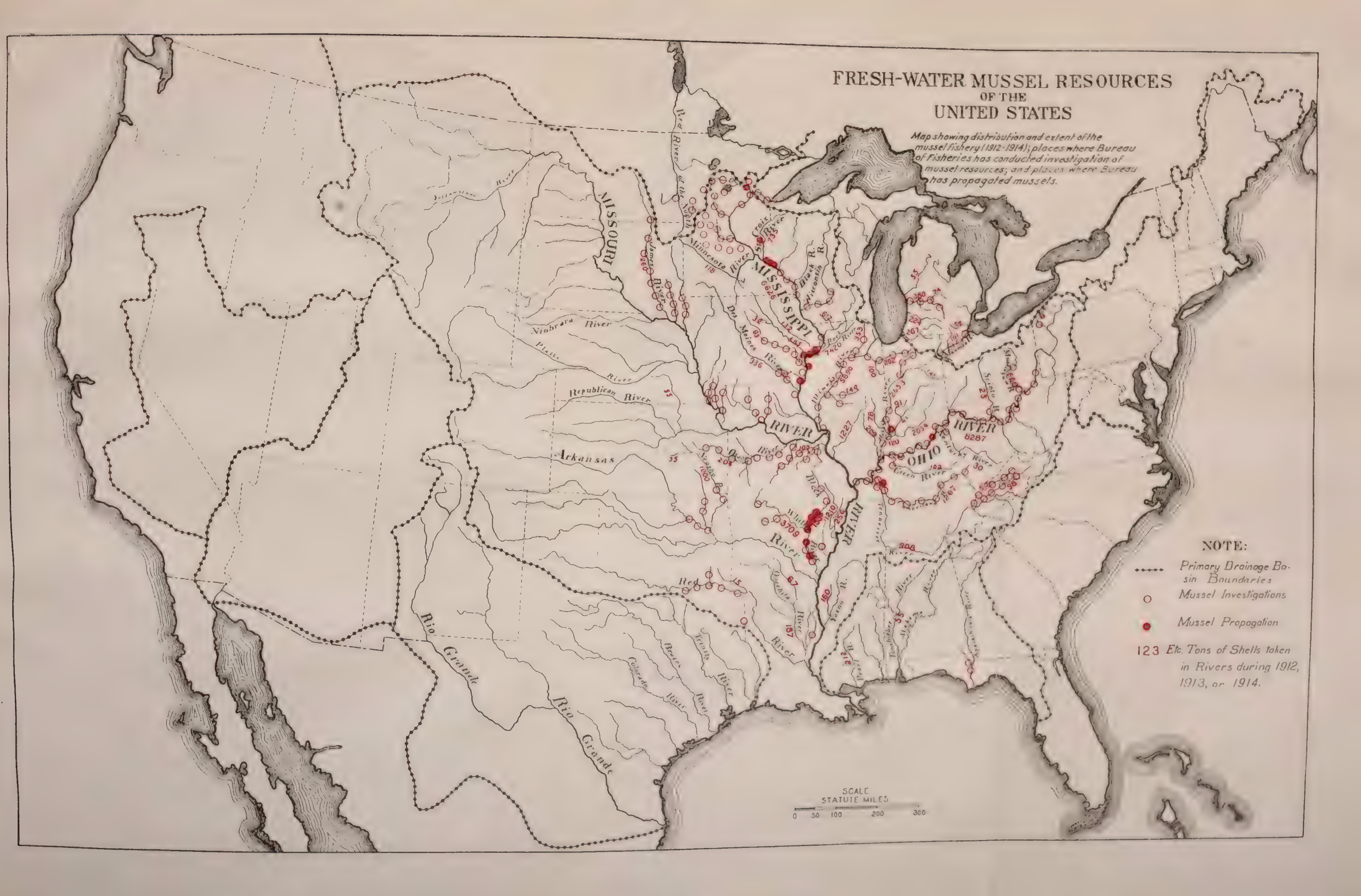



SOME LOCAL AND TEMPORARY ASPECTS OF THE FISHERY.

The mussel fishery is a permanent and important industry, and in scarcely any locality where a shell fishery was once established has it ever been entirely abandoned; yet the intensity of the fishery in any locality may vary from year to year, as it is sub)ject to a variety of infuences, such as the demand for shells of certain qualities, the stages of the river, the condition of local industries or of the button industry, and the degree of exhaustion of the material.

The natural movement of the territory of fishery from regions more or less depleted to virgin streams has been discussed on page 39. A limitation upon the rate of expansion is imposed by the cost of transportation of the product from its original source to points of manufacture; but the principal determining factor in this respect is the qualit $y$ and abundance of the material, since cutting plants will follow the fishery if justified by the nature of the arailable material. There may be given, first, some illustrations of the extent of the fishery in certain localities as they have come more or less directly under the observation of the writer.

The statistical bulletins published by the Bureau show the value of the product from the scveral streams, each taken as a whole, but the high productivity of certain beds before the process of depletion has advanced is not brought out in such reports. In the Illinois River in 1909 there were estimated to be about 2,600 boats engaged in the mussel fishery. One hunclred or more boats would be engaged upon the same bed at one time, and, as a consequence, cutting plants sprang up all along the river. In I9I the writer counted 125 mussel outfits lying idle tpon the banks at one point, Merdosia, I1l., while some 15 or 20 were engaged upon the river at varying distances from the town and mostly out of view. The exhaustive effect of the fishery of the three years preceding IgI I accounted in some measure for the number of idle boats. In I912 only about 400 boats could find occupation in the mussel fishery on this river, although a more effective method of capture (the dip net) had been devised.

In each of the two years 1912 and 1913 , according to reliable information, about $\$ 20,000$ worth of shells and pearls were marketed at Madison, Ark., a village of about 300 inhabitants. This represented the product of beds largely depleted but yielding shells of high quality.

In 1910, I,600 tons of shells, principally niggerheads, were taken in the rapids above Keokuk, Iowa, mostly within a stretch of 4 or 5 miles, and these shells represented a value of about $\$ 30,000$. In 1912 a little over 400 tons were taken in the same region. This bed has been lost to the industry since the submergence of the rapids following the construction of the dam.

In the immediate region of I,e Claire, Iowa, and Port Byron, Ill., in Igro, about 700 tons of shells were taken, representing a value of some $\$ 14,000$. Fishing at Le Claire, Iowa, began about I 997 , and the large catch of I9IO was due to the condition of very low water, enabling the fishermen while wading to pick by hand the shells which could not be taken in ordinary stages because of the rocky character of the bottom.

These are not insignificant figures, considering that the harvest was reaped without expense of planting or cultivating. Such harvests can not, however, be often repeated, since the rate of removal exceeds the rate of natural replenishment. 
The variable quality of the several species of mussels is discussed on page $x 6$ of Part I in connection with the commercial qualities of shell. Only a word is necessary in this connection in regard to the geographic aspect of the subject and its effect upon the fishery. The profitableness of shelling in any locality is determined largely by the quality of the more abundant species. Some species are nearly always rare, or, at least, are never the dominant species of mussel beds. Nevertheless it is a striking feature of the mussel fishery that in different streams or in different portions of the same stream. different species may dominate. We may have niggerhead streams, mucket streams, pig-toe streams, etc., but we do not expect to find maple-leaf streams, buckhorn streams, or butterfly streams, although these forms are widely distributed.

In that portion of the Mississippi constituting Lake Pepin, the Lake Pepin mucket comprises as much as 60 per cent of the catch from many beds, in spite of the large number of other common species present. Since this shell as found in Lake Pepin is of the best quality in so many respects, the region of the lake may be expected to be the scene of active fishery as long as the beds are reasonably productive.

Certain portions of the Mississippi River may show from so to 85 per cent of niggerheads against all other species combined. At Le Claire, Pleasant Valley, and other points above Davenport, Iowa, 75 or 80 per cent of niggerheads are reported. Counts of shell piles above Keokuk, October, I9I2, showed so per cent niggerheads, and Io per cent monkey-faces, while 7 other species constituted the remaining Io per cent. There were a few discards not included in the count. A similar predominance of niggerheads is observed in Arkansas, especially in the White and St. Francis Rivers. In the St. Francis near Madison, Ark, in 1913 , about 16 species were taken, but 75 per cent were niggerheads. In such regions one may expect a steady fishery until the beds are nearly exhausted. It is reported that in the lower Pearl River of Mississippi and Louisiana the niggerheads constitute more than 99 per cent of the mussels in beds that have been fished, but the quality of the shell has not been definitely ascertained; if the report of percentage is correct, these beds are the most remarkable known for the predominance of one species.

In the Illinois River Danglade ${ }^{a}$ found that in various beds blue-points may constitute 50 to 60 per cent of the catch, washboards 23 to 50 per cent, and warty-backs as much as 31 per cent. His observations regarding the river as a whole are succinctly expressed by the statement: "The Illinois is distinctly a washboard, blue-point, and warty-back river."

In piles of shells taken near Havana, Ill., washboards and blue-points constituted 95 per cent of the shells, while nine other species constituted the remaining 5 per cent. The fortune of the fishery in this stream will necessarily fluctuate with the demand for that class of shells, which is not at all constant. At times there may be a strong demand for blue-points and washboards for the making of buttons of the larger sizes; but, except with such a demand or with an excessive call for the higher-class shells, the market will not be the most favorable.

In the Ohio River, the Ohio River pig-toe may constitute as much as 80 per cent of the mussels of a bed, but this species is never in high favor; mixed in with the predominant species, there is always a certain number of mussels of other species, some of which may be of superior quality.

a Danglade, Ernest: The mussel resources of the Illinois River. Appendix VI, Report, U. S. Commissioner of Fisheries for $19 \mathrm{r}_{3}, 48 \mathrm{pp} ., 6 \mathrm{pl}$. including I map. Washington, $19 \mathrm{r}_{4}$. 
In the Cumberland River ${ }^{a}$ the Ohio River pig-toe is reported to run as high as 95 per cent of the catch from one bed, while the valuable southern nutuct is found in the proportion of 40 per cent in some beds in this river.

An unusual export demand, causing a high price for the best shells, will tend to throw the domestic trade back upon second-grade material, and thus stimulate the fishery in regions of inferior-shell product. On the other hand, a slack in exponts such as now prevails makes the best shells more readily available to American manufacturers and discourages the fishery for poorer shells.

Taking the principal mussel streans previously listed, we find the average price per ton for shells on the bank in the years rgiz-19I4 to be as follows. These figures are of value now only as inclicating the relative values of shells from the scveral rivers.

Relative Values of SHelis in Vartous Strfams, Based on SuRVeys of IgI2-Igr4.

\begin{tabular}{|c|c|c|c|c|c|}
\hline River. & Year. & $\begin{array}{l}\text { Average } \\
\text { ton price. }\end{array}$ & River. & Year. & $\begin{array}{l}\text { Average } \\
\text { ton price. }\end{array}$ \\
\hline$F \propto x \ldots \ldots \ldots$ & $19: 3$ & $\$ 22 . \infty$ & Wabash. & 1913 & 16.51 \\
\hline White, Arkansus ... ... & 1912 & 20.44 & Rock.... & 1913 & 16. or \\
\hline St. Francis...... & 1912 & 20.39 & Illnois............................. & 1913 & 14.95 \\
\hline Muskingum........ . . . & 1912 & 20.00 & Okaw. & 1913 & 14. 70 \\
\hline Mississippi..... . & 191.4 & 19.47 & Ohio.. & 1912 & I2.88 \\
\hline St. Crolx.......... & 2013 & IS. 87 & Cumberland. & 1912 & II. 73 \\
\hline White, Indiana & 1913 & $17 \cdot 70$ & Tendessee........................... & 2912 & II. 38 \\
\hline Pecatonica... ....... & 1913 & $17 \cdot 3 \mathrm{I}$ & Neosho................................................ & 1912 & $9 \cdot 97$ \\
\hline Black... $\ldots \ldots \ldots \ldots$.. . . & 3952 & I7. $\times 9$ & & & \\
\hline
\end{tabular}

Since mussels are always sold by the ton, it is of interest to note the number of shells constituting a ton in selected cases. No general statement is possible, since the number necessary to make a ton varies with the species, the size, and the thickness. The washboard shells of the upper Illinois averaged about a pound a pair, while those of the lower river averaged less than half a pound but were of better quality. The following counts are selected from a table given by Danglade and from counts made by the writer:

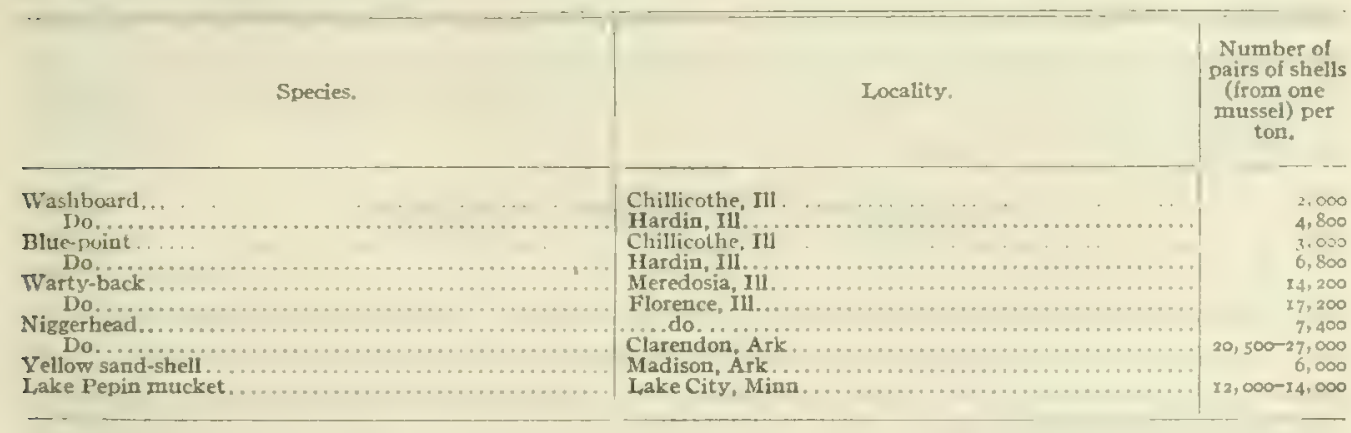

The table next following shows the number of pairs of shells (equivalent to number of mussels) of different species and sizes and from different localities, making a ton as weighed and measured at a factory. The data comprised in this table are not

a Wilson, Charles B., and Clark, H. Walton: The mussels of the Cumberland River and its tributaries. U. S. Bureau of Fisheries Document No. $78 \mathrm{x}, 63$ pp., $x$ pl. Washington, 19r4.

$$
110306^{\circ}-19
$$


strictly comparable to those in the preceding table, since the preceding table is based upon the shells taken from the river, and many of the smallest shells are lost before reaching the factory.

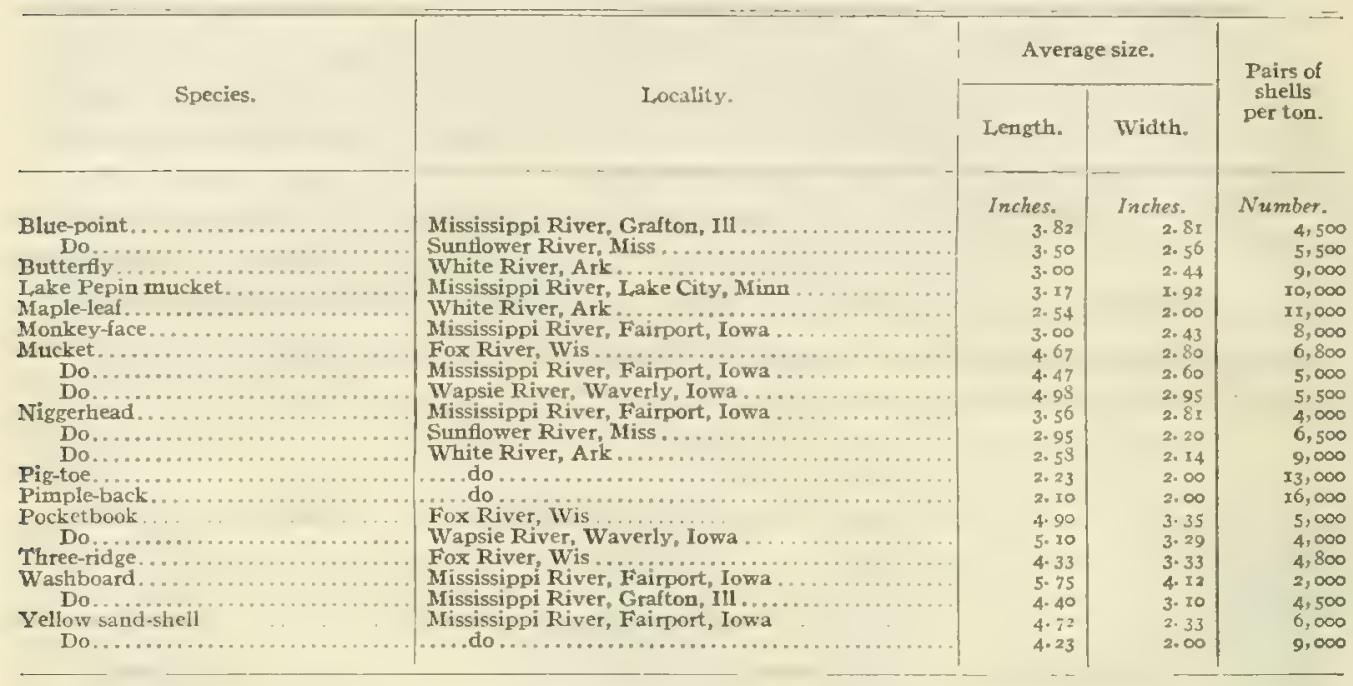

Many of the shellers are nomadic and therefore move readily with their launches from a region of poor fishery to a better locality. It is of ten the case, however, that in times of low water, when the mussels are easily obtained, the farm hands, miscellaneous laborers, and others engage temporarily in shelling, using any kind of available equipment or collecting by hand. It is in such cases that good beds are often rapidly and seriously depleted.

A noteworthy difficulty encountered in some places where the quality of shells is good is the high cost of transportation. In regions remote from manufacturing centers it is therefore advisable to have cutting plants, so that the expense of shipping the waste portions of the shell may be obviated. A cutting machine costs about $\$ I 6$. The cost of a plant of 12 machines, complete, with all equipment except power, was about $\$ 400$, as computed in I9I4. In I9I9 a cutting machine of improved type sells for $\$ 28$ and a 12-machine outfit is estimated at $\$ 725^{\circ}$

\section{DEPLETION OF THE MUSSEL RESOURCES.}

It has been mentioned that the extension of the fishery has been directed by the depletion of the mussel beds in the regions first worked. Generally speaking, it may be said that no stream or region has been entirely exhausted, but wherever a mussel fishery has once existed it has continued in operation to this time, although in reduced activity and with much irregularity.

The history of a shell bed in typical cases may be described. When first fished, there is usually a large proportion of very old shells which are coarse and heavy and often much croded. After the first year or two the yield of the bed is chiefly the medium-

G In referring to values and costs the writer feels obliged throughout this paper to give figures, when available, for both the years 1914 and 1919 . While it can not be assumed that prices of rgrg are normal, it seems reasonably sure that prices will not return to the level of I9r4. 
sized shells of the best quality. In the last stages the larger shells constitute a gradually decreasing proportion, while the smallest shells, the very infants, indeed, form a steadily increasing proportion. Here is a fatal defect of the present manner of fishery. The rate of depletion is automatically accelerated, since the fishermen are taking two or three for one. Where formerly from 5,000 to I0,000 mussels, more or less, constituted a ton, at a later time, when small shells prevail, each ton may represent some 30,000 mussels, as has been determined by repeated counts made by the writer in localities where the small shells are being marketed. The fact that the sheller can now take but a few hundred pounds a day, as against the former catches of half a ton or more, might lead one upon first thought to suppose that the beds thus automatically receive a measure of protection. The very contrary, however, may in practice be the case. The continued rise in price stimulates the sheller to save everything, and the last stages of impoverished fishery are thus the more exhaustive.

When shelling in a depleted locality becomes quite unremunerative, it may be practically entirely abandoned and almost forgotten, until after some years, it is found that the growth and natural reproduction of the mussels have so replenished the bed that it has again become a profitable one, and general shelling is resumed. Usually, however, the local shellers keep engaged, though irregularly, upon the same bed, or more exhaustive methods are employed, and the cases of natural recuperation are therefore conspicuous by their rarity.

In view of the conditions just described, the Bureau has advocated the compulsory closing of portions of rivers for periods of years, in order that the mussel beds might have such a condition of rest and freedom from all in jurious disturbances that the process of replenishment would be assured. It has also urged the adoption of size-limit regulations which would prevent the needless destruction of the small mussels. With such reasonable protective legislation, supplemented, preferably, by artificial propagation, the depleted regions generally might be aided to recuperate. Several States have in recent years enacted comprehensive mussel laws whose effective enforcement will go far to insure the perpetuation of the mussel resources and thereby the permanence of the mussel fishery and its dependent manufacturing industries.

There is no question that all of the better mussel streams are capable of supporting mussel resources many times as abundant as they do now, for they did so a score or less of years ago. For each stream, therefore, it is merely a question of whether commonsense measures will be applied to restore the abundance of mussels for the benefit of all or whether they will always exist only as scattering survivals of an over zealous fishery.

The conditions and the measures for protection have been fully discussed in other publications of this Bureau ${ }^{a}$ and need not be enlarged upon here. It may be said, however, that there is no important stream in which the mussel resources now exist in anything like their former abundance. There have been published photographs showing fishing through the ice in the Mississippi River in the early days, where the persons are grouped closely, each one with a considerable pile of shells about the hole

a Coker, Robert E.: The protection of fresh-water mussels. U. S. Bureau of Fisheries Document No. 793, 23 p., 2 pl. Washington, rgr4.

Coker, Robert E.: The utilization and preservation of fresh-water mussels. Transactions American Fisheries Society, Vol. XI,VI, No. I, New York, 1916.

Smith, Hugh Mf: Fresh-water mussels. Economic Circular No. 43, U. S. Bureau of Fisheries, 5 p. Washington, 19r9. 
through which he worked with a rake. ${ }^{a}$ Such photographs could not be duplicated now, for each sheller would have to work a large area, and probably no considerable quantity of shells could be taken without more ice cutting than the value of the product would justify, even at the higher unit prices prevailing. The practice of winter shelling has, therefore, been discontinued.

\section{APPARATUS AND METHODS OF FISHERY.}

\section{BAR AND CROWFOOT HOOKS.}

Principle: of Capture. - This method of mussel fishery is the one in most general use to-day, since it is adapted for the greatest varicty of conditions, is easily operated even by the inexperienced, and the construction and maintenance involve slight expense. The method is based on the characteristic habits of fresh-water mussels, which lie habitually half embedded in the bottom, with the hinder end of the shell
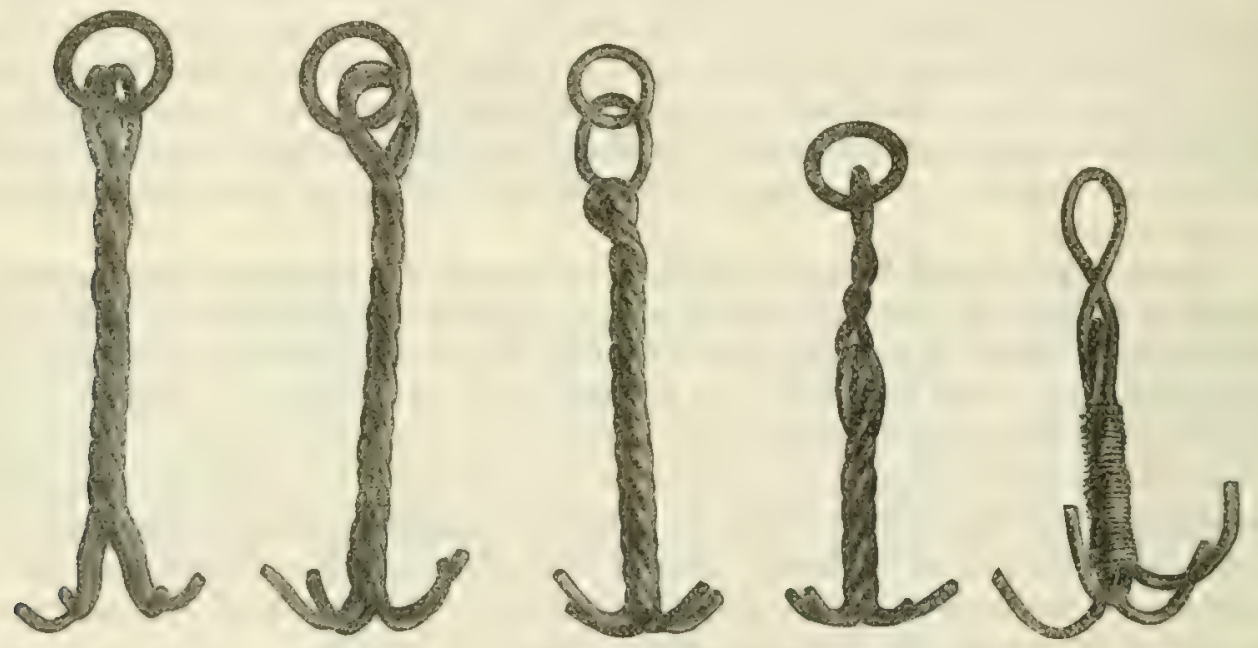

Fig. r.-Various types of crowfoot hooks.

directed against the current and slightly gaping. If a stick or hook be inserted into the opening of the shell, the mussel at once closes tightly and will hold for a long time, even while being dragged over the bottom and hauled up to the boat. Mussels are thus sometimes accidentally taken on ordinary fishhooks, while pearl fishermen working in shallow water have long employed a sharpened stick that could be inserted into the opening of the individual mussel. The more elaborate apparatus now used was first brought to the notice of the rivermen of the upper Mississippi early in the spring of $\mathbf{1 8 9 7}$, and its use soon spread throughout all of the commercial shell districts.

Description of Apparatus.-The crowfoot apparatus consists essentially of a bar or brail to which many short lines are attached bearing four-pronged wire hooks arranged at intervals (P1. XXVII, fig. I). By means of a towing line the bar is dragged above the bottom, while the hooks trail on the mussel bed in a direction parallel to the current. When a look enters a shell opening, the mussel closes firmly upon the hook,

a Smith, Hugh M.: The mussel fishery and pearl-button iadustry of the Mississippi River. Bulletin, U. S. Fish Commission for 1898 , Vol. XVIII, p. 289-314. Washington, 1899 . (See plates 67 and 68.) 


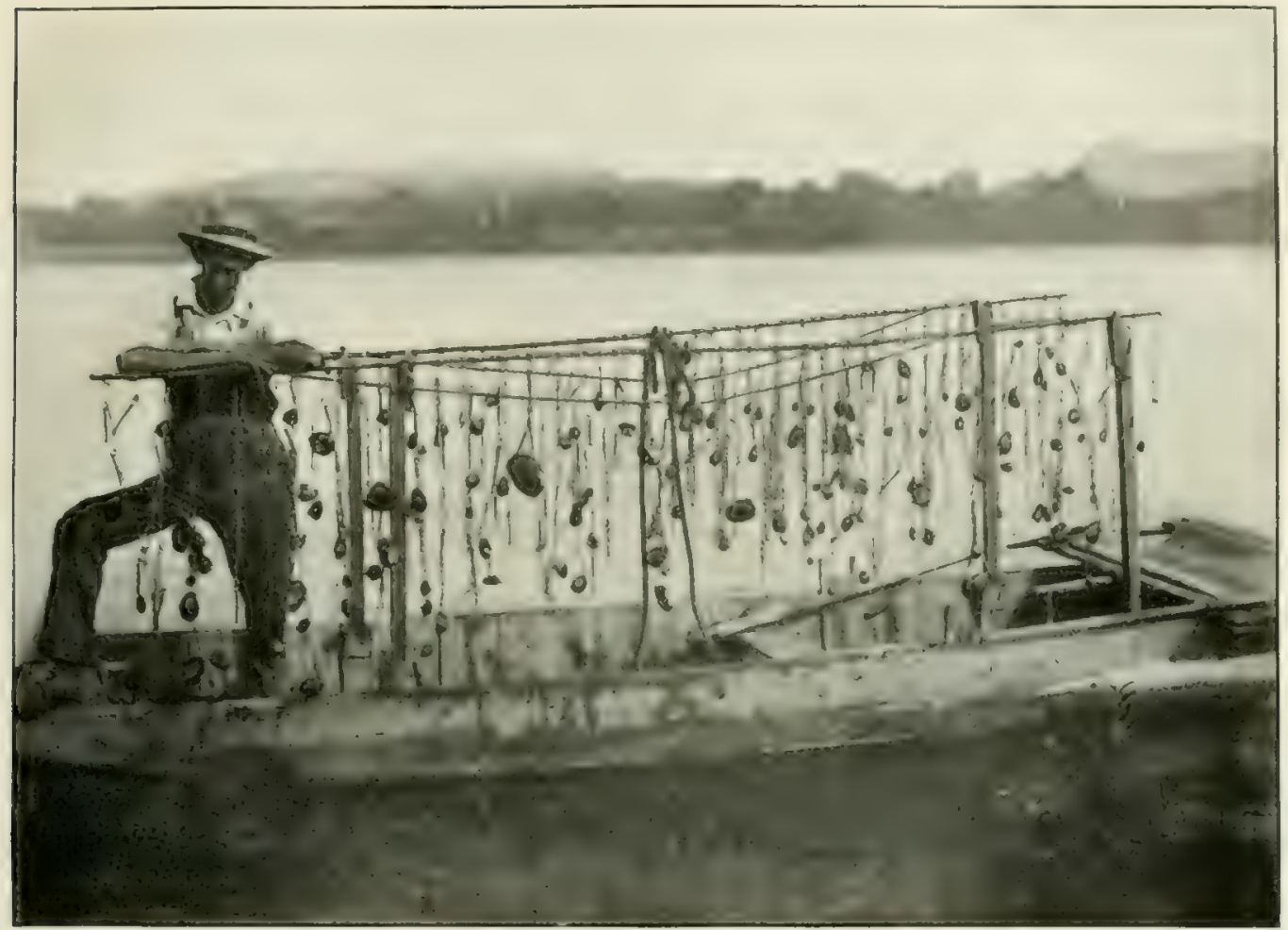

Frc. r. Bar and crowfoot outfit for taking mussels, consisting of john boat, two bars with crowloot hooks, and the "mule" (lying on stern of boat). (See D. 46.)

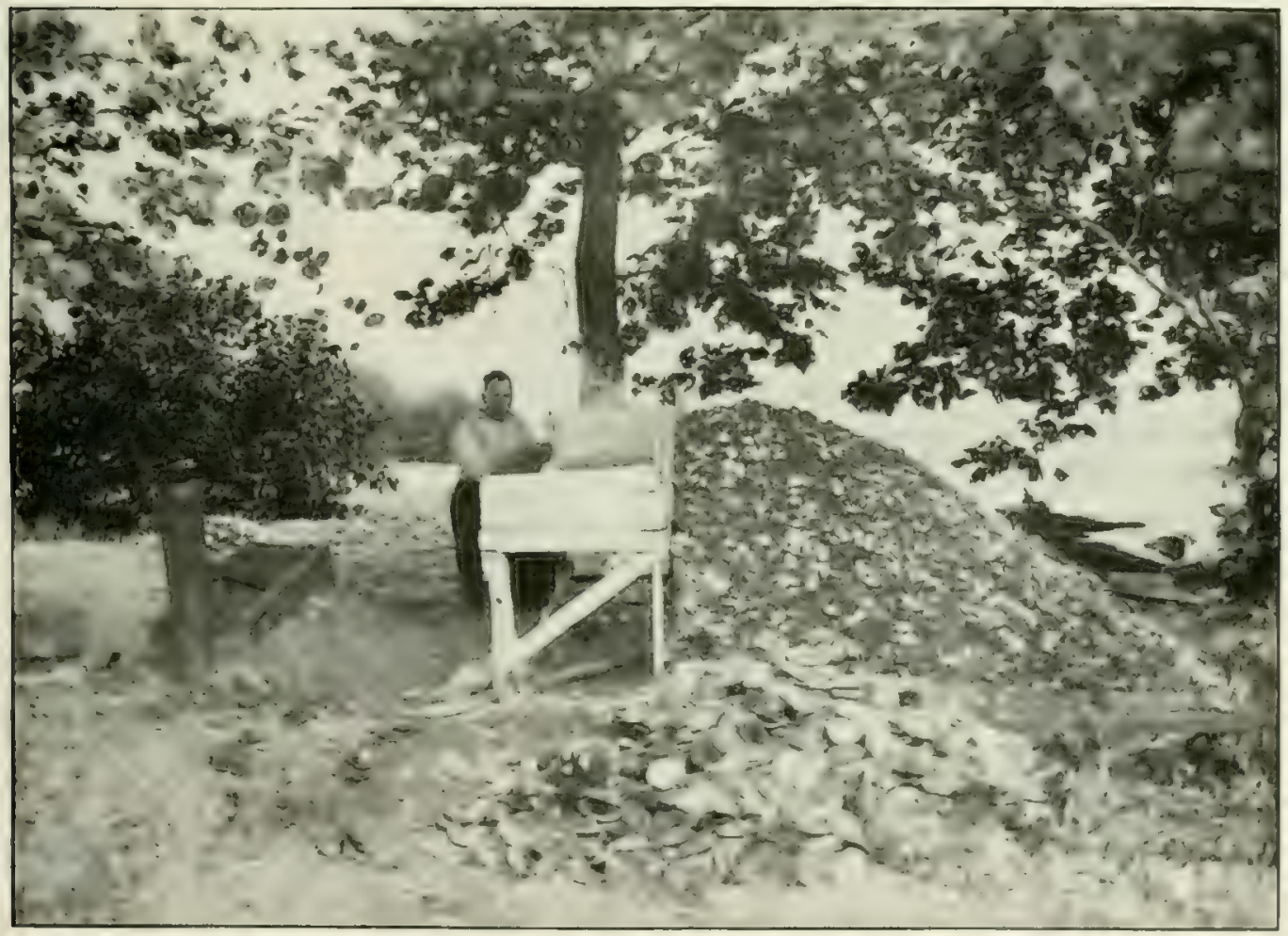

Fig. 2,--Shore outfit, consisting of cooker (at left), sorting table (center), and shells ready for sale. (See p. 6o.) 

and in consequence is dragged from the bottom. When the bar is raised after a suitable time, numerous mussels may be hanging from the hooks. The essential parts of this apparatus and the manner of its operation will be described in detail.

Hooks and mode of making them.-Although the principle of the crowfoot and the general method of manufacture are the same throughout the country, there is much variety in the style and size of hooks in use on the different rivers, and even in the same camps. Some of the most popular kinds of hooks are the single-eye, the double-eye, the ring, the wrapped, the untwisted or straight-wire hook, etc. (fig. I). Manufactured hooks are obtainable on the market, but the mussel fishermen more commonly make their own hooks, employing odd moments for this purpose with a corresponding saving in expense.

The material is usually No. I I galvanized or telephone wire. If very heavy work is to be done, a larger size, No. 9 or 10 , may be taken, although hooks from the stiffer

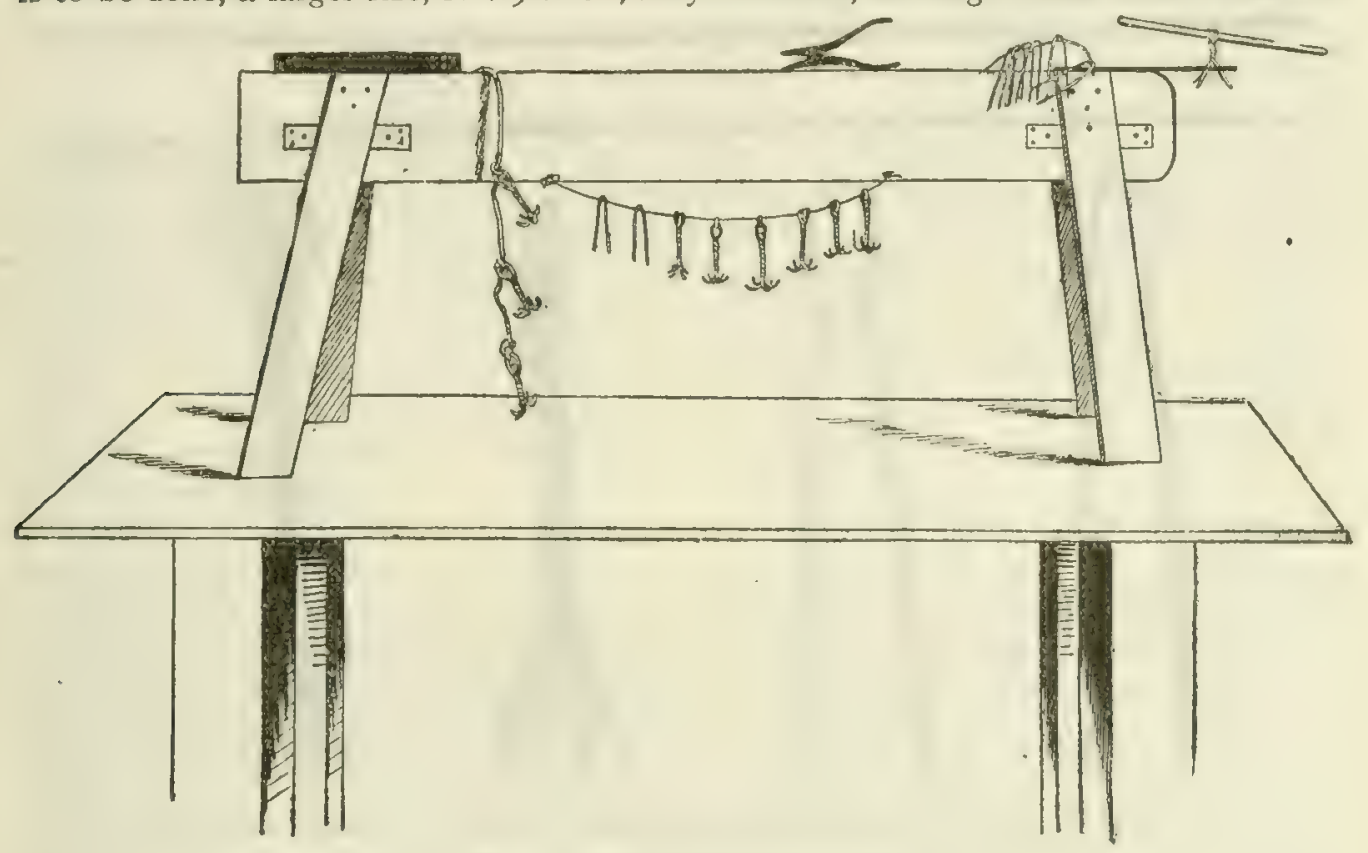

Fic. 2.-Process of making crowfoot hook.

wire are more difficult to make and cause more trouble when the apparatus is fouled on the bottom; the bar may be entirely lost from a hang-up if the hooks will not straighten out before the line breaks.

To make a hook one needs only a bench, an iron vise, or, preferably, an iron strap or steel plate with proper holes drilled through, a pair of pliers, and a pin or short rod for the twisting process (fig. 2).

The iron strap or steel plate is usually from 6 to 8 inches long by 1.5 inches wide and 0.25 inch thick. Near one end four holes of sufficient size to admit the wire are drilled in the corners of a 0.75 -inch square. Two or three additional holes are drilled in the opposite end of the plate, so that it may be fastened securely to a solid block, timber, or tressel of wood, leaving the end with the four small holes free. The 
wire is first cut into lengths of about 10.5 or I I inches, or up to 14 inches for extra long hooks (fig. 3). The "needles" thus made are then bent into "hairpins" or loops, with the sides parallel or nearly so. Two loops are placed diagonally into the small holes of the square and are forced down to the face of the plate, leaving just room enough for the turning pin. The twisting is done by hand and continued until there is about I inch of straight wire remaining in the plate. The hook is withdrawn and is complete, excepting that the ends must be cut off at even lengths and bent to the desired angle with pliers or with a piece of hollow umbrella tube. In making the single-eye hook one loop is placed half an inch in advance of the other, when they are introduced into the iron strap. In order to obtain the best results in making hooks, the holes in the plate should be kept well greased. The process is well illustrated by figure 2 , while some of the various patterns of hooks made by the mussel fishermen are shown in figure $\mathrm{I}$.

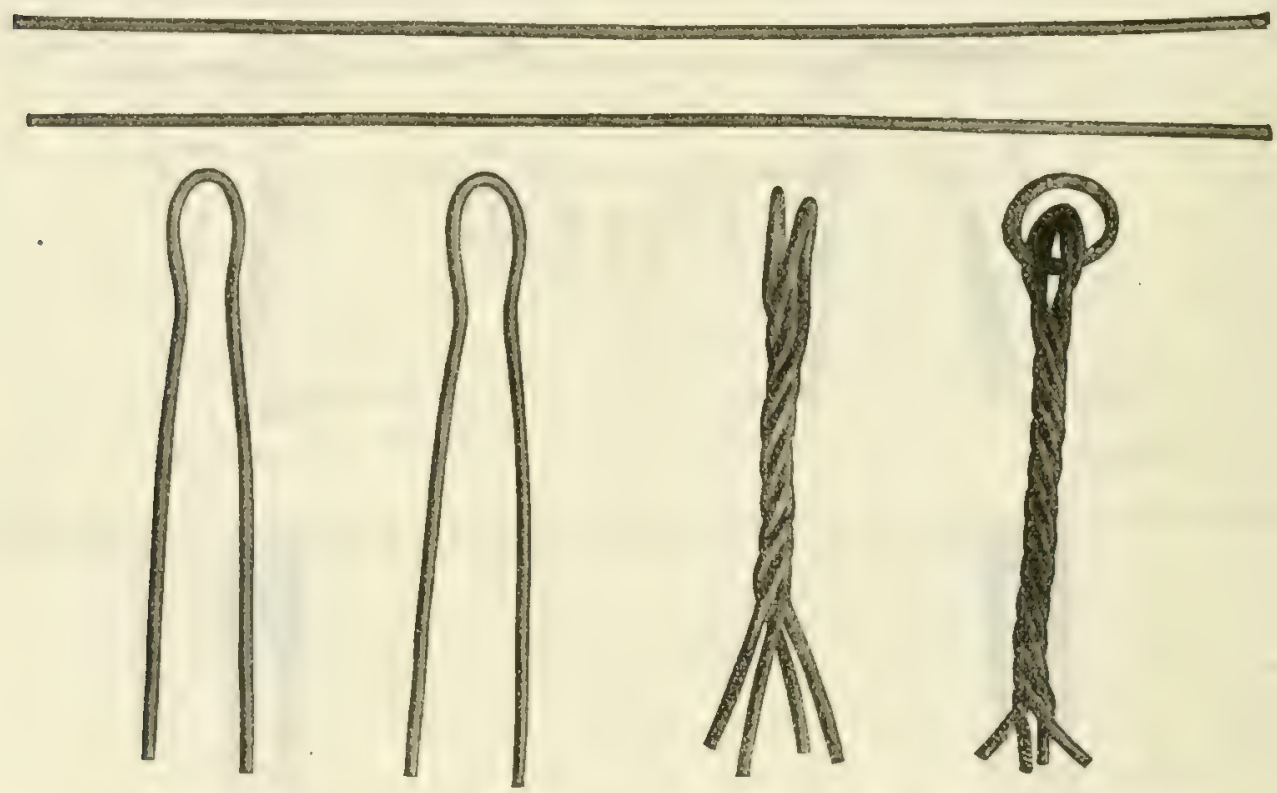

Fis. 3. -Stages in the process of making crowloot hook; "needles," "hairpins," and nearly completed hooks.

Bar and lines.-The bar, or brail, consists of a black or galvanized iron gas pipe from 12 to 20 feet in length and with a diameter of from 0.75 to I inch (Pl. XXVII, fig. 1). Caps are used or wooden pegs are driven into the open ends of the pipe to keep out the water; otherwise the bar would fill with water and cause an undesirable slop when raised to the standards of the boat. The bars are occasionally supported by small wheels at the ends, to prevent the bar from disturbing the mussels before the hooks have reached them. This is generally unnecessary, because, while the boat is in motion, the bar is slightly raised from the river bottom, and only the hooks can touch the mussels. On a few rivers a wooden bar is used by some mussel fishermen, but it does not appear to be so popular or to give as satisfactory results as the iron bar.

The strings or lines for carrying the hooks consist usually of soft trot-lines of No. 96 or 120 size, and are about 3 feet in length. They are attached to the bar at intervals of from 4 to 6 inches by a half-hitch knot, which is easily tied and readily loosened if a new 
string is to be substituted. The soft line wears better than any other kind, especially where the bottom has much sand and gravel. Chains, or long wire links, are sometimes used in place of the cotton twine, but, although they last much longer, they are not often employed, owing to the extra weight and cost. Each line carries from two to six hooks, attached at intervals of sufficient distance to prevent successive looks from interfering with one another.

The bridle is a small-sized rope, about 0.5 inch in diameter, and is attached to the bar near the ends. It is left loose, so that it may be tied to the main rope about 2 feet above the middle of the bar.

The main rope, or cable, is larger, being usually about 0.75 or I inch in diameter, while its length varies according to the depth of water, generally from 25 to 35 feet being required. The rope is tied to the middle of the bar and to the center of the bridle. To obviate difficulty from twisting and to make the rope available when desired for other purposes, the attachment to the bridle is usually made by a swivel snap and ring.

The mulc.-An essential feature of the outfit with this method of fishery, under ordinary conditions, is the underwater sail or mule, as it is called. When the mussel fisherman is ready for work and the boat is over the shell bed, the bar is thrown overboard. The hooks of the bar catch in the river bottom, as well as in the shells, and thus, acting as anchors, will stop the progress of the boat downstream, unless additional porver is supplied. In order to derive this power from the current, the mule is lowered into the river at the stern of the boat, to which it is connected by gtide lines. Its broad surface is at right angles to the current, and the entire outfit is thus forced slowly down the river, stern first, in spite of the drag on the bottom. By means of the guide lines the mule is easily regulated to steer the boat at a desired angle over the mussel bed, or to avoid a familiar snag.

There are two well-known types of mules in use on the different rivers-the common frame type and the roll mule.

The frame type is rectangular in form, the outline or framework consisting of light strips or narrow boards about 3 inches wide by 0.75 of an inch thick, sometimes with a center strip extending from the middle of the bottom to a few inches above the top. In Plate XXVII, figure 1 , a mule is shown lying on the stern of the boat; sce also Plate XXIX, figure I. The frame is covered with strong cloth, such as muslin, canvas, tarpaulin, gunny sacking, etc., which is left rather baggy in order to make the appliance more steady in the water; otherwise when the current strikes it at an angle it is liable to turn over, dart forward, and "kick." This characteristic accounts for its technical designation as "mule." It is connected to the boat by lines running from the four corners, excepting for those patterns having the center strip, when three connections are made with the lower comers and the top of the strip.

The roll mule is not used so extensively as the frame type, but it is very popular on the Illinois and some other rivers. It consists of a piece of canvas, tarpatilin, or heavy cloth cut according to the size and shape desired. An iron rod is attached to the bottom of the mule and a wooden bar at the top. To the four comers of the cloth small lines are secured for the purpose of adjusting the mule to the boat. This form of mule has the advantage over the other in that when not needed as a sail it can be rolled up and put out of the way in the boat or used as a tent against unfavorable weather. It is 
claimed that it is better adapted for steering the boat diagonally, and also that it does not kick.

There is much variety in the form and size of the mules, which are made according to the notions of the individual fisherman or in adaptation to the condition of the river. In a shallow stream the necessary surface is obtained by making the mule long and narrow, at times about 8 feet long by 5 inches deep. For deeper waters the sizes vary according to the strength of current and the drag of the bar; 2.5 by 6 feet and 3 by 7 feet are common sizes.

Boats. - The most satisfactory boat in use for the crowfoot method of fishery is the ordinary john boat, since it is inexpensive and may be made in the camps by the mussel fishermen themselves, according to their needs. Its length is from 14 to 20 feet, with a width at the center of from 3 to 4.5 feet, but it is always riarrower at the ends. It has square ends, a broad, flat bottom, long rakes particularly forward, and is usually of light draft (PI. XXVII, fig. I).

When the john boat is built particularly for this method of fishery, all unnecessary interior parts are omitted, while the needed special appliances are added. These consist of two perpendicular uprights or standards on each side of the boat a yard or so from the ends, a cleat at the bow, and nails or pegs at the stern. The standards are about + feet high and are made of light strips of wood, with notches at the top for holding the bars. When the shelling is very heavy and the bars are difficult to raise, there are added at times substandards or short strips of wood projecting outward from the standards near the gunwale; in this case the bars when lifted are first placed upon the substandards and then transferred to the standards. At the present time nearly all of the john boats are equipped with gasoline engines of power commensurate with the size of the boats. In the Black River, Ark., some of the john boats are propelled by small stern paddle wheels operated by hand power with a vertical lever on the side of the boat.

OPERATION OF THE CROWFOOT BAR. - When the john boat and all the appliances are complete for this method of fishery, the boat is either rowed or propelled by gasoline power to the mussel bed upon which the work is to be done. After selecting the exact locality for the first haul, usually near the head of the bed, the mussel fisherman lowers a bar into the river in such a way that it will lie at right angles to the shore and drag parallel with it. The rope connecting the bar is played out until the latter is dragging freely and is then secured to the cleat. Occasionally two bars are used at the same time; the second bar being placed into the water a short distance in advance of the first and a little to one side, with a shorter rope connection.

Unless the current be very strong, which is seldom the case where a good mussel bed is found, it is necessary to bring the mule into operation; and this can be so adjusted by the guide lines as to make the outfit go very slowly or more rapidly as desired, as well as to cause the boat to sheer toward or away from the shore.

After making a haul of about roo yards the bar is ready to be raised. The method of procedure is to remove the mule from the water and then slowly draw in the connecting rope until the bar can be grasped.by the hands and raised to the tops of the notched standards. The other bar is put into the river, and the mule is again set. The shells are then taken from the hooks and are thrown into the bottom of the boat. The process is repeated until the bed has been worked over, when the boat is returned to the initial point or taken ashore, if a boatload of shells has been obtained. 


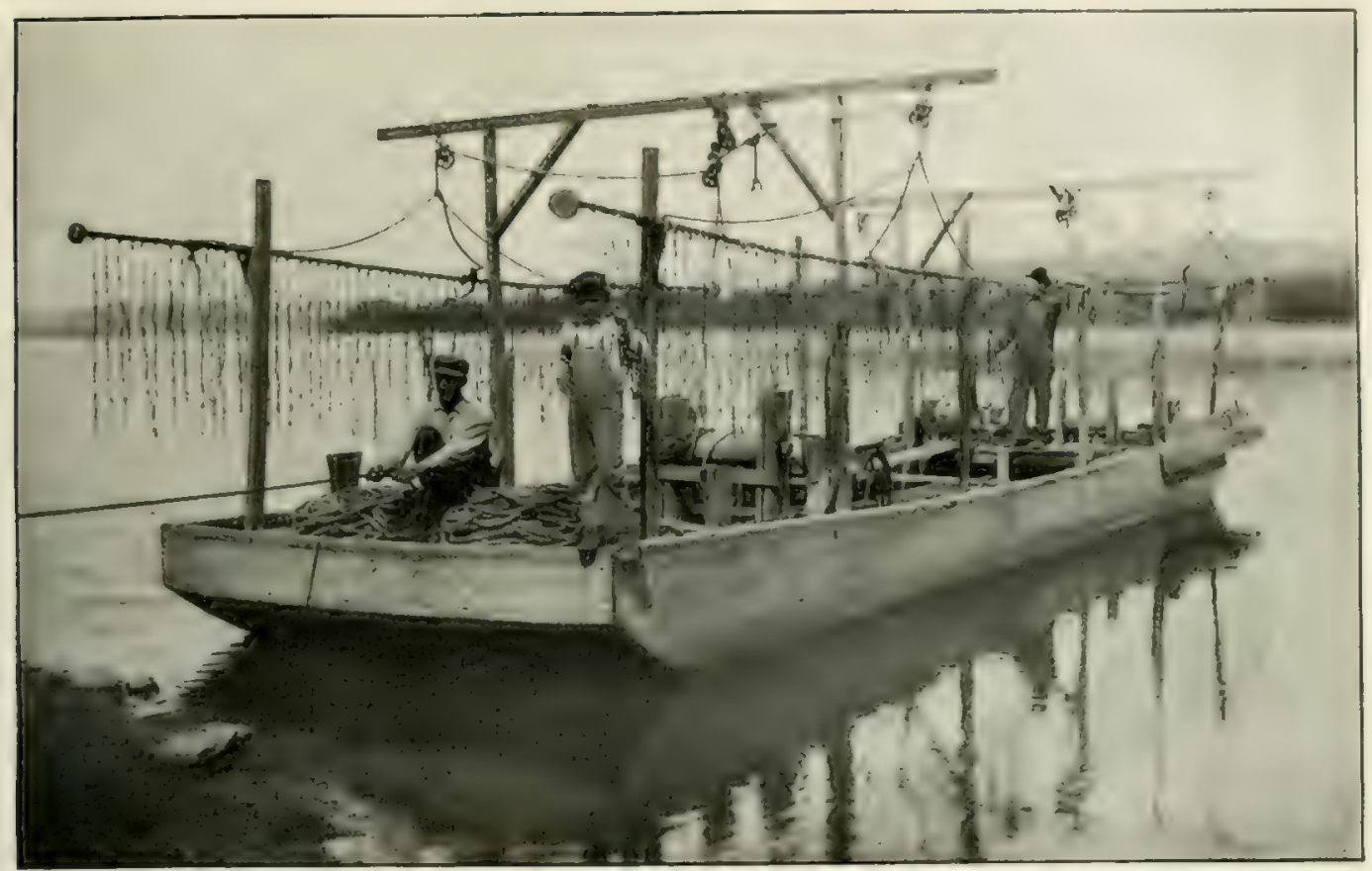

Fic. x.-Barge with long crowloot bars, employed on the Ohio River. Note rollers set on ends of bars to facilitate movement over the bottom. (See p. 5i.)

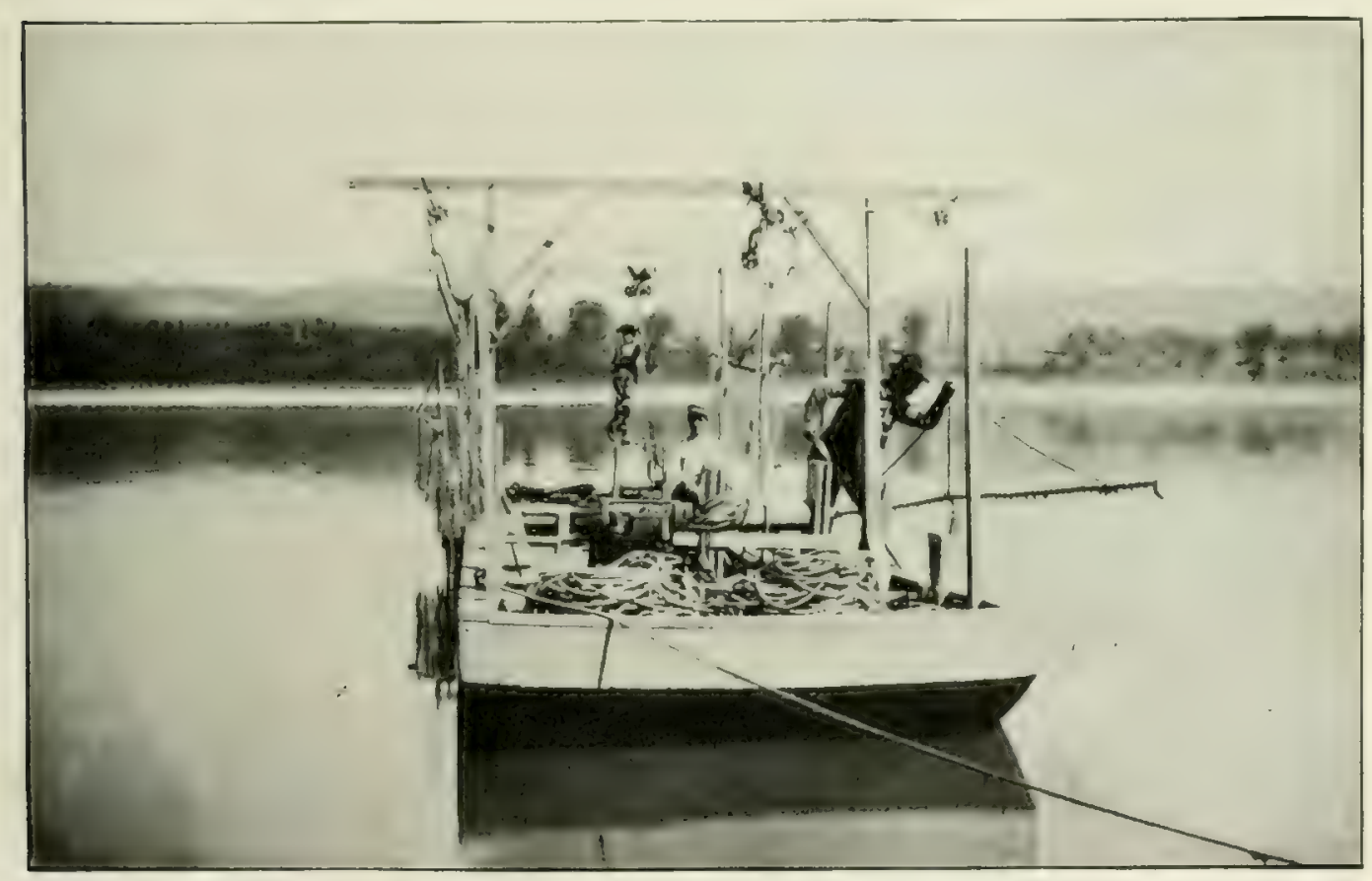

Fig, 2.-Iowering the crowfont har into the water, Ohio River. (See p. 5I.) 

Besides mussels the hooks bring up snags, small logs, and an almost unlimited variety of articles that have found their way into the river. There may be a greater or less number of larger hang-ups and other obstructions in the river, which may cause delay or the loss of a complete bar. No work is attempted in windy weather, ordinarily, on account of the trouble of handling the boat and the consequent danger of becoming entangled in the hooks or of being dragged overboard.

Where no current prevails, as in Lake Pepin, the propulsion of the boat was formerly accomplished by dropping an anchor with a very long cable attached to a windlass on the boat. The boat was then propelled away to a point where the bar was dropped. Turning the windlass by hand, the boat and bar were dragged over the mussel bed. The engine power itself was regarded as too violent, as well as too expensive, for the rate of movement desired in dragging. Now, however, the shellers on Lake P'epin generally use two boats, a flat boat attached broadside against the stern of a motor boat, $T$ fashion. In this way two or even folir bars may be dragged on the bottom at the same time, employing the motive power of the engine.

It is interesting to note that when this method was first brought into use in 1897 , the parts of the apparatus were small and the method of employment crude. The bar was only from 4 to 8 feet loug, provided with I 6 or more hooks, and dragged by a rope from the stem of the boat. Two men usually operated in partnership, one man handling the apparatus, while the other rowed the ont fit laboriously over the mussel beds. The hand motive power was later improved by the use of a driftboard or mule. By cliance it was discovered that a similar effect was had when the boat was allowed to drift broadside to the current. Although this method is still used in some places, it has not gained general favor with the mussel fishermen, probably because, when the boat is used broadside, there is more or less danger of dipping water or swamping.

When the boat is used broadside, a series of cleats are placed on the gurwales of the boat in the middle portions. If a drag rope is attached to the middle cleat, the pull of the drag will be directly opposed to the current. If, however, it is desired to steer away from the shore, it is only necessary to shift the rope to another cleat, shoreward, or channelward, as the case may be, and the resultant force of the current is in the direction desired. If there is not sufficient force in the current to move the boat fast enough, a leeboard, or mule, may be used as readily as with the ordinary fore-and-aft position of the boat.

For work on a much larger scale than can be accomplished by means of the ordinary-sized boats there are occasionally employed heavy barges of a type illustrated in Plate XXVIII. These are used successfully on the Ohio River, near Vevay, Ind., and, though somewhat similar in construction to the usual john boat, they are much larger and more solidly built; the dimensions are, approximately, Io by to feet. The barge is fitted with uprights and pulleys for handling the bars and with standards for holding them when raised. There are 4 bars 20 feet in length by 1.25 inches in diameter, to each of which are attached 76 strings, bearing 7 hooks each, thus making more than 2,000 hooks for the entire outfit. In operating this contrivance the bars at the opposite corners are lowered alteruately into the river, so that as far as practicable two bars are always in the water. Because of the weight and the resistance of the bars on the bottom, a very large mule is used during a good stage of water or in 
a strong current. In the low water of summer a mule is of no avail; at this season of the year a cable 400 to 500 yards in length is used, one end of which is anchored down the river, while the other is hauled through a pulley by means of a two-horsepower gasoline engine, located near the center of the barge. The engine is also employed to assist in raising the bars from the mussel beds. The barge is towed from place to place by a small gasoline boat alongside or at the stern. By this method three men have been known to gather 3 tons of shells in a day in favorable localities in the Ohio River.

Advantages And Disadvantages of THE METHod.-Exicept where snags are prevalent, good success is had with the bar and crowfoot under a wide variety of conditions. The daily catch probably averages less than 500 pounds of marketable shells. In severely depleted regions only 100 to 200 pounds may be taken, while a half ton or more may reward the fisherman in better localities. The fishermen claim that the mussels or clams bite best in the spring of the year, on rising water, and early in the morning.

A serviceable john boat could be made in I9I4 at a cost of from \$Io to \$I5; and the bars, hooks, and lines at from $\$ 5$ to $\$ 6$ per pair; the necessary ropes cost from $\$ 2$ to $\$ 3$, making a total of from $\$ 17$ to $\$ 24$. However, if an engine of suitable power is installed in the boat an additional amount of about $\$ 50$ to $\$ 100$ should be added to the above sum. On the basis of the prices of materials in r9rg, these costs appear approximately as follows: Boat, $\$ 23$; bar, hooks, and lines, $\$ 10$; ropes, $\$ 3$; total, excluding boat engine, $\$ 36$.

The method has these advantages: It is inexpensive, and not necessarily laborious; it is adapted for use in deeper waters where the hand rake or the tongs can not be used successfully, and it can be employed readily by the inexperienced.

The disadvantages of the crowfoot are not so obvious but are very important nevertheless:

I. The mussel beds are repeatedly dragged over by hundreds and thousands of hooks, with consequent possible injury to the mussels, especially the young. Gravid mussels, it is known, will often abort the immature spawn when disturbed.

2. Some mussels, after taking on the hooks, are pulled off while yet on the bottom with more or less injury. Experiments conducted at the Fairport station indicate that a large percentage of such mussels receive injuries from which they die. A considerable number of mussels were taken by hooks and by rakes; each set of mussels was divided into four lots, which were carefully balanced against one another in experimental ponds. After two months 38 per cent of the crowfooted mussels and only 5 per cent of the raked mussels had died.

3. The hooks take exceedingly small mussels, even down to 0.75 to $\mathrm{I}$ inch in length, which are not only useless for any economic purpose but are liable to a heightened nortality when thrown back into the river. 'The use of larger wire for the hook has been suggested, with a view to lessening the number of small mussels taken.

There are two or three designs of patented hooks on the market, and it is claimed that they have advantages over the ordinary kinds made by the mussel fishermen. One design, invented by the late J. F. Boepple, is like the ordinary twisted-wire hook, except that the wire prongs are compressed near the tips and finally expanded to form a ball or globular tip larger than the diameter of the wire. When the ball enters the opening of the mussel, the shell closes on the compressed neck, and it is very difficult for the mussel 
to fall off with the subsequent dragging on the bottom. These hooks are also slightly weighted by a wire wrapping at the lower end of the shank, and a dip in melted solder makes the entire hook less liable to untwist. Another hook, lately brought to the attention of the public and known as the "sanco-point" hook, has five prongs made in one piece and attached by means of a swivel to a center shaft. The tips are also globular to make a so-called locking device intended to prevent the escape of the captured mussels. For both of these designs, it is claimed that the small mussels are not captured on account of the enlarged tips, and that when the ordinary-sized mussels are once caught they do not fall off the hooks, so that no injured mussels are left in the beds. ${ }^{a}$ These claims remain to be effectively demonstrated; but such improvements are eminently desirable and worthy of careful test, for there is no question but that the ordinary crowfoot hook is distinctly injurious and that its use should be permitted only for a brief time, allowing opportunity for effectively improving it or displacing it altogether with other equally efficient apparatus.

Meantime, mussel fishermen everywhere are urged to learn the use of other methods, for it is evident that an injurious mode of fishing will not be tolerated indefinitely. 'The shellers themselves will recognize the propriety of excluding from use, wherever it can be replaced, an appliance which is actually destructive of shells that are not taken or that can not be marketed when captured. Various other methods now in practical use will be described in the following pages.

\section{DIP-NET DRAG.}

ORIGIN OF THE METHOD.-The dip net, as used in shelling was invented and introduced during the spring of 19 I I at Peoria, I1l. It had long been known that Peoria Lakethat part of the Illinois River which broadens into a lakelike expanse above the dam at Peoria - contained large beds of commercial mussel shells of good quality, but previous to I 9 I n nuitable method of taking them had been devised. The various tools and appliances, as the bar and crowfoot hooks, tongs, scissor forks, etc., which had been operated so successfully in other mussel rivers of the Mississippi Basin and in the major portion of this river, proved unsatisfactory in Peoria Lake. There was urgent need for some contrivance that would collect the shells in deeper water, where practically no current prevailed, and the dip net came to fill this want.

It is not known who invented this appliance, but probably the idea developed by a combination of the principles of the ordinary dip net as used in fishing and the clam rake. At the present time this apparatus is used in Peoria I ake almost exclusively, none other being employed, except in places where the bottom conditions are unfavorable for the operation of the dip net. Within very recent years its use has extended to other parts of the Illinois River and to Lake Pepin. One dip net was seen on the White River of Arkansas in 1913, but it had not been put into use.

The dip net is simple in construction, and in operation; it is also inexpensive and especially suited to those rivers and lakes which have soft mud bottoms free from obstructions, such as logs and hang-ups, and where there is but little or no current.

Description of Apparatus.-There appears to be no definite standard or general specifications for this mechanism, and consequently there are no two alike; the black-

a Several tests made by J. B. Southall, shell expert of the Fairport station, indicate that about 30 per cent of the mussels catching on ordinary hooks are lost, while only about 15 per cent of the mussels catching on the Boepple hooks drop off. 
smiths make them according to orders and with the material at hand. However, the various designs and patterns are very similar, the main differences being the size of the hoop and the length of the attached net. The method of operation is the same for all of them.

The frame of the dip net consists of a heavy iron hoop of one piece flattened on one side. The general form, therefore, is somewhat triangular, the bottom being straight, while the two sides are curved and attached by bolts to a pole or handle $x 6$ to zo feet long (fig. 4 in text and P1. XXIX, fig. 4). A large net of 2 -inch mesh, made of small chain or trot-line and having a capacity of a bushel or more, is fastened to the hoop by means of chain links, and trails behind it. A short bridle attached to the two

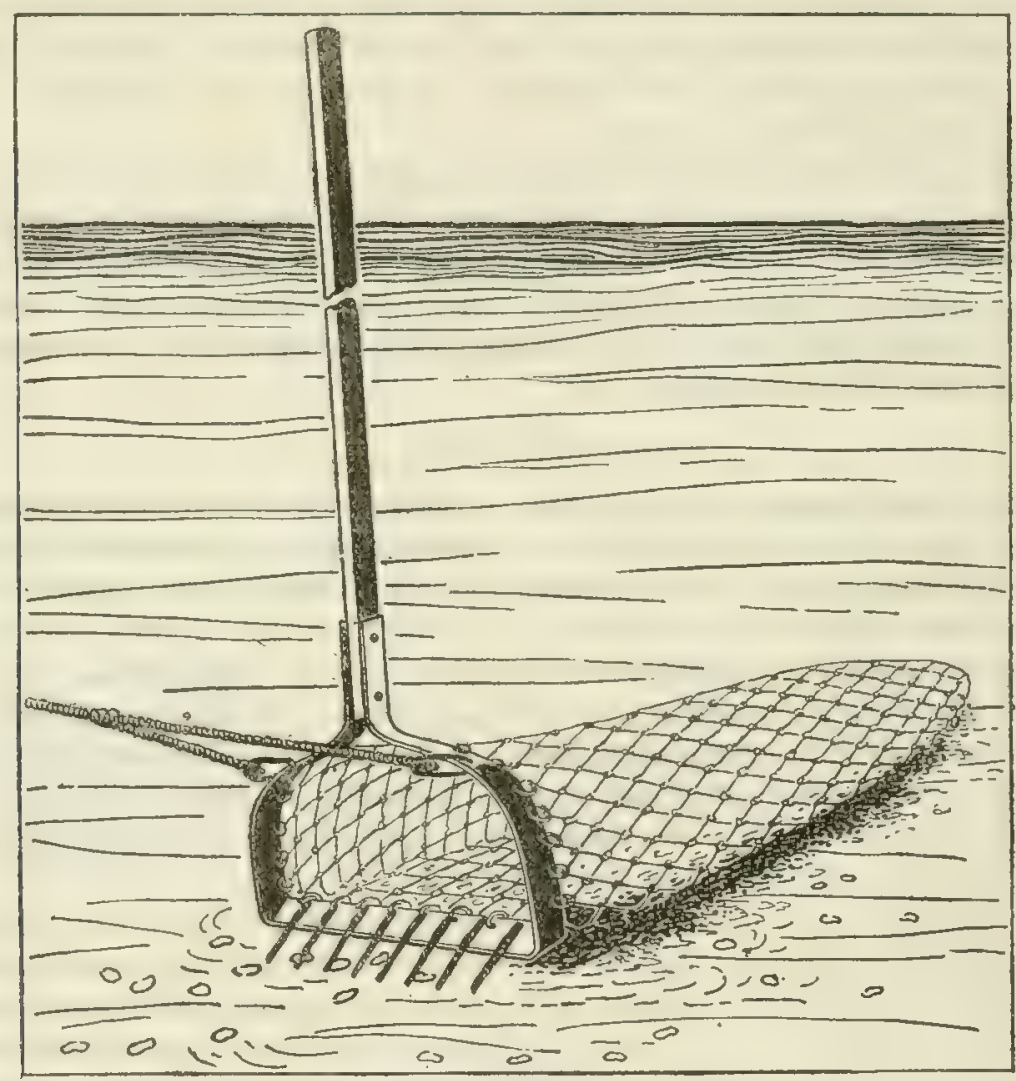

Firg. 4, -The dip net used in taking fresh-water mussels.

curved sides of the hoop lead forward to a single rope secured to the bow of the boat. To withstand the strain from dragging through the water and also to support the net with a heavy load of shells, the hoop is usually made of stout wagon-tire iron, about 2 inches wide by 0.25 inch thick. The straight bottom is from 18 to 36 inches in length; the edge is bent downward and usually provided with coarse teeth 6 to 8 inches long, and at times two or three additional teeth are riveted to the curved sides, near the bottom. However, in some hoops the teeth are omitted altogether, since none are needed where the bottom of the river is composed of very soft mud. The net varies in length 


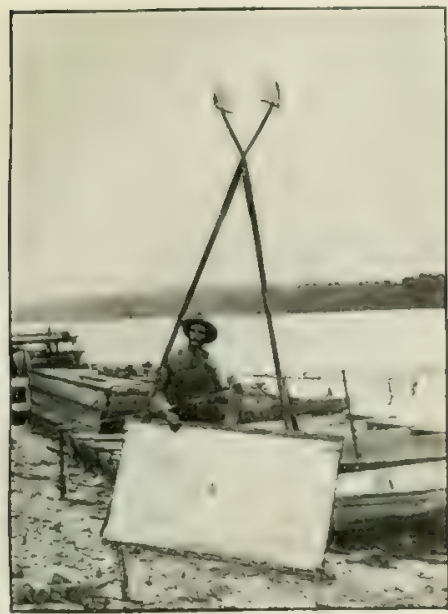

Fig. I - Shell tongs or scissors fork. The "mule" (in foreground) is not used with tongs, but in connection with crowfoot bars (in background). (See
p. 56. )
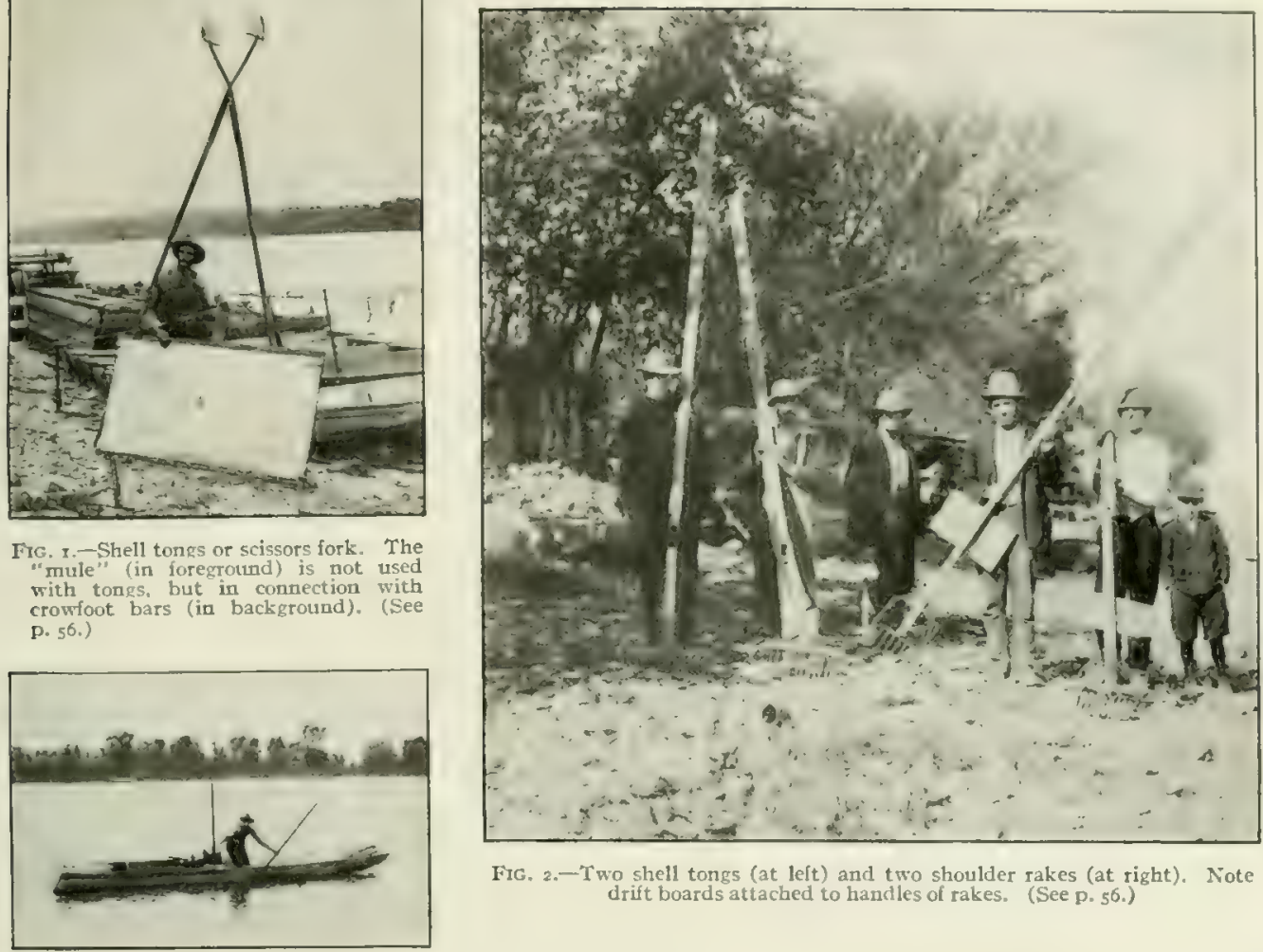

Fic. 2. - Two shell tongs (at leit) and two shoulder rakes (at right). Note drift boards attached to handles of rakes. (See p. 56. )

Fig. 3. Taking mussels with the shell tongs. (See p. 56 .)

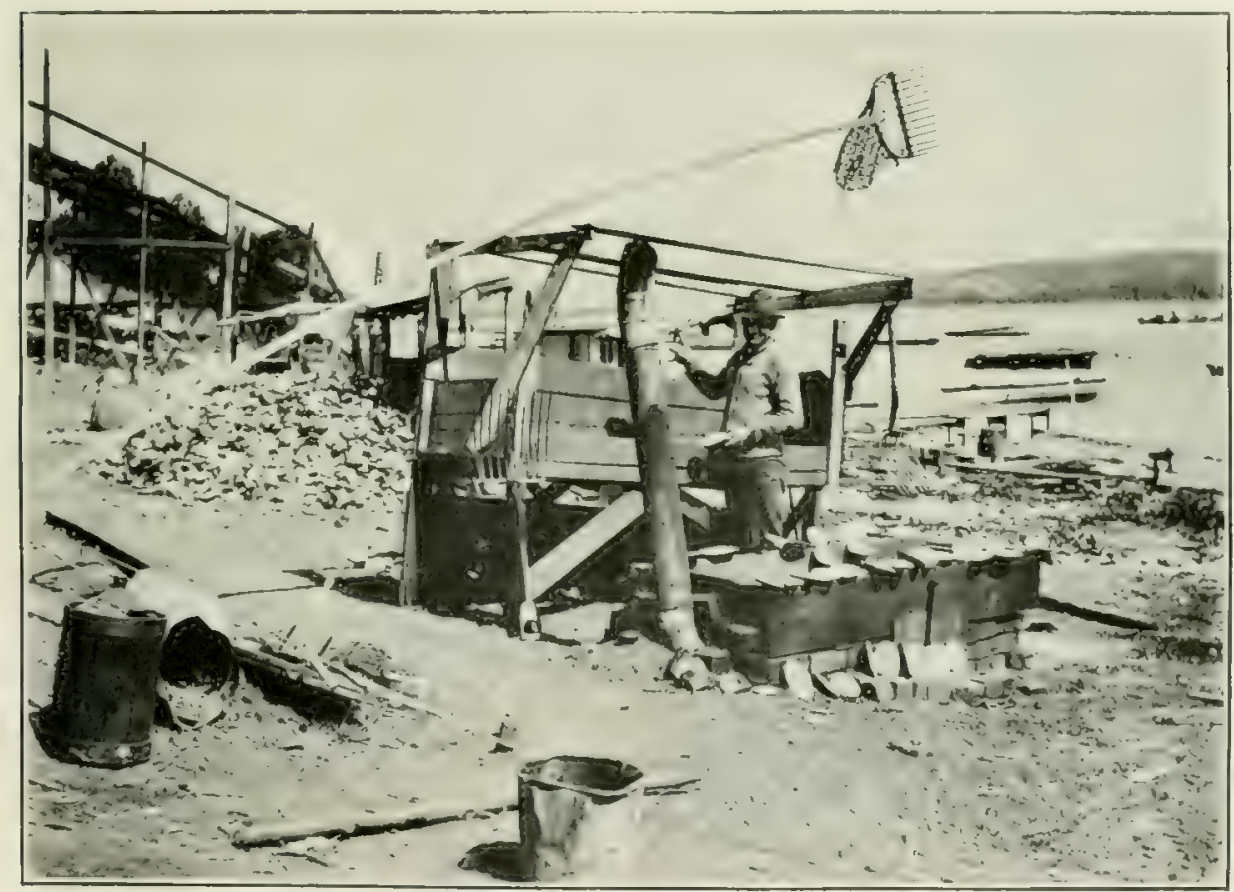

IIG. 4*-Dip net and forks with shore equipment. (See p. 54.) 

from 3 to 4.5 feet, according to the size of the hoop; when not made of chain, it is usually tarred to insure longer life. Soft twine is preferred to hard twine; the sizes used range from 36 to 96 , but the latter size is the one generally employed.

Power is a very important factor in the use of the dip net. The boat and engine, in fact, govern the size of the appliance, since it would be useless to work with a large dip net and very little power. Any ordinary john boat or launch, which the sheller may have, can be readily fitted up for use. Uprights or standards on the boat, as well as the mule, can be dispensed with. The engines are of the gasoline type and are from 4 to 20 horsepower.

The cost of the complete dip net, including the necessary ropes, is about $\$ 5$ to $\$ 7$, depending upon the size. Considering the good results obtained by this method of mussel fishery, together with the durability of the apparatus, the first cost is very small, indeed.

OPERATION OF DIP NET.-To operate a boat successfully, two men or a man and a boy are needed; one attends to the dip net and the steering, while the other looks after the engine and assists with the shells. When the boat is over the mussel bed, and running at full speed, the operator stands in the stern and steers with his foot or leg while manipulating the dip net with his hands. The apparatus is put into the water, usually at his right side, and when it reaches the bottom he bears down heavily on the handle. The towing line is attached, as previously mentioned, to the bridle at one end and to the bow of the boat at the other. The dip net, therefore, functions as a dredge, while the pole is handled by the fisherman in the stern in such a way as to change the angle of the net and cause it to dig into the bottom more or less deeply. Physical energy and endurance are required on the part of the operator, if the dip net is large and the power strong.

If the water be rather deep or the boat very short, the angle formed by the towing line and the upright handle may be too sharp for proper manipulation. In this case a boom pole is rigged out from the bow and a longer line attached to its forward end.

The teeth on the lower edge of the hoop dig up the mussels, which, due to the motion of the boat, roll into the net. Unless the net is placed at the stern in direct line of travel, the boat is retarded on one side and consequently makes a large circle over the mussel beds; this is usually desired. When the apparatus is raised after making a haul, the mud and small shells are washed out as well as can be done rapidly, and the contents are dumped into the bottom of the boat. The partner attends to the sorting out of the mussels, the trash and some of the dead shells being thrown overboard.

By this method of mussel fishery two men or a man and a boy have been known to take from 1,500 to $\mathrm{I}, 800$ pounds of shells in half a day in a good locality.

ADVANTAgES OF THE DIP-NET MithoD.-The dip-net appliance is strongly recommended to the attention of mussel fishermen, as it is especially adapted for use on softmud bottoms and in waters which are without strong current and also where the depth is too great or the mussels too scattering for the successful operation of the rake or tongs. It may also be employed where there is a good current, providing the bottom conditions are satisfactory.

The method will be at a disadvantage in very hard or gravelly bottoms or where there are numerous obstructions; in the first case the net will become overloaded with rocks, and in the second the progress will be stopped altogether. 
It is well to point out that the meshes of the net should be of such a size as to permit the small shells to pass through and remain at the bottom. Some small mussels will undoubtedly be held in the net by the mud and larger shells, but these can be culled out readily and returned to the water without any material injury.

It may be noted that occasionally some of the thinner-shelled mussels, such as the floater, paper-shell, etc., are pierced by the teeth of the dip net, which, of course, kills the mussel. These shells, however, are not now of any commercial value.

\section{SHOULDER RAKE:}

The shoulder rake can be used to advantage in comparatively swift water, especially when the bottom is not too hard and is free from hang-ups such as rocks and sunken logs. The implement consists of a metal rake about $\mathrm{I}$ foot long and provided with Io to 12 coarse teeth or curved tines, which may be about 9 inches long (PI. XXIX, fig. 2). The rake is securely bolted to a wooden handle 15 to 20 feet long, its length being adapted to the depth of water. A basket, made of poultry-wire netting, is attached to the rake and handle in such a way as to afford a concave receptacle for the shells. A small board, about Io inches by 2 feet, is usually fastened to the handle approximately I yard from the base. The method of operation is rather simple, though laborious. The boat in which the work is carried on is anchored over the mussel bed, and the rake is placed into the river at the head of the boat and slowly worked down to the stern, when it is raised to the surface. The shells are thrown into the boat. The board attached to the handle offers resistance to the current, and thus is of considerable assistance in raising the rake, as well as in driving it downstream over the bed; it therefore has the same function of an underwater sail as the. mule used in crowfooting, but the power of the current acts only upon the rake, and not upon the boat. The shoulder rake may be made from a coke fork. The tines are cut to the desired length, heated, and bent at right angles to the handle. A long handle must, of course, be substituted for the short handle of the coke fork.

The results of this method are generally satisfactory, if the shells are relatively abundant. Small shells inadvertently taken can be thrown back with assurance, generally, that they will live.

The shoulder rake is a common implement on the Mississippi River and other streams. On the St. Francis River, Ark., it is the principal method employed in the summer and fall, while the crowfoot is chiefly used in the high water of spring. The fork, to be described later, is also used in very low water.

\section{SHELL, TONGS.}

The shell tongs, or scissor forks, are used to some extent on the upper Mississippi, the Cumberland, the White, and some other rivers where the work can be carried on satisfactorily in rather deep water. It is possible, of course, to work between the free spaces of a series of logs or other obstructions. It is essentially a grapple, consisting of two rakes, or forks, on the ends of long handles which are pivoted together about 2 feet from the lower end, aiter the fashion of a pair of scissors (Pl. XXIX, figs. I, 2, and 3 ). The method of its operation is similar to that of the oyster tongs; the appliance is lowered into the water from an anchored boat, then by bearing down on the 


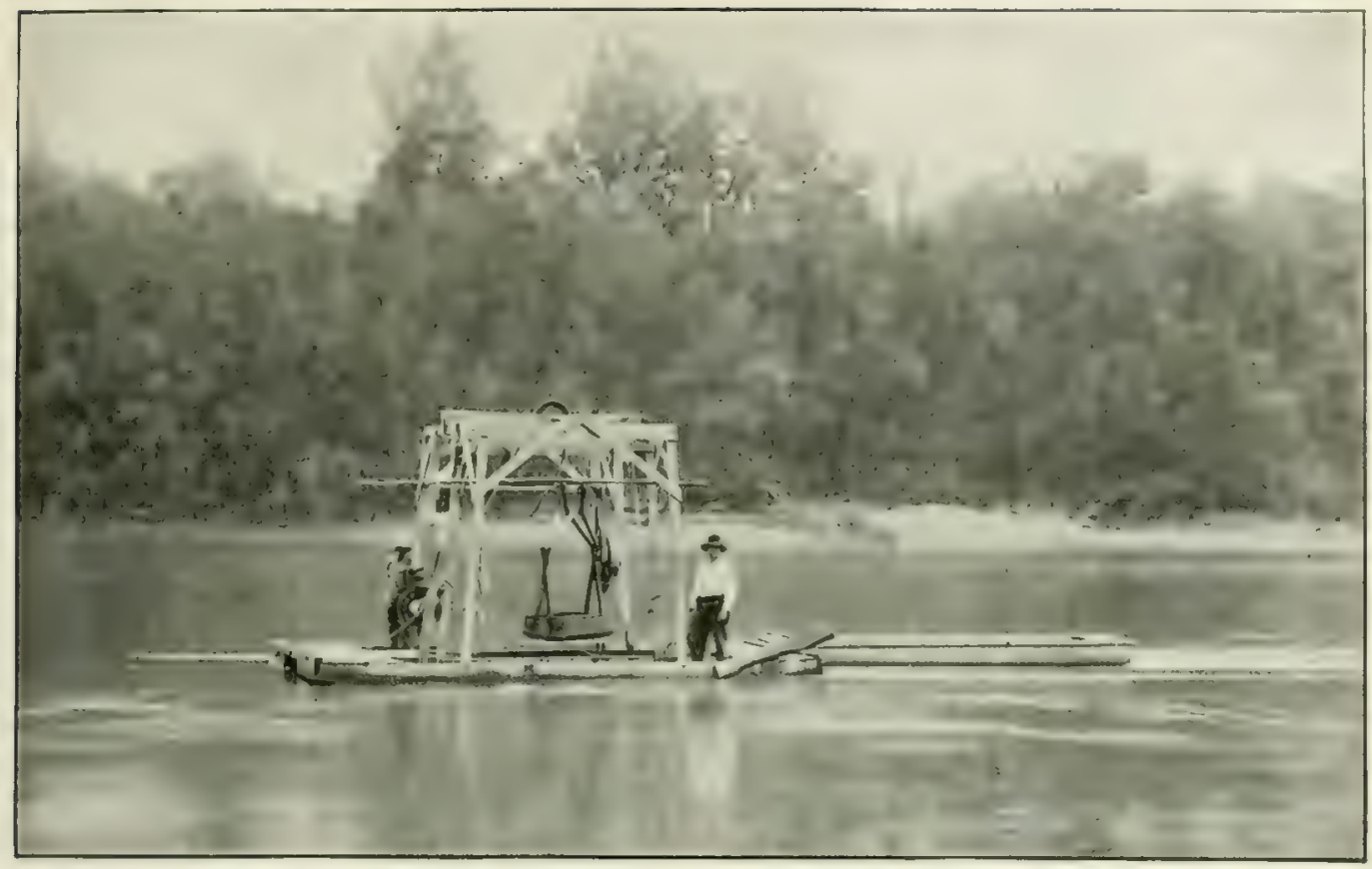

Fic. I. - The dredge ready to be lowered into the water, Black River, Ark. (See p. 57.)

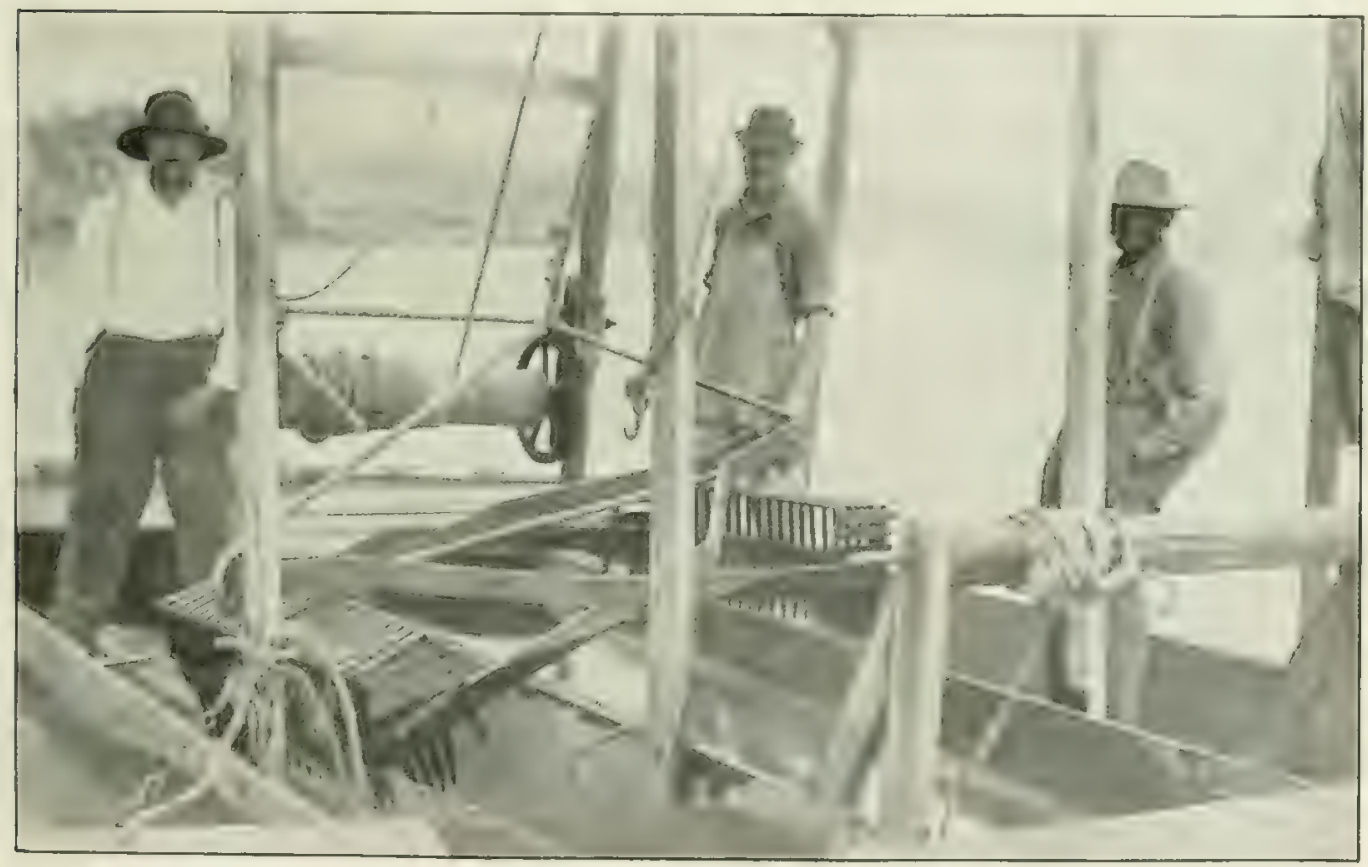

Fig. 2.--The dredge resting on gunwales of two boats forming the catamaran from which it is operated. (See p. 57.) 

handles and working them together the forks are forced into the bottom and closed on the mussels. When it is closed, the handles are held together while the implement is raised hand over hand to the surface; after washing out the surplus mud and sand by a vertical motion the shells are dumped inito the boat.

FORK.

Occasionally a common fork is used in the smaller streams, more especially during the low water of summer. The tool generally employed for this purpose is the coal or coke fork, such as is shown in figure 5. The manner of working with the fork is similar to that of spading a garden. The operator wades into the water from the shore or from his boat and begins to fork over the mussel bed systematically. On bringing each load to the surface of the river, the sand and mud are washed from the fork by dipping it a number of times into the water; the shells are thrown into the boat, which is always kept near by. Since it is much easier to go with the current, the shellers usually work downstream, and in consequence have more or less muddy water to contend with.

The method often yields good results, but involves more or less exposure to the water. It is not particularly to be commended, since the complete digging up of the beds is detrimental to the smaller mussels, as well as to the bed itself; the sand and mud of the bottom, to a certain extent at least, are carried away by the current to be deposited lower down in the river's course.

Since the fork can be employed only in very shallow water and during warm weather, its use is consequently limited and irregular. It may be found in use during low stages on the St. Francis River, Ark., the Wabash River near Vincennes, Ind., and in various isolated localities.

\section{DREDGE.}

The dip net is sometimes referred to as a dredge. There is also a typical mussel dredge that has been in limited use in Arkansas since 1912 . While this dredge requires a greater initial outlay than

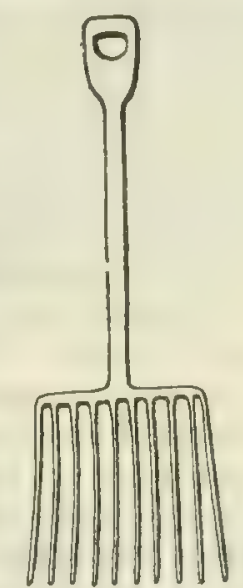

Fig. 5.-The fork used in taking fresh-water mussels in shallow water. the simpler forms of apparatus previously described, it offers much promise as a profitable method of taking mussels. The apparatus is well shown in the accompanying photographs (P1. XXX, figs. I and 2) and requires but a brief description.

The dredges are of various dimensions; of the two particularly observed, one was 18 by 24 inches, the other 36 by 72 inches. The dredge may be described as composed of two heavy, long-toothed rakes with the iron handles so pivoted together scissors fashion that the two rakes when closed or brought together, form an oblong basket. Each half of the smaller dredge was i 8 by 24 inches, the tines being 8 inches long and made of five-eighth inch square iron, pointed at the free ends. The remainder of the basket was made of flat iron about 1 inch wide. The dredge is operated between two boats firmly attached together by cross decking at the ends, but with a suitable space left between them.

In Plate XXX, the lower figure shows the larger dredge, 3 by 6 feet, spread, and held in this position by dogs on one side; it is resting across the boat. When the dredge is to be lowered, it is raised by the windlass until free of the boat, then swung around 
by hand to a fore-and-aft position ( $\mathrm{Pl} . \mathrm{XXX}$, upper figure); it is then lowered into the water by unwinding the windlass. The line from the windlass passes through a block overhead (not shown in the picture) and down to the bridle of the dredge. The two pulleys through which the bridle passes should be noted on the ends of the dredge handles. When the brake on the windlass is thrown off, the dredge falls to the bottom, and the dog releases automatically. The dredge now rests on the bottom, covering a space 3 by 6 feet, with the tines of the two ends sticking into the substratum.

The first effect of turning the windlass, after taking up the slack, is to lift the ends of the handles and bring them together, thus causing the dredge to close. As the dredge closes, the tines thoroughly rake the bottom, and when completely closed every mussel and rock in the space covered, except those so small as to pass through the openings, are taken in the basket. Continued winding of the windlass brings the dredge out of the water, when it can be lowered into one of the boats and opened. All débris must be sorted out and thrown away. A small hand rake, like a flower rake, is used to clear the small stones which may have been wedged between the tines. In view of the contingency that the dredge may be fouled by a $\log$ or heavy stone, it is necessary to have a clearing line attached to one end of the dredge. A small windlass must be used to operate this line if the dredge is very heavy. The effect of hauling on this line is to open the dredge, which may have been partly closed, and bring it up to the surface; the haul is of course lost in such a case. Heavy dredges are more effective than the light ones.

The cost of the larger dredge was $\$ 65$ complete, with boats and all; but there was very small expense for labor, as the work was done during the slack season and largely by the owner. The ordinary complete cost of such an outfit would be $\$$ Ioo or more.

If the openings between the tines are wide enough, the small shells will not be removed from the bottom. Comparing the dredge with the crowfoot drag, it may be noted that the latter takes mussels by chance and that repeated dragging over the same bottom is necessary to make an approximately clean catch, while the former makes a clean haul of only the mussels large enough to be taken. It will be seen, therefore, that the crowfoot apparatus, although less effective over a given small portion of bottom, is actually more destructive to the young mussels.

An entirely new form of dredge has recently been invented, which is operated by power and brings the mussels continuously from the bottom by means of an endless chain and buckets. No detailed description can be given at this time.

\section{LOCAL, MODIFICATIONS OF METHODS.}

Various other forms of apparatus have been devised at different times and put into temporary use, but none of them seems to have won a place in the established methods of fishery. There are many local variations of the typical methods described, but it is not practicable to describe them all. Two special modifications of the use of the coke fork and of the basket rake were thus described as used in the James River in $1913:{ }^{a}$

The mussels [at Riverside, S. Dak.] were gathered with a coke or coal fork, having a piece of 2 by 4 lumber fastened to the handle, the length of this piece being according to the depth of the river. This fisherman had a novel way of anchoring his boat. At each end of the boat a hole was bored through the bottom large enough to insert a piece of 1.5 -inch pipe, making a water-tight joint. These perpendicular

a Coker, R. E., and Southall, J. B.: Mussel resources in tributaries of the upper Missouri River. Appendix IV, Report, U. S. Commissioner of Fisheries for 1914, I7 D., I pl., I map. WVashington, I915. 


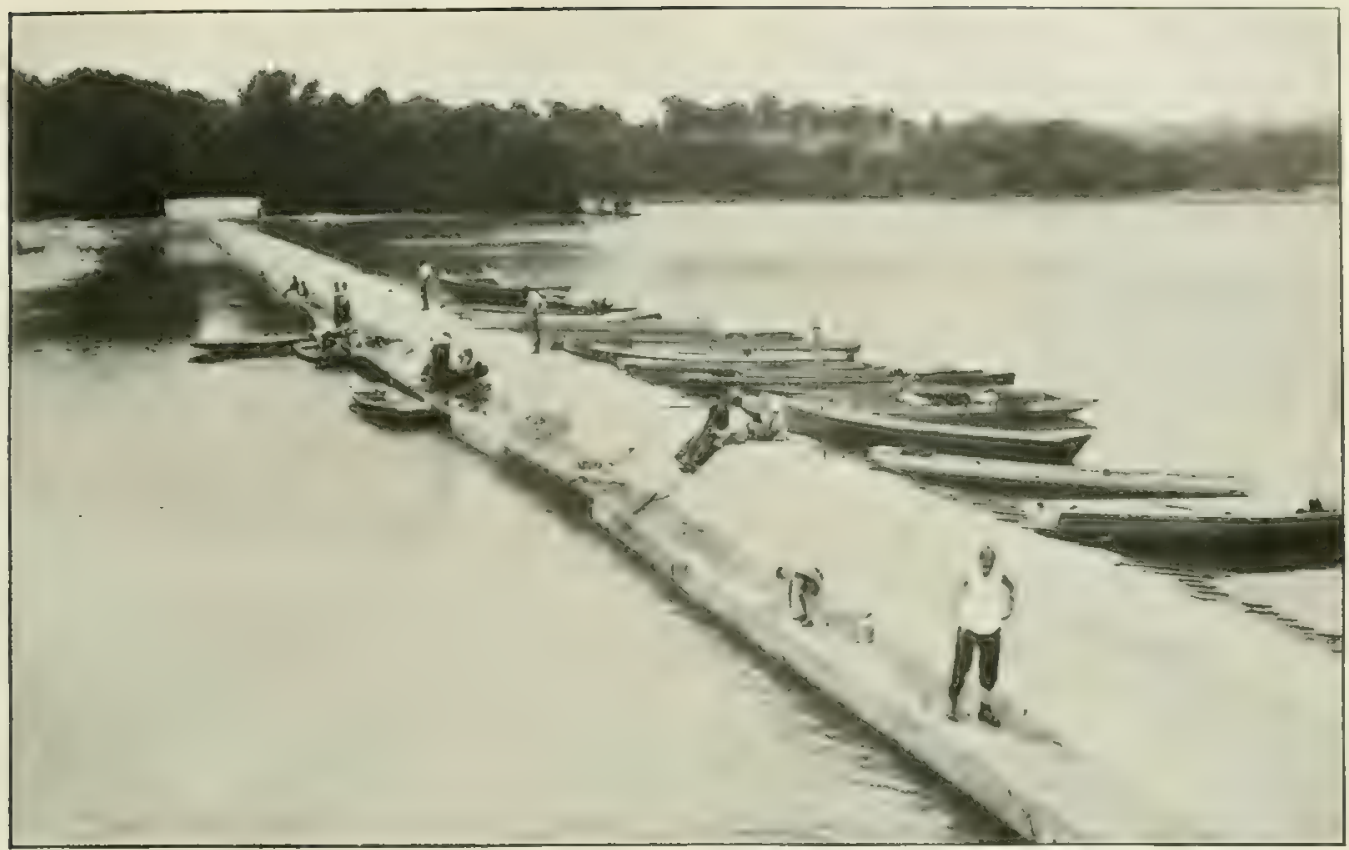

Fig. 1. -Mussel boats on Rock River Pool at Government locks, a few miles above the mouth of the river. The mussels are taken by hand while wading in the shoal water below the dam. (See p. 59.)

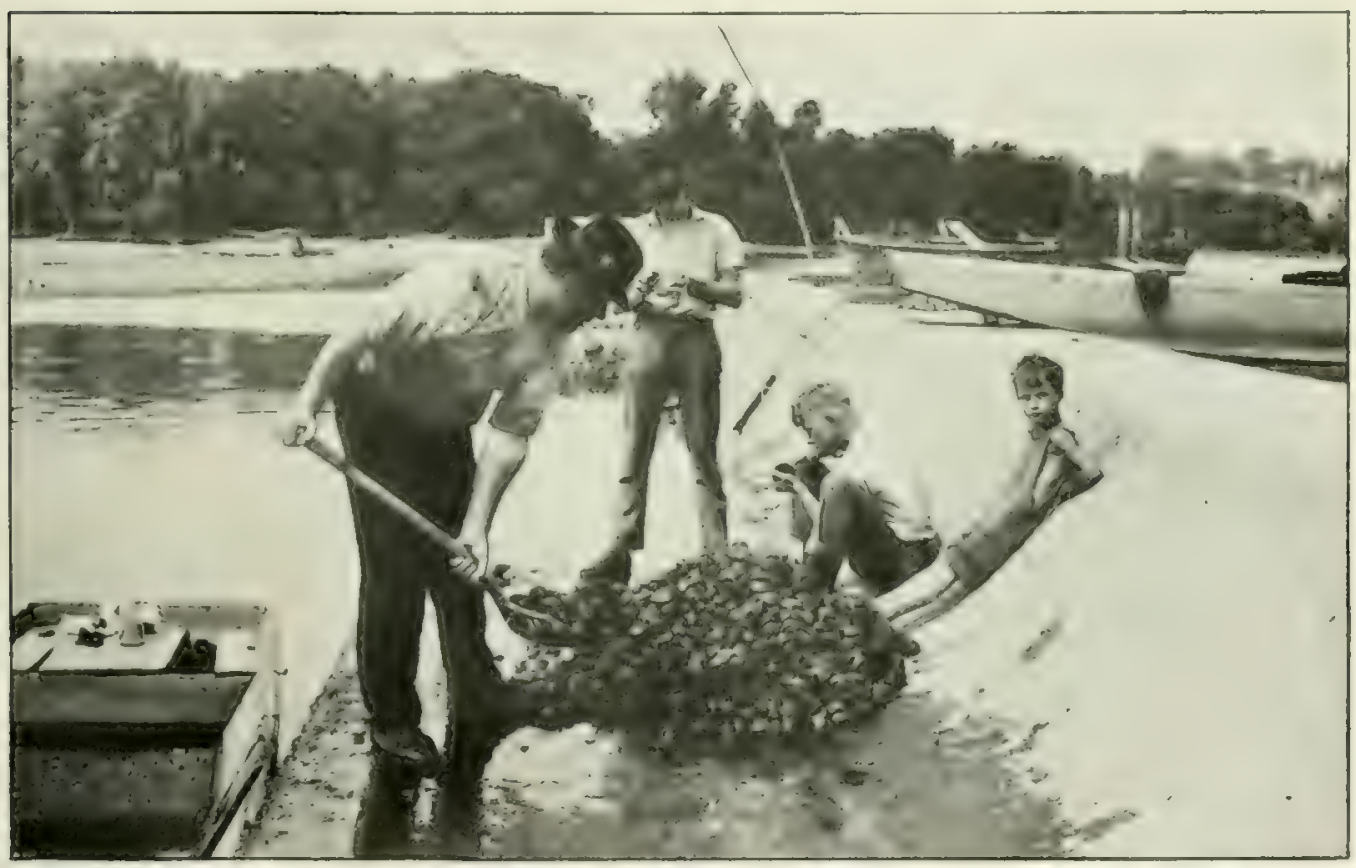

FiG. 2.-The mussels when taken are put into a small flatboat and conveyed to the dam, where they are transferred to another boat above the dam, as illustrated. In the second boat the mussels are taken to camp for cooking out. This is the scene of one ot the most extensive mussel fisheries where sbells are taken by hand, (See p. 59.) 

pipes, rising to the level of the gunwales of the boat, served as sockets or sleeves, through which a long iron rod could be shoved into the soft mud bottom of the river. By anchoring in this way the boat was kept abreast of the current, while the fisherman used the sides as a fulcrum for the handle of the fork. After gathering all the mussels possible within reach he would pull up the rods, let the boat drift downstream a suitable distance, or beyond the portion of river just worked, and then anchor and resumc operations as before.

At Milltown, mussels were gathered by means of the basket-rake dragged by a power-boat. The rake was peculiar in being without teeth but having a square brail made of 0.25 by 1.5 inch flat iron, $t$, which was fastened a wire basket of $\mathrm{I}$-inch mesl. With each boat was a crew of four men, three to work with the rilies and one to operate the engine. One dragged the rake at the rear of the boat, while the other two worked at the sides. In this manner a strip of the river bottom 6 feet wide was thoroughly scraped.

\section{SUMMARY OF METHODS OF FISHERY.}

The principal forms of apparatus are the crowfoot bar, the dip net, the shoulder rake (or basket rake), the forks, and the dredge. A considerable quantity of shells, about 500 tons each year, are taken by hand. (Cf. PI. XXXI.) The statistical reports previously cited (p. 39 above) show in detail the quantities of mussels taken by the several forms of apparatus. From these reports the percentages of the total of 51,57 I tons of shells taken in the territory covered, as credited to the several forms of apparatus, may be computed and stated as follows:

\begin{tabular}{|c|c|}
\hline Per cent. & Per cent. \\
\hline Crowfoot. ......................... & Dip net... \\
\hline Forks... $\ldots \ldots \ldots \ldots \ldots \ldots \ldots \ldots$ 10. 5 & Dredge $\ldots \ldots \ldots \ldots \ldots \ldots \ldots \ldots \ldots \ldots \ldots \ldots \ldots \ldots \ldots$ \\
\hline 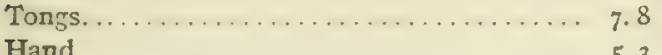 & Rakes................... 1.2 \\
\hline 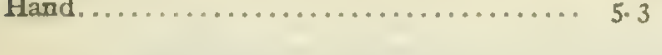 & \\
\hline
\end{tabular}

SHORE EQUIPMENT AND PROCESSES.

It is customary for the shellers to establish camps alongshore. Sometimes the camps are individual and occupied by one sheller with his family; in other cases a sort of village camp is found where a dozen or more families of shellers are grouped. The selection of a site is governed, first, by the proximity of a good shell bed; next by the convenience to wood and shade. Rude frame buildings may be constructed, or tents may be used. A very common form of divelling is the house-boat, or "shanty-boat," as it is generally termed (P1. XXXII, fig. 2). There are many different forms and sizes of shanty-boats, to suit the needs and ideas of the fishermen; popular sizes are about 10 by 35 feet and 12 by 40 feet. With such boats it is a simple matter for the sheller to move from place to place, according to the requirements of the fishery. One or two small flatboats and usually a larger boat with a small gasoline engine are almost always employed, whether or not the house-boat is used.

After bringing the mussels ashore the soft parts must be removed. Where pearling is the exclusive object, each mussel may be opened with a knife inserted between the valves of the shell, so as to sever the adductor muscles; the meat is then cut out and examined for pearls. This may be done while wading in the river and the meat and shell thrown away at once. Such a process is entirely too slow and tedious for preparing shells for market; hence the cooking out process is exclusively employed in the shell $110306^{\circ}-13-4$ 
fishery. The man may fish during the forenoon and cook out in the afternoon; in some cases the wife or children of the sheller attend to the cooking out, while the sheller continues the fishing operations.

The cooker consists of a vat about 5 feet long by 2 feet wide and from 12 to 18 inches deep (Pl. XXVII, fig. 2 extreme left, and PI. XXIX, fig. 4). The frame may be of wood and the bottom of sheet iron or stovepipe iron, brought up a few inches over the lower edges of the wood to protect it from the fire. The bottom of the cooker is usually made to slope upward at one end in order to facilitate the forking out of the shells. The vat is set over a trench or ditched-out furnace, the back part of which is fitted with a couple of joints of stovepipe or smokestack of some kind to furnish the necessary draft; driftwood may serve as fuel.

When the cooker is filled with mussels, a small amount of water is added, and the whole is covered with burlap or gunny sacks. The fire is started in the furnace and continued until steam is being given off in quantities sufficient to kill the mussels, so that they will open readily. The process may take about 20 minutes or longer. If the mussel camp is situated near a factory or some establishment from which steam can be obtained at a reasonable price, there is a great saving in time and trouble by making a direct steam-pipe connection between the boiler and the cooker. The shells are prepared in the same way, but instead of applying heat beneath the cooker the steam is admitted directly into the container.

The shells are removed with a fork and thrown on the sorting table which is about 3 feet high and of sufficient width and length to hold at least one-half of the contents of the cooker. The mussels must be handled separately, picking or shaking out the meats, which are put to one side for later examination for pearls and slugs, while the shells are thrown into heans on the ground or into small bins (Pls. XXVII, fig. 2, and XXXII, fig. I).

When all the shells have been cleaned, the water, or soup, in the cobker is carefully strained through a small mesh screen of wire netting in order to recover any pearls or slugs which may have become disengaged from the meats during the cooking-out process. It is said that pearls which have lain on the hot metal bottom for any length of time are permanently injured. The size of the screen is usually about $\mathrm{I}$ foot square. Most of the pearls are found in the meats, which must be examined one by one. The pearls are not always visible, but are found by slipping the meats through the fingers. Small pearls are sometimes recovered by allowing the meats to rot in kegs or half-barrels. When reduced to a pulp, the mass is rubbed through a fine-mesh sieve, the pearls and slugs being retained on the sieve.

Many mussels are cooked out merely with the hope of finding pearls. The noncommercial shells must be thrown aside, but there is no general practice of classification of the salable shells. Often this is done by throwing shells of a certain quality, such as niggerheads, pimple-backs, etc., into one pile and blue-points, washboards, and miscellaneous shells into another. This is usually an advantage to the sheller, since he may obtain an advanced price on the best grade shells; yet the practice of buying the river run at one price is still very common. Most of the shellers do sort out the yellow sandsliells, since these command a price several times higher than the others; but even this is not always done, and thus a good many yellow sand-shells are received at the factories along with other shells. These, of course, are sorted out at the factory, and resold to 


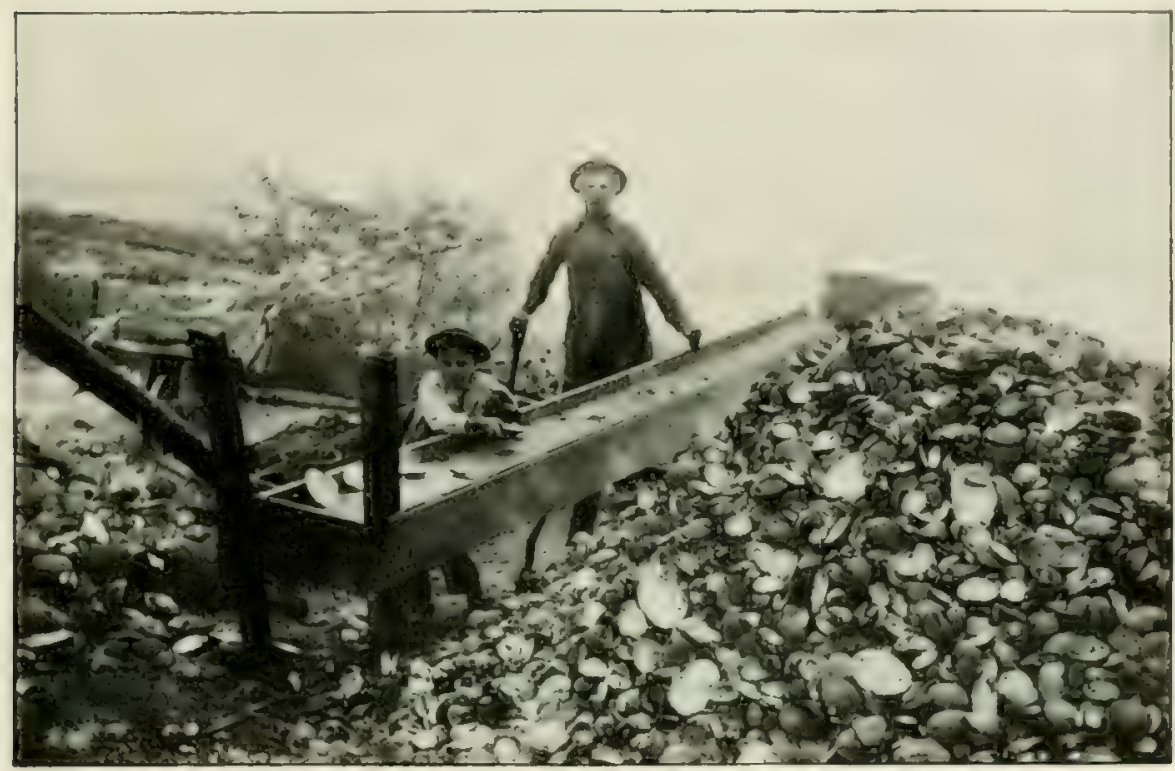

Fig. I. - Sorting table and heap of shells on river bank. (See p. 60.)

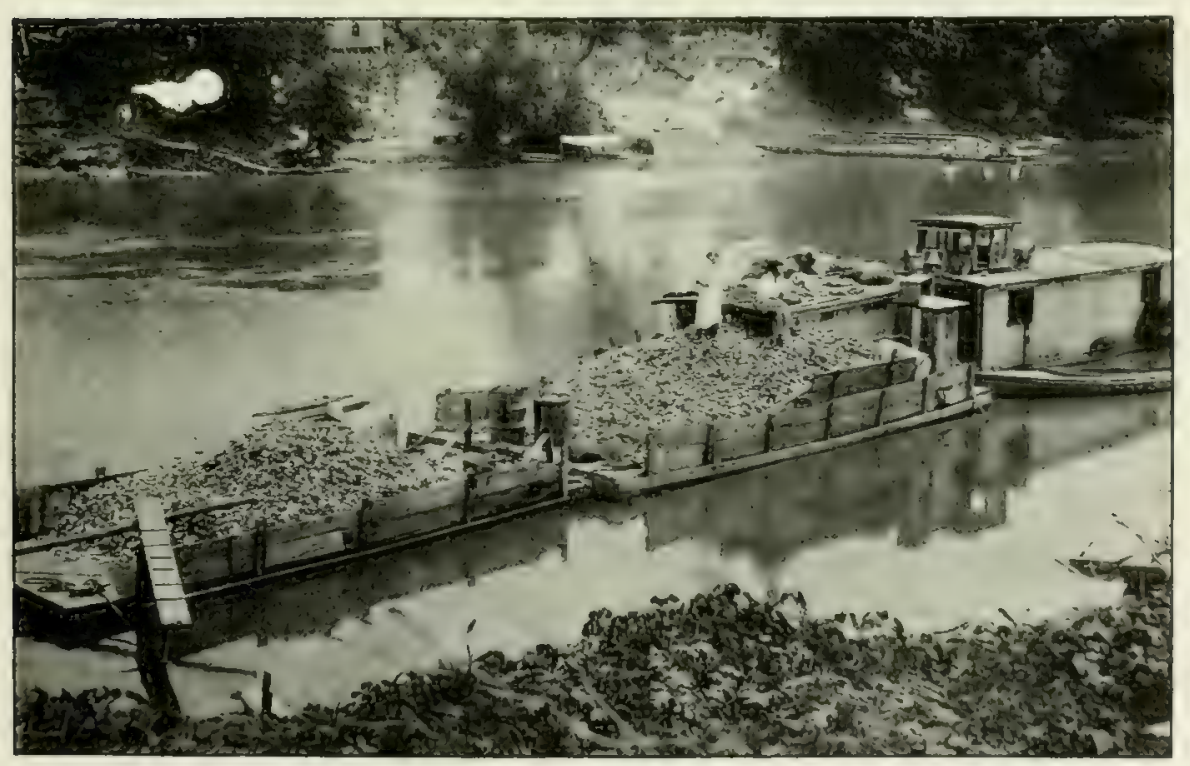

IIG. 2,-Barges loaded with shells and two shellers' house-boats, in Arkansas. (See p. 59.) 

the export trade. It seems to be mere shortsightedness on the part of many shellers that prevents the effective classifying of materials before sale.

The shells are sometimes sold to local buyers or local factories; more often they are bought by traveling buyers who may be agents of the larger factories or professional shell merchants who buy in large quantities and sell as they find the most favorable market. Some buyers maintain large power boats and barges (Pl. XXXIII), which may travel up and down the river, prepared to load the shells and convey them to a convenient manufacturing or shipping point. The greater part of the shells are shipped by rail in car shipments from the nearest freight station. At times and in some places it has been the practice for shellers to operate small cutting plants, but the scheme has not always worked well in practice. Each is a profession in itself, and the best cutting is done by those who are practiced in cutting and shop management and who can keep well advised as to the market demand for the various sizes and qualities of blanks.

\section{ELEMENTS OF WASTE.}

CULLS.

The piles of culls are usually not large in proportion to the heaps of economic shells, but they include a good many kinds of shells, worthless because of excessive thinness, undesirable color, spotting, or other evident defect. Among such culls are the papershells, the pink heel-splitter, black sand-shells of pink nacre, purple warty-backs, and often the purple or salmon-colored elephant's ears and spikes. The last-mentioned can be used for making smoked-pearl buttons, although they are not usually in demand. It sometimes happens, therefore, that at the close of the season a buyer will take the usable colored shells at a reduced price. The tendency of shellers to throw in all offcolored shells has given unfortunate discouragement to this practice.

MEATS.

In connection with the shells collected each year, there are taken some 10,000 tons of wet meats for which there is no appropriate use. Small quantities are sold locally for use as fish bait with trot-lines, or hoop nets, or as food for poultry or pigs. The fresh meats, after being allowed to sour in the sun, are considered particularly good for these purposes; but generally only a small proportion of the meats has been so used. It is often a serious question in the mussel camp to make proper disposal of this material. The meats that can not be sold locally are often dumped into the river, buried in the ground, or put into a "rot box." The throwing of meats into the river in largequantities becomes objectionable when those that are not eaten by the fish and turtles rise to the surface in a state of decomposition and are washed ashore to cause an offensive stench in the neighborhood of the camps.

The meats, when dried in the sun or by the use of artificial heat, can be ground to make a fine meal, in which condition they appear to keep indefinitely. For the purpose of sun-drying they are spread on frames made of coarse-mesh wire screen so arranged that the air can circulate freely between them. In dry, sunny weather the meats can be dried in from 30 to 72 hours to about five-eighths of their wet weight. When so dried, they can be ground in a coffee mill or similar machine; but the foot part becomes exceedingly hard and tough when partially dried and rapidly wears out the mill. Since the meats are usually too large to feed into the coffee mill whole, they should be reduced 
by pounding or, better, by chopping in a meat chopper before drying. Sand should be avoided in the whole process, as it will damage the grinder. If the foot is to be ground, the whole meats must be dried by artificial heat to about one-seventh of the wet weight. This entails some additional expense for fuel and ovens. The loss of nutritive substance in discarding the foot is not great; but it is obvious that practical difficulties are encountered in separating the tough from the soft parts before grinding. The whole trouble arising from the toughness of the foot is obviated by putting the wet meats through a sausage grinder before drying and then regrinding the dried masses of meat in any suitable mill; the product thus obtained is not a fine meal, but a coarsely granular material, practically dust free and very suitable in form for use as food for poultry or fish. At the Fairport station the ground meats have been found to be very acceptable to chickens when moistened to make a mash and mixed with grain. Experiments made by the Bureau of Animal Industry show that the dried mussel meats are a suitable food for chickens, having about the same value as fish meal. To obtain like results, a slightly larger quantity of these substances than of meals made from the red meats must be used. For some years fresh mussel meats have been used as a food for fish at the station, and it has been found best to allow them to sour a little before feeding them. The ground dry meats have also been used in feeding small fish in aquaria and in ponds, and they have proven a very satisfactory food material. The ground mussel meats have recently appeared upon the market in the form of feed for poultry and fish.

The meats of the mussels could, perhaps, be used for human food if they were collected under sanitary conditions and properly prepared. This question should be subjected to experiment; but it would be obviously impossible to consider with reference to human food the use of meats saved as a by-product of the shell fishery under the conditions now prevailing.

Analysis of the mussel meats made for this Bureau by the Bureau of Chemistry indicates a very desirable content of protein, glycogen, phosphoric acid, and lime, if the meats are considered with reference to their use as a food for poultry or fish. Approximately the percentages are: Protein, 44 per cent; glycogen, 9 per cent; phosphoric acid, 9 per cent; and lime, 8 per cent. An analysis in detail of meats of fresh-water mussels from the Mississippi River is stated in the following table:

ANalysis of Dry MUSSEl Mejats.a

Per cent.

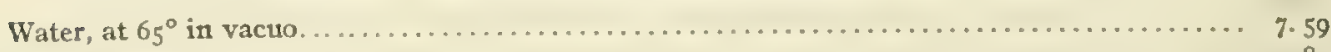

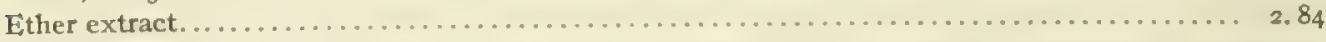

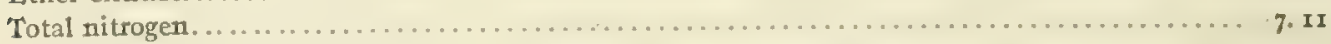

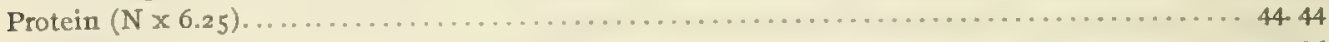

Glycogen . . . . . . . . . . . . . . . .

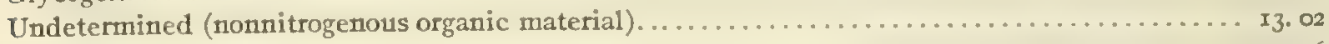

Ash . . . . . . . . . . . . . . .

Ash content:

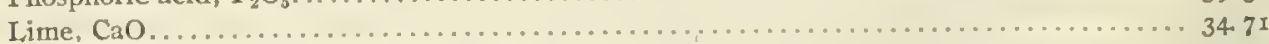

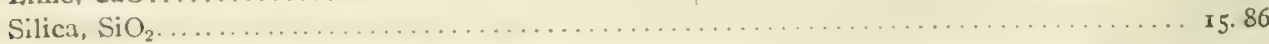

Qualitatively, there were present in the ash small amounts of sodium, potassium, iron, magnesium, and a considerable amount of manganese. No copper or zinc was detected.

a The sample for analysis was from a lot of more than roo pounds of ground, dry mussel meats, representing a collection of all of the ordinary species taken in the Mississippi River near Fairport, Iowa, and Lake City, Minn. 


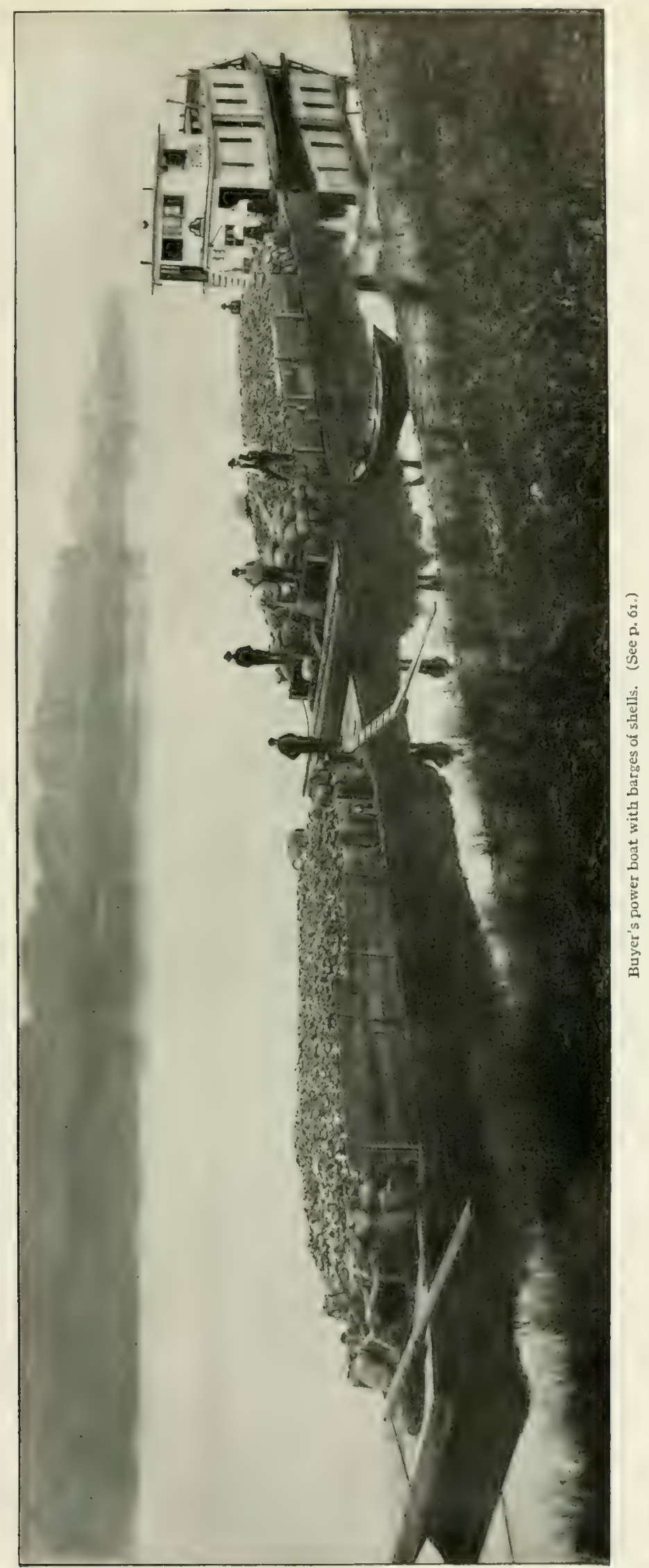



An article in the Journal of Biological Chemistry, I9 Io, volume 8, page 237, by $\mathrm{H}$. C. Bradley, on "Manganese in the Tissues of Lower Animals" gives analyses showing the proportion of manganese in the ash as taken from a group of nine samples of mussels from the Mississippi River. The high proportion of manganese, as compared with its occurrence in other animal tissues, is of unusual interest, but is without economic significance as now understood.

Analysis of Mussels from xHe Mississippi River showing Higit Proportion of Manganest (AFTER H. C. BRADLEY).

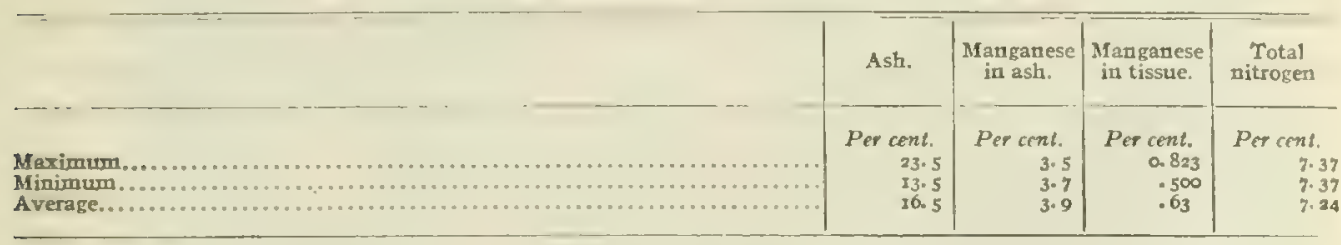

UNDERSIZED SHELLS.

The most serious waste in connection with the mussel fishery consists in the taking and killing of undersized shells. It is argued by some fishermen that the young mussels should not be thrown back, since a considerable proportion of the mussels taken by the crowfoot die when returned to the water. Several experiments conducted at the Fairport Biological Station indicate that from 35 to 40 per cent of the mussels taken with the crowfoot and returned to the water die in a short time. However, careful counts of weights of shells actually taken in the mussel fishery and under 2 inches in greatest dimension show that it requires from 33,000 to 174,000 to make a ton, with an average of about 90,000 . Should these mussels be returned to the water and should only one-third live to attain a size of 2 inches in greatest dimension, the surviving mussels would weigh much more than a ton, and would thus be of greater value to the fisherman than the entire original quantity marketed as small shells. They would yield a far greater number of buttons per ton, and thus would be of more value to the industry. Furthermore, the larger mussels would have spawned and taken part in replenishing the beds, and thus would have been of inestimably greater benefit to the conservation of the mussel beds. 


\section{Part 3. MANUFACTURE OF PEARL BUTTONS FROM FRESH-WATER MUSSEL SHELLS.}

\section{ESTABLISHMENT OF THE INDUSTRY.}

Neither the manufacture of buttons nor the abundance of fresh-water mussels in the United States are occurrences peculiar to recent years. Nevertheless it is strictly a modern development for the fresh-water shells to be the material for button manufacture in any important way; for the making of fresh-water pearl buttons, now the principal branch of the industry, dates only from 1891 . Buttons of brass and wood have been made in this country since about 1750 , buttons of metal since 1800 , buttons of horn since 1812 , buttons of marine shell since 1855 , and buttons of composition since 1862 . Meantime, mussel shells eminently suitable for button manufacture, and readily available, have grown abundantly in the streams of the Mississippi Basin through all historical times.

Long before an effective beginning was made, it seems to have occurred to various persons that the fresh-water mussel shells might be made useful for button manufacture. Indeed, there seems to have been an early industry on the Ohio River in the carving of cuff buttons from mussel shells more than 100 years ago. ${ }^{a}$ As early as 1872 , it is said, a man in Peoria, I1l, conceived the idea that the pearly shells of the Illinois River should have a value for manufacturing purposes, and he accordingly collected some of them and shipped them to Germany. It is very interesting to note that to this fugitive idea, resulting in a single small shipment, the actual establishment of the industry some 20 years later may perhaps be traced. However, it is evident that the matter was entirely abandoned for the time. According to local reports, a shipment of shells was sent from Beardstown, on the same river, to a factory in the East about 1876 , but the material seems to have been considered impracticable of use. A more practical venture was made about 1883 , when a commercial plant is reported to have been started at Knoxville, Tenn., where it was endeavored to make buttons and novelties from the shells of the Tennessee River. Unfortunately, the factory was discontinued after a. short time, probably because of the lack of suitable machinery. It should be remarked that sometime in the late eighties pearl-button factories were in operation in Cincinnati, Ohio, and St. Paul, Minn., using as raw material the imported ocean-pearl shells. Although these plants were located on the very banks of good shell-bearing streams, there is no evidence that the river naterial was even experimented with.

a Curiously enough, there is found in an early book of travels mention of a long-forgotten fresh-water button industry. The writer is indebted to Emest Danglade for the reference. Dr. F. A. Michaux in rSoz, under the auspices of the zainister of the interior of France, made an extended tour for exploration in the United States, especially through that part lying west of the Alleghanies, or in the Obio Valley. His record of a button industry on the Obio River is now of rare interest. He observes (translating from the French): "In the Ohio, as well as in the Alleghany, the Monongahela, and the other rivers of the West, there is found in abundance a species of mussel having a length from 2 to 5 inches. It is not eaten at all, but the nacre, which is thick, is used to make cuff (or sleeve) buttons. I have seen some of them at Lexington, Ky, which were equal in beauty to those used in Europe. This new species, which I have brought back, has been designated, by citizen Bosc, under the name of $U$ nio ohiotensis." 


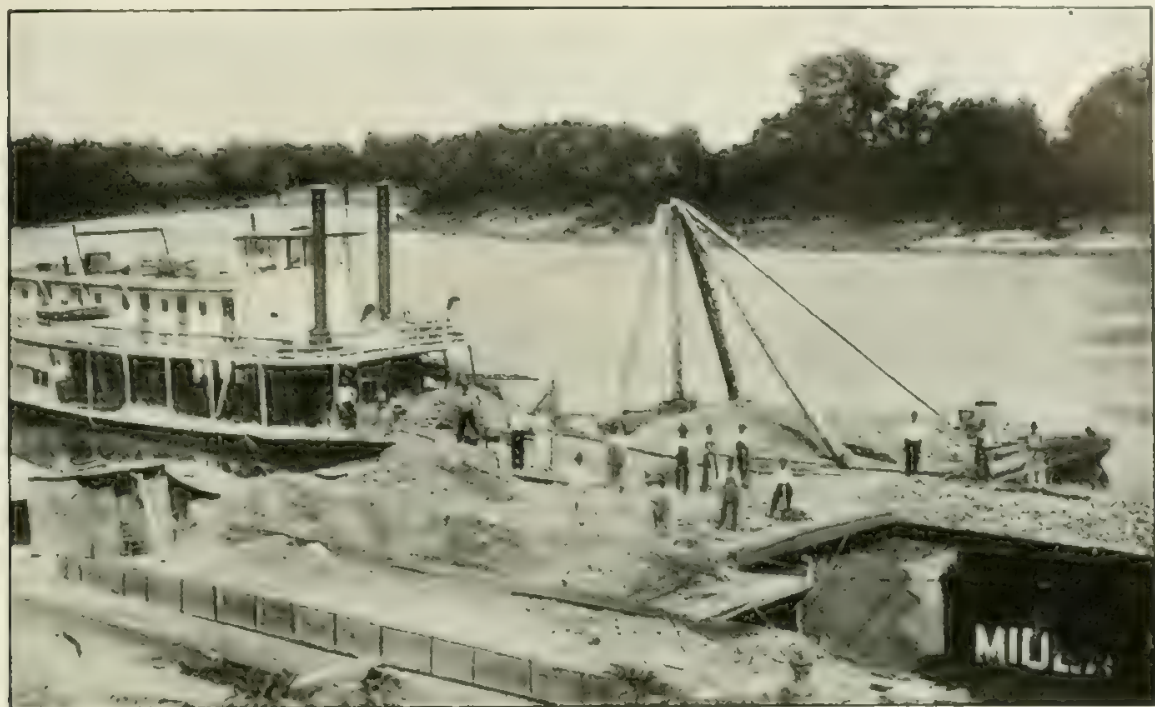

FTG. r. - Receiving shells at boat landing. (See p. 6r.)

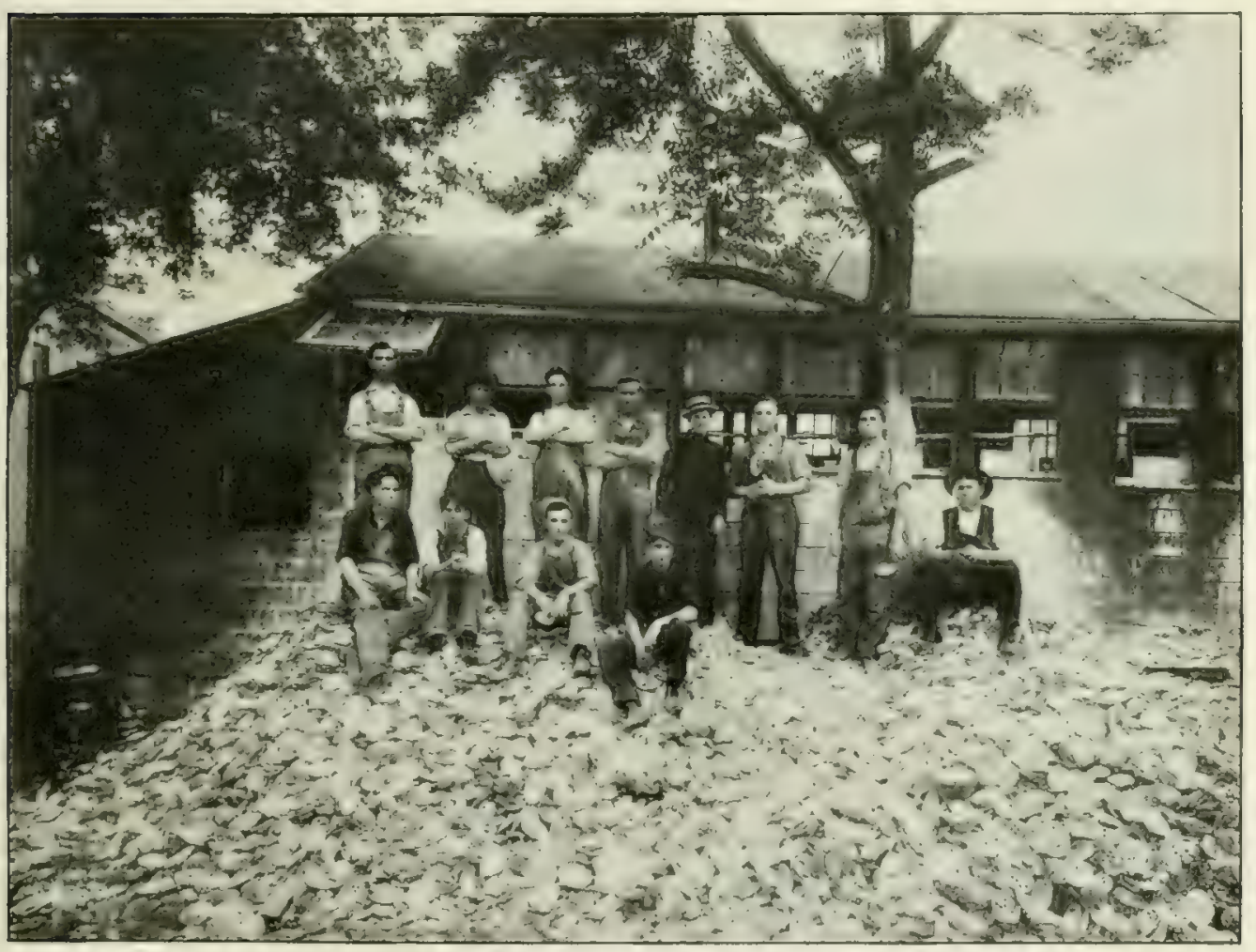

Fis. 2.-Small cutting plant and operatives on Mississippi River. (Sice p. 72.) 

It must be said, in explanation of the seemingly half-hearted endeavors and repeated failures, that the use of any form of pearl for button making was not widely practiced in the United States, and that, in the countries where the manufacture was principally pursued, fresh-water shells of suitable quality were quite unknown. Furthermore, the river shell is quite distinct from ocean pearl in its qualities, so that the same machinery and methods, as experience has proven, can not well be applied to both kinds of shell.

For the practical initiation of the fresh-water pearl-button industry credit must be given to the late J. F. Boepple, a man of singular tenacity of purpose, indefatigable and unyielding by nature. His characteristics did not adapt him for commercial success, but they did enable him to battle against the varied obstacles that would have overwhelmed a weaker or less persistent character. By its conception and practical initiation, the fresh-water pearl-button industry is Boepple's; by its development and elevation to the plane of an important national industry it is the product of other resolute persons, who persisted through the period of threatened failures to compel the adaptation of the industry to the requirements of business efficiency.

Mr. Boepple was a tumer and button worker in Ottensen, Germany, near Hamburg, when a friend and fellow worker brought to the shop a box of shells of a kind entirely unfamiliar to them. ${ }^{a}$ He said that they had been shipped to his father from America a good many years before, but did not know from what place they came, except that they were taken from a river "somewhere about 200 miles southwest of Chicago." After some experimentation at odd times it was concluded that these mussel shells would be good for making buttons. In the following year Mr. Boepple sold his business and, taking with him a turning-lathe equipment and some other trade tools, embarked for America, where he landed in March, i 887. He first engaged in farm work near Gibson City, Ill., and a little later, July, I887, stopped at Petersburg, Ill., on the Sangamon River. He says, "While in bathing one day my foot was cut, and upon examination of the cause I found the bottom of the river covered with mussel shells." The vivid picture of the situation which confronted the young immigrant is given by his own words: "At last I found what I had been looking for; yet there still was a problem before me. I was without capital in a strange land anong strange people and unfamiliar with the language."

The next few years he spent in farm work and railroad-construction labor; but during this time he located other shell beds, in the Rock River near Rock Island, I11., in the Mississippi near Muscatine, Iowa, and in the Iowa River near Columbus Junction. At the last-mentioned place, having formed a shop, partly with equipment he had brought from Germany, he engaged after work hours and during the winter in making shell novelties, such as pins, bridle buttons and cuff buttons, for which he found a sale. (See Plate XXXVI, fig. I.)

Learning later that the price of buttons was becoming higher, he went to Muscatine, where he enlisted the financial and mechanical assistance of William Molis and R. Kerr, and there the first button factory was launched in the early part of $189 \mathrm{I}$.

a The following account of the beginning of the ind ustry is based on a statement written by Mir. Boepple at the request of the director of the Fairport station. It was the recollection of Mir. Boepple that the shells experimented with at Otteasen wero muckets and three-ridges, and it is presumed that these are the shells shipped by Wm. Salter from Peoria, III., in 2872. 
This factory and a following one did not succeed against the inevitable difficulties confronting a new venture. Better success was had in the ensuing year, when a market for the product began to be found, but it was hardly before $\mathbf{1} 895$, after several factories in the hands of various parties were in operation, that the industry could be said to be fairly established. ${ }^{a}$

The greatest expansion occurred in 1897 and 1898 , when a condition of more than local excitement prevailed. Thus, in 1897 there were 13 button or blank establishments in 4 cities on the Mississippi River, while in 1898 there were 49 plants in 13 towns on the same river, besides at least 12 factories in as many different cities more or less remote from the Mississippi River. The territory of the new industry now extended from Omaha, Nebr., to Janesville, Wis., and Cincinnati, Ohio, with the center still at Muscatine, Iowa, where there were 28 blank-cutting plants, or "saw works," as they were then called, and 5 complete factories.

The next great advance came in Igor with the invention of automatic facing and drilling machines; by subsequent invention (1903) these machines were combined into one, the automatic facing and drilling machine. Both the single and the double machines are still in use, although improved by many minor changes and additions. These machines are very ingenious in design, and not only enable an operator to turn out four or five times as great a number of buttons per day, as compared with the product of the foot-power lathes formerly in use, but also insure a greater uniformity of finish.

\section{SOME ECONOMIC EFFECTS OF THE INDUSTRY.}

\section{DEVELOPMENT OF THE INDUSTRY.}

Recent as the establishment of the industry is, the effects have already been noteworthy. The United States Census reports show that in 1849 , before pearl material was in use, the value of American button products was $\$ 964,000$, and in $1859 \$ 949,000$. The manufacture of ocean-pearl buttons and of composition buttons began about this time, or in 1855 and 1862 , respectively, and perhaps it is due to this that in 1869 we find the value of all button products amounting to $\$ 1,779,000$ and in 1879 to $\$ 4,450,000$. No increase is shown in the next decade, for in 1889 the value was but $\$ 4,127,000$. It was during the two following decades that the fresh-water button industry developed with such rapidity. The value of the button product of the country in 1899 was $\$ 7,696,000$, in $1904 \$ 1 \mathrm{I}, 134,000$, and in $\mathrm{r} 909 \$ 22,708,000{ }^{b}$

It is uniortunate that the figures for pearl-button manufacture alone are not available for other years (prior to I914) than 1900 and 1905 , but from the reports of these years we find that the fresh-water pearl-button product was valued in 1899 at $\$ 2,766,053$ and in 1904 at $\$ 4,370,241$. Between these two dates the first automatic machinery was jut into use. During the same period the output of ocean-pearl buttons fell from nearly $\$ 2,000,000$ to about $\$ 1,500,000$ in value. It will not appear, however, from facts given below that the great development of the fresh-water pearl manufacture has caused any general decline in the other branches of the industry. The census taken for 1909 gives

a It should be recorded that Mr. Boepple, who subsequently removed to Davenport, Iowa, and later to Cannelton, Ind., continued to engage actively in the button industry until February, 19ro. At that time he became shell expert of the Fisheries Biological Station at Fairport, Iowa, where he rendered invaluable service until his death in January, Igr2.

$b$ Exclusive of buttons manulactured as by-products of other establishments not engaged primarily in button manufacture. All the figures above are reduced to even thousands for convenience of examination. 
no classification from which data can be obtained regarding pearl materials; but from a statistical survey which the Bureau of Fisheries conducted for the year $1912^{a}$ it is ascertained that the value of the button product from fresh-water shells alone amounted to $\$ 6,173,486$, with blanks for sale amounting to $\$ 2,511,217$, and by-products with a value of $\$ \mathrm{IS}, 60 \%$. As reported by the Census Bureau's summary concerning the button industry for 1914 , fresh-water pearl buttons, exclusive of blanks and by-products, were valued at $\$ 4,879,844$.

\section{DEVELOPMENT RELATIVE TO OTHER IBRANCHES OF THE BUTTON INDUSTRY.}

Fresh-water pearl has gradually come to assume first place among materials for button manufacture, as shown by a table herewith. The principal materials are freshwater pearl, ocean pearl, metal, vegetable ivory, celluloid, cloth, bone, and miscellaneous materials elsewhere listed.

RELATIVI: RANK OF FFESII-WATER PEARL AMONG THF DIFFERENT MATERIALS FiMPLOYED FOR BUTTON MANUFACTURE, at VARTous DaTes.

\begin{tabular}{|c|c|c|c|c|c|c|}
\hline Material. & 1889 & 1899 & 1904 & $\$ 909$ & $a_{1952}$ & 1914 \\
\hline
\end{tabular}

a Fresh water only.

Dixclusive of buttons to the value of more than $\$ 1,000,000$, made in each year 1904 and roog by establishments engaged primarily in the manufacture of other products.

- Not classified.

The product of Iowa ahd Illimois in 2897 was $\$ 243,655$ and in $289 \$ \$ 252,570$ (Smith).

e Some of the materials from which buttons are made, in addition to those indicated in the table, are brass, composition (clay, etc.), wood, glass, gold. lioof, iron, ivory, leatlier, paperboard, porcelain, silver, steel, aud also, in some cases, skin milk (casein), animal blood, and probably bakelite.

$f$ Probably fresh-water pearl chiefly.

Partly fresh-water pearl products.

$\$$ Includes blanis, or molds, snap lasteners, and all other products in amount, $\$ 4.558 .78 \%$

The census report of I goo states: "In I 890 there was not a single fresh-water pearl button made in the United States. In 1900 the making of these buttons constituted the second most important branch of the button industry." Yet, at the next census, only five years later, the fresh-water pearl buttons are found not only in the first rank, but actually exceeding in value the combined product of the two next highest-ocean pearl and vegetable ivory. ${ }^{b}$

It would be of value to compare the production in gross of buttons and the price per gross during the years from I 899 to r 909 . Unfortunately, the census report gives no classification except for the years I 899 , I904, and I9I 4 ; but the table following sup. plies the blanks by computation, the basis for each computation being explained in footnotes.

a It is well known that for several reasons there was a temporary decline of button manufacture between I 909 and I9 2.

$b$ The Ggures for ror 4 are not quite representative for the fresh-water industry, since the blanks and by-products aggregated at the bottom of the table are probably principally fresh-water products, as may be inferred from the total for that industry given by the census report in another place as $\$ 4,370,000$ 


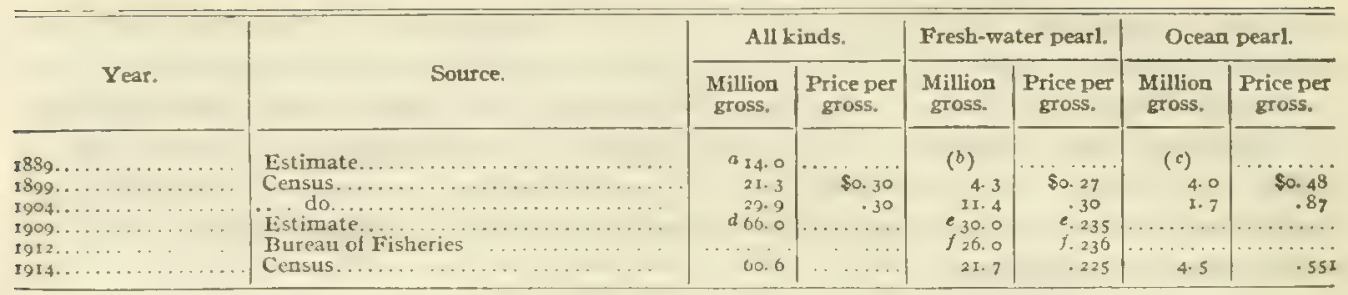

a Obtained by dividing census value of $\$ 4,217,000$ by assumed average price of 30 cents per gross.

$b$ None.

c Unkrown.

d Obtained by dividing census value of $\$ 22,708,000$ (aggregate), reduced to $\$ 20,000,000$ to allow for value of waste products, by assumed average price per gross of 30 cents. This average price taken from censuses of 1900 and 1905 .

e Unofficial estimate.

$f$ From statistical survey of the fresh-water mussel industry conducted in $r_{9} 3$ by the Bureau of Fisheries.

IMPORTS AND EXPORTS OF BUTTONS.

The history of imports of buttons of all kinds since $189 \mathrm{I}$ has an interest in connection with the domestic industries and is shown in an accompanying table. The exports of domestic buttons are also shown for the few years for which they have been sepa. rately shown in the schedule. (See table below.) We find, first, a substantial decline in imports approximately coincident with the inauguration of the fresh-water pearl industry, but evidently not related thereto, this decline being attributable to the financial stringency of I892-I894; second, a substantial recovery of import trade in I895 and i 896 ; third, a marked decline in imports coincident with the rapid expansion of the freshwater pearl-button industry in 1897 and the following years; fourth, a general slow rise in the amount of importations, beginning about 1900 , although never, until I9I3, rising to more than about one-half of the importations of I $89 \mathrm{I}$. Nevertheless, the difference in value between the imports of 189 I and r 910 is not at all commensurate with the output of the fresh-water pearl industry. In the later years there is not a wide difference between the value of imports and exports. Imports of pearl buttons have never been of considerable value, except about I896, I903, and r9i 7 .

IMPORTS AND EXPORTS OF BUTTONS.a

\begin{tabular}{|c|c|c|c|c|c|c|c|}
\hline $\begin{array}{l}\text { Year ending } \\
\text { June } 30\end{array}$ & $\begin{array}{l}\text { Imports, all } \\
\text { kinds } \\
\text { (dutiable).b }\end{array}$ & $\begin{array}{l}\text { Exports, all } \\
\text { kinds. }\end{array}$ & $\begin{array}{l}\text { Imports (for } \\
\text { consumption) } \\
\text { of pearl and } \\
\text { shell buttons, } \\
\text { including } \\
\text { imports from } \\
\text { Philippines. }\end{array}$ & $\begin{array}{l}\text { Year ending } \\
\text { June } 30-\end{array}$ & $\begin{array}{l}\text { Imports, all } \\
\text { kinds } \\
\text { (dutiable). }\end{array}$ & $\begin{array}{l}\text { Exports, all } \\
\text { kinds. }\end{array}$ & $\begin{array}{l}\text { Imports (for } \\
\text { consumption) } \\
\text { of pearl and } \\
\text { shell buttons, } \\
\text { including } \\
\text { imports from } \\
\text { Philippines. }\end{array}$ \\
\hline $1891 \ldots . . . \ldots \ldots . . .$. & $\$ 2,096, \infty$ & & $\$ 100, \infty 00$ & $1905 . . . \ldots \ldots$ & $\$ 866,000$ & & $\$ 172, \infty 00$ \\
\hline $1892 \ldots \ldots \ldots \ldots$ & $x, 317, \infty 00$ & ... & $292, \infty 00$ & $1906 \ldots . . . .$. & 873,000 & & 334,000 \\
\hline $1993 \ldots$ & $x, 410,000$ & ......... & 275,000 & $2907 \ldots \ldots$ & $936, \infty 00$ & .... & $164, \infty 00$ \\
\hline 1894 & $465, \infty 00$ & ........ & 38,000 & $1908 . . . \ldots \ldots$ & 653,000 & & 93,000 \\
\hline $1895 \ldots \ldots$ & $x, 071, \infty 00$ & & 376,000 & $2909 \ldots . . . . .$. & $767, \infty 00$ & $\cdots$ & 87,000 \\
\hline $1896 \ldots \ldots \ldots \ldots$ & $x, 424,000$ & ........ & 332,000 & $1910 \ldots . . . \ldots \ldots . .$. & $1,056,000$ & $\$ 474,000$ & $10 \%, 000$ \\
\hline I\$97 ............. & 950,000 & & 259,000 & $1911 \ldots . . . \ldots \ldots \ldots$ & $762, \infty 00$ & 557,000 & 100,000 \\
\hline $1898 \ldots \ldots \ldots \ldots \ldots$ & $43^{6, \infty}, 00$ & . & $37, \infty 00$ & $1912, \ldots \ldots \ldots$ & $I, I 30,000$ & 724,000 & 72,000 \\
\hline I899................. & 451,000 & & 24,000 & $1913 \ldots \ldots \ldots$ & $1,856, \infty 00$ & 849,000 & 137,000 \\
\hline $1900 \ldots \ldots \ldots \ldots \ldots$ & 593,000 & ........ & $36, \infty 00$ & $19 \pm 4, \ldots \ldots \ldots \ldots \ldots$ & $2,082,000$ & 654,000 & 253,000 \\
\hline $1901, \ldots \ldots \ldots \ldots$ & $55 x, 000$ & $\ldots \ldots$ & 76,000 & $1915 \ldots \ldots \ldots$ & $1, \infty 05, \infty$ & $x, 171,000$ & 280,000 \\
\hline $1902 \ldots$ & 954,000 & $\ldots \ldots \ldots$ & 424,000 & $1916 \ldots \ldots \ldots$ & 789,000 & $\mathbf{I}, 903,000$ & 546,000 \\
\hline $1903 \ldots \ldots \ldots \ldots$, & $1,190, \infty 00$ & & 469,000 & $1917 \ldots .$. & $I, 207,000$ & $1,982,000$ & $1,058,000$ \\
\hline $1904 \ldots \ldots \ldots \ldots$ & 893,000 & & 157,000 & $1918 \ldots \ldots \ldots$ & $1,276, \infty$ & $2, x 05,000$ & $9 \times 4,000$ \\
\hline
\end{tabular}

a From Government reports and information furnished by the U. S. Bureau of Foreign and Domestic Commerce, but in each case reduced to the mearest even thousand.

Imported buttons of high price are principally glass, pearl, and metal; of medium price, Philippine pearl (small quality); of low price, agate, bone, and rickel bar and recently Japanese pearl.

c Including pearl buttons to the value of $\$ 600,666$. 
When the imports are added to the domestic production we observe the enormous increase (in consumption) from about $\$ 9,000,000$ to about $\$ 23,000,000$, during the course of 20 years, an increase entirely disproportionate to the growth in population during the same period. The per capita consumption of buttons grew from about 37 in 1891 to about 106 in $1910 .{ }^{a}$

This magnified consumption can not be attributed simply to increased prosperity or to growing extravagance. It is a matter of common experience that where relatively expensive buttons were formerly hoarded and used again and again, the modern cheapness of good material has lead to the general abandonment of this laborious practice. The real significance of the fresh-water pearl industry is that it has, by its direct and indirect effects, made good buttons low in price and more generally used; as, indeed, would be the result in any industry that found a new and abundant resource to yield a quality of product formerly obtainable only from less available and more expensive materials.

During the last few years there has been increasing activity in varicus branches of the button industry, notably in vegetable ivory and celluloid, but fresh-water pearl still ranks as the paramount material used by button manufacturers.

\section{SUMMARY OF ECONOMIC EFFECTS.}

We may thus summarize the broader effects attributable in large part, though we would not say exclusively, to the development of the fresh-water mussel industry. Although affording employment to many wage earners and giving occasion for an important fishery, it has not caused a material diminution, if any, in the output of any other branch of the button industry. The fresh-water pearl product alone is now greater than the entire output of the button industry in 1890 ; but at the same time the product of other branches of the industry is greater than in 1890 . The fresh-water product is simply an addition by so much to the available wealth of the country. It has made a good button almost universally available, so that the total consumption has been greatly augmented. The economic rating of this industry will always depend in considerable measure upon its supplying a good product at a relatively low price; and this condition will be maintained only by preventing the depletion of the native resources and by promoting economy in manufacture.

\section{DEVELOPMENT OF MODERN METHODS.}

In the early stages of the industry the making of buttons was accomplished largely by hand machinery, so-called. The shells were held against the revolving saws by hand while the blanks were being cut out. Each blank was held with the finger against a revolving emery wheel, first to be backed, or ground to a smooth surface, and next to be turned or faced to a proper form with the central depression worked out. Then the blanks individually were placed in chucks for the drilling of two or four holes. Only the final polish was administered to the buttons in bulk. Sorting and carding was, of course, done by hand.

a These figures are based on the computation that the $\$ 4,216,000$ worth of buttous of $1 \$ 90$ represented, at 30 cents per gross, $14,000,000$ gross, or $2,000,000,000$ buttons, while the output in rgro is computed in the same way as 9,500,000,000. Importations are added and exportations deducted. 
Most of these processes have become obsolete in the United States with the development of modern machinery. It is, indeed, to the automatic machinery that the industry owes its present relative importance. The old process of sawing remains practically unchanged, but the grinding, facing, and drilling, the principal features of button making, are accomplished by automatic machinery. For the three processes either two or three machines are used; in some cases a grinder attachment to the double automatic makes it possible to combine the entire process in one machine.

The sorting, or grading, of the buttons requires nice judgment and must still remain a hand process; but recently a machine has been introduced for the attachment of buttons to the cards.

Not only the departures in the mechanical equipment but the improved efficiency of labor and better shop management are combining to increase the output and to promote economy of production with better quality and uniformity of product. These, and such other present-day features as the utilization of waste materials and the introduction of sanitary devices, will undoubtedly be more generally and effectively applied in the future.

\section{PROCESSES OF MANUFACTURE.}

The description of the general process of button making as given below is essentially that of the average modern plant, although in each factory characteristic modifcations of method are encountered.

\section{PREPARATION OF SHELIS.}

STORAGE.-When the mussel shells are received by barge or freight car, they are hauled to large covered or exposed storage bins at the factories, to be kept until ready for use. A rough sorting is often done at this stage, so that each bin will contain shells of a relatively uniform size and quality. There is no apparent deterioration of the quality of shells if protected from the weather. If not so protected, they are liable in time to lose the luster and become lifeless or chalky. The exterior of the shell is most readily affected once the horny covering is worn or scaled off. For this reason shells which have been long exposed on the banks or "dead" shells from the rivers are considered undesirable.

CLASSIFYING-When the shells are taken from the bins for use, they are first sorted by hand according to species or quality of material, if this has not previously been done, and are then classified as to size. The latter process is accomplished by a machine called a classifier, which, though larger, is similar in principle to the classifier used for blanks (Pl. XXXVIII, fig. I). The shells are put into a large hopper, from which automatically they are fed slowly onto an endless belt leading to the classifier, which consists, primarily, of two hollow metal rollers about 6 inches in diameter and 8 feet in length. By falling between the two rollers the shells are to be separated, roughly, into four or five grades, according to size and thickness. To this end the rollers are set with an incline and are not quite parallel with each other, being more widely separated at the lower ends. As they revolve outwardly the shells slip, or roll down the incline to a point where the opening between the rollers permits them to fall into one of a series of buckets placed below. The smaller and thinner shells are found in the buckets nearest the head. 
The classification of shells by size and character has obvious advantages for adaptation of material to particular grades of buttons and to uniform speeds of machinery.

SoAkING.-After classifying, the shells are placed into large metal tanks or vats, each holding about a ton, or sometimes into barrels. The containers are then filled with water, in which the shells are allowed to soak for a week or more. The process is intended to soften the material, which would otherwise be too hard on the saws, as well as so brittle as to chip and yield blanks with rough edges. The smaller sizes of shell may simply be put into damp cellars, sprinkled, and covered with wet cloths.

Curiously enough, there is a difference of opinion among manufacturers as to the merits of this treatment, the contrary view being held by some that the material works better if not soaked, but simply sprinkled, before cutting. The custom of soaking is one that is generally desired by the cutters, however, since it is held to lessen the labor of resharpening the saws.

An obvious but probably unnecessary disadvantage of the soaking process consists in the fact that the shells as marketed have small bits of meat attached, so that after soaking the water may become more or less foul. In handling the shells scooped from the vats there is the possibility of contamination in the event of abrasions upon the hand. This is undoubtedly the cause of an infection to which cutters are more or less liable. The addition of an antiseptic compound to the water of the vats should be a universal feature of this process.

\section{SAWING OR BLANK CUTTING.}

THE Machine.-The cutting machine is essentially a lathe fitted, on the one hand, with a tubular saw of the necessary diameter to obtain the required size of button, and, on the other hand, with a wooden plug and a ratchet handle or lever for gradually forcing the rough shell against the rapidly rotating saw (Pl. XXXV, fig. 3). The shell is held in position either by tongs or by the hand protected with a mitten. During the cutting process small jets of water are directed against the shell to keep it, as well as the saw, cool and also to prevent the production of troublesome and injurious dust (P1. XXXVIII, fig. 2). Successive blanks as they are cut are crowded through the tubular saw to fall into a receptacle below. When the desired blanks are removed, the shell is thrown into a bucket or box to be subsequently dumped upon the shell heap, unless the shell is to be passed to another machine for a second cutting of smaller and thinner blanks. The cutting machine, including the saw, is about the only one of the many used in button factories on which no radical improvements have been made since it was first introduced and adapted to the fresh-water shells. The original invention may or may not be the best solution of the problem, but as yet none of the machines put forth as improvements has earned an established place in manufacture.

The saws must be made of specially hardened steel, and are obtainable from only a few shops. When received from the factory, each saw is simply a rolled cylinder tapering at one end, being without teeth at this stage (Pl. XXXVII, fig. 1). They are made of different tempers as extra-hard, hard, regular, soft, and very soft, for adaptation to the varied texture of the material to be cut.

The sizes of the buttons are determined by the inner diameter of the cutting end of the saw, and the unit of button measure is one-fortieth of an inch, called a line. Buttons from fresh-water shells vary in size from $\mathrm{I}_{4}$ to 40 lines (from about one-third of an 
inch to I inch). Buttons of ocean pearl are sometimes made as small as one-fourth of an inch, and the same size of fresh-water buttons is made in novelty works as well as the larger sizes up to 60 lines (1.5 inches) or larger.

The button-cutting machine is equipped with a three-step cone pulley so that the speed may be adapted to the shell and line to be cut. For blanks of 14 to 20 lines a speed of over 400 revolutions per minute may be used, while about 275 revolutions would be used for 22 to 36 lines. The largest sizes, 36 to 60 lines, would be cut with a speed of only about i 80 revolutions per minute. The speed will, of course, be adapted somewhat to the shell and to the whim of the individual operator.

The cost of a cutting machine installed was estimated four years ago at about \$24. (See page 44.) The number of machines operated in one plant varies from three or four in small blank-cutting shops to one hundred or more in larger factories.

Detached Cutring Plants. - While button factories commonly include cutting rooms (PI. XXXVIII, fig. 2), where the blanks, or buttons in the rough, are cut from the shells, there are yet a good many establishments devoted exclusively to the finishing arid grading. In such cases the cutting is done in detached cutting plants (P1. XXXIV, fig. 2), which may be located at convenient points in different States and from which the blanks may be shipped to the factory. There are also numbers of independent cutting plants, or button shops, which may be more or less portable. The owners of such plants take the shells from the river or buy them and cut out the blanks, which are then sold to the manufacturers of buttons. It has frequently occurred that when a new region of abundance of commerrial shells has been discovered numerous small cutting plants have sprung up along the banks or on house-boats. A single fisherman may purchase and install a single machine and small gasoline engine to cut the shells that he and his family take, or a number of machines may be installed, labor employed, and the product of other fishermen purchased. In a few cases the cutting plants are cooperative, a number of shellers operating each a particular machine and cutting and marketing his own blanks. The blanks may be sold to the owner of the machines or in the open market.

Most manufacturers purchase blanks when it is more profitable to do so than to produce them in the factory; but generally a manufacturer prefers to produce his own blanks, since greater care can be exercised in proper cutting. There are cases where the independent cutting plants are particularly to be recommended, as where the shells are too scattering for convenient shipment in carload lots, or, in remote localities, whence the freight charges on the bulky shells are practically prohibitive. In some streams it appears that the best solution of the marketing problem would be had by the operation of small cutting plants on house-boats, which can be floated down the river, cutting the shells as they are found and throwing the waste shell back into the river. The blanks can be shipped from time to time from convenient points. This plan has also its advantages where the shells are abundant but so spotted or stained that the proportion of good shell to waste is relatively low. It is of interest to note that the freight charges paid for transportation of shells and blanks in 1912 were reported at $\$ 131,000$.

WORK AND WAGE OF CUTTER.-The cutters are men. Each cutter is ordinarily expected to provide himself with a few tools, such as three to five saw spuns, a buttoncutter's hammer, shell tongs, saw, files, and hose and bibb. This equipment may be 
purchased either from the factory or elsewhere; its cost in prewar times was about $\$ 2$ and approximately $\$ 4$ in 1919 .

The button cutter, having had his shells weighed out to him and having received his saw, proceeds to fit the saw into the spun, or saw holder, and then sets the spun in the chuck fixed in the machine, which is thrown into operation to test if the saw is set perfectly true. If not found to be running true, adjustment is effected by tapping, or by refitting. It may require several minutes, at least, to obtain a correct adjustment. With a slender three-cornered file the teeth (I I to 20 or more in number, according to the size of blank to be cut) are then cut into the saw, after which the teeth are set, and the machine is ready for practical work. (See P1. XXXVII, fig. I.) In quantity of production, quality, and economy, as will be more fully shown later, much depends upon the skill and interest of the cutter, as well as upon the good judgment of the manufacturer in the purchase and assignment of material.

Roughly speaking, a cutter may use about 100 pounds of shell per day, cutting 25 gross or more of blanks. The number of pounds of shell required to produce a gross of buttons varies with the line, the character of the shell, the skill and interest of the cutter, and with the care of the management.

Once a week the cutters take their blanks to the foreman and are paid at a given price per gross. There is usually some system by which the cutter is beld responsible for excessive waste of shell. The wages of cutters vary widely, according to the skill and regularity of the individual.

Since the number of gross is computed from the weight of the blanks in bulk, it is customary to give the blanks a preliminary shaking over sieves adapted to the size to be used. The openings in the sieve are just a little smaller than the blanks, so that, not only the chips and dust are removed, but also such imperfect blanks as have one diameter less than that of the opening.

Representative prices in 1914 and in I9I9 (figures in parentheses) were as follows:

$6(7 / 2)$ cents per gross of 14 lines.

$6(8)$ cents per gross of 16 lines.

$7\left(8 \frac{1}{2}\right)$ cents per gross of 18 lines.

$8\left(9 \frac{1}{2}\right)$ cents per gross of 20 lines.

$9\left(10^{2} / 2\right)$ cents per gross of 22 lines. ro $\left(x I^{\pi} / 2\right)$ cents per gross of 24 lines.

I3 ( 15 ) cents per gross of 30 lines.

I7 (I8) cents per gross of 36 lines.

2 I (26) cents per gross of 40 lines.

At these prices a cutter could earn from $\$$ Io to $\$ 20$ per week in 1914 , or from $\$ 12$ to $\$ 35$ in I919. A small bonus may be paid for full-time work.

PRODUCTION OF BLANKS. - IVith good cutting of niggerhead shells roo pounds of shell will yield 12 to 14 pounds of blanks, but the production is usually much lower, of ten only about 9 pounds. A fine grade of muckets from Lake Pepin, being light and of comparatively uniform thickness, will yield 20 pounds of blanks per ıoo pounds of shell.

The table following prepared by the shell expert of the Fairport station is of interest as illustrating how the different species and sizes of shells may be adapted for different lines of buttons. The cutting practice in any plant will, however, be adapted to varying market demands, rather than to any theoretically ideal scheme for the most effective use of the shell. 
Speches and Sizess of Shelr. That May be Adapted for Difrerent Lines of Buttons.

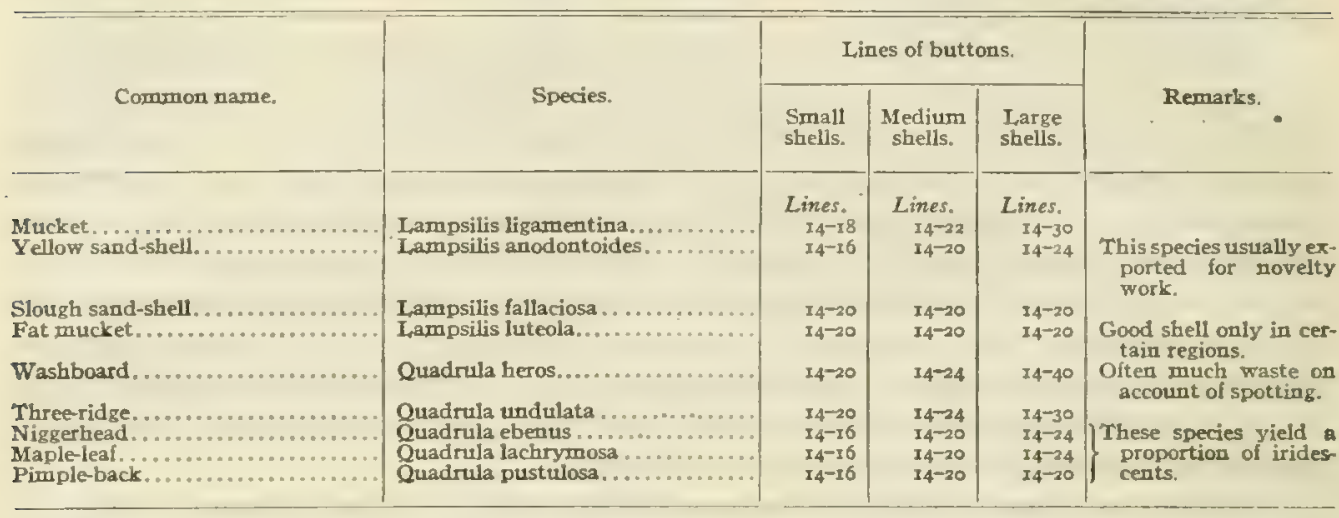

Tips are cut from all of the above-named shells. Take, for example, large washboard

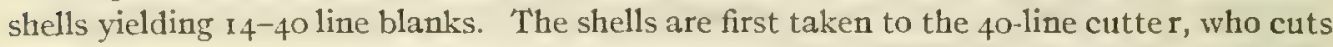
out all the 40 -line blanks that are of the proper thickness with a true face (Pl. XLIV). They are then taken to another cutter, who cuts out all the 24 -line blanks that are available. Finally, they are passed to the tipper, who cuts the remainder of the available material into 14 and 16 line tips. These tip blanks when run through the blank classifier may turn out a good per cent of blanks that are classed as butts, meaning by this that they are thick enough to make into any style of button; the tips are usually so thin that they must be finished with a machined face that requires the least material to be taken from it.

At first glance the process of cutting might appear a very simple one, yet it is properly an operation requiring much skill on the part of the laborer and the wisest type of management. A fuller discussion of the significance of the cutting room in the proper utilization of shells is given on pages $82-87$.

\section{FINISHING PROCESSES.}

PREPARING THE BLANKS.-Before going to the finishing machines the blanks are usually passed through four intermediate processes.

The blank classifier is essentially similar to the shell classifier on a smaller scale and need not be described in detail (Pl. XXXVIII, fig. I); by falling between rollers the blanks are separated into different lots according to thicknesses (Pl. XXXVII,fig. 2).

They are then placed in tumblers, consisting of heavy and slowly revolving barrels of iron or wood (P1. XXXV, fig. 2). In these the blanks are churned with water and pumice stone to clean them and remove the rough edges, making them easier to handle and more workable. Lye is sometimes used in connection with the pumice stone. As a cheaper abrasive of more rapid action, fine sand may be used with the pumice stone.

The blanks are now ready for the grinder, a machine fitted with an emery wheel which grinds away the horny backs and reduces the blanks to a uniform thickness (P1. XXXV, fig. 5). These machines are operated by girls, who place the blanks face down upon moving belts 3 or 4 inches wide, while the belts convey the blanks underneath the emery wheels. These machines, as well as all others that require it, are generally connected by suction tubes with blowers for removing the dust that would otherwise 
BULL. U. S. 13. F., 1917-18.

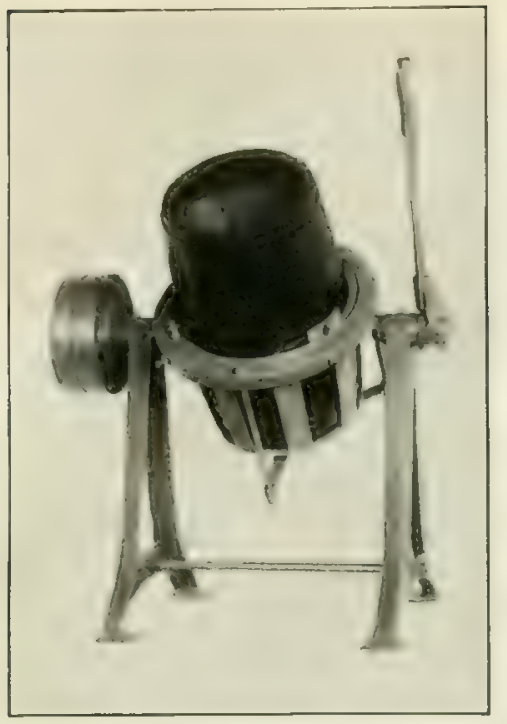

FrG. r. - The chum used in polishing buttons. (See p. 77.)

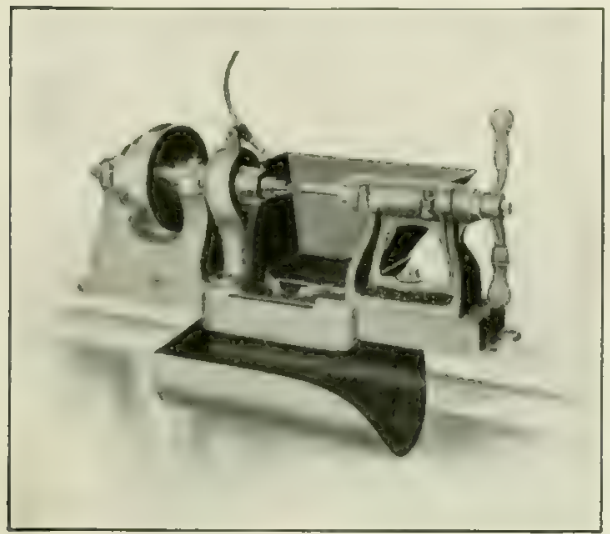

Fic. 3,-A cutting machine of simple type. (See
p. 7 I. $^{\text {) }}$ )

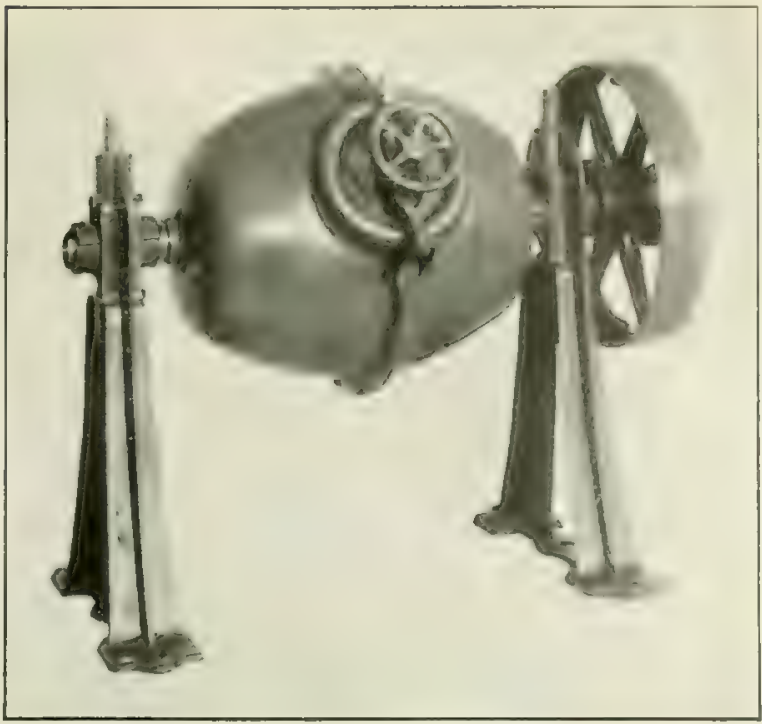

FIG. 2.-The tumbler employed for buffing blanks or buttons. (See p. 74.)

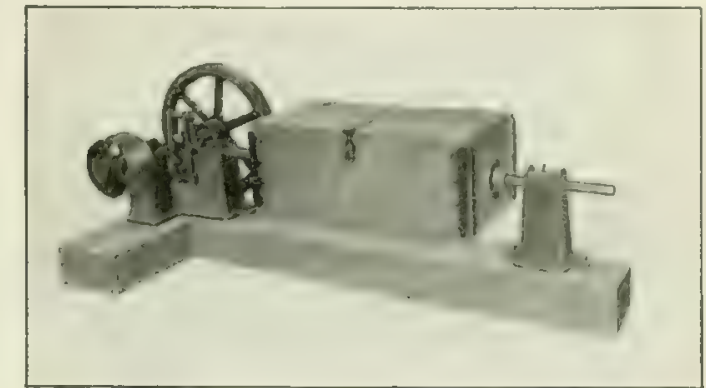

Fig. 4.-The shaker in which the buttons receive the final polish. (See D. 77.)

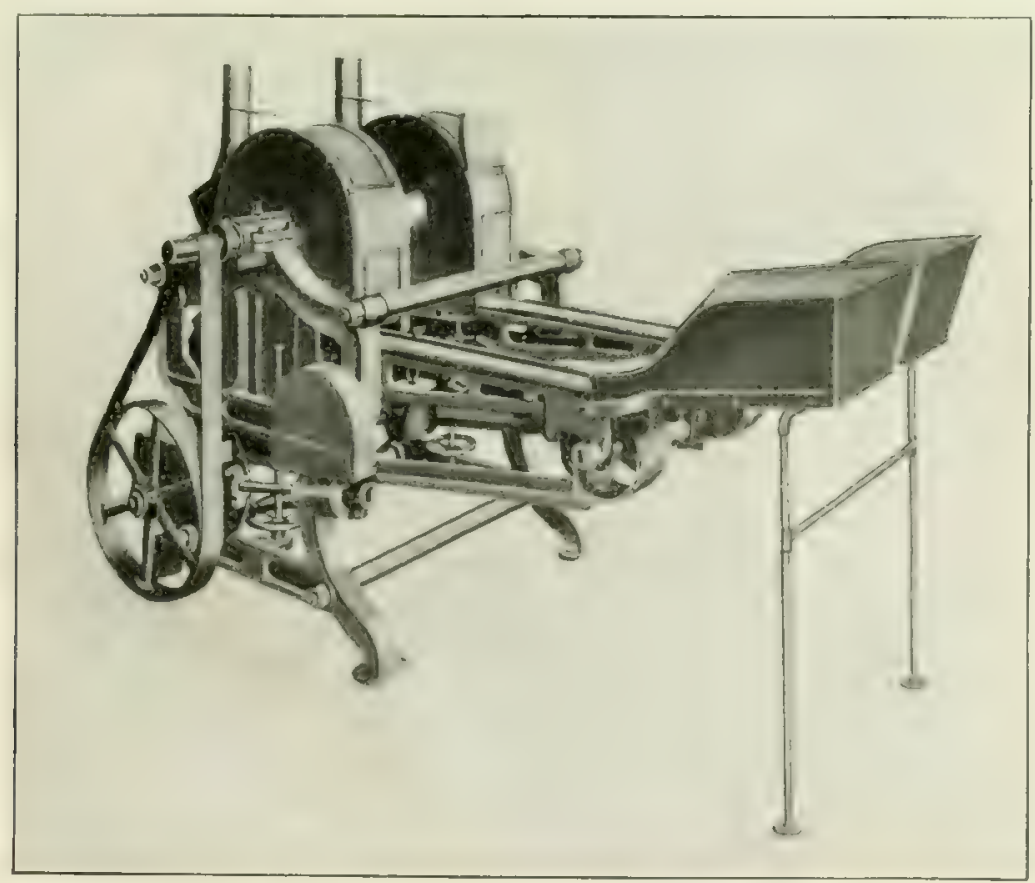

IiG. 5. The belt grinder employed to remove the backs from blanks and bring them to desired thickness. (See p. 74.) 


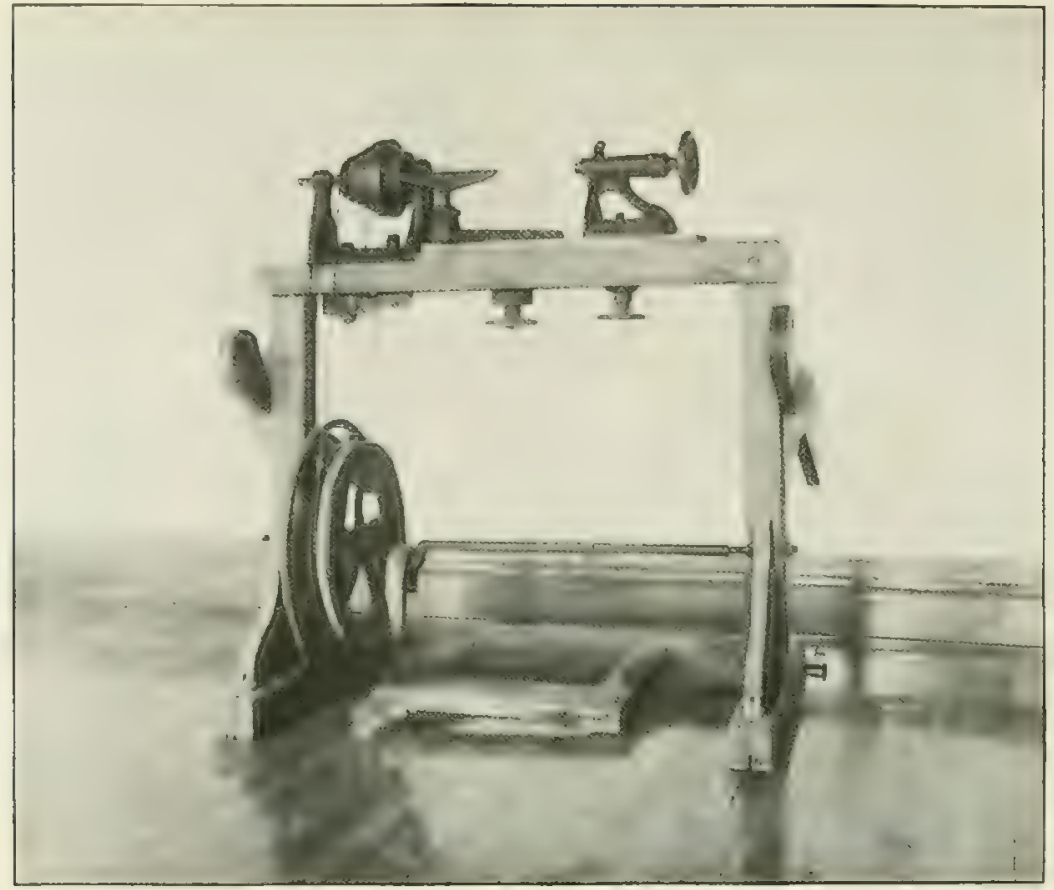

FTG. I-The original foot-power lathe employed by Mr. Boepple in the inaumation of the fresh-water pearl-buttors industry. (See p. 65.)

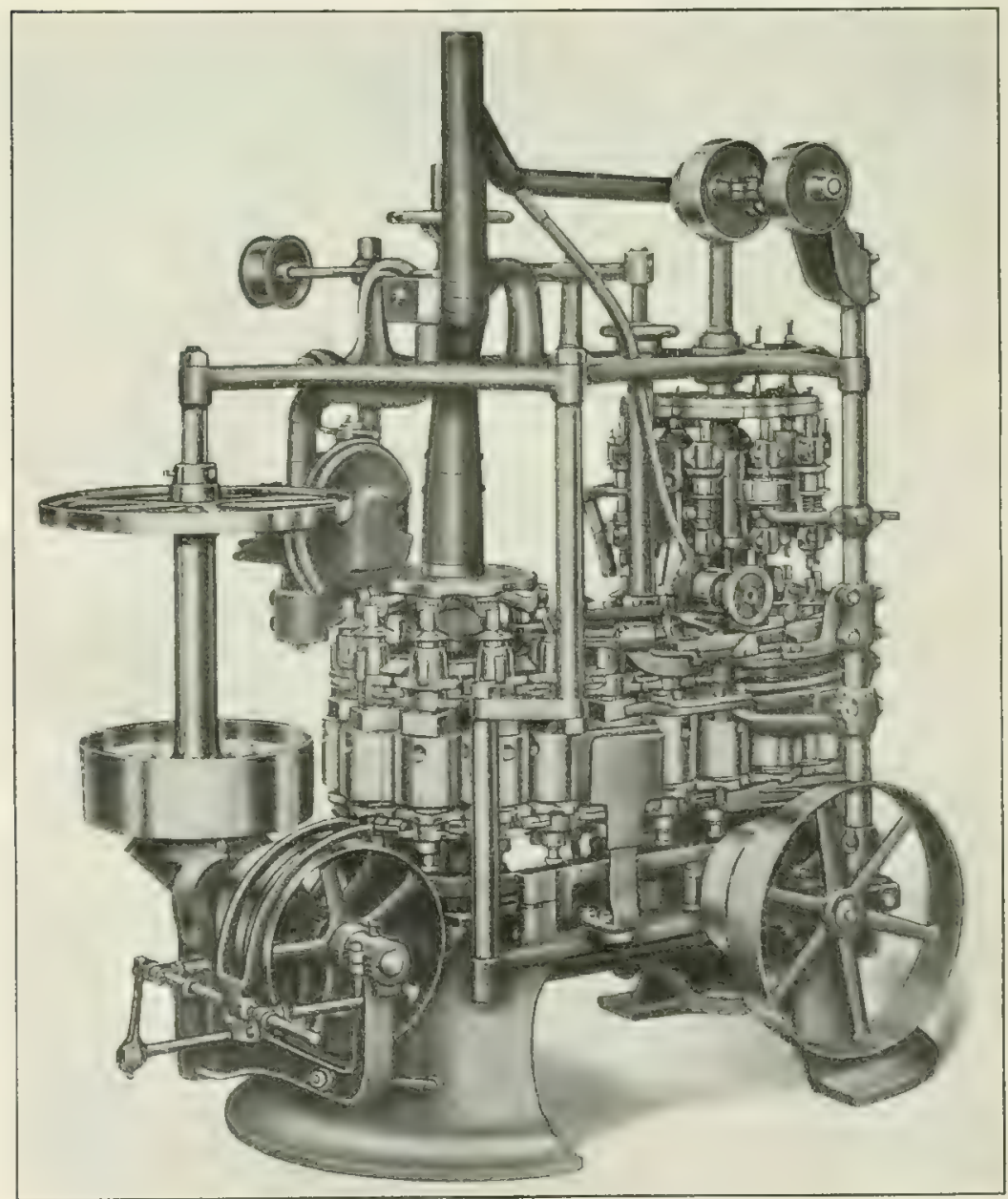

FíG. 2.-A modern automatic machine for shaping and drilling buttons. (See p. 75.) 


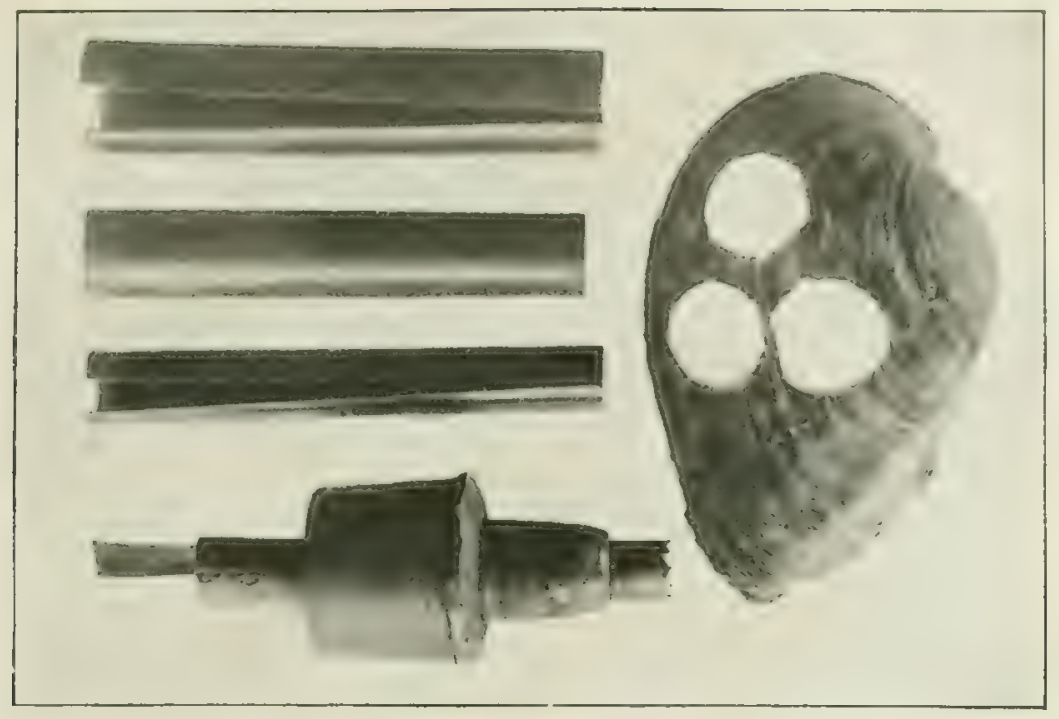

Fig. r. - Tubular saws of different sizes, saw and spun fitted into the chuck, and shell from which blanks have been cut. (See p.78.)

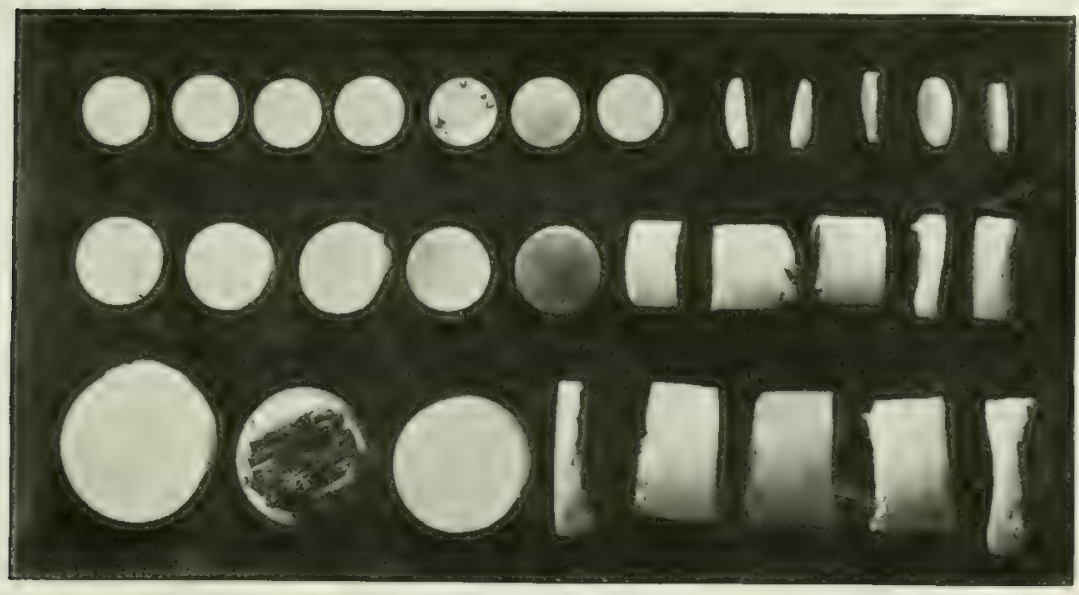

Frg. 2.-Blanks of various sizes and thickmesses as cut from the shell and before submission to the "backing" process. (See p. 74)

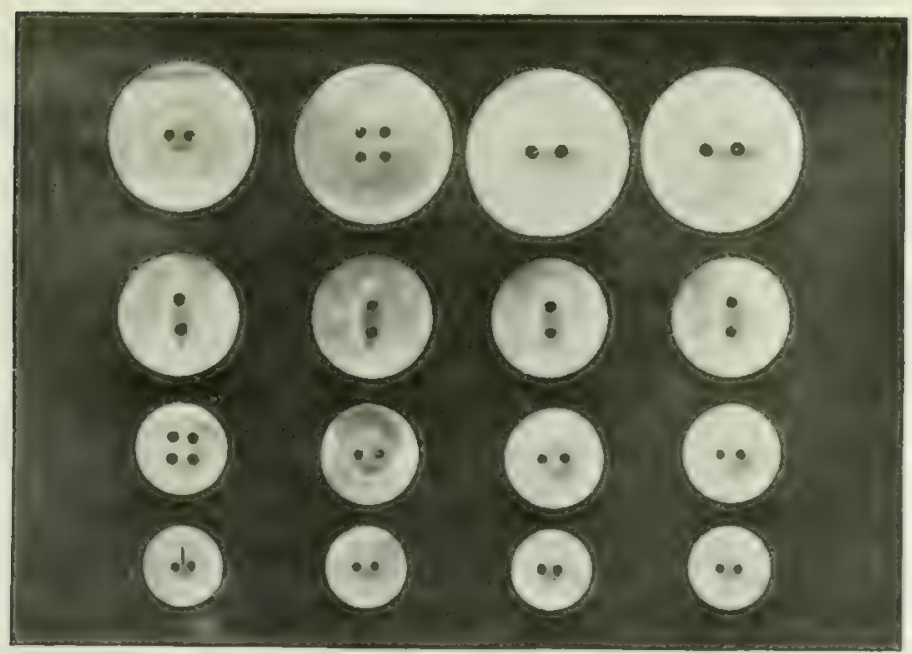

FIG. 3.-Finished buttons of several sizes and patterns. (See p. 76.) 


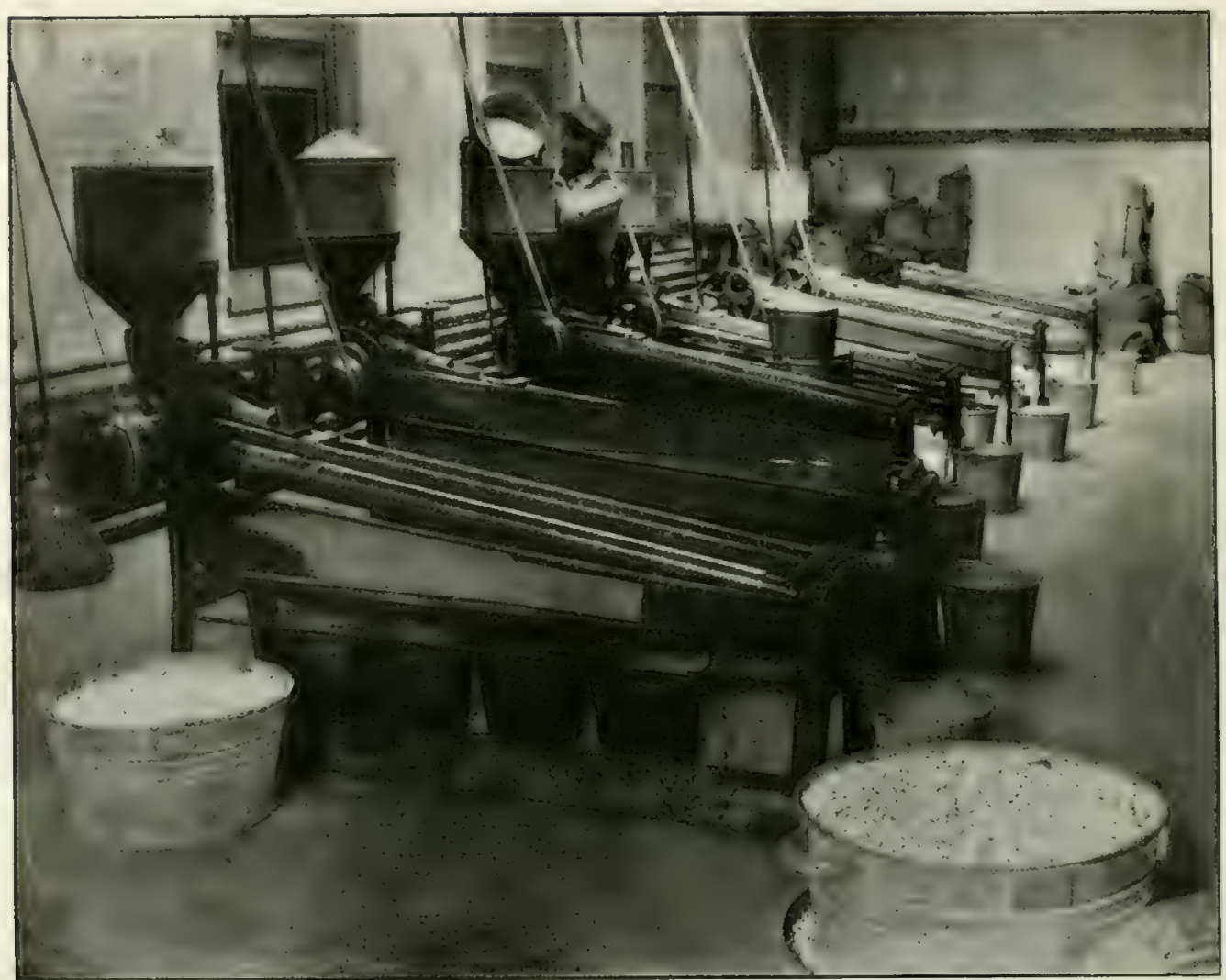

FitG. I. - Blank classifiers for separation of blanks according to thickness. (See p. 74.)

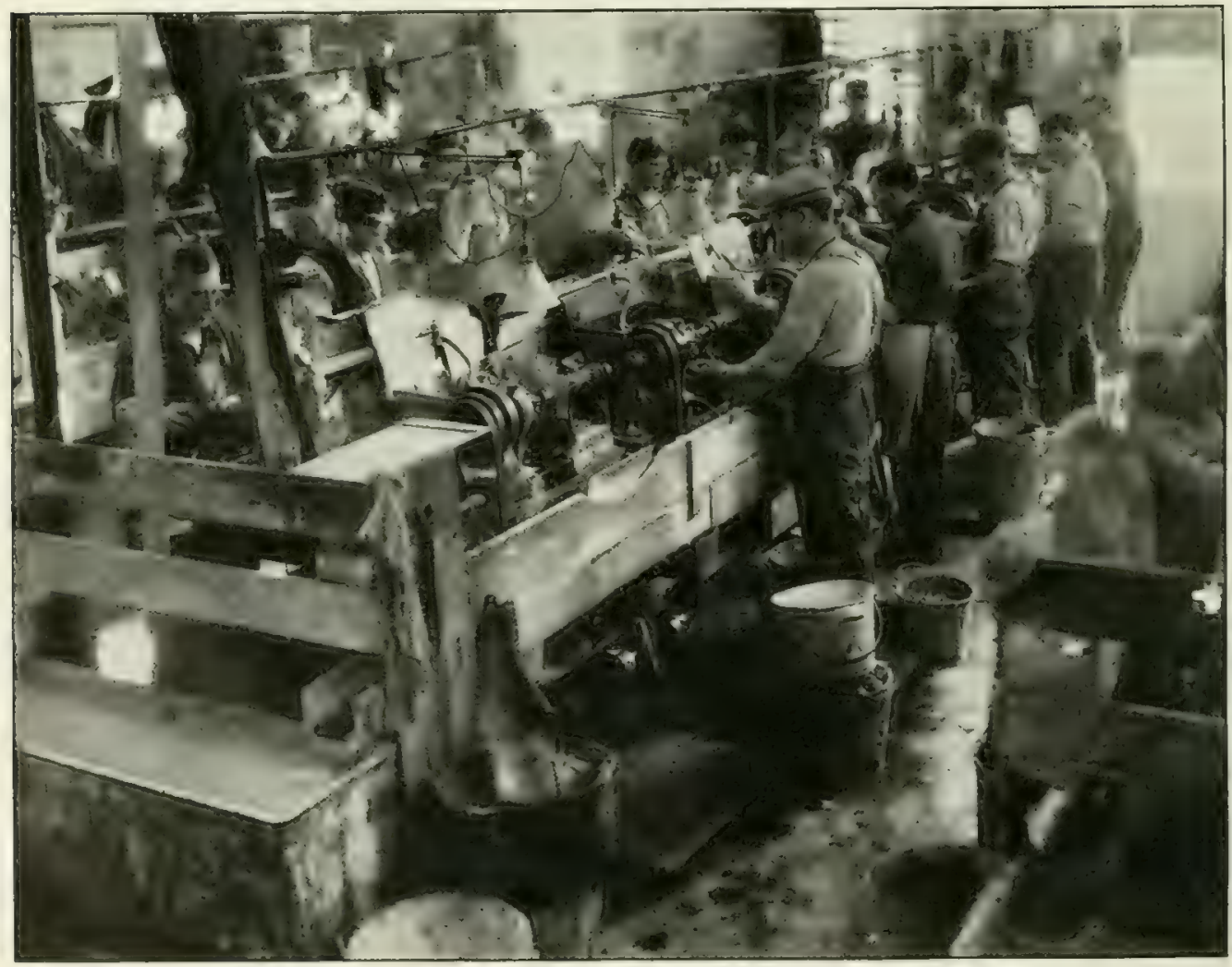

FrG. 2.-The cutting room, where blanks are cut from the raw shells. (See p. 72.) 


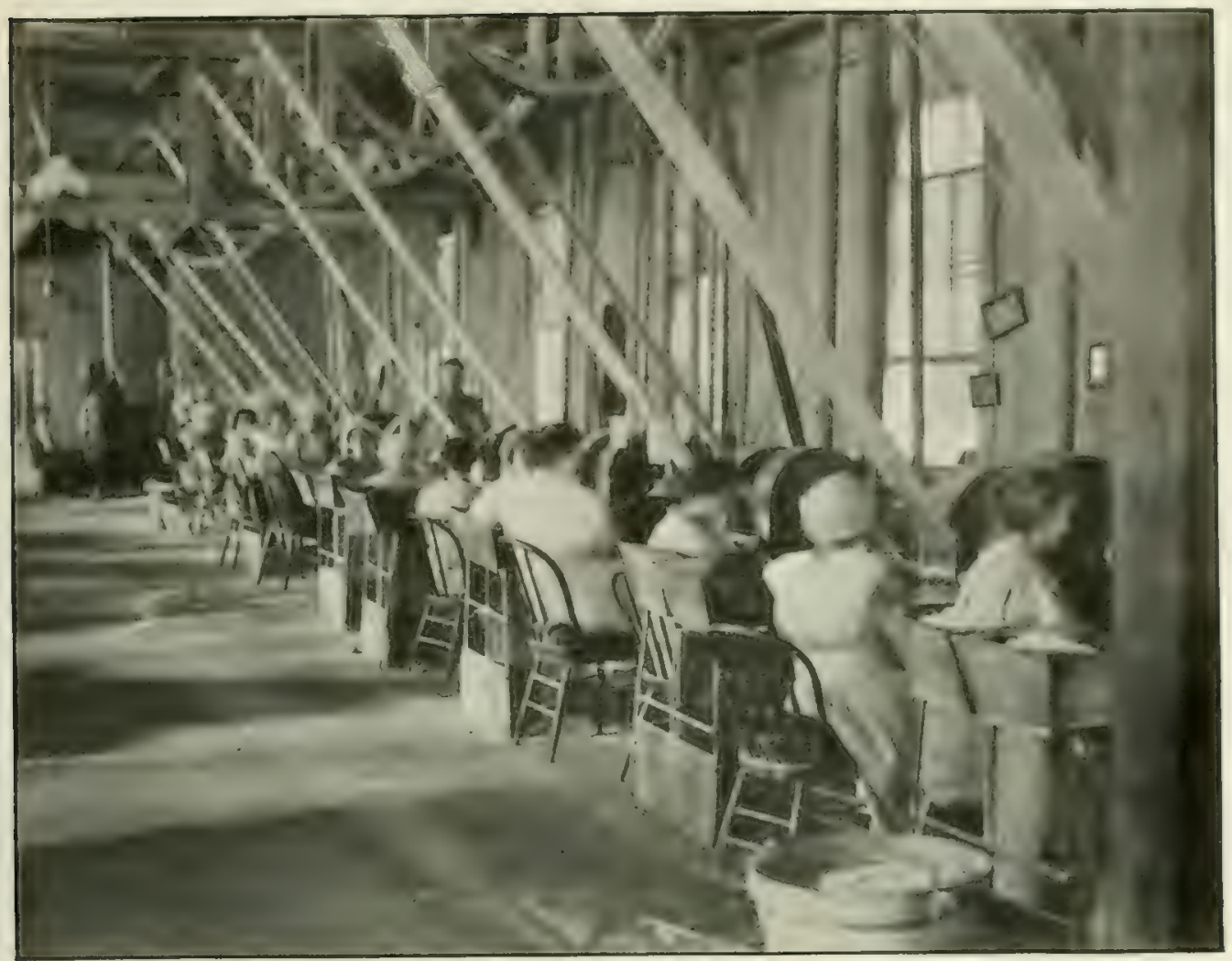

FiG. r. - The belt grinders, where blanks are brought to uniform thickness. (See 1). 75.)

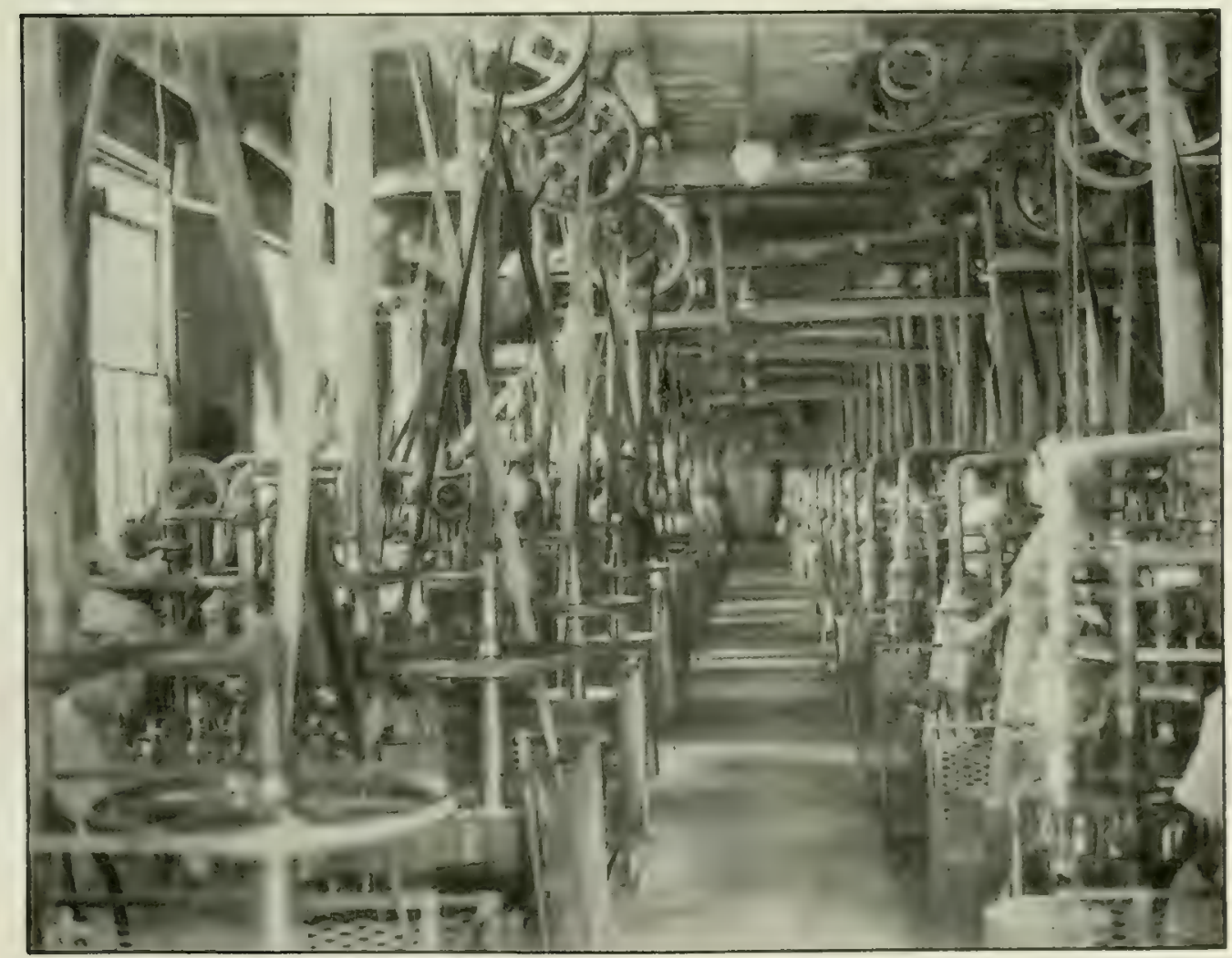

FIG. 2. -The "finishing" room, where the blanks are converted into buttons by automatic facing and drilling machines, 

be obnoxious and injurious to employees (Pl. XXXIX, fig. I). Grinders are paid from I 5 to 25 cents per roo gross, according to size and thickness of blanks, earning from $\$ 9$ to $\$$ I 5 per week.

Finally the blanks are again soaked in water to be softened for the finishing machine. In some cases, if too much mixed in quality or size, the blanks may be sorted by hand.

MAKING THE BuTrons.-Having been classified, tumbled, backed, and soaked, the blanks are now ready for the essential processes of button making, which are accomplished by an automatic machine of comparatively recent invention and of very ingenious design. The illustration (Pl. XXXVI, fig. 2) will aid in an understanding of the brief description of the working of the machine which can be here given. (See also P1. XXXIX, fig. 2.) The blanks are fed by hand into depressions in the tops of vertical chucks, which are arranged in series constituting an endless chain. As the chucks in endless chain pass around the circumference of the machine each blank is automatically operated upon by various tools, and each tool is automatically sharpened and prepared for the succeeding blank. The processes accomplished in the machine consist in rounding the edges and carving out the center in the desired pattern to make the face of the button and in drilling two or four holes according to pattern. After the first hole the drill rises, the button makes a turn through a fourth or a half of one revolution (according to whether it is to be a four-hole or two-hole button), when the drill again descends to make a new hole. After the last hole is drilled the chuck opens automatically to release the button, which is sucked into a tube connected with the blower system to be dropped into a bucket through a counting tube.

Some twenty-odd distinct operations are combined in the double automatic machine, and it is interesting to record them. Let it be noted that the button travels in an oblong orbit, while the carving tools and the drills, respectively, travel in smaller circular orbits at opposite ends of the button orbit.

1. The traveling chuck, which is open after releasing a finished button, closes on the new blank placed in the top depression.

2. The chuck with the blank begins to revolve rapidly on its axis while continuing to travel to the right.

3. The face of the revolving and traveling button is applied to a carving tool of proper form to make the desired face. The tool itself is stationary on its axis, but travels in orbit with the buttons.

4. The facing completed, the tool rises.

5. The rotation of the blank is stopped.

6. The tool, continuing on its orbit, is sharpened on an emery wheel.

7. Before meeting another blank the tool is lowered by a small fraction of an inch to compensate for the shortening due to the grinding on the emery wheel.

8. The chuck, with its blank, leaves the orbit of the carving tool at a tangent to pass over to the orbit of the drilling tools.

9. When the blank is in just the right position, one of the drills descends to make the first hole in the blank. In this operation the drill revolves, while the blank is stationary on its axis, but both travel together.

Io. The drill rises.

I I. The chuck, with blank, turns through one-fourth of a revolution.

$110306^{\circ}-19-5$ 
i2. The drill descends for the second hole.

13. The drill rises.

i4. The blank turns another fourth of a revolution.

I 5. Third hole is drilled.

16. Drill rises.

17. Blank turns.

I8. Fourth hole is drilled.

19. Drill rises.

20. Drill continues in its shorter circular orbit, to return into proper position for a later blank.

2I. Button chuck rises a little and releases the button.

22. As the chuck passes beneath a suction tube the button is drawn up against a small, fine screen in the tube.

23. The button drops of its own weight upon a small trap.

24. When a number of buttons corresponding to a given weight have accumulated on the trap it releases and drops the buttons into a bucket.

25. The tripping of the door or trap registers the number of buttons finished.

Another feature of the machine is the equipment of little screened suction tubes, some traveling, and some stationary, which draw away the dust whenever it is generated by carving or drilling. The amount which the carving tool may be lowered to compensate for grinding can be fixed by a large ratchet disk over the machine, which permits of adjustment to the one-thousandth of an inch.

When the fisheye pattern (cf. P1. XXXVII, fig. 3, buttons in second row from top) is desired, a thin, revolving emery wheel, or a steel fish eyo cutter, is placed so that as the button passes from the carving orbit to the drilling (without central depression) the tool swings down and at one stroke cuts out the fisheye. There may also be an attachment for causing the blank to turn upside down, so that the back may be hollowed out instead of being left flat or rounded, as is ordinarily the case.

This machine as described is the double automatic button machine. Somewhat older types are the single automatics, where separate machines embody the processes of facing and drilling. These are still in use in some factories. A very recent addition to the button machine consists in an automatic grinding and feeding attachment, whereby the blanks are first backed and then dropped into the chucks from an endless belt. As the machine is generally used, the blanks are placed individually in the chucks by the attendant, usually a woman; who becomes very expert.

It will be recalled that the blanks were tumbled before being backed. In consequence, as they come to the automatic machine the back edges are slightly sharper than the edges corresponding to the inside surface of the shell. It is possible, therefore, for a deft operator to distinguish at the touch the outside surface from the inside and so to place the blanks in the chucks that the one side or the other (as desired) will be finished. There seems to be some difference of practice, nearly all manufacturers believing that the inside gives the best finish, while some find a better product by finishing the outside. Experiments made at the Fairport station do not indicate a marked difference. Possibly a better or more uniform gloss is obtained on the outside, while a more pearly "water" results from finishing the surface corresponding to the interior of the shell. However, an obvious advantage in carving the inner surface 


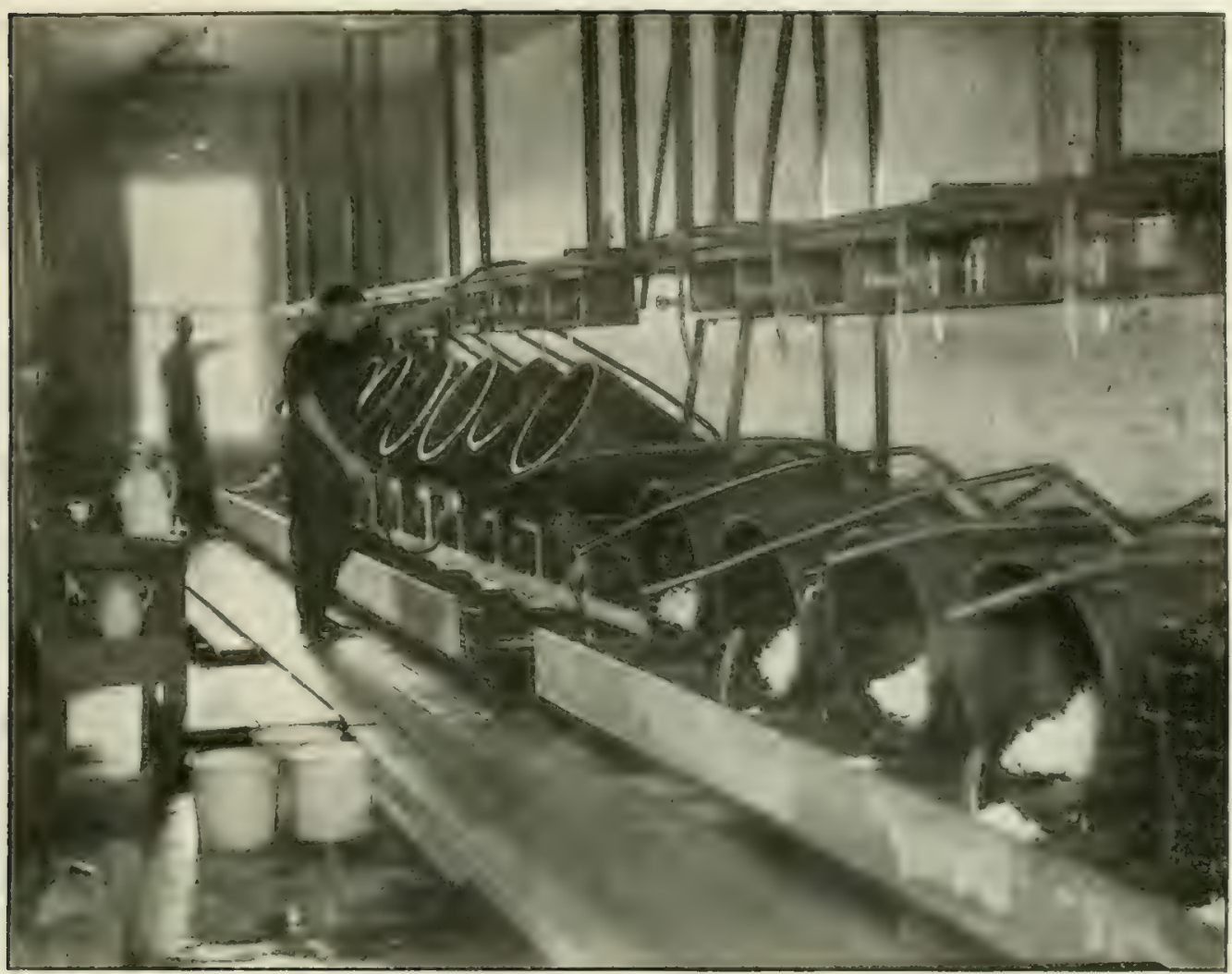

Frg. $x$.- The churns, with buttons receiving polish by the use of acid and steam. Note the funnels from which acid solution drips into the churns. (See p. 77.)

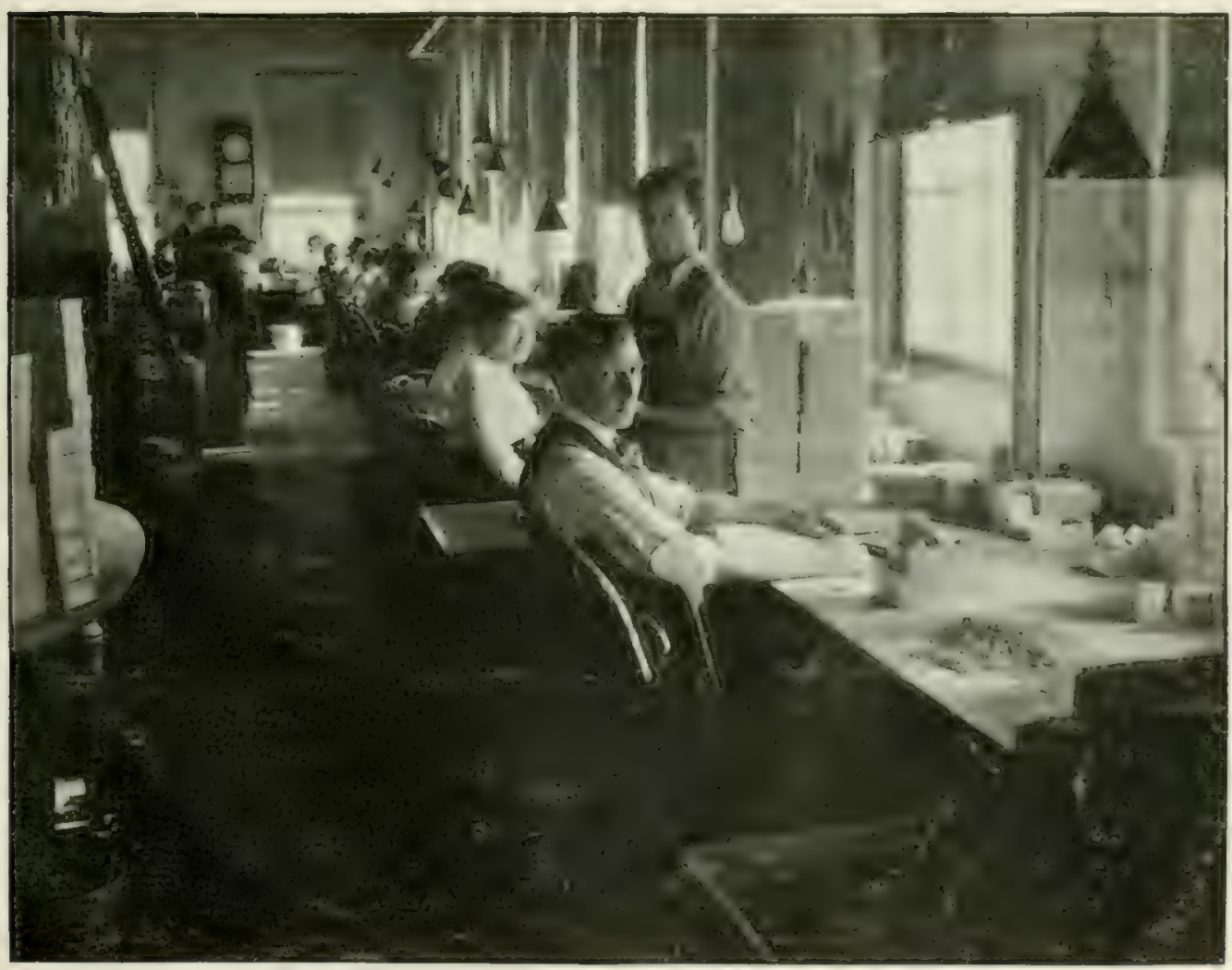



arises from the fact that the outside, after having been backed, is flat and true, while the inner face may have a natural unevenness. The blank on its back or flat side thus rests more securely in the chucks of the finishing machine and, when finished, both sides are in such true form as desired.

Assuming each chuck to be properly filled in turn, a machine might finish from 33 to 72 buttons per minute, according to the speed given it. Ordinarily the capacity varies from 1 oo to 190 gross per day. In the days of handwork the output of a single operator in shaping was about 20 gross per day, and the buttons had then to be passed to the driller, who could turn out about 50 gross per day. The cost of a double automatic machine in I9r4 was about \$I,300, with about \$300 additional for the feeding attachment, but a machine would probably cost $\$ 2,500$ in r9i9. The operators are usually women, who were paid, in 1914 , I to 2 cents per gross and earned $\$ 7$ to $\$ 1$ I per week. In 1919 the rate of pay and earnings are $33 \frac{1}{3}$ per cent higher.

The automatic machine has revolutionized the industry of button manufacture from fresh-water shells. It makes possible not only a far greater yield, but a better uniformity of product than was ever possible with handwork. Something is yet to be desired in the way of lessening the amount of breakage of blanks in process of manufacture, but the machine is being continually improved and perfected.

Polishing.-From the machine the buttons are taken to the chums, where they are tumbled, or churned, with water and pumice to clean them, take off the rough edges, and make them ready for receiving the final polish (Pl. XXXV, fig. I and Pl. XL, fig. I).

The polishing is also a tumbling process, in which, however, sulphuric or other acid is used in conjunction with steam. After the buttons are dried in shakers with sawdust (Pl. XXXV, fig. 4), they are placed with dry sawdust and washing powder in a combined tumbler and shaker. This process removes any trace of limy deposit and gives the final luster. Finally the buttons are conveyed in buckets or boxes to the sorting room.

SoRTING.-A very important feature of a button factory is the sorting room, for the qualities and grades can not be sold if mixed indiscriminately. The classifying according to sizes and thicknesses has already been accomplished in the blank stage, but the grading according to freedom from defects of manufacture or from natural shell stains and with respect to color, luster, and iridescence must be accomplished by the hands and eyes of skilful sorters. Girls are always employed for this work on account of their superior deftness, or quickness of selection, and the most expert sorters can separate the buttons into I2 grades with extreme rapidity. They are provided with a well-lighted room and work seated in rows at long tables before windows (P1. $\mathrm{XL}$, fig. 2). The buttons are handled individually and thrown into series of boxes or drawers arranged about the operator; from 85 to 200 gross of buttons may be sorted in a day, so that sorters might earn, in 1914 , from $\$ 5.25$ to $\$ 12$ per week, on the basis of pay at one cent a gross. In 1919 , sorters are apparently eaming from \$io to \$I9 per week on a sliding scale wage of 0.6 to r. 5 cents per short gros: according to the number of grades (from 2 to 12 ) sorted.

The number of grades varies with the several establishments, but it would not be practicable to enumerate them. Some factories make a specialty of iridescents or shiny-backs, as they were originally called. The iridescents are made from the hinder portion of the niggerhead, pimple-back, and related shells. If a niggerhead shell is 
polished on the outside, there is seen to be an almost exact dividing line between the smaller brilliantly iridescent portion and the larger merely lustrous portion. Muckets and related shells produce no iridescent buttons. Some may be obtained from the bluepoint, three-ridge, and washboard, but these are often not otherwise up to grade in quality. Buttons from these shells often require bleaching, and it has been observed that the process of bleaching increases the degree of iridescence.

Although iridescents, when carefully selected, command a good premium, they are comparatively too few to make it generally worth while to work particularly for them. Care must be taken that the entire button is cut from the iridescent portion without overlapping of the forward portion of the shell. As a rule, no special effort is made to cut them, but as a number are cut incidentally, a premium may be paid to the sorters to separate them from the others. In consequence a limited number of clear iridescents are obtained which can be sold at a good price. When ordinary buttons of good grade were bringing $3^{3}$ to to cents per gross, iridescents would bring 75 cents. Indeed, if there were any regularity of supply the price could undoubtedly be raised much higher and still the demand be good.

BleAching AND Dyeing.--References have previously been made to the prevalence of stained, spotted, or otherwise discolored shells. Such shells or portions of shells constitute a considerable proportion of the undesirable waste. Manufacturers have long striven to find proper processes of removing the discoloration without detriment to the quality of the product. Old methods of bleaching embraced the use of alkalies which injured the shell and caused the buttons to disintegrate or to break in the laundries. Hence bleaching came into disfavor in the trade, and some purchasers decline to purchase buttons believed to have been bleached. Bleaching as now generally practiced, however, is not injurious. Factories employing this process have each their own peculiar formulas or methods, but until very recently the essentials of the process were probably the same in most plants-peroxide, chloride of lime, and heat, with variations in the degree of heat and the period of action. Other chemicals are now employed in secret processes which seem to be very effective.

Without bleaching, discolored buttons may be used to advantage for the production of smoked-pearl buttons, which are blackened by staining with sulphur and silver nitrate. Various dyes are also used in the production of fancy buttons of bright colors, as red, green, or bluc, to suit the capricious demands of fashion. Some are now being so treated chemically as to produce an excellent imitation of the buttons made from the Trocha shells of Japan, but with better finish. Many shells in nature have beautiful colorings of purple, salmon, or pink, but the shades are not adapted to market demands, and it is claimed that the colors are liable to fade unevenly. Consequently, beautiful as some shells appear in natural condition, they must be classed as waste unless some effective process of bleaching or staining be applied.

Carding, PACKing, AND SALE.-Certain factories work for the bulk trade-that is, for the supply of garment manufacturers who do not require the goods carded; others for the carded trade exclusively, while some are prepared to supply both.

If the bulk trade is supplied, it remains after sorting only to pack and ship; otherwise, the buttons must be attached to suitable cards. Sometimes the sewing is done in the factory; in other cases, more so in the past than at present, buttons are given out to women at home who wish to earn pin money at spare moments. 
Within the last two years a machine has been introduced for neatly attaching the buttons to the cards with small wires. It has the advantage of not only saving time, but of attaching the buttons individually, so that a single button may be removed without loosening the others from the card. This is a convenience to the consumer as well as to the manufacturer; for if, after carding, it is noted that a defective or an off-grade button appears on a card, it can easily be removed and another put in its place with a special machine. These wire-stitching machines are usually operated by girls, with one or two men to keep the machines in order. A single machine may turn out I 50 gross per day, more or less. The record in May, I9I4, was 240 gross stitched to the cards in 9.5 hours. The operators were then paid from seven-tenths of a cent to I cent per gross (about 1.2 cents in 1919 ), and might earn $\$ 6$ to $\$$ ro per week ( $\$ 810$ SI I in 1919). The machines were not sold, but were operated on a basis of hire or lease.

After carding, the buttons are ready to be boxed and sold. Individual manufacturing establishments have specialties in the way of attractive cards and boxes or display outfits. Naturally the departments of advertising and selling have much to do with the success of the factory and constitute a considerable element of overhead expense. The wholesale price of buttons varies between wide extremes. Buttons of 45 lines and excellent quality may be sold as high as $\$ 2.25$ per gross; or an overproduction and accumulation of low-grade lines have led to sales at as low a figure as I cent per gross. Owing to the large number of low-grade buttons sold in bulk, the average price per gross, as computed from a statistical survey of the industry conducted by the Bureau for the year I912, was about 23.5 cents per gross. As this price probably covered freight, insurance, and discounts, the net factory price would have been correspondingly lower.

The clements of cost in the manufacture of buttons must vary very widely according to the grade of the shell, the line of the button, the quality of labor, the size and output of the plant, and the systems of management. By courtesy of a manufacturer we may illustrate by the following citations of costs in particular lots of material which were carefully followed through the various processes of manufacture. The items in each case are as nearly correct as could then be made (I9I5), but the same tables would not apply exactly to other batches of the same lines. The data serve a useful purpose as illustrating relative costs of the several processes, although the prices of shells and the cost of labor have increased materially (approximately 75 per cent) since 1915 .

Relative Costs in tue Several. Processes of Button Making, as of the Year igi5.

\begin{tabular}{|c|c|c|c|}
\hline Items of cost. & $\begin{array}{l}\text { Example } \\
\text { of } 16 \text {-line } \\
\text { buttons. }\end{array}$ & $\begin{array}{l}\text { Example } \\
\text { of zo-line } \\
\text { buttons. }\end{array}$ & $\begin{array}{l}\text { Example } \\
\text { of } 28 \text {-line } \\
\text { buttons. } \\
\text { better } \\
\text { grade. }\end{array}$ \\
\hline (2) & $\$ 0.0335$ & So. 0524 & 10. 1667 \\
\hline ( & .0523 & .0689 & .1075 \\
\hline 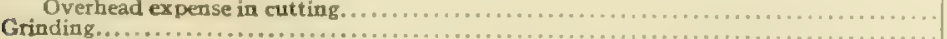 & .0196 & .0194 & .0393 \\
\hline Overhead expense in grinding & .0015 & $\begin{array}{l}.0018 \\
.0125\end{array}$ & $\begin{array}{l}.0057 \\
.0125\end{array}$ \\
\hline 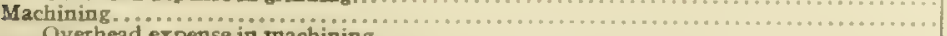 & $.0 \mathrm{r}$ & $.0 x$ & .015 \\
\hline Overhead expense in machinin & .015 & .015 & .015 \\
\hline $\begin{array}{l}\text { Sorting............................. } \\
\quad \text { Overhead expense in sorting... }\end{array}$ & .01 & . or & .01 \\
\hline & & & .014 \\
\hline 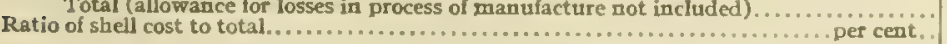 & $\begin{array}{r}-1684 \\
20\end{array}$ & $\begin{array}{r}-2 r_{40} \\
26\end{array}$ & - 3857 \\
\hline
\end{tabular}


Many of the cheaper buttons are manufactured, really, in the way of by-products; that is, the shells must be bought for the making of good buttons, and the cost of the shell is chargeable to these profitable lines; it is better then to cut the remainder of the shell into very cheap grades than to throw it away. There are times, however, after the demand for the poorer grades has been oversupplied, that it becomes actually necessary to discard waste shell, unless one is to manufacture at a serious loss.

UTILIZATION OF WASTE PRODUCTS.

In 1912, according to a statistical survey conducted by the Bureau, 55,67 I tons of shells were used for the manufacture of buttons. Assuming that only 90 per cent of this material became a waste product in course of manufacture, we find 50,000 tons of waste material. This waste consisted principally of shells discarded after cutting out the blanks, but a considerable quantity was in the form of finely pulverized shells or dust generated in the processes of cutting, backing (or grinding), facing (or carving), and drilling. This dust is not permitted to escape into the air, as otherwise the atmosphere of a factory would be unendurable. It is removed and concentrated by streams of water played on the shell while cutting and by a system of blowers and suction tubes connected with the several elements of finishing machinery. The dust is, therefore, made available for use.

The uses of the waste material would be various were it not for the fact that other cheaper materials are available for many of the purposes for which it is adapted. For instance, the waste shell might be bumt for lime or used for the improvement of soils or for many common purposes.

The principal use of the waste shell is for the production of poultry grit, for which purpose it is prepared by passing it through crushing machines, which divide it into the desired fineness; defective or broken blanks and unmarketable buttons also pass into the crusher (PI. XLI). The waste shells are sometimes used also as road-building material. The shells are very hard and do not pulverize so readily as oyster shell. In this respect there are obvious disadvantages as well as advantages.

The dust is useful in stock food, and in condition powders for hogs and poultry; it serves also appropriate purposes as an element in the manufacutre of artificial marble, tile floorings, etc. It is said to form a constituent of some jewelry polishes, soaps, and cleansing powders. The present market for dust is, however, nearly negligible.

In 1912, 22,530 tons of crushed shell were sold, yielding $\$$ I 4,722 , besides about I 0,500 tons of shell not crushed which were sold (probably largely to crushers) for $\$ 7,600$. The sale of dust amounted to only $\mathrm{I}, 220$ tons, bringing $\$ 3,470$. The shell commanded about $\$ 5.50$ per ton, and the dust about $\$ 4$ per ton. In I9I9 shell and dust yield, respectively, about $\$$ I $2.50_{2}$ and $\$$ I per ton. Both the shell and the dust possess certain exceptional qualities, and undoubtedly in time a better place in industrial uses will be found for them.

USE OF SHELLS FOR NOVELTIES.

The production of novelties from fresh-water mussel shells takes a wide variety of forms (P1. XLII). In I 9I 2 there were six novelty works with an output valued at $\$ 6$ I, 800. From small whole shells or from portions of shells there were made such articles as watch charms, hatpins, stick pins, buckles, chains, cuff buttons, fancy buttons of all sizes and 


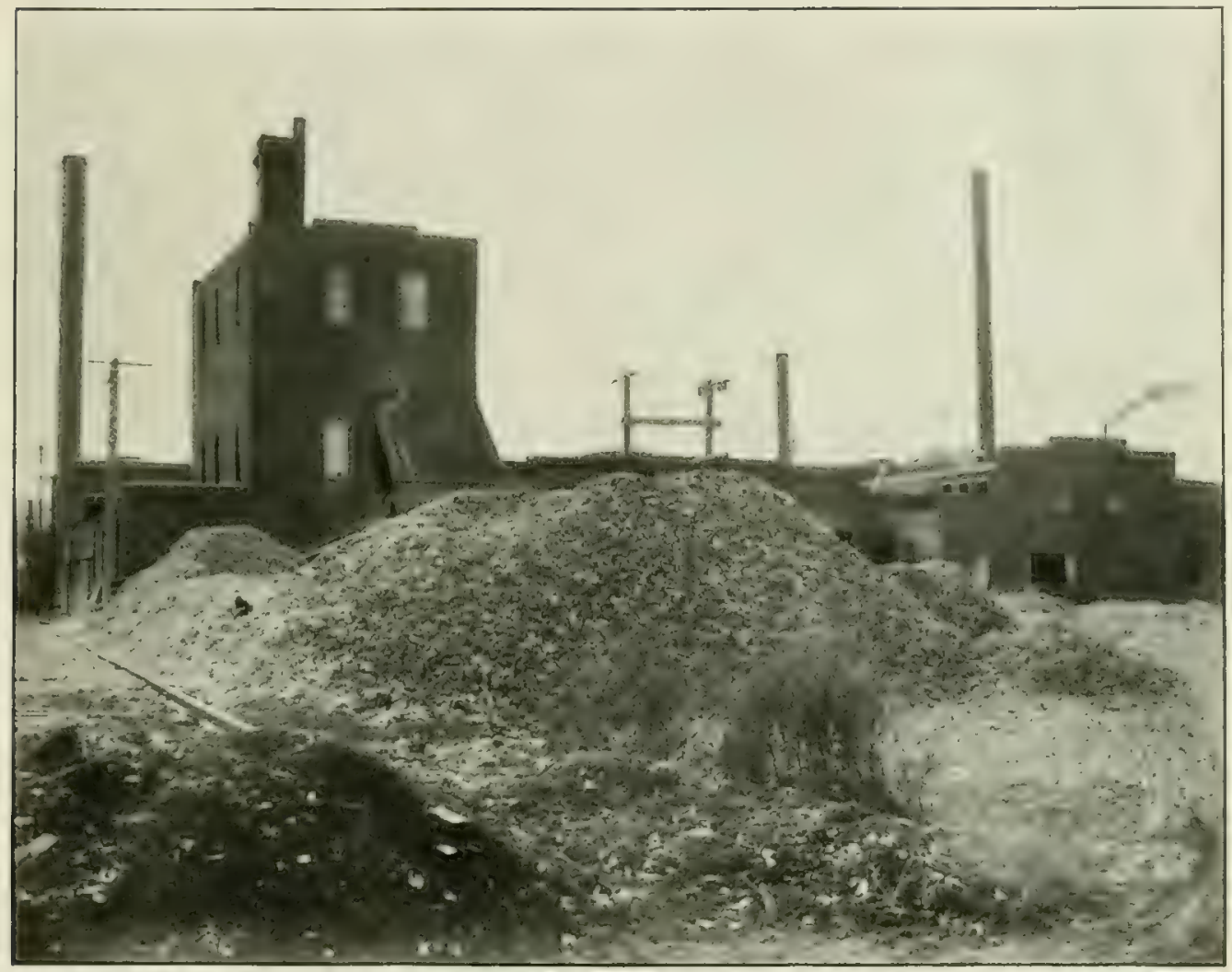

Crushing plant where waste shell and defective blanks are converted iato chicken feed and other useful groducts. (See p. 8o.) 


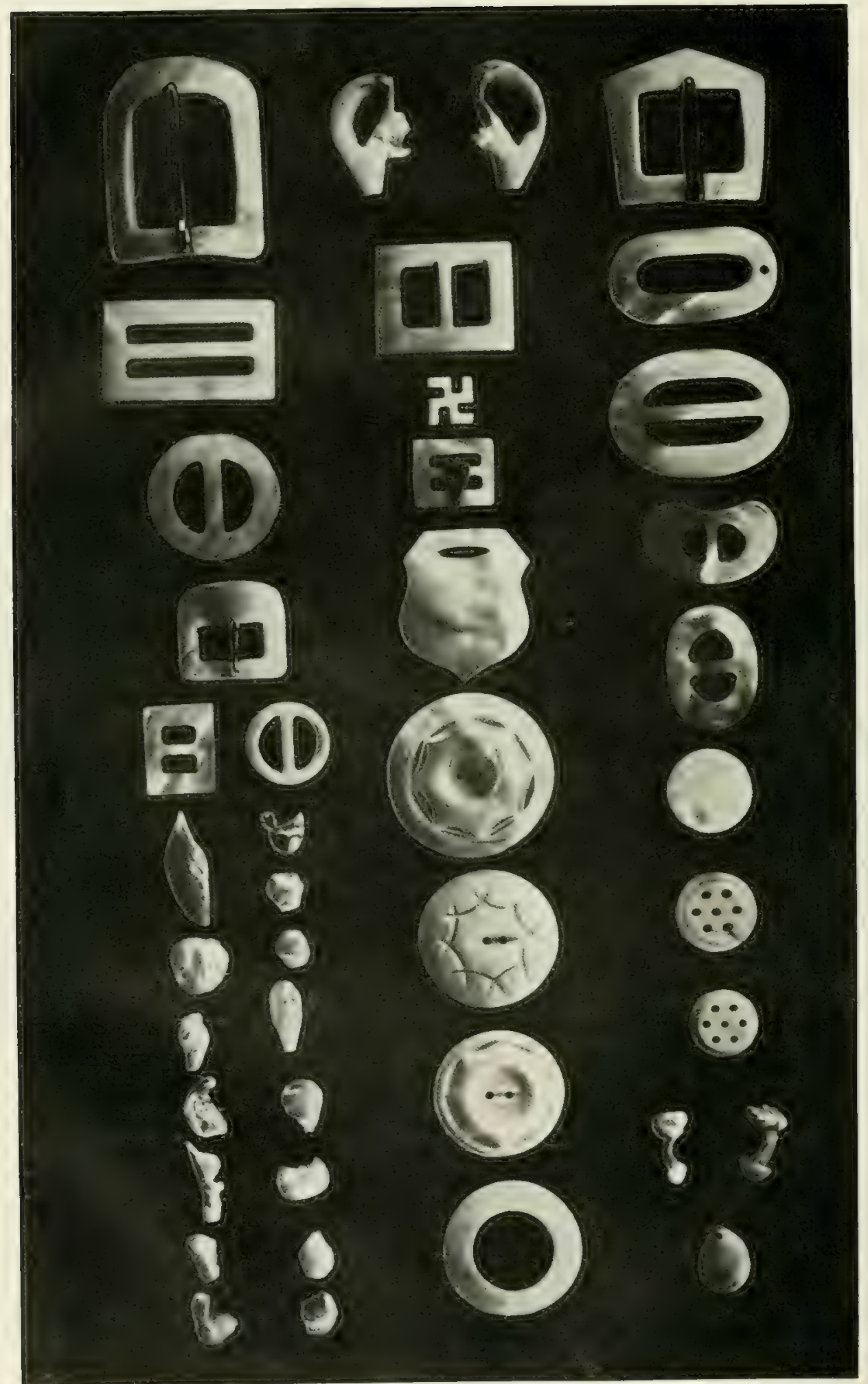

Novelties made from portions of fresh-water mussel shell. (See p. 80.) 
many patterns, perforated tops for salt shakers, inlaid work, etc. Most or the novelty works are located in Muscatine, Iowa.

The yellow sand-shell, being a rather long, straight-lined shell of peculiar pearliness, though not a clear white, is particularly adapted for novelty work, and thus commands such a high price that, under normal conditions, no manufacturer can afford to cut buttons from it. Shells of this species were often sorted out by the shellers on the river bank to be sold at a price two or three times the value of button shells, or from $\$ 40$ to $\$ 60$ per ton. Such shells as were not sorted out, but sold along with less valuable material, were subsequently again sorted out by the manufacturer for resale. Practically all of these shells were exported to Germany, where they were highly valued. Such shells for export sold as high as $\$ 90$ per ton f. o. b. New York.

The Daily Consular and 'Trade Report of January 6, I9I4, stated that there was a steady demand in Hamburg for the following grades of American shells, prevailing prices c. i. f. Hamburg per 220 pounds being quoted as follows:

\begin{tabular}{|c|c|c|}
\hline & & $\begin{array}{l}\text { Equivalent } \\
\text { price per ton of } \\
2,240 \text { pounds. }\end{array}$ \\
\hline 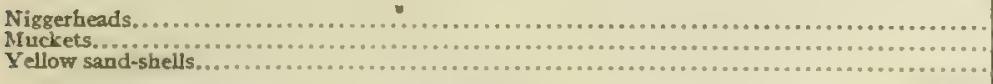 & $\begin{array}{l}\$ 5.95 \\
476-\$ 13.09 \\
17.90-26.66\end{array}$ & $\begin{array}{l}\$ 60.58 \\
48.47-\$ 133.37 \\
I 3 I .16-169.63\end{array}$ \\
\hline
\end{tabular}

Prices of marine shells at the same time were reported as ranging from $\$ 7.14$ to $\$ 107.10$ per 220 pounds (equivalent price per ton, $\$ 72.43$ to $\$ 1,090.47$ ).

Processes for Polishing Shells.-Polished shells of the iridescent varieties make attractive souvenirs or table ornaments. The polishing may be accomplished by one of the following methods, as described by J. B. Southall, shell expert of the Fisheries Biological Station at Fairport:

Buffing process.- The outer surface of the shell is ground off by an emery whecl or grindstone, the former being preferable, as it grinds much faster. If the surface of the shell is grooved, a file is generally used to remove the portions of the surface not touched by the grinding wheel. After the outer surface has been removed the shell is polished by holding it against a felt polishing wheel revolving at the rate of 2,000 to 3,000 revolutions per minute, fine polishing paste being applied to the surface of the wheel as needed. When all the emery scratches have been removed, the shell receives its final polish by holding it against a canton-flannel buffing wheel revolving at the same rate as the polishing wheel. If many shells are to be polished a double emery-wheel stand can be used to advantage by having the polishing wheel on one end of the spindle and the buffing wheel at the other end.

Chemical process.-If the entire shell is to be polished-that is, the inner and outer faces-prepare the shell the same as for buffing. After the surface has been ground off the shells are placed in a cylindrical tumbler, using enough water to cover and a reasonable amount of fine pumice powder. It usually requires 8 to io hours of tumbling to remove the emery scratches and smooth the outer face of the shells. After the shells are smooth enough they are taken from the tumbler and placed in the polishing machine.

Polishing machines can be purchased on the market, but a very good homemade machine can be constructed at a small outlay. Mount a short piece of I-inch shaft in a frame so that the shaft inclines at an angle of $45^{\circ}$, and at 
the upper end fasten an earthenware jar of suitable capacity. The ordinary speed for the polisher is 40 to 60 revolutions per minute. The jar being tipped at an angle of $45^{\circ}$, the shells are tumbled over one another instead of resting on the bottom of the jar and moving with it, thereby allowing the acid to remain on the shells and cause pitting. A most convenient acid dropper is made by cutting a very narrow groove in the side of a cork and inserting it firmly in the tube of a glass funnel. With a little practice the number of drops to the minute can be regulated by the size of the groove in the cork. The next operation is to place the shells in the polishing machine and pour in a measured quantity of water just sufficient to cover them completely. A quantity of sulphuric acid equivalent to 20 minims for each 8 ounces of water in the jar is then placed in the dropper, which should be suspended over the polisher and so adjusted that the acid will fall into the jar at the rate of 10 to 15 drops per minute. A very good plan is to take some of the water out of the jar and add it to the acid in the glass funnel, thus diluting the acid, and diminishing the danger of pitting the shells by allowing the pure acid to drop on them. It generally takes from 45 to 60 minutes for the polishing, if the acid has been gauged correctly. Just before the shells are polished the water becomes milky. Do not allow the shells to stay in the water long after the milkiness appears, as the shells soon become coated with a white substance which is very hard to remove. After the desired polish is obtained dump the shells out and wash thoroughly with clean, cold water; then wash the polisher, place the shells back into it, cov. ering them again with clean water, and revolve as before, applying steam to the water with a hose until it boils. Just as the water comes to a boil pour in an amount of commercial muriatic acid equal to that of sulphuric acid used in the first operation and allow the shells to tumble a couple of minutes after the acid has been poured in. Remove the shells and wash as before. After washing the shells allow them to dry for 48 hours; then place them in a box tumbler and allow them to tumble in good, clean sawdust for a couple of hours. In this way the shells are buffed and receive the finishing polish.

\section{ECONOMY AND WASTE.}

\section{THE PROBLEM OF CUTTING.}

In the early period of the button business, owing to the entire want of skill of the cutters and the apparent abundance of the shells, a most wasteful use of shell prevailed. Two or three blanks were cut from shells which should have yiclded two or three times as many (Pl. XLIII). Factories could not now exist with such sacrifice of raw materials as then occurred. As a matter of fact, when new factories were continually forming in the early days, each eager to obtain cutters from other factories, it was impossible to maintain system in the cutting department, and a confessedly unfortunate condition prevailed.

With a condition of greater stringency bringing a necessity for better economy, the difficulties in the administration of the cutting department were augmented to the point of becoming a serious menace. Naturally, the need for betterment was first appreciated by the manufacturer; but the ways and means of bringing system and economy out of a condition of disorder and waste were at first baffling.

The process of cutting is at first glance a very simple one, and until rather recently the work of cutting was not generally understood to be skilled labor, nor was it really practiced as such. Nevertheless, in no part of the factory is the opportunity greater for 
BULL. U. S. B. F., I9I7-I8.

PLATE XIIII.

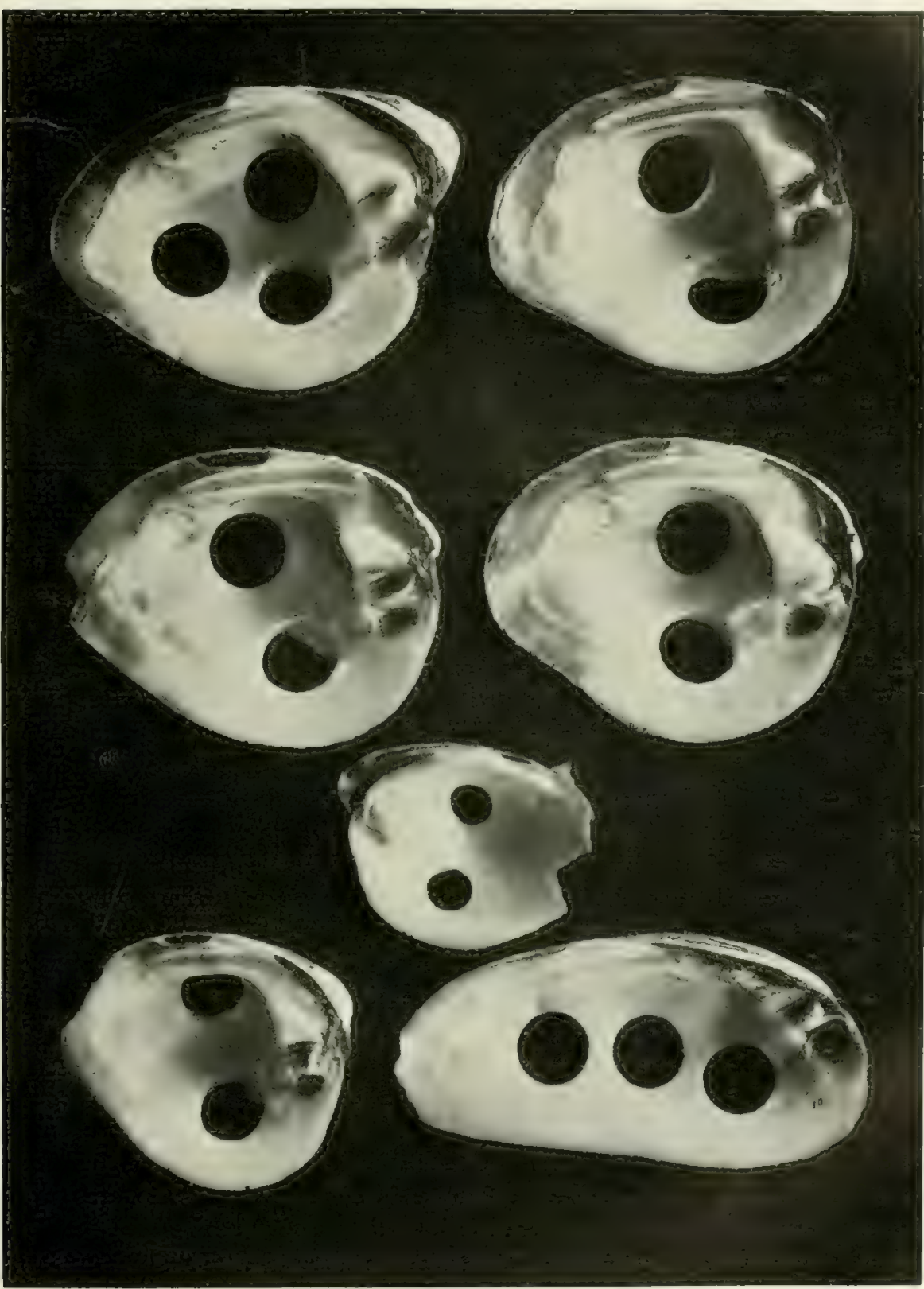

Illustrating wasteful cutting practiced in earliest stages of fresh-water pearl-button manufacturing industry. Compare ensuing plates. (See p. 82.) 

the exercise of care and good judgment on the part of the laborer or for intelligent and sympathetic cooperation between management and labor.

The problem of the cutting room is, indeed, a complex one owing to the difficulty of maintaining an exactly definable standard or of arriving at a system of count and payment that is at the same time neither open to criticism in some features nor conducive to waste. The desideratum of course, is a working plan, that neither denies to the cutter any portion of his reward, nor, on the other hand, relieves him of due responsibility for the cutting of shells in the best interest of manufacture and in accordance with proper usage of material.

A great variety of shells are used, differing in size, weight, shape, and quality. No single shell is of uniform thickness throughout, but all taper, more or less, from thicker forward and center portions to thinner rim and tip; each shell, may, therefore, produce good, inferior, or worthless blank. By poor spacing an unnecessary portion of the shell may be wasted, or, from careless manipulation, an undue proportion of the blanks may be inferior or worthless. It is quite possible, too, to waste more time in the careful cutting of material than is warranted by the saving of material. Consequently it is essential to impose checks in relation to the quantity and the quality of the output and to the proportion of product to materials consumed.

\section{DEFECTIVE BLANKS.}

Since no shell is of uniform thickness in all parts, the blanks from any given shell may vary from very thick to very thin. (See Pl. XXXVII, fig. 2.) All blanks wholly or in part thinner than two lines (one-twentieth of an inch) are called tips and can only be used for very inferior buttons. ${ }^{a}$ A blank is never too thick to be acceptable, since it can be ground down to the desired thickness; unfortunately splitting is not yet practicable with fresh-water shells. A cutter, however, may cause a rim blank to split by twisting the shell when half sawed through, thus increasing the count though the resulting blanks are undesirable. Such an unfair practice is detected when blanks are found without a back, or covering, of horny epidermis. From too much haste or too little care, the blanks, instead of being sawed clean through, may be pushed out, leaving flanges of shell and horny matter on the outside which cause much trouble in the succeeding processes. In very thick shells it is often undesirable to cut the rim, on account of the blanks having such a pronounced bevel as to work poorly or to fly out of the chucks in the process of facing and drilling and perhaps injuring the chucks or drills. It is usually better, therefore, to let this portion of the shell be wasted. Blanks cut through the eyespots (muscle scars) or through certain shell defects are sometimes undesirable. The cutter may space the blanks too closely, overlapping them, and thus producing buttons that are not round. In such a case, too, there is a danger of the saw being destroyed by the unrolling of the cylinder. (See Pl. XLV, lower left-hand corner.)

This brief account of the more conspicuous possible defects in cutting will account for the practice of counting out certain blanks; that is, of requiring that a blank, to count for payment, must be two lines or moie in thickness, must have the back on, be round, clean-cut, or without ragged edges, and be not cut through such spots or portions of the shells as may be prescribed. These specifications are simple and can be complied with by any conscientious cutter. The more difficult problem is that of getting the greatest number of blanks from the shells consumed. 


\section{CHOICE OF SHELLS FOR PARTICULAR LINES.}

Particular sorts or sizes of shell will work up most economically for particular sizes and grades of buttons. Accordingly, much discretion may be exercised in the apportionment of shells to the most appropriate uses, having in view the market demands to be supplied. A shell may be cut entirely into one size of blanks by one cutter, or the good blanks, the button blanks, may be cut out at one machine, while the remainder is passed directly, or after a lapse of time, to another cutter for taking out the tips. In other cases the shell is first worked for a few large blanks, and subsequently more completely used for smaller sizes. In this respect a large factory has a certain advantage over the small, independent cutting shop, since the latter must cut whatever shells are on hand into the particular lines for which the market is calling, while the larger factory may select from the bins the shells suited to the temporary needs, or may return to the bins, if desired, the partly cut shells. The detached cutting plant, on the other hand, may have an advantage in the saving of freight charges on useless shells.

The assignment of the shells for particular lines depends upon the judgment of the foreman or manager alone; but a proper quantity and quality of output and the elimination of unnecessary waste are contingent upon efficient labor in the cutting room. It will be of value in this connection to give some details of shop management, especially as observed in plants marked by the economical use of shells.

\section{SHOP MANAGEMENT.}

Disregarding minor differences, the shop management is, in brief, as follows: Each button cutter is assigned a machine, but is expected to furnish certain tools. The shells are weighed out to him, and he is assigned the proper line. Cutters with the best records may be favored with the most desirable lines. At certain intervals he turns in the blanks which he has cut and receives pay at so much per "count". The count, or "gross," as it was formerly called, is not the ordinary gross of 12 dozen, but an arbitrary and long-established unit of I4 dozen. ${ }^{a}$ Since it would be impracticable to count the entire output of each cutter, his blanks, after shaking to remove chips and dust, are turned out into a tub on the scales and the gross weight recorded. A handful may then be taken at random to weigh out a given small unit in the pan of a balance scales. The buttons from the pans are then counted individually on the table, those not acceptable (for defects previously mentioned) being discarded from the count.

The manner of count in different factories is divergent. In one, all blanks are counted as of the same value; in another, the blanks under four lines but over two lines in thickness are counted two for one. The latter plan is based on the fact that the thin blanks can be cut rapidly, and, although usable, are of relatively little value in manufacture. The former plan, that of giving the same count to tips as to good blanks, is simply "an acceptance by the manufacturer of responsibility for the shape of the shell."

a Thus we find that, in the language of button manufacture, neither the unit of measure, the line, nor the unit of count for blanks, the gross, corresponds to the common usage. The line is adopted from European practice and represents one-fortieth of an inch. The gross of 168 was originally based on an allowance for brealkage and other losses in the manufacture of the blaule into buttons. The terms although unfortunate, are matters of custom and are understood by all immediately concerned. 
Upon the basis of the sample count and the gross weight of the blanks the total count is readily computed for the purpose of payment. According to divergent methods payment may be made either at a flat rate per gross of I 68 blanks, or the weight of shells used may first be charged against the sheller, and payment (at a higher unit rate, of course) is then made by deducting from the computed value of the blanks the cost of the shell at a fixed price previously agreed upon.

The difference in the two methods has to do with the fixing of responsibility for the economic use of shells. In the first case, the management alone is responsible for economy, in the second the responsibility is divided. The latter seems really fairer to the cutter than the former and puts a proper premium upon careful and efficient work.

In case of payment exclusively upon the basis of blanks returned, the interest of cutter and management are continually in conflict. The cutter is tempted to sacrifice economy of material to gross output of blanks per day, while the management must be continually endeavoring to prevent undue waste of shell. This is a condition provocative of friction and liable to result in discharges or in docking.

In the other case, the cutter understands that waste of shell diminishes his earnings. Suggestions from the foreman to show how more blanks could be taken from a given shell are, thereforc, received as personal help rather than as rebukes. A single instance that came under the observation of the writer will serve to illustrate: A cutter had laid down a cut shell when the foreman pointed out how two more blanks might be cut. The cutter readily accepted the suggestion, which was to his own interest, and as the manager went away remarked to the writer: "Under the old system there would have been a regular 'call down' about that."

Cutter and management soon learn that care and system profit more than haste. The cutters earning the best wage are those who begin at the right place, plan out the cutting to use the most of the shell, cut in rows, and take the time necessary to avoid mistakes. (CF. Pls. XLIV, XLV, and XLVI.)

Under such a plan there can be no occasion for discharge. The cutter who lacks the intelligence, the aptitude, or the character to become a skillful cutter, even with help, must find the business unprofitable and seek employment in other lines for which he may be better adapted. The work passes naturally into the class of skilled labor, and the skillful do not have their proper earning diminished by an average rate which is lowered by the waste and scant production of the unskillful.

This report is not, however, concerned with the relative merits of systems of management except as they may affect the waste of raw materials. Propagation, protection, and the economical use of material are phases of the general conservation problem that are indissolubly linked. Without regard to the details of any system of administration, it may be said that the economic use of shells will necessarily be promoted by a plan (I) which divides between management and labor the responsibility for waste of shell; (2) which does this in such a way as to remove as far as possible the necessity for arbitrary docking or rebuke or discharge; and (3) which consequently substitutes for such forms of discipline a true spirit of cooperation between employer and employee for mutual advantage. The best spirit and the best intelligence of all concerned may well combine for the most advantageous use of materials, having in view both the diminution of waste and the improvement of quality of product. It is futile to imagine 
that in the long run the interest of cutter or manufacturer is promoted by waste or antagonism to legitimate improvement.

\section{PROPORTIONS OF PRODUCT AND WASTE.}

The unavoidable waste in the commercial use of mussel shells is remarkably high, assuming the most economical use possible of materials under present conditions. The waste involved in the combustion of coal is often cited as an example of unavoidable loss, where, under the most efincient methods in use, only a small per cent of the latent energy is converted into power. In button manufacture we find that only 5 to 8 per cent of the original gross weight of the mussel enters into the button product; but the remainder in this case is not all lost, since there are waste products which are utilizable at a less profit. In the first place, when the mussel is taken from the river, we find that about 3 per cent of the dry weight is thrown out as meat. ${ }^{a}$ The losses in the shell at different stages of manufacture, as determined by averages from several specific tests made by J. B. Southall, are shown in the following table:

Losses in Suells of Certain Species During Manufacture of Butrons.

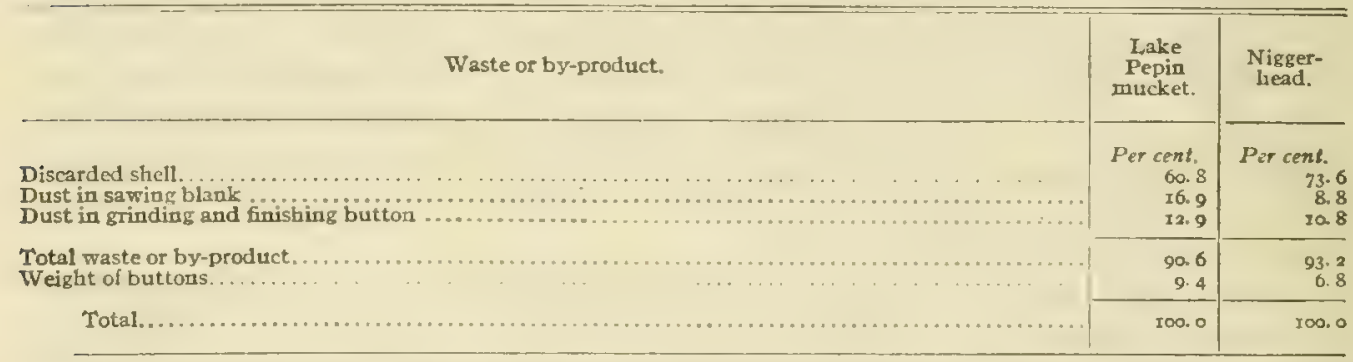

Roughly speaking, 7 per cent of the total weight of heavy shells like the niggerhead is marketed from the factory in a form worth $\$ 2.16$ per pound, ${ }^{b}$ while of the remaining 93 per cent, a portion is entirely thrown away and another portion sold as crushed shell, or dust, at a quarter of a cent per pound. ${ }^{c}$

The table and data are not of purely academic interest. They point to the significance of the problem of the utilization of the now unavoidably wasted material, and they emphasize the importance of putting more of the shell into the high-priced product, the buttons.

It remains to differentiate the instances of waste which are prevented by correct practice in cutting and those which arise from the form or character of the shell, and which consequently may be obviated only by new discoveries in method or by changing demands of the trade.

\section{WASTE IN CUTTING.}

It may be conceded that there is some waste which it would be possible but not desirable to avoid. Given the present economic conditions, it will appear that parts of the shell which could be cut are better left uncut, because the cost in labor

a The proportion of dry meat to shell varies widely with the different species. It is safe to say, however, that, on the average, the meats with all water dried out represent one thirty-fifth of the total dry weight of the mussel. The utilization of the ments is discussed in part 3, page $6 x$ on the mussel fishery.

b Figuring 3,248 buttons to the pound at is cents the gross (good quality r6 line).

e Price of crushed shell, \$5.50 per ton. Price of dust, \$4 per toz. 


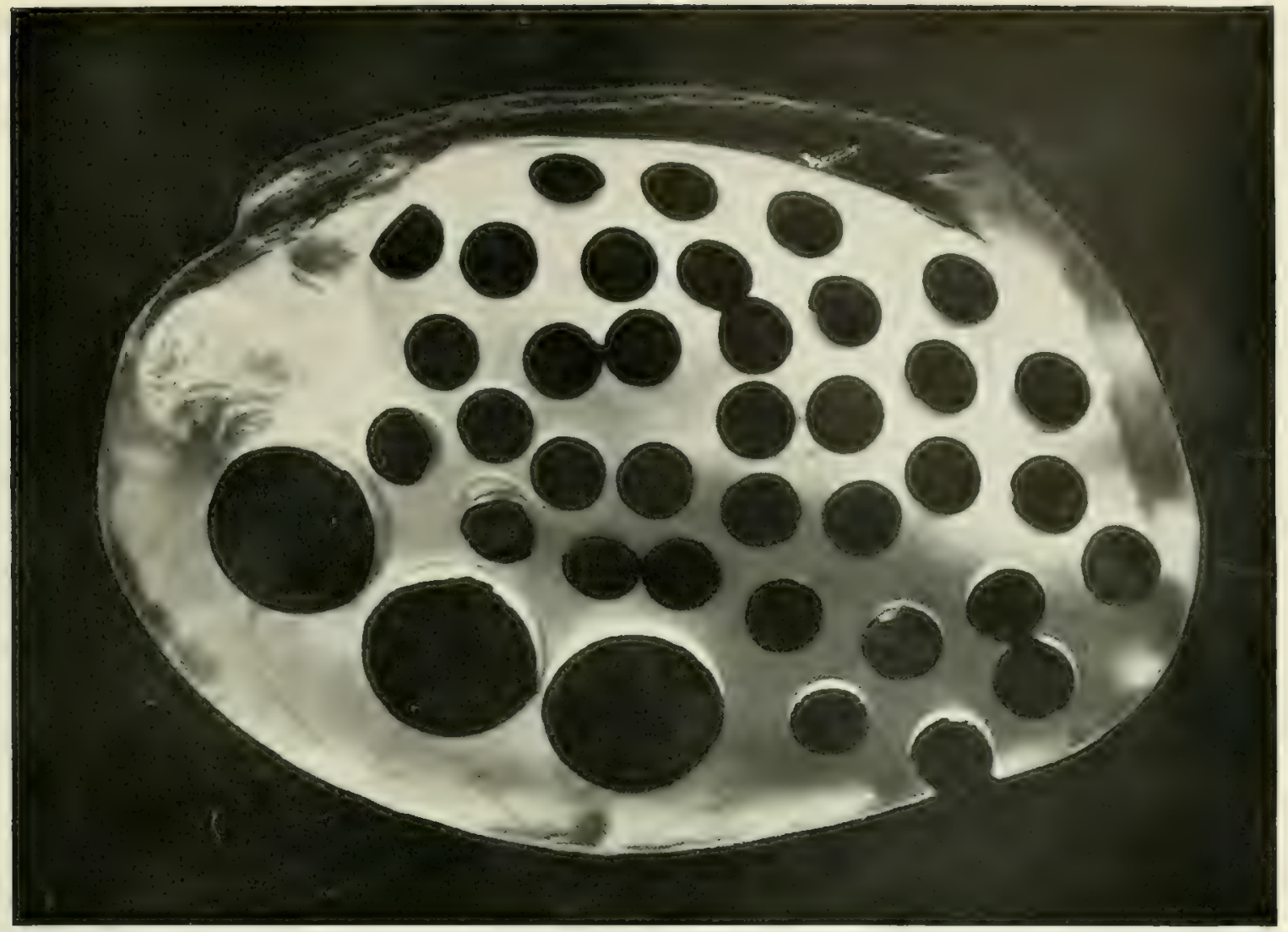

FIG. I. -Poor cutting due to want of care or lack of experience. Note poor spacing, overlapping of blanks, and exposed margins of shell, indicating that blanks were pushed out. (See p. 87.)

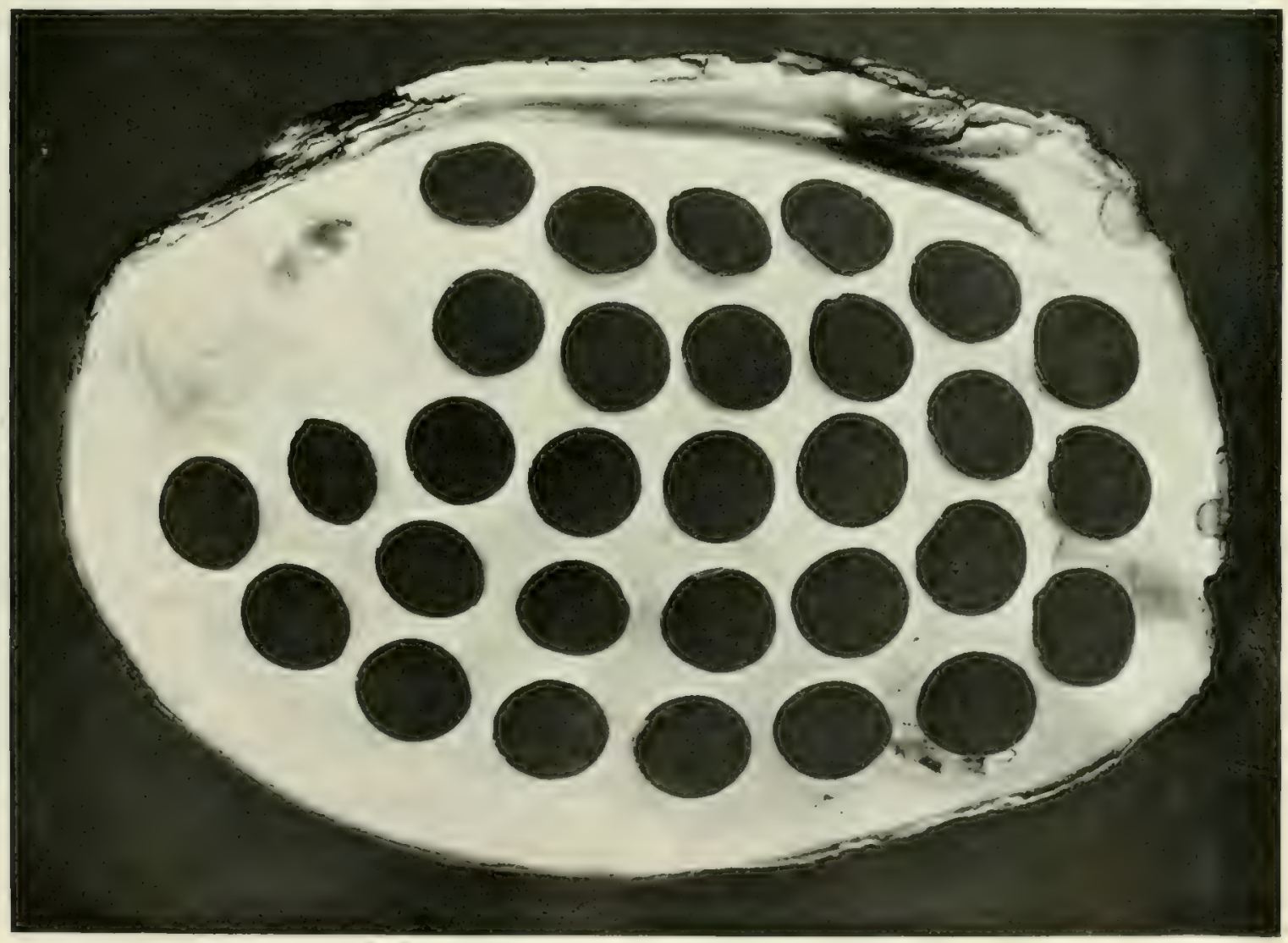




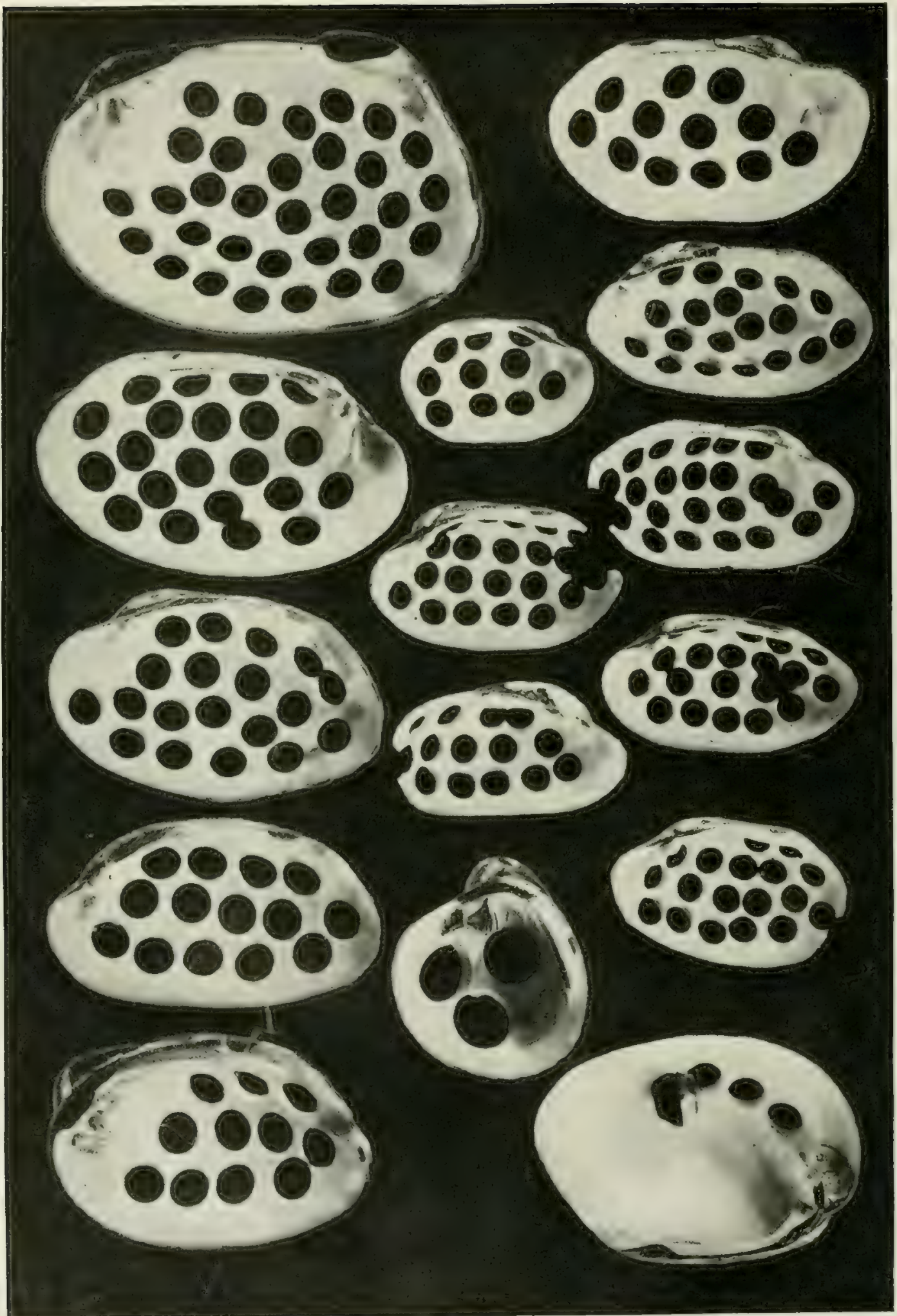

Illustrating reasonably careful practice in cutting. In endeavoring to cut too closely the shell in lower tight-hand corner the saw was destroyed. (See p. 87. . 


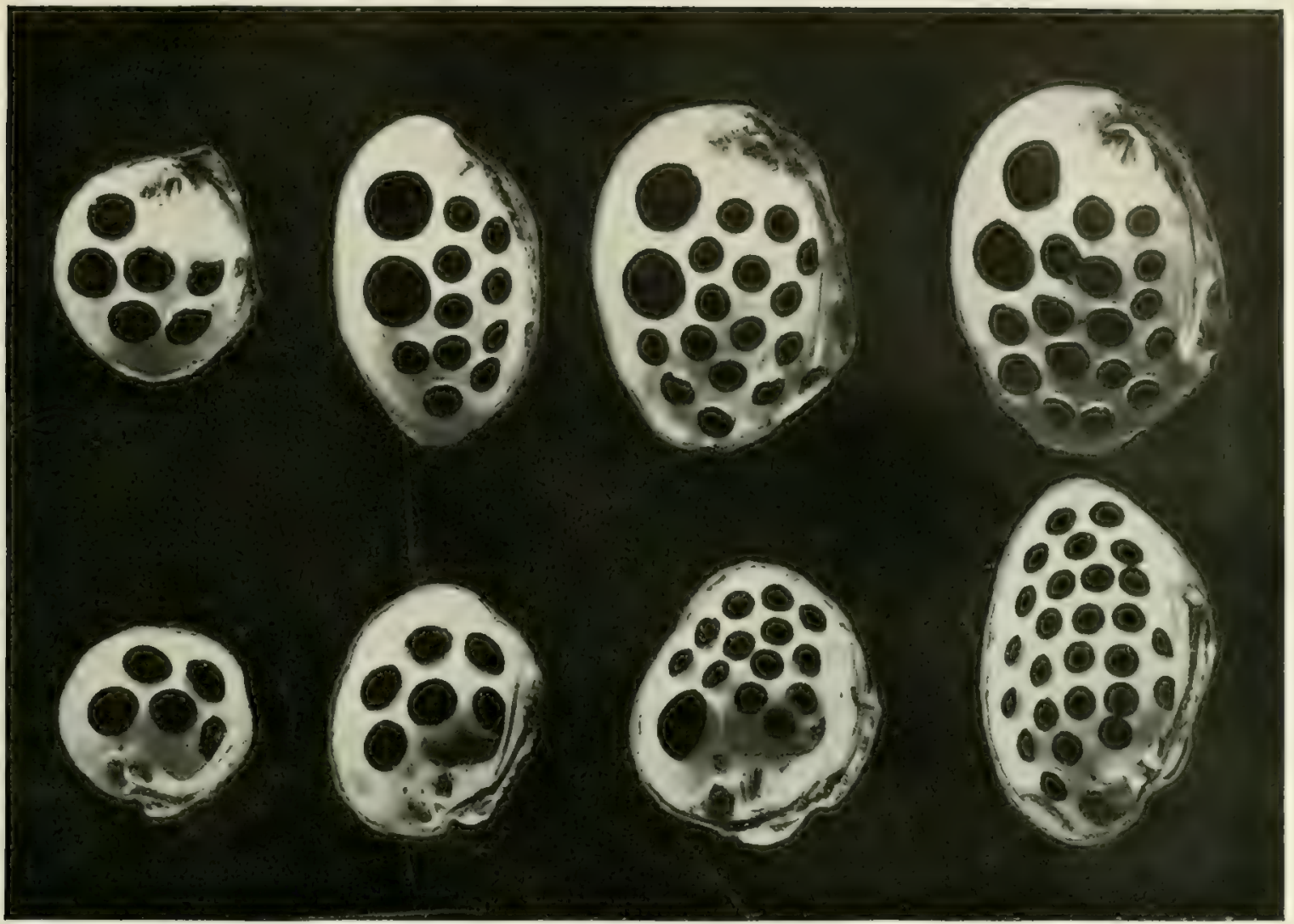

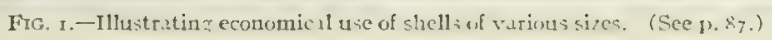

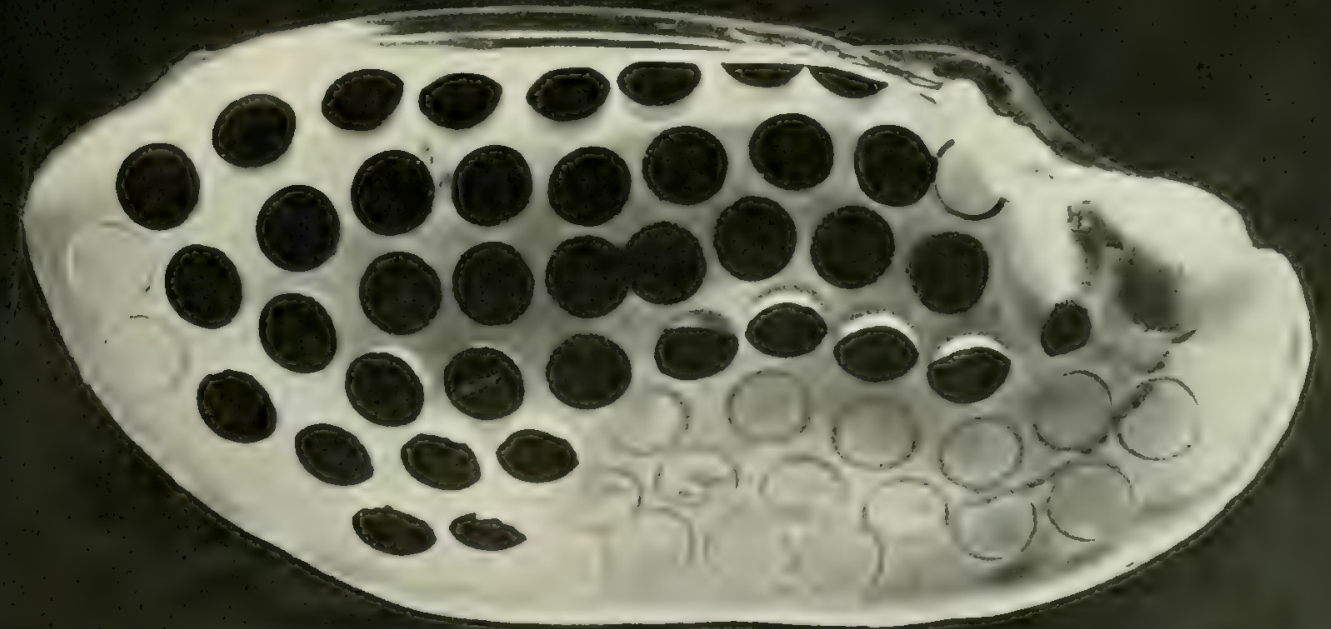



or in injury to machinery would more than counterbalance the saving of material. Nevertheless, all factories are not equally efficient, and some waste occurs that could be prevented by watchful and judicious management and by proper training of labor. It will not be out of place to illustrate this fact by the use of a few photographs with brief explanation.

Plates XLIV, XLV, and XLVI illustrate the progress in good cutting.

Plate XLIV, figure 1 , show:s a single shell where the cutter, though exerting some care to avoid waste of material, showed a lack of experience or judgment. The blanks were irregularly and poorly spaced. In some cases, too, the blanks were spaced too closely; so that true circular buttons could not have been obtained. Contrast this with the lower figure on the same plate, where the cutting was in rows, with best practicable use of shell.

Plate XLV includes shells from various plants where the cutting is done with more than average economy; the shell in the lower right-hand corner illustrates a danger in too close cutting, where, because of overlapping a space previously cut, the cylindrical saw was caused to unroll with more damage than a slight loss of material would have entailed. The shell was evidently thrown away in disgust. The avoidance of the rim blanks in the heavier shells of this illustration may be noted. Blanks obtained from the rim of such shells have so much bevel that they will not work successfully in the further processes and are liable to cause injury to machinery.

Plate XLIV, figure 2, and Plate XLVI illustrate the most economical cutting feasible under present conditions, and also show how shells are used to practical advantage by double cutting; that is, by taking out the larger lines first and then removing the smaller lines. Plate XI,VI, figure 2, shows an excellent spacing of blanks in a very favorable shell.

WASTE DUE TO EXCESSIVE THICKNESS.

A serious source of waste is found in excessive thickness of shell. If a shell is of sufficient thickness for buttons throughout, and in no part of excessive thickness, the waste consists in the spaces between blanks and the unutilizable portions of shell such as the hinge, umbones (knuckles), and rim. Many otherwise excellent shells, however, are very thin at the tips, while the blanks from the forward portion of the shell are so heavy that from one-half to three-fourths or more of the thickness must be ground off (P1. XXXVII, fig. 2). It is unfortunate that such blanks can not be split. Very thick blanks from ocean-pearl shells may readily be sliced or split into as many blanks as desired; but in the fresh-water mussel shells there are irregularities of stratification, or faults, in the shell which cause the splitting to occur in such irregular fashion that with any method or device so far employed the waste is quite out of proportion to the saving.

Between shells which produce 700 gross of buttons per ton and those which produce $I, 000$ gross per ton there is a distinct difference in economic value, assuming quality to be the same; also, there is a saving in the working of lighter shells, since there is evidently a useless waste of time involved in the sawing of thick shells and in the subsequent grinding away of excessive thickness. Furthermore, the heavy shells are of much slower growth. Assuming an equal quality from shells which are lighter and more nearly uniform in 
thickness, there will be a quicker return from efforts at propagation of such species and a greater likelihood of being able to maintain the supply.

There will undoubtedly develop a more insistent demand for the best yielding material, causing an advancing price, while the shells which are found to work with less economy will decline (relatively) in price to a point where they can be used with actual profit.

WASTE IN DISCARDED SHELLS.

A discussion of the general subject of economy would not be complete without reference to the discarding of certain classes of shells which have some good qualities, but which for one reason or another are not suitable. In the very beginning it was thought practicable to use only shells of comparatively uniform thickness. Accordingly, muckets and sand-shells were bought, while niggerheads, pimple-backs, etc., were refused. It was not long before the excellent qualities of these shells became apparent, and it was found practicable to cut them.

The discards at the present time are almost exclusively shells which could not yield buttons for which there is a market. Such are thin shells, colored shells, and shells exceedingly stained and spotted; not all of these are wasted. Some pink and purple shells, when thick enough, are found to be of a particularly good working quality; they can be used for making the smoked-pearl buttons by staining with silver nitrate. The demand for such buttons is limited, and, as many pink or discolored buttons are cut incidentally and culled from the better grades, there is little actual market for the pink shells beyond the limited requirements of the novelty trade. The elephant's ear is a rather common shell of beautiful pink, purple, or salmon color, and it is said to be superior in working qualities to the better grades of white shells. It is unfortunate that a simple, satisfactory method of bleaching has not been available or that there is no market for the natural pink and purple buttons produced from it. Many discolored shells may be bleached, though somewhat imperfectly, but bleaching methods have been greatly improved in recent years.

The discoloration is generally attributable to disease or parasites. Discolored shells seem to be more common in sluggish water and in portions of streams polluted with sewage.

\section{RÉSUMÉ OF MANUFACTURE.}

The fresh-water shells are used preeminently in domestic button manufacture, though a small proportion enters into the producton of novelties, and up to I9I4 an increasing number were being exported both for novelty and button making.

The process of button manufacture consists in classifying and soaking or moistening shells, cutting (either in detached cutting plants or in a room of the complete factory), cleaning, tumbling, backing, and soaking the blanks, facing and drilling (in one or two automatic machines), cleaning, polishing, drying and sorting the buttons, and finally sewing them upon the cards or packing in bulk. Processes of bleaching and of staining may be introduced as desired.

The principal operations of skill are the cutting of blanks and the sorting of buttons. The chief desiderata are the perfection of an automatic cutting machine and the elimination of waste as far as practicable at all stages. These needs are receiving the careful 
attention of many manufacturers and mechanics. Remarkable improvements in buttonmaking machinery and systems of management have taken place in recent years. Perhaps conspicuous advances in the future may be made, not only in such improvements of management and existing machinery as are always to be expected, but in the invention of an efficient machine for blank splitting and in the perfection of bleaching processes; also in the greater utilization of unavoidable waste.

In 1912 there were 196 separate plants employing mussel shells in manufacture. Of this number 153 plants were devoted to cutting only, while 36 factories engaged in finishing and grading. Of these latter 20 included cutting rooms, also, and thus comprised all the processes of manufacture. In addition there was a single branch plant devoted exclusively to the grading of buttons. There were 34 shell-crushing plants, of which 32 were connected with button factories, and there were 6 novelty works. These establishments were located in 20 States as follows: Alabama, Arkansas, Kansas, Kentucky, Illinois, Indiana, Iowa, Maryland, Massachusetts, Michigan, Minnesota, Missouri, New Jersey, New York, Ohio, Oklahoma, Pennsylvania, Tennessee, West Virginia, and Wisconsin.

The industry is peculiarly American. The material has until recently been obtained in no other country, and the machinery and methods are largely of American design and development. 





